\title{
Dinámica antroponímica y estructura demogenética en Casabindo: siglos XVI al XXI
}

\author{
Tesis doctoral \\ Emma Laura Alfaro Gómez
}

\section{Directora: Dra. María Ester Albeck Co-Directora: Dra. Evelia Edith Oyhenart}

Facultad de Ciencias Naturales y Museo Universidad Nacional de La Plata 


\section{INDICE GENERAL}

AgRADECIMIENTOS

RESUMEN

ABSTRACT

\section{INTRODUCCIÓN}

CAPÍTULO I: PROPÓSITO GENERAL Y ORGANIZACIÓN DE LA TESIS

CAPÍTULO II: ANTROPONIMIA

Breve historia sobre la costumbre del uso de apellidos

Los apellidos en el estudio de las poblaciones humanas

Los apellidos como variables culturales y biológicas

Supuestos teóricos considerados para usar apellidos en el estudio de

poblaciones humanas

Ventajas y desventajas del uso de apellidos

CAPÍTULO III: LA POBLACIÓN Y SU ESTRUCTURA

La demogenética

La estructura de población y los apellidos

Los apellidos como indicadores de migración

CAPÍTULO IV: EL MÉTODO ISONÍMICO 


\section{FUENTES Y MÉTODOS}

CAPÍTULO V: LAS FUENTES

CAPÍTULO VI: LOS CASABINDO $\quad 46$

El área de estudio

CAPÍTULO VII: LOS MÉTODOS

Análisis de nombres y apellidos $\quad 55$

Análisis de la estructura demográfica 56

Análisis de la estructura genética $\quad 57$

\section{RESULTADOS}

CAPÍTULO VIII: TAMAÑO POBLACIONAL, NÚMERO Y DISTRIBUCIÓN

DE LOS APELLIDOS

CAPÍTULO IX: ANÁLISIS DE NOMBRES Y APELLIDOS 66

CAPÍTULO X: DisTRIBUCIÓN DE LOS PARÁMETROS ISONÍMICOS 83

Consanguinidad de las poblaciones (Øii) 83

Indicadores de aislamiento y sedentarismo $\quad 85$

Indicadores de dinámica de población $\quad 89$

CAPÍTULO XI: ANÁLISIS DE lOS DATOS DEMOGRÁFICOS 95

Comparación entre dos registros de población de casabindo a fines $\quad 107$ del siglo XVIII 
DISCUSIÓN

CAPÍTULO XII: DINÁMICA ANTROPONÍMICA

121

CAPÍTULO XIII: ESTRUCTURA DEMOGENÉTICA

135

CONCLUSIONES

157

BIBLIOGRAFÍA

159

ANEXO

173 


\section{INDICE DE TABLAS}

Tabla 1: Correspondencia de localidades entre registros

Tabla 2: Cantidad de individuos, de individuos con apellidos o apelativos, $\mathrm{N}^{\circ}$ de apelativos diferentes, de apelativos únicos $\mathrm{y}$ relación $\mathrm{N}^{\circ}$ de individuos $/ \mathrm{N}^{\circ}$ de apellidos para Casabindo

Tabla 3: Cantidad de individuos, de individuos con apellidos o apelativos, $\mathrm{N}^{\circ}$ de apelativos diferentes, de apelativos únicos $\mathrm{y}$ relación $\mathrm{N}^{\circ}$ de individuos $/ \mathrm{N}^{\circ}$ de apellidos para el Área Norte

Tabla 4: Cantidad de individuos, de individuos con apellidos o apelativos, $\mathrm{N}^{\circ}$ de apelativos diferentes, de apelativos únicos $\mathrm{y}$ relación $\mathrm{N}^{\circ}$ de individuos $/ \mathrm{N}^{\circ}$ de apellidos para el Área Este

Tabla 5: Cantidad de individuos, de individuos con apellidos o apelativos, $\mathrm{N}^{\circ}$ de apelativos diferentes, de apelativos únicos $\mathrm{y}$ relación $\mathrm{N}^{\circ}$ de individuos $/ \mathrm{N}^{\circ}$ de apellidos para el Área Oeste

Tabla 6: Siete nombres indígenas o apellidos más frecuentes por sexo y por año para Casabindo

Tabla 7: Ejemplos de transmisión de segundo nombre paterno en el padrón de 1688

Tabla 8: Comparación de los 7 apellidos más frecuentes y porcentaje de la población cubierta por ellos en Casabindo y en los cuatro curatos de la Puna de Jujuy según el Censo de 1778

Tabla 9: Promedio y desviación estándar de la consanguinidad por isonimia al azar ( Øii ) de la población de Casabindo por año (valores x100)

Tabla 10: Indicadores de aislamiento y sedentarismo para el total de la población de Casabindo, por sexo y por año

Tabla 11: Indicadores de aislamiento y sedentarismo para el total de la población del Área Norte, por sexo y por año

Tabla 12: Indicadores de aislamiento y sedentarismo para el total de la población del Área Este, por sexo y por año

Tabla 13: Indicadores de aislamiento y sedentarismo para el total de la población del Área Oeste, por sexo y por año 
Tabla 14: Promedio y desviación estándar de los indicadores v de Karlin-McGregor (valores x 100) y alfa de Fisher para el total de la población de Casabindo, por sexo y por año

Tabla 15: Promedio y desviación estándar del indicador v de KarlinMcGregor (valores x 100) para cada una de las áreas, por sexo y por año

Tabla 16: Promedio y desviación estándar del indicador alfa de Fisher para el total de la población de Casabindo, por sexo y por año

Tabla 17: Promedio y desviación estándar del indicador alfa de Fisher para cada una de las áreas, por sexo y por año

Tabla 18: Distribución de la población según estado civil en los distintos documentos

Tabla 19: Comparación de población entre localidades en 1778 y 1786

Tabla 20: Distribución de las familias según el lugar de residencia en 1786

Tabla 21: Comparación entre 1778 y 1786 de la frecuencia de 27 apellidos característicos de Casabindo 


\section{INDICE DE FIGURAS}

Figura 1: Área ocupada por los casabindos en la época colonial

Figura 2: Localidades registradas en los distintos documentos

Figura 3: Ejemplo de una familia de 1654 donde los descendientes llevan un segundo nombre distinto al de los progenitores

Figura 4: Ejemplo de una familia de 1654 donde el hijo varón lleva el segundo nombre del padre y dos de las hijas el de la madre.

Figura 5: Distribución porcentual de los apellidos según su origen

Figura 6: Distribución porcentual de la población según el origen del apellido

Figura 7: Apelativos presentes en 1654 que aparecen como apellidos en varones hasta los siglos XVIII y XIX

Figura 8: Apelativos presentes en 1654 que aparecen hasta hoy en varones

Figura 9: Evolución de la proporción de varones sobre la población total según grupos de edad en los distintos documentos

Figura 10: Proporción de varones en los distintos cortes temporales

Figura 11: Evolución del tamaño familiar

Figura 12: Pirámide poblacional de Casabindo 1778

Figura 13: Proporción sexual terciaria en Casabindo 1778

Figura 14: Pirámide poblacional del Área Norte 1778

Figura 15: Pirámide poblacional de Área Este 1778

Figura 16: Pirámide poblacional de Área Oeste 1778

Figura 17: Pirámide poblacional de Casabindo 1895

Figura 18: Principales núcleos de residencia de los casabindos a fines del siglo XVIII

Figura 19: Composición familiar según número de integrantes 
Figura 20: Distribución del total de familias de 1786 según su situación en 1778

Figura 21: Genealogía de familia no registrada en 1778

Figura 22: Genealogía de familia idéntica en el período analizado

Figura 23: Genealogía de familia que difiere entre los dos registros analizados

Figura 24: Distribución del total de individuos de 1786 según su situación en 1778

Figura 25: Distribución porcentual de la residencia familiar

Figura 26: Porcentaje de individuos portadores de los 25 apellidos del núcleo de 1654 presentes hasta hoy en el NOA (Fuente: Albeck et al., 2007)

Figura 27: Cantidad de portadores de antropónimos del núcleo original de 1654 por provincia (Fuente: Albeck et al., 2005m.s.) 


\section{AGRADECIMIENTOS}

Recién con la tarea concluida puedo ver el largo camino recorrido que sólo fue posible gracias al apoyo de muchas personas quienes me brindaron su tiempo, conocimientos, experiencia, espacio, entusiasmo, confianza y amistad.

Dejo aquí expresado mi más sincero reconocimiento a todos aquellos que de una $u$ otra forma me acompañaron en este recorrido y que con su aporte profesional, afectivo y material permitieron que este trabajo se concretara.

A la Dra. María Ester Albeck por su acompañamiento, orientación y respaldo durante todas las etapas de elaboración de este trabajo, así como por su incentivo para la conclusión del mismo.

A la Dra. Evelia Oyhenart por los consejos y sugerencias aportados pero principalmente por la confianza manifestada en todo momento.

A la Universidad Nacional de Jujuy por haberme proporcionado el lugar de trabajo y los medios para realizarlo.

Al Mag. José E. Dipierri por su apoyo incondicional y su constante estímulo intelectual.

A Estela Chaves por su permanente y desinteresada colaboración y compañía, por su paciencia.

A Graciela Bailliet por abrirme las puertas de su casa y de su familia y por encontrar siempre las palabras de aliento que me ayudan a seguir adelante.

A mis amigos y compañeros del Instituto de Biología de la Altura y de la Facultad de Humanidades y Ciencias Sociales de la UNJu por su continuo apoyo tanto profesional como personal.

A mis amigos del IMBICE por permitirme formar parte del equipo y alentarme de las formas más diversas.

A Emilio, a Ely, a Judy, a Benito y a tantos otros amigos que, a través de las interesantes charlas y buenos ratos compartidos, han contribuido, de uno u otro modo, a que esto salga bien.

A mi querida familia por estar siempre a mi lado. 
“... Si el ámbito de investigación está suficientemente circunscrito, cada serie de documentos puede superponerse en el tiempo y en el espacio de manera tal que nos permita encontrar al mismo individuo o grupo de individuos en contextos sociales diferentes. El hilo de Ariadna que guía al investigador en el laberinto de los archivos es el que distingue a un individuo de otro en todas las sociedades que conocemos: el nombre".

Carlo Ginzburg y Carlo Poni (1991), "El nombre y el cómo" 


\section{RESUMEN}

Las formas de denominación de las personas desempeñan un papel fundamental en la estructuración de las sociedades ya que los nombres y apellidos confieren identidad, singularidad y permiten señalar la pertenencia de quienes los portan a una o varias familias o linajes.

En este trabajo se utilizan los antropónimos de los casabindos, grupo indígena propio de la puna de Jujuy, Argentina. Se realiza el seguimiento de los casabindos y sus descendientes a lo largo de un período de más de 400 años, a partir de la información consignada en una serie secuencial de registros de población, para analizar las características del sistema nominativo y la estructura poblacional. Las fuentes primarias utilizadas corresponden a un documento del siglo XVI sobre el bautismo del cacique de Casabindo; al padrón más antiguo existente para casabindos y cochinocas, de mediados del siglo XVII; a un padrón de tributarios de Casabindo fechado en 1688; a dos registros de población de fines del siglo XVIII; al Segundo Censo Nacional de la República Argentina realizado en 1895 y a los padrones electorales de 1982 y 2001.

Se analizó el origen (autóctono o foráneo), la frecuencia y perduración de las formas de denominación y su transformación entre 1557 y 2001. La estructura demogenética se estimó mediante el cálculo de parámetros isonímicos indicativos de consanguinidad, aislamiento, sedentarismo y migración que se relacionaron con información demográfica como tamaño poblacional, distribución de la población por edad y sexo, estado civil y composición familiar.

Los resultados obtenidos permiten conocer una serie de antropónimos usados en Casabindo en épocas prehispánicas, que sufrieron un proceso selectivo que transformó a los nombres nativos masculinos en apellidos y provocó la desaparición de los nombres femeninos. 
La evolución del sistema nominativo en Casabindo se caracteriza, durante el siglo XVI, por la presencia exclusiva de nombres autóctonos, simples o compuestos, propios de cada sexo y que cambian de generación en generación. La población del siglo XVII todavía registra antropónimos diferentes en varones y mujeres donde la mayoría presenta un primer nombre español otorgado en el bautismo y un segundo nombre indígena mientras que en una ínfima proporción se observa que ambos apelativos son de origen español. A fines de este siglo comienza la transmisión del segundo nombre entre generaciones con sistemas paralelos padre-hijo y madre-hija. En el siglo XVIII, en cambio, toda la población presenta un primer nombre español y un segundo nombre indígena que corresponde a los propios de los varones en los siglos anteriores. El segundo nombre paterno, ya transformado en apellido, se transmite a toda la descendencia.

En cuanto al origen se advierte que los apelativos autóctonos son los más frecuentes y que representan más del $90 \%$ de la población total hasta el siglo XVIII y descienden al 50\% en el período que va desde 1895 a 2001 con el correspondiente aumento de los portadores de apellidos foráneos, fundamentalmente de origen español. Esto representa un cambio significativo y marca la apertura de la población de Casabindo al descender el aislamiento en el que se encontraba hasta este momento.

Durante los dos primeros siglos analizados se registra una población aislada donde las barreras no serían geográficas sino que estarían relacionadas con la organización familiar y administrativa colonial representada por el ayllu y la encomienda respectivamente. Esta explicación se fortalece por los elevados coeficientes de consanguinidad y sedentarismo y los bajos valores encontrados para los indicadores de inmigración reciente y diversidad de apellidos que definen a la población de Casabindo como cerrada, al menos hasta fines del siglo XIX. El escaso movimiento poblacional reconocido en Casabindo, en virtud de las diferencias intersexuales que presentan los dos últimos indicadores mencionados, habría estado a cargo de las mujeres y relacionado con la residencia virilocal propia del sistema de encomiendas. 
A pesar de estos acontecimientos sociodemográficos y de la dinámica antroponímica, es posible establecer la perduración en el área original de cuatroapellidos, originalmente nombres indígenas, por más de 400 años y de un conjunto de otros 21 nombres desde mediados del XVII hasta hoy. A principios del siglo XXI se observa una dispersión gradual selectiva del tronco antroponímico original de los casabindos en los territorios vecinos, el NOA y otras regiones argentinas.

El seguimiento de los antropónimos, en cortes temporales de aproximadamente 100 años, permitió analizar, indirectamente, la estructura demogenética de las poblaciones por el método isonímico y la dinámica poblacional en la zona de Casabindo entre los siglos XVI y XXI identificando fenómenos demográficos y microevolutivos como la migración y el aislamiento.

La permanencia espacio-temporal de estos antropónimos sugiere el probable mantenimiento de características biológicas distintivas en descendientes de la población colonial del área de Casabindo, que hacen que estos apellidos puedan ser homologados a marcadores moleculares para inferir el posible origen de un individuo o sus antepasados, según sus apellidos.

La relación entre antroponimia y marcadores moleculares en la población actual y en restos humanos arqueológicos ofrece nuevas posibilidades de reconstruir el tronco original de la población prehispánica del sector central de la Puna de Jujuy, contribuyendo a profundizar el conocimiento sobre la identidad y el patrimonio bio-cultural de la población actual de la zona Casabindo y de la provincia de Jujuy. 


\begin{abstract}
The forms of denominating people play a key role in the social structure, because name and family name confers identity, uniqueness, and permit to point out the family or linage to which the bearer belongs to.

In this work, the antroponyms of the casabindos, a aborigin group from the jujenean Puna (Argentina), are used. Based on the information recorded in a series of population archives, the tracking of the casabindos and their descendents was done for a period of over 400 years, allowing the analysis of the characteristics of the nominative system, and the population structure. The main sources for this work correspond to a document about the baptism of the Casabindo cacique, dating back to the 16th century; the oldest registry from the casabindos and cochinocas, from midst of the 17th century; a registry of tax payers of Casabindo dated on 1688; two population records from the end of the 18th century; the Second National Census from the Argentine Republic done on 1895; and the electoral register from 1982 and 2001.

The origin (autochthonous or foreign), the frequency, the persistence of the denomination forms, and their transformation between 1557 and 2001 was analyzed in this work. The demogenetic structure was estimated by means of isonymy parameters that indicated consanguinity, isolation, sedentarism, and migration. These data were related with demographic information such as population size, population distribution by age, sex, marital status, and family composition.
\end{abstract}

The obtained results allowed knowing a series of antroponyms used in Casabindo during pre-Hispanic times. These antroponyms underwent a selective process, in which native male names were transformed into family names, while native female names disappeared.

The evolution of the nominative system during the XVI century in Casabindo is characterized by the presence autochthonous names exclusively. 
They could either be single or compound names, unique for each sex, and they could change from generation to generation. The 17th century population exhibit different antroponyms for males and females, where most of them have a Spanish first name given at the baptism, as well as a second native name. On the other hand, a very small proportion of the population has both first and second names from Spaniard origin. The transmission of a second name from one generation to the following generation, with parallel systems of father-son and mother-daughter transmission, begun at the end of the 17th century. Conversely, at the $18^{\text {th }}$ century, the entire population presents a first Spaniard name and a second native name. The second name is derived from native male names of the previous centuries. The paternal second name, once transformed in family name, is then transmitted to the descendants.

It has been observed that $90 \%$ of the population has native names until the end of the 18th century. Between 1895 and 2001 the proportion of native surnames was reduced to $50 \%$, meanwhile the incorporation of foreign last names (mainly from Spanish origin) increased. This significant change indicates the breakage of the isolation of the Casabindo population.

The population from the first two centuries presented socio-cultural barriers related to the familiar organization (ayllu) and the colonial administrative organization (encomienda). This is associated to an elevated consanguinity and sedentarism, as well as low recent immigration and family name diversity. In addition, the "encomienda" system favored a high proportion of women immigrating into the population.

Only four originally native names are present in the Casabindo area since 1557. From the middle of the $17^{\text {th }}$ century 25 names have been reported in the population. In the beginnings of the 21st century a gradual and selective geographic dispersion of these 25 names has been observed. 
The tracking of the antroponyms, in intervals of 100 years between the $16^{\text {th }}$ and $21^{\text {st }}$ centuries, allowed the indirect analysis of the demogenetic structure of the Casabindo population.

The permanence of the antroponyms in space and time suggest the possible maintenance of a genetic background with distinctive characteristics which could be associated to molecular markers.

The relationship between the molecular markers and the surnames in the actual population as well as archeological human remains opens new possibilities to reconstruct the original pre-Hispanic population tree from the central part of the jujenean Puna. This would further contribute to the better understanding of the bio-cultural identity of the Casabindo and Jujuy population. 


\section{INTRODUCCIÓN}

\section{CAPÍTULO I: PROPÓSITO GENERAL Y ORGANIZACIÓN DE LA TESIS}

El propósito general de esta tesis es indagar sobre la historia, el surgimiento y consolidación del sistema nominativo en una población indígena del sector central de la Puna de Jujuy: los casabindos. También se intentará reconstruir la estructura genética y demográfica de la población y su permanencia en el área de origen.

Se presenta un conjunto de datos obtenidos a partir del análisis de distintos registros de población tomando como eje el estudio de los nombres y apellidos. Se plantea el seguimiento de los casabindos y de sus descendientes a lo largo de cuatro siglos a partir del reconocimiento y análisis de las transformaciones experimentadas por las formas de denominación de este grupo y la comparación de los nombres etnohistóricos e históricos con los presentes actualmente en la zona y en el resto de la provincia de Jujuy. Este seguimiento permitirá indirectamente, a través del comportamiento de los antropónimos, determinar la estructura genética de las poblaciones casabindo por el método isonímico y analizar la dinámica poblacional en la zona que habitaban entre los siglos XVI y XXI.

La profundidad temporal de este estudio representa una ventaja considerable ya que permite evaluar procesos de larga duración experimentados por los casabindos durante el período analizado.

La identificación de las formas originales de denominación de este grupo y su persistencia hasta la actualidad permite disponer de un indicador antroponímico que puede ser fácilmente asociado a individuos y/o poblaciones y a marcadores moleculares, abriendo así nuevas perspectivas de estudios genéticos en la población actual y en restos humanos arqueológicos. 
Este trabajo forma parte de una investigación mucho más ambiciosa que busca integrar el conocimiento arqueológico, lingüístico, biológico, histórico y actual de las poblaciones de la puna de Jujuy.

Algunas líneas de investigación planteadas a partir de esta aproximación interdisciplinaria comprenden:

a) el análisis del territorio de los casabindos prehispánicos cruzando información colonial y arqueológica,

b) la definición de una variedad lingüística local relacionando la información antroponímica con la toponimia de la zona,

c) la comparación de los nombres y apellidos de Casabindo con los registrados para las áreas aledañas en los siglos XVII y XVIII,

Dada la conformación actual de la población de la Provincia de Jujuy, con un importante sustrato autóctono, los resultados de esta tesis y los que puedan obtenerse a partir de las nuevas líneas mencionadas resultan de gran interés no sólo para el ámbito académico-científico sino también para las comunidades locales preocupadas por el conocimiento de su patrimonio biológico y cultural.

En las páginas siguientes no se intentará reconstruir el pasado tal como fue sino proponer una mirada que, utilizando información édita e inédita y planteando hipótesis y explicaciones, refleje una imagen lo más ajustada posible.

Para ello esta tesis se estructuró en 13 capítulos. En los Capítulos II, III y IV se describen los antecedentes teóricos sobre los cuales se basa este trabajo. En el capítulo IV se realiza además una revisión de las referencias bibliográficas relacionadas con el estudio de nombres y apellidos y su relación con la estructura poblacional. En los Capítulos V y VI se describen las fuentes utilizadas en el análisis de antroponímico y en la estructura demogenética, la caracterización de la población colonial de Casabindo y el territorio que ocupó. En el Capítulo VII se detallan los métodos empleados en cada uno de los 
aspectos analizados en esta tesis. Los Capítulos VIII a XI presentan los resultados alcanzados y en los Capítulos XII y XIII se discuten las características del sistema nominativo de Casabindo, su transformación entre los siglos XVI y XXI, la estructura poblacional evaluada a través de los parámetros isonímicos y demográficos y la interrelación entre estos abordajes.

Finalmente se presentan las conclusiones alcanzadas, la bibliografía y un anexo donde figuran los listados y frecuencias absolutas de los nombres (hasta 1688) y apellidos (desde 1778 hasta 2001) en el área de Casabindo. 


\section{CAPÍTULO II: ANTROPONIMIA}

La Antroponimia estudia el origen y la significación de los nombres de persona (RAE, 2009) e intenta, además, explicar su evolución y variación en función de su localización, época y cultura.

Desde la antigüedad el hombre se valió de diferentes convenciones para distinguirse de sus congéneres, diseñando sistemas de identificación basados en establecer factores diferenciales y relaciones de pertenencia respecto a otros individuos o grupos de personas a través de un elemento designador concreto: un antropónimo o nombre propio, hecho que parece universal en todas las culturas humanas (De Luca, 1997; Faure et al., 2001; Wilson, 1998).

La primera forma de identificación está representada por los nombres de pila, motes o apodos inspirados en defectos o atributos de la personalidad, procedencia o relación con accidentes geográficos o cualquier circunstancia capaz de establecer una diferenciación con sus semejantes. A partir de estos se fueron estructurando sistemas identificatorios acordes a la idiosincrasia de los pueblos, a los usos y costumbres de las distintas regiones del mundo (De Luca, 1997; Elián, 2001; Medinaceli, 2003).

Los apellidos pueden ser concebidos como el sustantivo que acompaña al nombre de las personas teniendo una función diferente. El nombre propio o de pila identifica al individuo mientras que el apellido caracteriza a la familia o linaje que integra. Ambos tuvieron un origen descriptivo, son nombres genéricos y apelativos que sirven para reconocer a una persona y al grupo al que está unida, ya sea por lazos de sangre (parentesco biológico o consanguíneo) o por relaciones derivadas del matrimonio (parentesco por afinidad) y que, con el tiempo se volvieron permanentes con fines de una identificación más segura (Castro de Guerra, 1987; Faure et al., 2001; Elián, 2001). 


\section{Breve historia sobre la costumbre del uso de apellidos}

La costumbre del uso de apellido es casi universal y parece ser muy antigua. Los romanos fueron los primeros europeos en hacer uso regular de los nombres de familia y entre los griegos algunas familias acostumbraban a identificarse por el patronímico (apellido que antiguamente se daba a los hijos, formado por el nombre de uno o ambos padres) de un antepasado real o afamado (Elián, 2001).

En Europa durante el siglo $X$, en los años que precedieron al sistema de nombre y apellido, la forma de designar a los individuos se fue transformando lentamente. En ese momento las comunidades eran poco numerosas y una palabra bastaba para identificar, sin ambigüedad, a una persona por lo que los nombres eran simples (Castro de Guerra, 1987). Se registraba una gran riqueza de antropónimos y una prolífica aparición de nuevos apelativos en todo momento (De Luca, 1997, Medinaceli, 2003). Cada persona sólo tenía un nombre significativo al que se le anexaba "hijo de..." para distinguirse en el medio social al que pertenecía. También se acostumbraba adicionar el lugar de procedencia, que podía ser el de nacimiento o el de residencia según las circunstancias.

En la última mitad del siglo XI, y ante el aumento de la población, el repertorio antroponímico se empobreció y la repetición de nombres en un mismo ámbito social provocó innumerables confusiones. Así comenzó a hacerse necesaria una segunda denominación, agregada al nombre por lo que la aparición del apellido como complemento fue indispensable para paliar la pérdida del papel diferenciador del nombre principal (Elián, 2001; Faure et al., 2001).

Al comienzo el uso de un segundo nombre era personal y por tanto cambiaba en cada generación. En España los primeros patronímicos se habilitaron en el siglo XIII cuando se empezó a relacionar los nombres propios entre las distintas generaciones, de tal modo que el nombre de pila del padre pasaba a ser apellido del hijo, así cada persona tenía un patronímico distinto al 
de su progenitor debido al carácter no hereditario de los apellidos (Castro de Guerra, 1987; Elián, 2001).

A partir del siglo XV los patronímicos comenzaron a trasmitirse a las generaciones sucesivas, no obstante lo cual, siguió habiendo casos excepcionales de individuos que convirtieron en apellido el nombre de su padre hasta avanzado el siglo XVII (Faure et al., 2001; Wilson, 1998).

El requisito de que los apellidos se pasaran de padre a hijo se hizo ley eclesiástica como consecuencia del Concilio de Trento, encuentro ecuménico de la Iglesia Católica celebrado en la ciudad de Trento en el norte de Italia entre 1545 y 1563, como respuesta a la Reforma Protestante. Este concilio también obligó a adoptar el nombre de un santo de la Iglesia con lo que se redujo mucho la riqueza en la elección de nombres y estableció, además, el registro obligatorio de todos los nacimientos, muertes, matrimonios y confirmaciones, así como el patrón específico para esos registros (Castro de Guerra, 1987; Dipierri, 2004; Medinaceli, 2003).

En los comienzos de la transmisión del apellido a los hijos, ésta no respondía a ninguna regla, cada cual podía usar el de un antepasado cualquiera, o combinaciones variadas, por lo que hasta fines del siglo XVI era muy común encontrar padres, hijos y hermanos con diferentes apellidos.

Todavía en el siglo XVII no hay una reglamentación estricta en la herencia de los apellidos como patronímico, aunque se observa cierta tendencia de dar el apellido del padre al hijo mayor y el de la madre a la hija mayor (De Luca, 1997; Faure et al., 2001).

En España se aplicaron diferentes criterios para la construcción de los patronímicos familiares, aunque en casi todas las culturas pueden reconocerse cuatro categorías (Elián, 2001).

\section{a) Toponímicos:}


Una de las asimilaciones más difundidas para la construcción de los nombres de familia han sido los lugares de nacimiento, residencia o procedencia y los nombres de ciudades, comarcas, parajes y los respectivos gentilicios que representaron una fuente de identificación primaria. Se registra la asimilación directa de topónimos, sobre todo de localidades importantes, lo que puede llevar a la repetición de apellidos en distintas zonas relacionados con los signos topográficos de cada una. Entre otros Arroyo, Campos, Costas, de la Colina, del Prado, Villa, etc.

Cuando la asimilación no se realiza con un lugar determinado sino con plantas, árboles, frutos o semillas, los apellidos se denominan fitonímicos como por ejemplo Castaño, Centeno, Escobar, Olmos, Robles, etc. y zoonímicos si la asociación se realiza con especies animales como Aguilar, Cordero, Gallo, Lobo, entre muchos otros.

\section{b) Patronímicos:}

Si se basan en el nombre de pila del padre están seguidos del sufijo "ez" que significa "hijo de..." por ejemplo, Rodríguez hijo de Rodrigo. Se relacionan con el linaje o alcurnia y representan a las personas unidas por lazos de sangre a través de sucesivas generaciones lo que equivale a decir "perteneciente a la familia de..." haciendo referencia al fundador del grupo familiar.

Es la forma más difundida en tiempo y espacio, lo que ha provocado un fenómeno de masificación o reproducción excesiva de los apellidos basados en esta metodología. La deformación de nombres debido a variantes producidas en la grafía ha provocado modificaciones sustanciales como por ejemplo el reemplazo de la letra $X$ primero por $\mathrm{J}$ y luego por $\mathrm{G}$ (Ximénez, Jiménez y Giménez). Algunos apellidos con el transcurso del tiempo han sufrido transformaciones en su escritura debido a los usos y costumbres de la región donde se originaron, lo que representa una causa generadora de numerosas variantes idiomáticas. Entre estos encontramos por ejemplo Alvar, Álvaro, Álvarez o Hernando, Hernán, Hernández, Hernáez. 


\section{c) Indicativos:}

Forma bastante difundida por consagración de sobrenombres, motes o apodos que originalmente servían de complemento a los nombres propios y que con el tiempo se transformaron en apellidos. Las características personales basadas en atributos, oficios, ocupación, defectos físicos u otra circunstancia facilitan la identificación de los individuos y sirve para diferenciarlos en el núcleo social donde conviven permitiendo reconocer a sus descendientes por simple asociación. Como ejemplo de apellidos originados a partir de características físicas podemos mencionar Albino, Calvo, Crespo, Delgado, Gordillo, Moreno, etc. Entre los correspondientes a oficios podemos mencionar Herrero, Quintero, Tejedor, etc.

\section{d) Descriptivos:}

Relacionados con distintas circunstancias de la vida para señalar conductas o particularidades individuales vinculadas con la jerarquía civil (Alcalde, Caballero, Jurado, Noble), con una dignidad eclesiástica (Bautista, Cardenal, Cura), grados militares (Coronel, Escudero, Guerrero), atributos morales (Cortés, Galán, Leal), etc.

Puede decirse que el principio de estabilidad del nombre está asociado al perfeccionamiento de los registros parroquiales (De Luca, 1997). El registro formal de la identidad y del estado civil, elementos esenciales para organizar la vida en sociedad, se hacía originalmente en una sede eclesiástica, quedando asentados en libros parroquiales los casamientos, bautismos y defunciones que ocurrían en cada jurisdicción. La seriedad y responsabilidad que caracterizaba a los actos eclesiásticos hizo que dicho registro no tuviera mayores exigencias en cuanto a la probanza de los datos filiatorios alegados por los declarantes, estaban basados en la buena fe de los interesados ya que el objetivo principal era dejar constancia del cumplimiento de preceptos religiosos. 
El proceso de conquista y colonización reprodujo en América los sistemas económico, político, social y cultural imperantes en las metrópolis europeas y con ellos, por supuesto, la costumbre del uso de apellidos. Una vez rotos los vínculos de dominación política, esa costumbre permaneció en la población americana legislada en el marco de los estados independientes.

Los estudios de la población en el caso de América Latina colonial y poscolonial en general, presentan algunas dificultades heurísticas por la particularidad que ofrece el mundo colonial sobre todo en términos de diversidad étnica y cultural, mestizaje, relaciones de dominio y reciprocidad, así como de patrones productivos (López, 2006).

El análisis cuantitativo de los episodios históricos en el poblamiento de América, de las migraciones históricas y actuales y del impacto de ambos en la estructura y distribución geográfica de la población actual, ha estado muy limitado debido a la escasez de fuentes de datos estadísticos apropiadas para el estudio de poblaciones completas (Mateos et al., 2006).

La conquista y posterior colonización generó situaciones vitales de gran relevancia que no siempre se registraron con fidelidad en las fuentes documentales: abruptos descensos de la población indígena durante los siglos XVI y XVII, presencia de importantes contingentes de migrantes esclavos y españoles, que incidieron en el crecimiento y composición de la población, coexistencia de modelos familiares diferentes a pesar del intento de uniformidad por parte de la Iglesia, un alto índice de uniones consensuales y de ilegitimidad, masiva movilidad de la población (López, 2006). La escasa información demográfica que ofrecen las fuentes coloniales y poscoloniales sobre estas cuestiones no invalidan su utilidad pues, mediando los recaudos críticos necesarios, ayudan a reconstruir el tamaño, distribución y composición de la población americana del período pre-censal, a la vez que descubren pautas históricas y culturales fundamentales para analizar estas sociedades.

En las poblaciones prehispánicas americanas el uso del apellido no parece haber sido una costumbre generalizada. El Tercer Concilio Limense, 
reunión considerada un hito en el sistema nominativo americano, normatiza en 1583 el uso paralelo de nombres femeninos y masculinos (Medinaceli, 2003) y se ocupa "de los nombres de los yndios" estableciendo que: "Para que se eviten los yerros... totalmente se les quite a los yndios el usar de los nombres de su gentilidad e ydolatría y a todos se les ponga nombres en el bautismo cuales se acostumbran entre cristianos... Mas los sobrenombres para que entre sí se diferencien, procurense que los varones procuren los de sus padres, las mugeres los de sus madres” (Medinaceli, 2003).

Los primeros gobiernos republicanos aceptaron los usos y costumbres imperantes durante la colonia por lo que esta función siguió estando a cargo de las autoridades religiosas hasta la última década del siglo XIX cuando, a partir de la creación de los Registros Civiles en la República Argentina (De Luca, 1997), el Estado recién tiene injerencia en esta materia.

Con la instauración de los primeros Registros Civiles, las actas demostrativas de los acontecimientos demográficos se rodearon de mayor formalismo ya que debían certificarse las relaciones de parentesco, vínculo de consanguinidad, causas de fallecimiento y todas las circunstancias personales relativas a la filiación de los participantes del acto.

\section{LOS APELLIDOS EN EL ESTUDIO DE LAS POBLACIONES HUMANAS}

Los apellidos son el resultado de procesos históricos y culturales, constituyendo una variable que ofrece, por esta circunstancia, múltiples posibilidades y direcciones de estudio de una población. Por este motivo, los apellidos pueden aplicarse tanto para la reconstrucción de la historia cultural y biológica de una población como para analizar la estructura de la misma desde el punto de vista genético y demográfico. 


\section{Los apellidos como variables culturales y biológicas}

Los apellidos, como los nombres, constituyen rasgos culturales que se transmiten de distinta manera. Mientras los apellidos, en la mayoría de las sociedades, se difunden patri y/o matrilinealmente a través de un mecanismo vertical comparable a la transmisión genética, los nombres lo hacen horizontalmente de un modo similar a la transmisión epidémica o endémica (Guglielmino et al., 1991). Debido a estas características los apellidos se comportarían aproximadamente como marcadores genéticos, constituyendo una variable sociocultural universal, limítrofe entre la evolución biológica y cultural (Manrubia y Zanette, 2002).

De acuerdo con Pinto Cisternas y Castro de Guerra (1988) los apellidos pueden ser utilizados para estudios biológicos y sociales de distintas maneras:

1) como discriminante étnico o sociocultural;

2) como elemento analítico;

3) como elemento propio desde el campo de la lingüística, siendo el mismo apellido el objeto analizado.

Como discriminante étnico los apellidos ofrecen la posibilidad de evaluar el mestizaje experimentado por las poblaciones ya que permiten, en función de su origen étnico, separar a las mismas en distintos subgrupos y ponderar la contribución de cada uno al pool génico y a la antroponimia de las poblaciones. Chakraborty et al. (1989) evaluaron, en la población aymara de Chile y Bolivia, el grado de certeza de la clasificación étnica de los individuos por sus apellidos y la mezcla genética experimentada por estas poblaciones. Estos autores observaron que existe una razonable correspondencia entre la clasificación étnica por apellidos y el fenotipo de los individuos establecido por marcadores moleculares.

En función de su origen étnico los apellidos también revelan identidad y parentesco y pueden ser rastreados a través del tiempo. Marcadas discontinuidades en la distribución de los apellidos pueden ser producidas por 
migración de las poblaciones y relocalización de grupos étnicos (Sokal et al., 1992). La distribución espacial de apellidos sugiere localización y la presencia de discontinuidades regionales implicaría casos de flujo génico (Sokal et al., 1992). El análisis de la distribución espacial y temporal de los apellidos permite conocer o ponderar, de manera aproximada, cuántos individuos continuarían viviendo en el área donde sus ancestros se encontraban asentados cuando se comenzaron a utilizar los apellidos (Manni et al., 2005). En otras palabras, la distribución actual de los apellidos revelaría los efectos no sólo de la migración reciente sino también de la del pasado (Mascie Taylor y Lasker, 1990).

Como elemento analítico, los apellidos permiten estudiar la estructura de las poblaciones en términos de su consanguinidad y parentesco biológico. Rodríguez Larralde (1986) propone una categoría de análisis basada en la frecuencia y distribución espacio-temporal de los apellidos que permite evaluar el aislamiento, el sedentarismo, la semejanza y relación de poblaciones en un área geográfica determinada (Castro de Guerra et al., 1990).

Tomando a los apellidos como el elemento a ser analizado, fundamentalmente desde el campo de la lingüística, se considera el significado, uso, relaciones, origen, difusión, cambios y extinción de los apellidos.

\section{Supuestos teóricos considerados para usar apellidos en el estudio de poblaciones humanas}

Como se ha mencionado previamente, los apellidos son un hecho prácticamente universal e, independientemente del significado que tengan, son nombres de familia que se heredan, característica que los ha hecho muy útiles en los estudios de poblaciones humanas.

Sin embargo, para su uso se parte de las siguientes suposiciones básicas:

1) Los apellidos son monofiléticos

Todas las personas con igual apellido descienden de un antepasado común, es decir, están emparentados biológicamente. 
2) Los apellidos están sujetos a regulación hereditaria

En la mayoría de las culturas los nombres de familia o apellidos son transmitidos de padres a hijos de generación en generación. Puede decirse entonces, que, simultáneamente con la transmisión de los apellidos hay una herencia biológica involucrada o que la herencia del apellido en alguna forma es similar a la herencia genética.

Generalmente los apellidos son transmitidos a través de la línea masculina y por eso muchos autores los conciben como análogos a un locus presente en el cromosoma Y. Pero esto no es cierto para todas las culturas ya que, en algunas, los apellidos son transmitidos matrilinealmente. Cualquiera sea el mecanismo de transmisión del apellido, estos pueden ser considerados similares a marcadores genéticos para la determinación de antepasados comunes en una población.

3) Los apellidos se reparten proporcionalmente en la población

Los apellidos son transmitidos por el padre o la madre a toda su descendencia, independientemente del sexo de ésta, y por tanto, se reparten uniformemente en la población.

4) Los apellidos son selectivamente neutros

Puesto que se les concibe como alelos de un locus del cromosoma Y, se supone que su evolución es similar a la de los genes y que no confieren ventajas biológicas a quien los usa, es decir, son selectivamente neutros. Sin embargo, esa neutralidad biológica muchas veces se ve alterada por presiones de tipo social. Los apellidos están estrechamente asociados con creencias personales, religión y tradición (Azevedo, 1980), de allí que como fenómeno cultural, estén sujetos a presiones selectivas de tipo socio-económico que pueden invalidar la suposición de neutralidad.

5) Los apellidos permanecen constantes a través del tiempo 
Los apellidos se distribuyen proporcionalmente en ambos sexos en la población; este hecho, aunado a que las mutaciones o cambios en los mismos son poco comunes, hace posible que los apellidos permanezcan constantes a través del tiempo.

\section{Ventajas y desventajas del uso de apellidos}

Las principales ventajas resultan de ciertas características de los apellidos:

1) Fácil acceso y disponibilidad de los datos

Pueden obtenerse listas de los habitantes de un lugar a través de muchas fuentes de información. Las fuentes de listas de apellidos más comúnmente utilizadas son de tres tipos:

a) Registros civiles: matrimonios, actas de nacimiento, actas de defunción. Archivos municipales: documentos de propiedad, listas de contribuyentes.

b) Registros eclesiásticos: dispensas matrimoniales, actas matrimoniales, actas bautismales, actas de defunción.

c) Otros: bancos de sangre, directorios telefónicos, padrones electorales, censos de población, registros de conductores.

2) El uso de apellidos reduce el tiempo y los costos de la investigación

Esta ventaja se desprende directamente de la citada anteriormente, ya que la variedad y disponibilidad de las distintas fuentes de información hace posible que los datos puedan ser obtenidos rápidamente y a costos muy bajos.

Sin embargo, el uso de apellidos en el estudio de poblaciones humanas tiene algunas desventajas, producto casi siempre del incumplimiento de los supuestos mencionados anteriormente. Entre las más relevantes pueden mencionarse las siguientes: 
1) Polifiletismo: El origen de los apellidos en las poblaciones debe ser monofilético, es decir, todos los representantes de un mismo apellido deben provenir biológicamente de un antepasado común, transmisor inicial del apellido en cuestión. En la mayoría de las sociedades los apellidos son de origen polifilético, razón por la cual muchas personas que portan el mismo apellido pueden no tener parentesco biológico.

2) Inconsistencia: La herencia del nombre debe seguir a la herencia biológica, razón por la cual, en sociedades muy heterogéneas, la inconsistencia en la forma en que se transmite el apellido, la ilegitimidad, la adopción, cambios de apellidos y/o letras o simples errores de transcripción pueden hacer difíciles o erróneas algunas suposiciones de tipo genético.

A pesar de las restricciones impuestas por estas desventajas y la imposibilidad de cumplir con los supuestos teóricos previamente enunciados, los apellidos constituyen en la actualidad un recurso metodológico esencial de la bioantropología y de la genética de poblaciones humanas. El disponer de los apellidos de toda la población permite tener una visión global del comportamiento genético y demográfico de ésta, visión que no siempre es posible lograr utilizando, sobre todo en genética, otros métodos más costosos, lentos o difíciles (Pinto Cisternas y Castro de Guerra, 1988). Aplicando el método adecuado para cada caso y considerando que los resultados representan una medida relativa y no absoluta de la afinidad biológica inter o intra-poblacional, los apellidos conforman un excelente material de estudio biodemográfico para analizar la estructura genética de una población. 


\section{CAPÍTULO III: LA POBLACIÓN Y SU ESTRUCTURA}

En principio y en general, se podría definir una población como un conjunto de individuos con características comunes. Este concepto tiene un carácter relativo, ya que el compartir determinadas propiedades no excluye la posibilidad de que exista variación entre ellos. Por tanto resulta necesario definir, previamente, una serie de atributos a partir de los cuales sea posible que un grupo de individuos, aparentemente disperso, forme parte de una misma unidad. Se podría decir entonces que una población es un conjunto de individuos que es homogéneo con respecto a una serie de atributos comunes definidos de antemano.

La definición precedente corresponde a una población ideal, atemporal, descontextualizada. Las poblaciones humanas, como todas las poblaciones biológicas, se pueden definir también como un conjunto de individuos que ocupan un "espacio dado en un momento específico" (Krebs, 1985) y que comparten ciertas propiedades biológicas determinantes de una alta cohesión reproductiva y ecológica en el grupo.

Las poblaciones humanas no son simples conjuntos de personas, son grupos de individuos, organizados sobre un espacio físico definido, que comparten un conjunto de características biológicas, sociales y culturales. Estas características, propias de cada población y que la estructuran de manera particular, son producto de un complejo desarrollo bio-socio-cultural (Castro de Guerra, 1987).

La complejidad de la población como objeto de estudio y sus problemas asociados justifican la interdisciplinariedad de su abordaje y la necesidad de un enfoque global que contribuya a integrar las múltiples interrelaciones entre los diversos fenómenos característicos de las poblaciones humanas (demográficos, sociales, biológicos, económicos, etc.) (Dipierri, 2004). Todo esto hace que la definición de población humana resulte problemática, no sólo por la diversidad espacial y temporal de las estructuras sociales, demográficas, genéticas, 
económicas, etc., entre y dentro de las poblaciones, sino también por los límites lábiles mediante los cuales las poblaciones se auto-perciben y son percibidas (Macbeth y Collison, 2002).

La estructura poblacional hace referencia fundamentalmente a la dimensión espacial, mientras que la dinámica poblacional se relaciona con la dimensión temporal intentando escribir e interpretar los cambios ocurridos en los aspectos analizados. Pero la estructura difiere de acuerdo a cada enfoque disciplinario.

\section{La demogenética}

La demografía, en su sentido más amplio, consiste en el estudio estadístico de las poblaciones humanas. En sentido restringido, e incluyendo parámetros geográficos y socioeconómicos, la estructura demográfica se refiere a la composición de la población por edad y sexo, al análisis de las frecuencias de nacimientos, muertes y migraciones que ocurren en ella y a la manera en que estos factores influyen en el tamaño de la población (Cavalli-Sforza y Bodmer, 1981; Alfaro y Dipierri, 2000; Avena et al., 2001).

Desde una perspectiva biodemográfica la estructura de la población se refiere a todos los factores que la conforman biológicamente y que contribuyen a su diversidad genética. Concretamente, considera los factores demográficos que determinan la dispersión de genes en el tiempo y en el espacio, dentro y entre individuos, así como la magnitud de la deriva genética (Fuster, 2003).

La estructura genética se relaciona con las desviaciones de la panmixia o uniones al azar como consecuencia del número limitado de ancestros, de la preferencia por determinado tipo de uniones consanguíneas, por la migración ocurrida en determinados espacios sociales o geográficos (Dipierri et al., 2005) y tomaría en cuenta además factores tales como el tamaño y distribución de las poblaciones subdivididas (Lasker y Mascie-Taylor, 1993). Sin embargo, los modelos convencionales de genética de poblaciones se aplican a caracteres con un número restringido de alelos, que se heredan de una generación a la 
siguiente ignorando la estructura por edad de la población, su distribución espacio-temporal y sus características socioeconómicas y de comportamiento (Cavalli-Sforza et al., 1994).

La genética demográfica o demogenética combina la teoría genética con los datos demográficos. Como una extensión y generalización de la genética de poblaciones, la demogenética toma en cuenta la información demográfica detallada de las poblaciones humanas para proponer un modelo de la estructura genética de las mismas y ofrecer un espacio de reflexión sobre los cambios evolutivos y los procesos ocurridos para conformar esta estructura (Lasker y Mascie-Taylor, 1993; Acreche et al., 2000; Demarchi et al., 2000).

El estudio de la estructura de poblaciones no es fácil, ya que deben considerarse todos los aspectos que confieren a las poblaciones sus características particulares. Las poblaciones humanas están sometidas a procesos biológicos, sumergidas en complejas instituciones sociales, culturales y económicas y ocupan espacios (sociales, geográficos y ecológicos) cambiantes y diversos. Por tal motivo, el método utilizado debe considerar el mayor número de factores posibles, con el propósito de obtener un modelo lo más completo posible de la realidad que se está estudiando. En este sentido, los apellidos han permitido proponer algunos elementos útiles en el estudio de poblaciones humanas.

En esta tesis se intentará analizar la dinámica antroponímica y la estructura demogenética de Casabindo. En el caso de la genética se recurrirá a la utilización de indicadores construidos a partir de una variable cultural, los apellidos. La escasez y dispersión de la información demográfica para esta localidad y la inexistencia de la información genética para el período considerado constituyen, a la vez, una limitación y un estímulo para llevar a cabo este análisis. 


\section{La estructura de población y los apellidos}

La distribución de los apellidos puede suplir la información cuantitativa sobre la estructura genética de las poblaciones humanas. Como se mencionara previamente, las desviaciones de las uniones al azar o panmixia determinan la estructura genética de una población (Cavalli-Sforza y Bodmer, 1981).

Estas desviaciones pueden ser evaluadas a través del coeficiente de consanguinidad F (Wright, 1951), por lo tanto la estimación del F constituye una tarea básica y fundamental en el estudio de la estructura genética de una población (Cavalli-Sforza y Bodmer, 1981). Una estimación de la consanguinidad poblacional puede obtenerse mediante el uso de apellidos aplicando el método isonímico.

\section{Los apellidos como indicadores de migración}

El fenómeno demográfico de la migración constituye un factor importante en la evolución biológica de las poblaciones humanas que afecta también su estructura. La comparación de las estimaciones de las tasas de migración, inferida a partir de la distribución de apellidos, con las

proporcionadas por las fuentes demográficas tradicionales, indica que la distribución de los apellidos de una población permite obtener estimaciones confiables de los patrones migratorios recientes y de los cambios en la distribución geográfica de las poblaciones subdivididas (Piazza et al., 1987; Mourrieras et al., 1995).

En 1967 Karlin y McGregor propusieron el modelo de distribución teórica de los alelos neutros que se esperan en una población de $\mathrm{N}$ individuos, sujetos a procesos de muerte al azar, cada uno portando 1 de cada $\mathrm{k}$ diferentes alelos. Dado que los apellidos se consideran como múltiples alelos de un mismo locus (Piazza et al., 1987), estos se pueden analizar recurriendo a la teoría de Karlin y McGregor (1967).

La teoría prevé que los individuos muertos sean reemplazados por otros que portan el mismo apellido o externamente, con una tasa $\mathbf{v}$, por mutaciones 
de los apellidos y por la introducción de otros apellidos por inmigración. Dado que el v de Karlin-MacGregor (1967) equivale a la suma de los apellidos mutados, fenómeno poco frecuente en sociedades con transmisión regular de los patronímicos, más la tasa de inmigración, mucho más frecuente, razonablemente se puede asumir que v equivale a esta tasa (Piazza, et al., 1987; Zei et al., 1993). Otra manera de evaluar la migración de una población a partir de la distribución de los apellidos es la sugerida por Rodríguez Larralde (1986), a partir del análisis de la frecuencia y distribución espacio-temporal de los apellidos. 


\section{CAPÍTULO IV: EL MÉTODO ISONÍMICO}

Isonimia o isonomía es un término que significa ocurrencia del mismo apellido en dos individuos, la proporción con la cual ésta se presenta (Lasker, 1985) o la similitud en el apellido (Rawling, 1973).

Los antecedentes del uso de la isonimia para estimar consanguinidad se remontan a 1875 cuando G. H. Darwin (nieto del célebre Charles Darwin) sugirió su empleo para estimar las frecuencias de casamientos entre primos hermanos (Valls, 1982). El fundamento estadístico para el empleo de apellidos en el cálculo de la consanguinidad sostiene que en una población los matrimonios entre personas del mismo apellido que no sean parientes, son proporcionales a la frecuencia de cada apellido en la población. Posteriormente Crow y Mange (1965) empleando el mismo principio desarrollaron el método isonímico para estudiar la consanguinidad, no sólo entre primos hermanos, sino de toda la población, asumiendo que todos los individuos con el mismo apellido han heredado éste a partir de un ancestro común. La propuesta de Crow y Mange (1965) permite superar la imposibilidad del cálculo de la consanguinidad en poblaciones sobre las cuales no se dispone de información genealógica o la información genética no existe o está incompleta.

Crow y Mange (1965) advirtieron la relación constante, independientemente del grado de parentesco, entre la probabilidad de los parientes de tener el mismo apellido o isonimia (I) y el coeficiente de consanguinidad de su descendencia (F), tal que I/F es siempre igual a 4.

$$
\mathrm{I} / \mathrm{F}=4
$$

El F estimado por isonimia está compuesto por: a) un componente al azar de las uniones $(\mathrm{Fr})$ que se expresa como una función del número con determinado apellido, por sexo en la población; b) un componente no azaroso (Fn) que resulta de la preferencia o rechazo intencional de las uniones. 


$$
\mathrm{Fr}=\sum \text { piqi } / 4
$$

donde pi es la frecuencia del apellido i en los hombres y qi del mismo apellido en las mujeres. En el caso de las poblaciones donde no se dispone de listados matrimoniales

$$
\mathrm{Fr}=\Sigma \mathrm{i} \text { pi2 }
$$

El componente no azaroso Fn se estimaría de acuerdo a la siguiente fórmula:

$$
\text { Fn }=\left(I-\sum \text { piqi }\right) /\left[4\left(1-\sum \text { piqi }\right)\right]
$$

donde I es la frecuencia observada de uniones isonímicas en la población

\section{Antecedentes locales, nacionales e internacionales}

A nivel local, Eric Boman, incluyó dentro de sus investigaciones del NOA un relevamiento de nombres y apellidos de esta región (Boman, [1908] 1992). Sin embargo, los primeros estudios realizados en el país recurriendo al método isonímico fueron concretados en el año 1985 en la Provincia de Jujuy (Dipierri et al., 1991). Estos análisis se llevaron a cabo en la población histórica (1734-1810) de la Parroquia de Humahuaca y la fuente de información procedió de los Libros Parroquiales de Bautismo. A este trabajo sucedieron otros sobre la consanguinidad y la relación interpoblacional por isonimia y el aislamiento de las poblaciones jujeñas localizadas a distintos niveles altitudinales, recurriendo a diferentes fuentes de información (padrones electorales, actas de matrimonios civiles, etc.). Gran parte de los resultados de estos estudios ya han sido publicados (Alfaro y Dipierri, 1995, 1996; 1997; Alfaro et al., 2007; Bejarano et al., 2009; Costa-Junqueira et al., 2000; Dipierri y Alfaro, 1996; Dipierri, et al., 
1991; 1994; 1999; 2005; 2007; Mascitti et al., 1991; Morales et al., 2003; Ocampo et al., 1988).

En el marco de los estudios de antroponimia que se vienen realizando para la Puna de Jujuy, y en especial para Casabindo desde fines de la década de 1990, son varios los trabajos elaborados sobre el tema. Entre ellos se destaca el análisis, a partir de los apellidos, de la estructura poblacional de los cuatro curatos de la Puna de Jujuy (Alfaro et al. 1998 m.s.; Alfaro et al., 2001 m.s.), el estudio de la consanguinidad y de la identidad de los casabindos a través del origen de sus apellidos (Alfaro et al. 1999 m.s.; Albeck et al.,2000; Albeck et al., 2005 m.s.), la comparación de la antroponimia entre Casabindo y Atacama a fines del siglo XVII (Albeck et al. 2000 m.s.) y el seguimiento de los apellidos y de los cambios en la estructura sociodemográfica de la población de Casabindo por más de 400 años (Albeck et al. 2007; Alfaro et al. 2005).

Además de los estudios isonímicos realizados en la provincia de Jujuy (Albeck et al., 2000; Alfaro y Dipierri, 1993, 1995, 1994 1996a; 1996b; Dipierri et al., 1988a, 1988b, 1994, 1985a, 1985b, 1986, 1991), existen escasos antecedentes referidos a otras provincias del NOA (Alfaro, 2000, Alfaro y Dipierri, 2000, Dipierri, 2004; Dipierri et al., 2005; 2006; 2007).

Trabajos relevantes de isonimia han sido realizados tanto fuera como dentro de nuestro país, en vista a lo expresado por Colantonio et al. (2003) en su revisión.

En 1983 Human Biology dedicó un número especial a trabajos originales y revisiones sobre el tema de isonimia. Para esta misma época, Lasker (1980; 1985) realizó una exhaustiva revisión sobre estudios de apellidos y estructura genética realizados en Asia, Oceanía, el continente europeo y América del Norte.

El Dr. Rodríguez Larralde del Instituto Venezolano de Investigaciones Científicas (Venezuela) y el Dr. Italo Barrai de la Universidad de Ferrara (Italia), desde la década de los '80 vienen aplicando el método isonímico para evaluar la estructura genética de ciudades o estados de Venezuela (Rodríguez Larralde, 
1990; 1993; 1997; Rodríguez Larralde et al., 1993a; Rodríguez Larralde y Casique, 1993; Rodríguez Larralde y Barrai, 1997a, 1997b, 1997c; 1998), Italia (Barrai et al., 1987; 1991; Beretta et al., 1993; Rodríguez Larralde et al., 1993b; 1994) y Argentina (Bronberg et al., 2009) o bien de todo un país tales como: Italia (Barrai et al., 1999), Venezuela (Rodríguez Larralde et al., 2000), Suiza (Barrai et al., 1996; Rodríguez Larralde et al., 1998c), Alemania (Barrai et al., 1997; Rodríguez Larralde et al., 1998b), Austria (Barrai et al., 2000), España (Rodríguez Larralde et al., 2003), Estados Unidos (Barrai et al., 2001), Holanda (Barrai et al., 2002) y Argentina (Dipierri et al., 2005).

En cuanto a los antecedentes latinoamericanos sobre el uso de los apellidos en estudios de estructura poblacional, los mismos no son tan abundantes como los realizados en otros continentes (Pinto Cisternas y Castro de Guerra, 1988; Lasker, 1991) y fundamentalmente se aplican a estudios de: 1) diferenciación étnica; 2) consanguinidad y estructura genética; y 3) relación por isonimia inter o intrapoblacional (Ri) (Lasker, 1977, 1985). Los mismos se han concretado fundamentalmente en Venezuela (Rodríguez Larralde, 1993; Rodríguez Larralde et al., 1993a; Rodríguez Larralde y Casique, 1993; Rodríguez Larralde, 1997a; Rodríguez Larralde y Barrai, 1997a, 1997b, 1997c), Chile (Costa-Junqueira et al., 2000), Argentina (Alfaro y Dipierri, 1995, 1996; Barrai et al., 2005; Colantonio, 1998; Dipierri y Alfaro, 1994, 1995, 1996; 2006; Dipierri, et al., 1985a, 1985b, 1986, 1988a, 1988b, 1990, 1991, 1994; Mascitti et al., 1991; Ocampo et al., 1988;); Perú (Lasker, 1977); Colombia (Pineda et al., 1999), Brasil (Azevedo y Freire, 1989).

En la comunidad científica latinoamericana se reconocen avances metodológicos importantes, concretados sobre todo en el Instituto Venezolano de Investigaciones Científicas (IVIC). Pinto Cisternas et al. (1985), basándose en el hecho de que en algunas poblaciones latinoamericanas y en España cada individuo porta dos apellidos, modificaron el método de Crow y Mange (1965) para el cálculo de la consanguinidad por isonimia en poblaciones latinoamericanas y diseñaron el IASS (Iberoamerican Surname System). Rodríguez Larralde (1986) propuso la utilización de los indicadores de 
aislamiento y sedentarismo. Castro de Guerra et al. (1990) por su parte, y considerando la distribución espacial (geográfica) y la frecuencia de los apellidos, diseñaron una clasificación de los mismos teniendo en cuenta estas dos características.

Esta síntesis revela que los apellidos como estimadores de estructura de población cuentan con sólidas bases teóricas y metodológicas reconocidas en los abundantes antecedentes sobre su empleo en la comunidad científica tanto nacional como internacional. 


\section{OBJETIVOS}

\section{Objetivo general}

Esta investigación se propone utilizar los apellidos como discriminante étnico y como elemento analítico para evaluar la dinámica antroponímica y la estructura demogenética entre los siglos XVI y XXI de la población comprendida en el espacio propio de los casabindos en la época colonial.

\section{Objetivos específicos}

1) Analizar los nombres o apellidos autóctonos y registrar su persistencia, mutación o extinción durante el período considerado

2) Establecer la diferenciación étnica a partir de la frecuencia de apellidos autóctonos y foráneos.

3) Determinar la estructura poblacional a partir de parámetros demográficos (tamaño poblacional, índice de masculinidad, movimientos migratorios, etc.) y de indicadores isonímicos (consanguinidad, aislamiento, sedentarismo, etc.)

4) Evaluar la variación espacio-temporal dentro y entre las poblaciones consideradas.

5) Establecer relación entre los procesos demogenéticos y el desarrollo del sistema antroponímico. 


\section{FUENTES Y METODOS}

\section{CAPÍTULO V: LAS FUENTES}

Para el cumplimiento de los objetivos propuestos, fue necesario obtener la información a partir de diversas fuentes de datos.

Las fuentes primarias utilizadas en este trabajo comprenden:

a) un documento sobre los casabindos del siglo XVI;

b) el padrón más antiguo existente para casabindos y cochinocas, correspondiente a mediados del siglo XVII;

c) un padrón de tributarios de Casabindo fechado en 1688;

d) dos registros de población de fines del siglo XVIII;

e) el Segundo Censo Nacional de la República Argentina realizado en 1895;

f) padrones electorales correspondientes a 1982 y 2001 .

El documento más antiguo para Casabindo que presenta una serie de nombres nativos, si bien breve, corresponde al año 1557, poco más de 20 años después de la entrada de Diego de Almagro. Se trata del bautismo del cacique de Casabindo, su mujer, su hija y otras cuatro niñas. Este documento ha sido transcripto y publicado por Martínez (1992). A los fines de este trabajo, lo que interesa es la presencia de un conjunto de nombres, tanto masculinos como femeninos, utilizados en una fecha muy temprana. Aunque los bautizados en esa oportunidad fueron pocos, se registraron los nombres de los progenitores de todos ellos. Por dicha razón, para este primer período sólo se cuenta con los nombres de 7 individuos de sexo masculino y 12 de sexo femenino.

El segundo documento corresponde al padrón que se realizó al pasar la encomienda de casabindos y cochinocas a Pablo Bernárdez de Obando en 1654 
(Palomeque y Tedesco, m.s.). Dicha encomienda había quedado vacante con la muerte de Fernando de Sanabria en 1653. En el documento se hace referencia a padrones anteriores (1630 y 1636) que no han sido localizados hasta el momento. Este empadronamiento fue realizado teniendo como base los padrones previos, a los cuales se hace referencia en varias oportunidades, y en él se corrigen las denominaciones de unos pocos individuos que anteriormente habían sido registrados en forma errónea. El padrón de 1654 comprende un total de 394 individuos para Casabindo y 174 para Cochinoca estimándose que podrían corresponder al total de la población en ese momento ${ }^{1}$. El empadronamiento fue realizado por categoría tributaria incluyendo la familia y, además de identificar a cada habitante por nombre, se detalla la edad, estado civil y cargos ("cacique", "alcalde") o funciones ("señalado para cantor", “danzante”). Este padrón discrimina únicamente entre Casabindo y Cochinoca, sin detallar otras localidades menores.

El tercer documento es el Padrón de la encomienda de Juan Joseph Campero de Herrera realizado por Miguel Bernárdez de Ovando con asistencia de Joseph de Rentería en 1688, poco más de 30 años después del anterior. En este documento se consigna para cada individuo nombre, edad, estado civil y cargos ("cacique", "sacristán", "alguacil") o funciones ("maestro cantor", "cantor"). Se registran 182 varones y 162 mujeres y se dice expresamente que no se registran las viudas y los huérfanos.

Los documentos de fines del siglo XVIII considerados son el Censo ordenado por Carlos III al crearse el Virreinato del Río de La Plata, que para la puna de Jujuy fue realizado en 1778/79 (Rojas, 1913), y el padrón de tributarios de 1786 para la misma zona geográfica². El Censo se halla rubricado por el tercer Marqués de Yavi y Tojo (Juan Joseph Martierena del Barranco) y el

\footnotetext{
1 "con lo cual se acabo este padron y Don Juan Quipildor governador y casique principal y Pablo Tabar, casique alcalde que se hallaren presentes y dixeron que no ay mas indios ni xente ni saven ni tienen noticia de otros mas presentes y ausentes y que este padron se a hecho con toda rectitud fidelidad sin ocultar persona alguna..." (Palomeque y Tedesco m.s.)

2 El padrón de 1786 fue consultado en base a la fotocopia del documento original localizado en AGN por S. Palomeque.
} 
padrón fue levantado por Joseph de Medeyros. Ambos discriminan la población según su residencia en diferentes localidades, tanto para Casabindo como para Cochinoca. El censo de 1778/79 comprende 1089 individuos y, al tratarse de un censo de población, no distingue entre originarios y forasteros. El Padrón de 1786, en cambio, diferencia estas dos categorías tributarias y suma una población de 1467 personas para Casabindo. Según nuestro análisis, en el primer caso es muy probable que el Censo se haya realizado por unidad doméstica porque con las familias nucleares se incluyen otros integrantes con diverso grado de parentesco (por ejemplo sobrinos huérfanos). En 1786, en cambio, el registro se hizo según las categorías tributarias incluyendo con cada categoría la familia nuclear a cargo y listando aparte los huérfanos. En ambos casos se consignó la edad, estado civil, parentesco, cargos ("gobernador", “segunda persona").

Se analiza también el segundo Censo Nacional de Población realizado en $1895^{3}$ y que para el área de Casabindo comprende un total de 1051 individuos, 551 mujeres y 500 varones. En este documento se registra localidad, apellido y nombre, sexo, edad, estado civil, nacionalidad y para algunos individuos ocupación (cura, sacristán, comerciante, médico) o características particulares (sordo, ciega, rengo, muda, loco).

Las fuentes más recientes consultadas corresponden a los Padrones Electorales de 1982 y 2001, donde los electores se encuentran discriminados en mesas masculinas y femeninas. Para cada individuo consta el apellido, nombre, número de documento, ocupación y lugar de residencia. A los datos anteriores se agrega la "clase" o año de nacimiento en el caso de los varones. Para 1982 se registran en Casabindo 1725 individuos repartidos en 697 varones y 1028 mujeres. En el padrón de 2001 figuran empadronados 1752 individuos mayores de 18 años (758 varones y 994 mujeres).

3 Se consideró el Segundo Censo Nacional en tanto en el Primero, de 1869, realizado durante el gobierno de Sarmiento, toda la población fue censada bajo Cochinoca, no pudiéndose discriminar la parte correspondiente a Casabindo. 


\section{CAPÍTULO VI: LOS CASABINDOS}

La puna de Jujuy se encontraba, al momento del contacto español, poblada por una diversidad de grupos autóctonos cuyos nombres han perdurado a través de la documentación etnohistórica pero que fueron desapareciendo como consecuencia de distintos procesos de disrupción étnica (Lorandi y Otonello, 1992). Aparentemente, los grupos propios de la Puna de Jujuy fueron los apatamas, los casabindos y los cochinocas.

Casi desde los albores de la arqueología argentina las etnías de la puna de Jujuy han sido tema de discusión y su estudio ha involucrado a varios autores (Boman [1908]1992; Canals Frau 1940; Krapovickas 1978; Martínez 1991; Vignati 1931). En función de los conocimientos aportados por estos investigadores, se puede plantear un panorama tentativo de la ubicación espacial de las poblaciones que habitaban las áreas aledañas a Casabindo. Entre ellos, parece indiscutible la presencia de pueblos chicha inmediatamente al norte de Cochinoca, abarcando un territorio que continuaba por el sur de Bolivia; de omaguacas flanqueando toda la zona por el este, de atacamas al oeste; de urus ${ }^{4}$ en el oeste y de diaguitas en los valles mesotérmicos al sur (Carrizo 1989). Sin embargo, los casabindos y cochinocas no han podido ser incluidos en ninguno de los grupos colindantes, en forma categórica.

A partir de los datos arqueológicos y de algunas referencias coloniales (Krapovickas, 1978; 1983; Albeck, 2003; 2007) se ha planteado que los casabindos y cochinocas ocuparon la mayor parte de la Puna de Jujuy en tiempos prehispánicos. En la actualidad, se los considera como grupos con una identidad distintiva que los diferenciaría de pueblos aledaños como los atacameños, chichas y apatamas (Presta, 2001), omaguacas y diaguitas (Krapovickas 1978) aunque, hasta el momento, las evidencias arqueológicas no permiten discriminar a los casabindos de los cochinocas, ambos incluidos

4 Reflejados en la toponimia como “Urusmayo” y otros afines (Carrizo 1989). 
dentro de una gran unidad arqueológica conocida como "casabindo", en gran parte coincidente con el área ocupada en la época colonial por ambos "pueblos de indios" 5 pero que incluye también otros sectores de la puna.

El territorio de las sociedades preincaicas de la Puna se vio notablemente restringido por la instalación de españoles a fines del siglo XVI y principios del XVII, fundamentalmente por la explotación de menas metalíferas (Albeck y Palomeque, 2009). Hasta 1602 tanto casabindos como cochinocas residían, aparentemente, en sus solares prehispánicos y a partir de allí se los instaló, según las pautas españolas, en los "pueblos de indios" donde fueron reducidos ocupando las áreas aledañas a las localidades actuales del mismo nombre (Sica, 2006).

Después de la llegada de los españoles los casabindos y cochinocas fueron encomendados en una fecha temprana, antes de mediar el siglo XVI, aunque permanecieron sublevados hasta la última década de dicho siglo (Palomeque, 2006). A principios del siglo XVII fueron reducidos y la encomienda se efectivizó; en 1654 se encuentra en manos de Pablo Bernárdez de Ovando para continuar bajo el Marquesado de Tojo durante toda la época colonial (Madrazo, 1982; Palomeque y Tedesco m.s.; Zanolli, 2005). En 1655, el flamante encomendero Bernárdez de Ovando, pidió en merced ${ }^{6}$ el sector central de la Puna que incluía en este espacio a las reducciones y áreas productivas de los casabindos y cochinocas (Albeck y Palomeque, 2009). Dicha merced abarcaba fundamentalmente la cuenca de Miraflores-Guayatayoc y una pequeña parte al sudeste de la de Pozuelos7. Posteriormente los casabindos obtuvieron, por "donación" de Campero8, las áreas de Barrancas y Cobres

\footnotetext{
5 Se entiende como "pueblo de indios" al resultado del poblamiento concentrado al que fue obligada la población indígena por parte de las autoridades coloniales.

6 Conocida como “Merced de la Quebrada de la Leña” (Sica 2006)

7 Bernárdez de Ovando en 1662 solicitó a su vez la adjudicación de toda la parte sur y oeste de la Puna, casi hasta el actual límite con Chile.

8 Juan José Fernández Campero, yerno de Bernárdez de Ovando, quien sería, años después, el primer Marqués de Tojo
} 
(actualmente Salta), conformándose así el territorio colonial de los cochinocas y casabindos.

En algunos de los registros coloniales de población (padrones y censos), que comprenden una serie que se inicia a mediados del siglo XVII y culmina a principios del XIX, se destacan los lugares de residencia de los pobladores. La secuencia en que se nombran las localidades y su proximidad geográfica ha permitido asignar determinadas localidades a los casabindos y otras a los cochinocas. Estos últimos se ubicaban en el sector más septentrional: el sur de la cuenca de Pozuelos y la parte norte de la cuenca del Río Miraflores. El área ocupada por los casabindos comprendía la cuenca del río Doncellas, la falda oriental de la sierra de Casabindo, la falda occidental de la sierra del Aguilar, la cuenca inferior del río de las Burras y la margen oriental de la laguna de Guayatayoc (Albeck, 2003) (Figura 1). Sin embargo, hay que recordar que ésta fue el área donde fueron reducidos y que su espacio, posiblemente, haya sido más amplio y menos compacto, debido a la presencia de otros grupos.

En este contexto debe tenerse en cuenta la propuesta de Martínez (1991) sobre la presencia de una "territorialidad interdigitada" entre los diferentes grupos de la puna árida, aunque este planteo merecería una discusión interdisciplinaria. Desde lo arqueológico se distingue la presencia de grupos con diferentes tradiciones culturales cuyos territorios están, en general, claramente marcados por la presencia discreta de determinados patrones de asentamiento, técnicas de construcción, elementos muebles (cerámica, puntas de flecha), funebria y otros (Albeck y Ruiz, 1998). La presencia de estos elementos se ve refrendada, además, por una toponimia diferencial en la actualidad, en parte coincidente con los datos arqueológicos y etnohistóricos (Albeck, 2009a). 


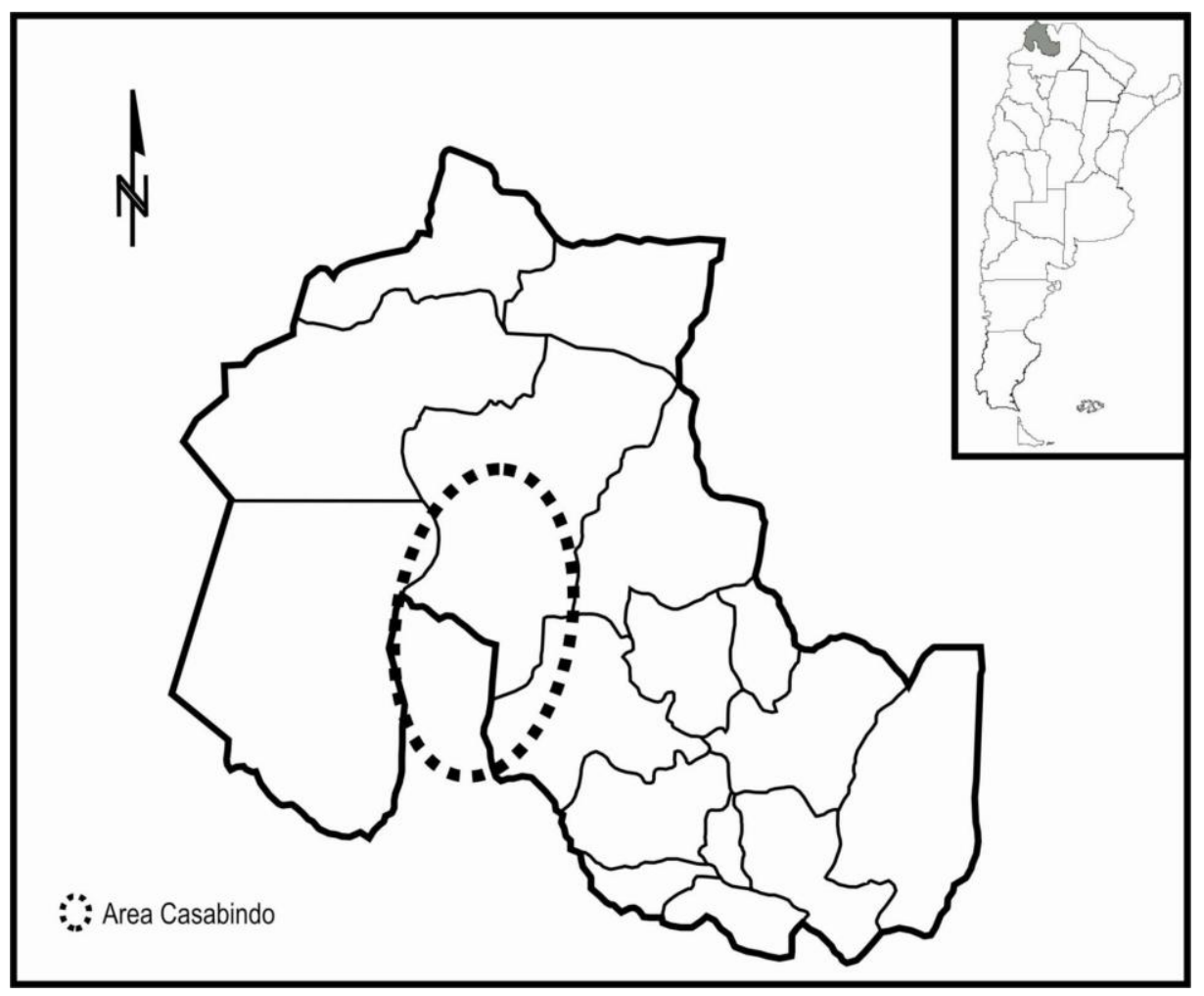

Figura 1: Área ocupada por los casabindos en la época colonial (Fuente Alfaro et al., 1999 m.s.)

La zona de Casabindo tiene un emplazamiento central en la puna de Jujuy y se encuentra relativamente próxima a zonas ecológicas muy diferentes como las selvas, el chaco, los oasis trasandinos y los valles mesotérmicos. Esta proximidad tuvo una importancia fundamental en el pasado prehispánico, dada la movilidad de personas y productos que generaba, y que se evidencia claramente en el registro arqueológico (Albeck, 2003). Una característica que diferencia a Casabindo de otras zonas de la puna, es el rol que cumplió la agricultura para las sociedades prehispánicas y aún las coloniales (Madrazo, 1982; Albeck 2003). La fuerte presencia agrícola en Casabindo seguramente permitió a los pobladores prehispánicos complementar la subsistencia basada en prácticas ganaderas. La carne, la lana y los tejidos debieron constituir bienes de gran importancia en el tráfico regional. Otro recurso económico de gran interés e importancia en el intercambio con las regiones vecinas y de fácil acceso desde Casabindo, estaba representado por la sal extraída de las Salinas Grandes. 
La documentación del siglo XVII muestra a los casabindos como el grupo más importante en la Puna de Jujuy, tanto política como numéricamente, quedando los cochinocas como una entidad subordinada. La autoridad principal de Casabindo había logrado el reconocimiento colonial de "Governador y cacique principal" que lideraba a ambos "pueblos de indios" de Casabindo y Cochinoca, cargo que se heredaba dentro de una descendencia o linaje, al menos en los siglos XVI y XVII (Palomeque, 2006). La situación preeminente de Casabindo parece revertirse en un momento posterior, quedando subordinada a Cochinoca, al menos en lo eclesiástico y administrativo.

Los casabindos lograron mantener el tronco de la población originaria hasta principios del siglo XIX. En dos padrones (1786 y 1806), realizados después de las reformas borbónicas, se destaca Casabindo como caso único en toda la puna jujeña por la ausencia de registro de "indios forasteros" ${ }^{\prime}$. En 1786, momento en que se empadronaron tanto los indios originarios como los forasteros en un mismo padrón, aparece claramente que en Casabindo figuran exclusivamente "originarios con tierras" mientras en Cochinoca se registra población de ambas categorías (originarios y forasteros). En 1806, momento en que nuevamente se censa ambas categorías pero separando en padrones distintos a los originarios de los forasteros, nuevamente la información es coincidente, en tanto la población de Casabindo vuelve a figurar únicamente como "originarios con tierras" (Palomeque, 1994). Lo destacable es que, a diferencia de Cochinoca, en Casabindo en 1806 no residían familias donde ambos cónyuges eran forasteros. Esto permitiría suponer que la totalidad de la población de Casabindo de principios del siglo XIX descendía, por línea paterna o materna, de la población originaria del siglo XVI. Esto distingue a Casabindo de las demás localidades de la Puna de Jujuy registradas a fines de la época colonial (Cochinoca, Yavi, Rinconada y Santa Catalina).

9 Se entiende por "indios originarios" a aquellos que permanecen en el mismo pueblo donde sus ancestros fueron reducidos por las autoridades coloniales; y como "forasteros" a aquellos procedentes de otro lugar que han abandonado el pueblo de origen. 


\section{EL ÁREA DE ESTUDIO}

En este trabajo se utilizará como unidad de análisis el área ocupada por los casabindos durante la colonia. Dicho espacio no es enteramente coincidente en los diferentes registros trabajados. En el del bautismo del cacique (1557), se hace referencia al "valle de Casabindo", sin poder establecerse, a ciencia cierta, a qué lugar podría corresponder. En el padrón de 1654 figura como localidad de empadronamiento "Santa Ana de Casabindo" que era el nombre de la reducción que, espacialmente, coincide con el actual pueblo de Casabindo; otro tanto ocurre en 1688. Ambos padrones discriminan únicamente entre Casabindo y Cochinoca, sin detallar otras localidades menores. No obstante, es muy probable que los empadronados habitaran también las áreas colindantes. Esto último se observa claramente en los registros de fines del siglo XVIII.

En 1778 el "Padrón del pueblo de Cochinoca y otros lugarsitos que corresponden a este curato" fue registrado con una modalidad en la que se subdivide el territorio según diferentes espacios de residencia. Para el "Pueblo de Casavindo" se detallan ocho localidades (Casabindo, Agua Caliente, Barrancas, Rinconadilla, Quebrada de la Leña, Agua de Castilla, Río de las Doncellas y Quesquesa) y cinco para Cochinoca (Cochinoca, Candelaria, Enquera, Caraguasi, Abra de Queta).

En 1786 también se discrimina la población según su residencia en diferentes lugares, tanto para el "Pueblo y Viceparroquia Asumpción de Nuestra Señora de Casabindo" como para Cochinoca. Los pobladores son empadronados en Casabindo y Doncellas, Barrancas y Rangel, Colorados y Saladillo.

En 1895 se incluye la población censada en las localidades registradas en las etapas previas, aunque tan sólo se discrimina entre Casabindo y Abralaite para el área de interés. En los Padrones electorales de 1982 y 2001 se seleccionaron los Circuitos homologables al área ocupada por los casabindos en el siglo XVIII. Dichos Circuitos son: Casabindo, Agua Caliente, Doncellas, Abralaite, Tusaquilla, Abdón Castro Tolay (Barrancas) y Rinconadillas en el 
Departamento de Cochinoca y Colorados en el Departamento de Tumbaya (Figura 2).

Debido a que las localidades consideradas en los distintos documentos no son idénticas, se plantea un problema a la hora de proceder a las comparaciones poblacionales por lo que se realizará el análisis considerando la población de Casabindo en conjunto. Sin embargo, se logró ubicar geográficamente las diferentes localidades censadas o empadronadas y situarlas en alguno de los tres núcleos principales de residencia de los casabindos a fines del siglo XVIII, definidos en función de su ubicación espacial en relación con la laguna de Guayatayoc: norte, este y oeste de la Laguna y de las Salinas Grandes; y a partir de allí se hizo entonces la comparación de los registros para 1778, 1786, 1982 y 2001 (Tabla 1). Es necesario aclarar que la localidad de Barrancas actualmente lleva el nombre de Abdón Castro Tolay.

Tabla 1: Correspondencia de localidades entre registros

\begin{tabular}{|l|c|c|c|}
\hline Área & 1778 & 1786 & 1982 y 2001 \\
\hline Norte & $\begin{array}{c}\text { Casabindo, Doncellas y } \\
\text { Quesquesa }\end{array}$ & Casabindo y Doncellas & Casabindo y Doncellas \\
\hline Este & $\begin{array}{c}\text { Agua Caliente, Quebrada } \\
\text { de la Leña y Agua de } \\
\text { Castilla }\end{array}$ & Colorados y Saladillo & Abralaite y Colorados \\
\hline Oeste & Barrancas y Rinconadilla & Barrancas y Rangel ${ }^{10}$ & $\begin{array}{c}\text { Tusaquilla, Abdón Castro } \\
\text { Tolay y Rinconadillas }\end{array}$ \\
\hline
\end{tabular}

10 La localidad de Rangel corresponde actualmente a la provincia de Salta. Se la incluye en los análisis efectuados hasta el siglo XVIII por cuanto no ha podido localizarse la información correspondiente a este lugar para el resto del período considerado. 


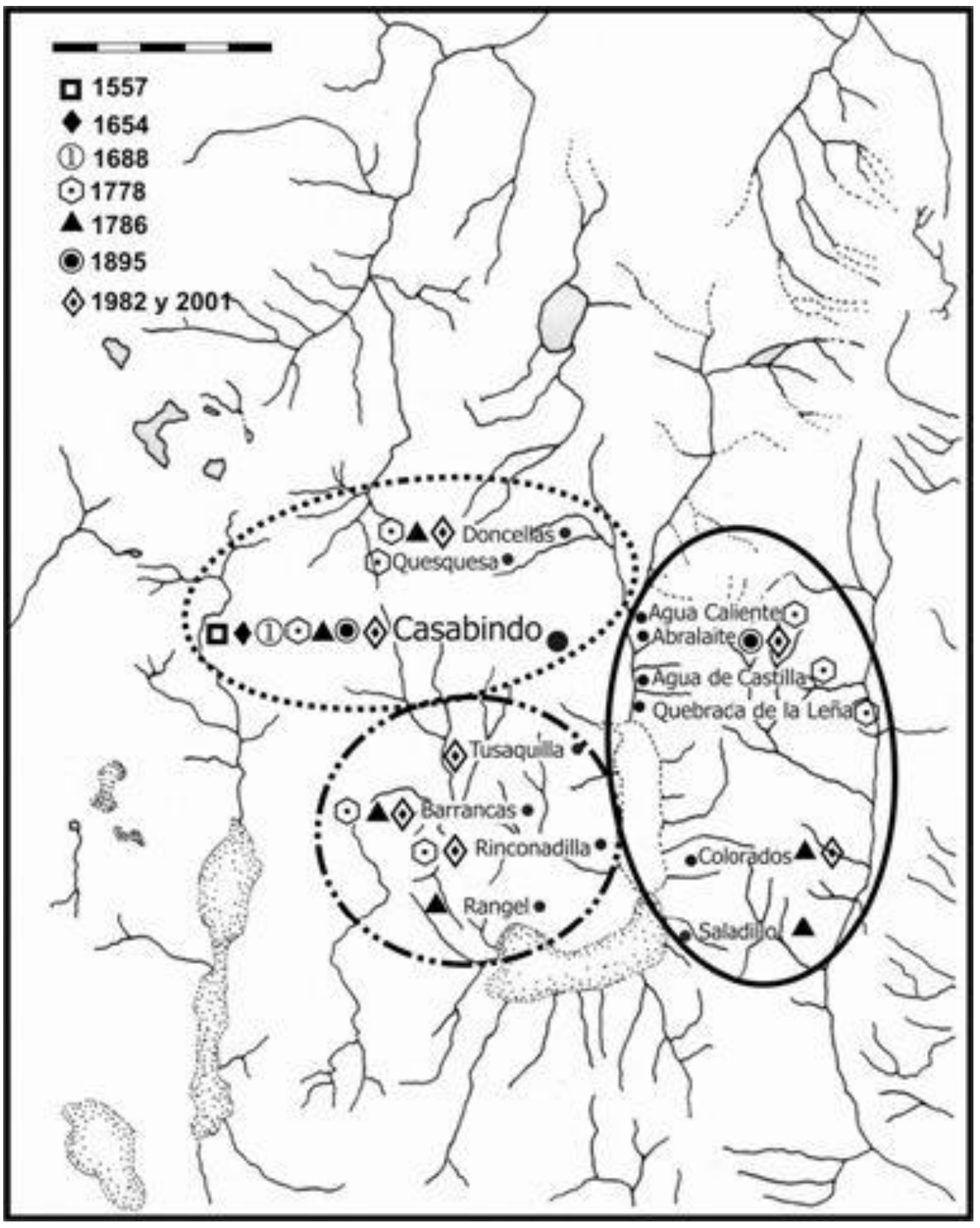

Figura 2: Localidades registradas en los distintos documentos (Modificado de Alfaro et al., 2005) 


\section{CAPÍTULO VII: LOS MÉTODOS}

La recolección de información fue realizada en dos etapas; la primera comprendió la revisión bibliográfica y obtención de datos de diversos tipos de registros civiles, con lo que se pretendía conseguir los antecedentes necesarios para describir el comportamiento espacio-temporal de los nombres y apellidos en la zona seleccionada.

Una vez cumplida esta etapa se procedió, para cada documento histórico analizado, a la elaboración inicial de bases de datos digitales las que incluyeron: nombres, segundos nombres o "apellidos" 11 (cuando aún no se presenta transmisión regular entre generaciones), apellidos (tal como los conocemos hoy), sexo, edad, parentesco, lugar de residencia al momento del registro y algunos datos ocasionales que hacían referencia a las características del individuo, a su función u oficio o a sus lazos de parentesco fuera de la familia nuclear.

A partir de la base digital, y en aquellos casos donde fue posible, se elaboró un gráfico genealógico que resumía los vínculos parentales para cada grupo familiar. A cada familia se le asignó un número correlativo, se consignó el lugar de residencia, nombre, apellido y edad de los miembros y se representó el vínculo parental. Esto se realizó para los documentos correspondientes a 1654, 1688, 1778 y 1786.

En el caso de los padrones electorales la base digital incluyó nombres, apellidos, sexo, sección y circuito electoral. Al no registrarse en estos documentos los vínculos de parentesco entre los individuos no fue posible la elaboración de los gráficos genealógicos.

11 De aquí en adelante se utilizará "apellido" entre comillas cuando se trate de la modalidad nominativa donde el segundo nombre, mayormente de origen indígena, aún no se transmite de forma regular a toda la descendencia. 


\section{ANÁLISIS DE NOMBRES Y APELLIDOS}

\section{DISCRIMINANTE ÉTNICO}

Los antropónimos provenientes de los documentos mencionados descriptos anteriormente, se agruparon en tres grandes categorías para analizar su origen étnico:

1) Autóctonos: aquellos en los cuales se reconoce la influencia (fonética o gráfica) de lenguas nativas tanto actuales como quechua y aymara o extintas como cacán y kunza. Para identificar estos apellidos se utilizaron distintas fuentes de información: catálogos, diccionarios, listados, etc. (Erdman, 1964, Nardi, 1979; 1986; Albeck, 2000; Medinaceli, 2003).

2) Foráneos: Son aquéllos que no pueden incluirse en la categoría anterior.

3) Indeterminados: Los apellidos que no pudieron asignarse a alguna de las categorías previamente señaladas, se clasificaron, en forma preliminar, como "indeterminados", hasta tanto se conozcan mejor los registros de nombres y sus respectivas frecuencias para las áreas aledañas a Casabindo y para el resto de la puna de Jujuy.

\section{ELEMENTO ANALÍTICO}

En los distintos documentos analizados, para cada una de estas categorías y para el total de los apellidos, se determinó por sexo:

1) recurrencia en los distintos documentos

2) $\mathrm{N}^{\circ}$ de apelativos diferentes ${ }^{12}$;

3) siete nombres o apellidos más frecuentes

4) $\mathrm{N}^{\mathrm{o}}$ de antropónimos únicos

$12 \mathrm{Al}$ contabilizar las frecuencias se unificaron las diversas grafías de un mismo nombre. Al tratarse de nombres indígenas y no existir reglas ortográficas en los siglos XVII y XVIII, un mismo nombre se podía escribir indistintamente de diversas maneras. Así se consideraron equivalentes Ba- y Gua- (Barcondi y Guarcondi) y ocasionalmente c y s (Basama y Guaçama). 


\section{ANÁLISIS DE LA ESTRUCTURA DEMOGENÉTICA DE LAS POBLACIONES CASABINDO Y SU VARIACIÓN TEMPORAL}

\section{ANÁlisis de lA ESTRUCTURA DEMOGRÁficA}

Se realizaron pirámides de población, diferencias de población entre los distintos documentos, análisis del desequilibrio de sexos, cantidad de varones que pudieran transmitir el nombre de su linaje, proporción de soltero/as, de casados, tamaño familiar, migraciones familiares e individuales (Boleda y Mercado, 1991; Henry, 1983; Keyfitz y Flieger, 1971; Pressat, 1983; Tapinos, 1988).

Las pirámides de población se emplearon para realizar la representación gráfica de datos demográficos básicos como la edad y sexo de las poblaciones correspondientes a los diferentes cortes temporales analizados. Esta representación permite percibir la ocurrencia de algunos fenómenos demográficos como el envejecimiento de la población, el equilibrio o desequilibrio entre los sexos, mortalidad infantil, etc. Es decir que, al analizar una pirámide de población se puede interpretar la dinámica y la evolución de una población $\mathrm{y}$, en algunos casos, ciertos factores que modifican su composición por edad y sexo.

Por otra parte, analizando varias pirámides de un mismo lugar correspondientes a diferentes momentos históricos, se puede reconstruir su historia demográfica, observando la evolución de los diferentes grupos etarios.

El análisis de las pirámides de población consistió en considerar el tamaño de cada grupo etario (la longitud de la barra que lo representa). El número inicial de individuos se va modificando por la mortalidad registrada por el grupo o por las variaciones debido a flujos migratorios, los cuales igual que la mortalidad, son selectivos. 


\section{ANÁlisis DE LA ESTRUCTURA GENÉTICA}

La estructura genética de una población está determinada, entre otros, por una serie de factores que limitan la elección de cónyuge debido a la edad, parentesco, religión, casta, tribu, etc. (Fuster, 2003). También la distancia geográfica entre los lugares de procedencia de los cónyuges, o entre el lugar de origen de éstos y el lugar donde transmiten sus genes, es un elemento restrictivo que afecta directamente la estructura de la población (Fuster, 2003).

\section{- Cálculo de la isonimia de una población:}

La isonimia o identidad de apellidos representa un estimador de la consanguinidad de las poblaciones ya que asume que todos los individuos portadores del mismo apellido están emparentados al haber heredado este apellido de un antepasado común.

Como se mencionara en el Capítulo IV el método isonímico parte del supuesto de que los apellidos se transmiten como los genes, de padres a hijos, y constituyen por esta razón un marcador de la ascendencia biológica a partir del cual puede estimarse la consanguinidad y parentesco entre individuos y poblaciones (Colantonio et al., 2008).

En base a la distribución de los apellidos en cada período se calculó la isonimia al azar esperada si las uniones sucedieran al azar. De acuerdo con Relethford (1988) la isonimia al azar obtenida de acuerdo a la siguiente fórmula, se denomina Isonimia sesgada

$$
\text { Is }=\Sigma \mathbf{k}\left(\mathbf{n}_{\mathrm{ik}} / \mathbf{N}_{\mathrm{i}}\right)^{2} \mathbf{m}+\mathbf{f}
$$

donde: $n_{\mathrm{ik}}$ es la frecuencia absoluta del apellido k en la población i,

$\mathrm{N}_{\mathrm{i}}$ es el número total de individuos de la misma población $\left(\Sigma \mathrm{n}_{\mathrm{ik}}\right)$

$\mathrm{m}, \mathrm{f}, \mathrm{m}+\mathrm{f}$ son las poblaciones masculina, femenina $\mathrm{y}$ total, respectivamente y la sumatoria es sobre todos los apellidos. 
Para salvar el inconveniente del sesgo se recurrirá a la determinación de la Isonimia al Azar No Sesgada o Correcta dentro de una población i (Insii) de acuerdo a Rodríguez Larralde et al (1993):

$$
\operatorname{Ins}_{i i}=\Sigma n_{i k}\left(n_{i k}-1\right) / N_{i}\left(N_{i}-1\right)=\Sigma\left(n_{i k} / N_{i}\right)^{2}-1 / N_{i}
$$

Consecuentemente $\mathbf{I n s}_{\mathbf{i i}}=\mathbf{I s} \mathbf{- 1 / \mathbf { N } _ { \mathbf { i } }}$; donde los términos son idénticos a los definidos previamente.

\section{- Cálculo de la consanguinidad de una población:}

La consanguinidad se refiere a los cruzamientos realizados entre individuos que tienen uno o más ancestros biológicos en común, mientras que la endogamia se define como el sistema de elección del cónyuge que implica que los cruzamientos se realizan en el interior de un grupo determinado, a partir de criterios diferentes (étnicos, nacionales, regionales, religiosos, etc.) (Cavalli-Sforza y Bodmer, 1981). A través de varias generaciones, la endogamia es equivalente a la consanguinidad, en un proceso que es más rápido cuanto más pequeño es el grupo. La consanguinidad, y por lo tanto también la endogamia, determinan a largo plazo los lastres genéticos que se acumulan e inciden en parámetros demográficos como fertilidad y mortalidad (CavalliSforza y Bodmer, 1981).

La estimación de la consanguinidad se realizará como expresión de la isonimia de las uniones al azar y se calculará de acuerdo a Relethford (1988) mediante la siguiente fórmula:

$$
\varnothing_{\mathrm{ii}}=\mathbf{I}_{\mathrm{ns}} / 4
$$

El error estándar de Øii será calculado según Rodríguez Larralde et al. (1993a) a partir de la siguiente fórmula: 


$$
\sigma\left(\varnothing_{\mathrm{ii}}\right)=(1 / 4) \sigma(\alpha) / \alpha^{2}
$$

Valores elevados de $\varnothing \mathrm{ii}$, indican mayor parentesco biológico intrapoblacional o consanguinidad de la población. Esto significa que en la población se encuentran pocos apellidos diferentes pero con elevadas frecuencias.

Los parámetros Is, Ins, Øii, v y $\alpha$ se calcularon con los programas DISTRIBU y ORMANNOS y sus valores se obtuvieron con el programa ISONIMIA.

- Cálculo de los indicadores de aislamiento y sedentarismo:

De acuerdo con Rodríguez Larralde $(1986 ; 1990)$ se determinaron los siguientes indicadores:

Indicador A: Porcentaje de la población cubierta por los apellidos únicos, entendiéndose por tal aquél con un solo representante en la población.

Este porcentaje puede considerarse como un estimador de migración (Rodríguez Larralde y Barrai, 1997; 1998), tanto de inmigración como de emigración, sobre todo cuando las poblaciones presentan saldos migratorios neutros. La inmigración reciente podría aportar a la población individuos con apellidos diferentes de los existentes, que no han tenido oportunidad de transmitirlo. Por el contrario, la emigración masiva de individuos con el mismo apellido puede reducir su representación en la población y convertirlo en un apellido único. A mayores valores del indicador A corresponde, en general, un mayor movimiento poblacional.

Indicador B: Porcentaje de la población cubierta por los 7 apellidos más frecuentes. 
B representa un indicador de aislamiento relativo (Rodríguez Larralde y Barrai, 1997; 1998) observándose que a mayores valores de $B$, mayor aislamiento y sedentarismo de la población.

- Cálculo de indicadores de dinámica de población:

Proporción de migración o indicador v de Karlin-MacGregor: Puede considerarse como un indicador de la inmigración reciente de una población según los fundamentos expuestos en el apartado Los apellidos como indicadores de migración (Capítulo III) y se calculó de acuerdo a Zei et al (1983) según la siguiente fórmula

$$
\mathrm{v}=(\mathbf{1}-\mathrm{Is}) /\left[\text { Is . }\left(\mathrm{N}_{\mathrm{i}}-\mathbf{1}\right)\right]
$$

En general se acepta que valores elevados de $v$ corresponden a altas tasas de migración

Abundancia de apellidos o indicador $\alpha$ de Fisher: Este indicador fue propuesto inicialmente por Fisher (1943) para estimar la abundancia de especies animales representativa de una muestra. Más recientemente Piazza et al. (1987) proponen su empleo para analizar las tasas de migración a partir de la distribución de apellidos a través de la estimación del número efectivo de apellidos de una población. El parámetro $\alpha$ evalúa así a la diversidad o riqueza de apellidos y se calculará de acuerdo a Barrai et al (1992):

$$
\alpha=1 / \text { Ins }
$$

Un valor pequeño de $\alpha$ indicaría mayor consanguinidad y deriva génica, mientras que valores altos indicarían migración y por lo tanto menor afinidad biológica intrapobalcional. Según Barrai et al. (2000) $\alpha$ constituye, simultáneamente, un excelente parámetro para predecir la dinámica evolutiva de un sistema y un indicador adecuado de la estructura de población. 


\section{RESULTADOS}

\section{CAPÍTULO VIII: TAMAÑO POBLACIONAL, NÚMERO Y DISTRIBUCIÓN DE LOS APELLIDOS}

Para el total de Casabindo se observa, en los cuatro primeros documentos analizados, que el número de personas registradas es mayor que el número de individuos portadores de un segundo nombre o apellido, situación que desaparece a fines del siglo XIX (Tabla 2). Esta diferencia es siempre mayor entre las mujeres ya que en estos primeros documentos sólo se las registra con su primer nombre mientras la información correspondiente a los hombres es mucho más detallada.

Las numeraciones correspondientes a los siglos XVII dan cuenta de un tamaño poblacional similar entre ambos documentos que también se observa entre las de fines del siglo XX y principios del XXI; sin embargo, las correspondientes al siglo XVIII registran una diferencia poblacional importante a pesar de ser las más próximas temporalmente, situación que se analiza en detalle más adelante y que se presenta en forma diferencial en las tres áreas analizadas (Tablas 2 a 5) como fueron definidas en el Capítulo VI.

En la Tabla 2 se muestra la cantidad de nombres o apellidos diferentes registrados en cada uno de los documentos considerados. Puede apreciarse que no existe un patrón homogéneo, ya que en algunos períodos las mujeres presentan mayor diversidad que los varones $(1778,1786,1982)$, en otros, ambos sexos tienen valores similares (1688) y finalmente otros donde el sexo masculino registra un mayor número de apelativos $(1654,1895)$. Al analizar la distribución de los apellidos diferentes en cada una de las áreas consideradas se observa que, independientemente del año y del área considerados, las mujeres registran mayor diversidad que los varones (Tablas 3 a 5) 
La Tabla 2 muestra el número de nombres o apellidos únicos y el porcentaje que representan con respecto al total de apellidos existentes en Casabindo y en cada una de las áreas en los distintos períodos considerados (Tablas 3 a 5). Al analizar la cantidad de nombres o apellidos portados por un único individuo se observa que hasta fines del siglo XIX las mujeres registran valores similares en todos los cortes temporales y que recién aumentan en forma importante a partir de 1982. A mediados del siglo XVII se registra en los varones un valor elevado mientras que, desde fines del siglo XVII hasta fines del XVIII existe una marcada diferencia intersexual presentando las mujeres los valores más altos (Tabla 2).

Tabla 2: Cantidad de individuos, de individuos con apellidos o apelativos, $\mathrm{N}^{\circ}$ de apelativos diferentes, de apelativos únicos y relación $\mathrm{N}^{\circ}$ de individuos/ $\mathrm{N}^{\circ}$ de apellidos para Casabindo

\begin{tabular}{|c|c|c|c|c|c|c|c|}
\hline & & $\begin{array}{c}\mathrm{N}^{\circ} \\
\text { individuos }\end{array}$ & $\begin{array}{c}\mathrm{N}^{\circ} \text { de } \\
\text { individuos } \\
\text { con } \\
\text { apellido }\end{array}$ & $\begin{array}{c}\mathbf{N}^{\circ} \text { de } \\
\text { apellidos } \\
\text { diferentes }\end{array}$ & $\begin{array}{l}\mathrm{N}^{\circ} \text { de } \\
\text { apellidos } \\
\text { únicos }\end{array}$ & $\begin{array}{c}\% \\
\text { apellidos } \\
\text { únicos }\end{array}$ & $\begin{array}{l}\text { Individuos/ } \\
\text { apellidos }\end{array}$ \\
\hline & $\overline{\mathbf{M}}$ & 181 & 163 & 32 & 17 & 53,13 & 5,09 \\
\hline 1654 & $\mathbf{V}$ & 213 & 206 & 52 & 26 & 50,00 & 3,96 \\
\hline & $T$ & 394 & 369 & 83 & 42 & 50,60 & 4,45 \\
\hline & $\overline{\mathbf{M}}$ & 170 & 114 & 24 & 12 & 50,00 & 4,83 \\
\hline 1688 & $\mathbf{V}$ & 181 & 165 & 28 & 6 & 21,43 & 5,97 \\
\hline & $\mathrm{T}$ & 351 & 279 & 45 & 13 & 28,89 & 6,42 \\
\hline & $\overline{\mathbf{M}}$ & 527 & 481 & 54 & 18 & 33,33 & 8,91 \\
\hline 1778 & $\mathbf{V}$ & 567 & 529 & 42 & 6 & 14,29 & 12,60 \\
\hline & $T$ & 1089 & 1010 & 59 & 19 & 32,20 & 17,11 \\
\hline & $\overline{\mathbf{M}}$ & 702 & 690 & 68 & 21 & 30,88 & 10,15 \\
\hline 1786 & $\mathbf{V}$ & 765 & 763 & 44 & 4 & 9,09 & 17,34 \\
\hline & $T$ & 1467 & 1453 & 70 & 22 & 31,43 & 20,76 \\
\hline & $\mathbf{M}$ & & 1 & 86 & 19 & 22,09 & 22,09 \\
\hline 1895 & $\mathbf{V}$ & & 0 & 101 & 33 & 32,67 & 32,67 \\
\hline & $T$ & & & 117 & 39 & 33,33 & 33,33 \\
\hline & $\overline{\mathbf{M}}$ & & 22 & 103 & 30 & 29,13 & 29,13 \\
\hline 1982 & $\mathbf{V}$ & & 7 & 85 & 19 & 22,35 & 22,35 \\
\hline & $T$ & & 19 & 115 & 32 & 27,83 & 27,83 \\
\hline & $\overline{\mathbf{M}}$ & & 4 & 98 & 33 & 33,67 & 33,67 \\
\hline 2001 & $\mathbf{V}$ & & 88 & 88 & 25 & 28,41 & 28,41 \\
\hline & $T$ & & 52 & 116 & 37 & 31,90 & 31,90 \\
\hline
\end{tabular}


En 1654 los nombres únicos representan aproximadamente el 50\% tanto entre las mujeres como entre los varones. A fines de este siglo los nombres únicos en varones reducen su representatividad al 21.4\% del total mientras que en las mujeres ésta continúa siendo del 50\%. Desde fines del siglo XVIII la proporción de apellidos únicos desciende marcadamente pero conservando diferencias intersexuales con mayores valores en el sexo femenino excepto para 1895 (Tabla 2).

Tabla 3: Cantidad de individuos, de individuos con apellidos o apelativos, $\mathbf{N}^{\circ}$ de apelativos diferentes, de apelativos únicos y relación $\mathbf{N}^{\circ}$ de individuos/ $\mathbf{N}^{\circ}$ de apellidos para el Área Norte

\begin{tabular}{|c|c|c|c|c|c|c|c|}
\hline & & $\begin{array}{c}\mathbf{N}^{\circ} \\
\text { individuos }\end{array}$ & $\begin{array}{c}\mathrm{N}^{\circ} \text { de } \\
\text { individuos } \\
\text { con } \\
\text { apellido }\end{array}$ & $\begin{array}{c}\mathrm{N}^{\circ} \text { de } \\
\text { apellidos } \\
\text { diferentes }\end{array}$ & $\begin{array}{l}\mathrm{N}^{\circ} \text { de } \\
\text { apellidos } \\
\text { únicos }\end{array}$ & $\begin{array}{c}\% \\
\text { apellidos } \\
\text { únicos }\end{array}$ & $\begin{array}{l}\text { Individuos/ } \\
\text { apellidos }\end{array}$ \\
\hline & $\overline{\mathbf{M}}$ & 286 & 261 & 43 & 13 & 30,23 & 6,07 \\
\hline 1778 & V & 288 & 267 & 34 & 5 & 14,71 & 7,85 \\
\hline & $T$ & 574 & 528 & 46 & 12 & 26,09 & 11,48 \\
\hline & $\overline{\mathbf{M}}$ & 280 & 274 & 47 & 19 & 40,43 & 5,83 \\
\hline 1786 & $\mathbf{V}$ & 301 & 298 & 33 & 15 & 45,45 & 9,03 \\
\hline & $T$ & 581 & 572 & 49 & 16 & 32,65 & 11,65 \\
\hline & $\bar{M}$ & & & 60 & 19 & 31,67 & 31,67 \\
\hline 1982 & $\mathrm{~V}$ & & & 47 & 16 & 34,04 & 34,04 \\
\hline & $T$ & & & 65 & 16 & 24,62 & 24,62 \\
\hline & $\bar{M}$ & & & 53 & 16 & 30,19 & 30,19 \\
\hline 2001 & $\mathbf{V}$ & & & 47 & 15 & 31,91 & 31,91 \\
\hline & $T$ & & & 63 & 19 & 30,16 & 30,16 \\
\hline
\end{tabular}

Este descenso registrado para el total de Casabindo no se observa al considerar cada una de las áreas por separado. El área Norte presenta aumentos y descensos entre 1778 y 2001 (Tabla 3), en el Este se registra un aumento de la proporción de apellidos únicos entre 1778 y 1982, y permanece constante entre este año y 2001 (Tabla 4) y el área Oeste registra un descenso inicial y luego un aumento sostenido (Tabla 5)

En cada una de las áreas se observan diferencias intersexuales que muestran un comportamiento heterogéneo ya que en la mayoría de los casos la 
proporción de apellidos únicos es mayor en mujeres, con diferencias marcadas como en el área Este a lo largo de todos los cortes temporales (Tabla 4), en otros casos los valores más elevados se presentan en el sexo masculino como en el área Norte entre 1786 y 2001 (Tabla 3).

Tabla 4: Cantidad de individuos, de individuos con apellidos o apelativos, $\mathbf{N}^{\circ}$ de apelativos diferentes, de apelativos únicos y relación $\mathrm{N}^{\circ}$ de individuos $/ \mathrm{N}^{\circ}$ de apellidos para el Área Este

\begin{tabular}{|c|c|c|c|c|c|c|c|}
\hline & & $\begin{array}{c}\mathbf{N}^{\circ} \\
\text { individuos }\end{array}$ & $\begin{array}{c}\mathrm{N}^{\circ} \mathrm{de} \\
\text { individuos } \\
\text { con } \\
\text { apellido }\end{array}$ & $\begin{array}{c}\mathrm{N}^{\circ} \text { de } \\
\text { apellidos } \\
\text { diferentes }\end{array}$ & $\begin{array}{l}\mathbf{N}^{\circ} \text { de } \\
\text { apellidos } \\
\text { únicos }\end{array}$ & $\begin{array}{c}\% \\
\text { apellidos } \\
\text { únicos }\end{array}$ & $\begin{array}{l}\text { Individuos/ } \\
\text { apellidos }\end{array}$ \\
\hline \multirow{3}{*}{1778} & $\mathbf{M}$ & 138 & 126 & 29 & 8 & 27,59 & 4,34 \\
\hline & $\mathbf{V}$ & 163 & 153 & 26 & 2 & 7,69 & 5,88 \\
\hline & $T$ & 301 & 279 & 32 & 8 & 25,00 & 8,72 \\
\hline \multirow{3}{*}{1786} & $\overline{\mathbf{M}}$ & 240 & 235 & 37 & 14 & 37,84 & 6,35 \\
\hline & $\mathbf{V}$ & 245 & 243 & 23 & 1 & 4,35 & 10,56 \\
\hline & $T$ & 485 & 478 & 38 & 14 & 36,84 & 12,58 \\
\hline \multirow{3}{*}{1982} & $\mathbf{M}$ & \multirow{2}{*}{\multicolumn{2}{|c|}{$\begin{array}{l}338 \\
238\end{array}$}} & 60 & 26 & 43,33 & 43,33 \\
\hline & V & & & 49 & 18 & 36,73 & 36,73 \\
\hline & $T$ & \multicolumn{2}{|c|}{576} & 73 & 32 & 43,84 & 43,84 \\
\hline \multirow{3}{*}{2001} & $\overline{\mathbf{M}}$ & \multirow{2}{*}{\multicolumn{2}{|c|}{$\begin{array}{l}326 \\
251\end{array}$}} & 60 & 28 & 46,67 & 46,67 \\
\hline & $\mathbf{V}$ & & & 48 & 17 & 35,42 & 35,42 \\
\hline & $T$ & \multicolumn{2}{|c|}{577} & 73 & 32 & 43,84 & 43,84 \\
\hline
\end{tabular}

Al calcular el promedio de individuos por apellido (total de individuos/total de apellidos) obtenemos que, en el siglo XVII, los valores más bajos se encuentran tanto en el total de población como para cada sexo por separado (Tabla 2). Para Casabindo en su conjunto como para cada una de las áreas analizadas, la cantidad de personas por apellido aumenta gradualmente a partir del siglo XVIII siendo los valores inferiores en las mujeres hasta fines del siglo XIX, comportamiento que se revierte en los dos últimos cortes temporales considerados. 
Tabla 5: Cantidad de individuos, de individuos con apellidos o apelativos, $\mathrm{N}^{\circ}$ de apelativos diferentes, de apelativos únicos y relación $\mathrm{N}^{\circ}$ de individuos $/ \mathrm{N}^{\circ}$ de apellidos para el Área Oeste

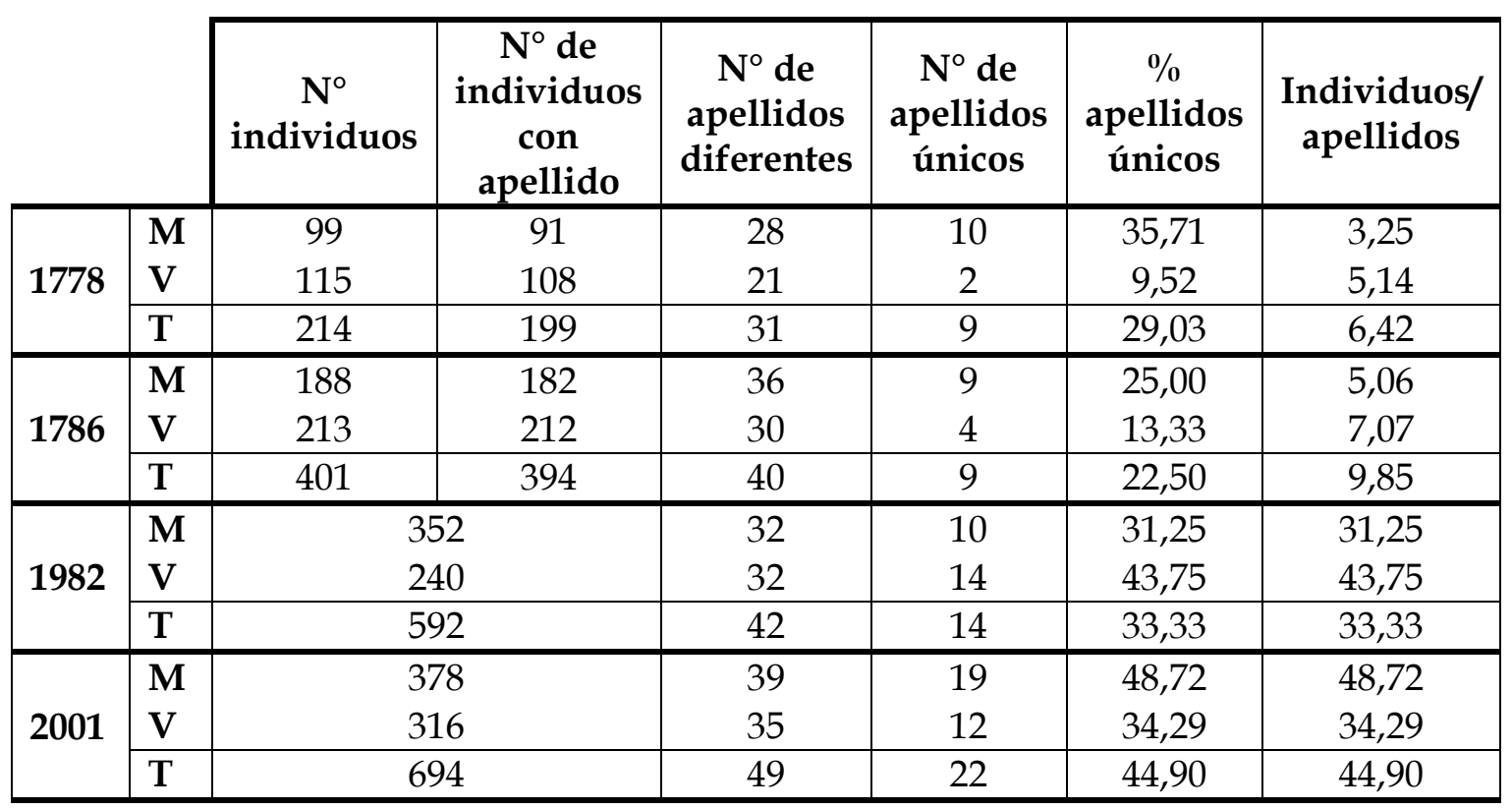




\section{CAPÍTULO IX: ANÁLISIS DE NOMBRES Y APELLIDOS}

Los nombres y apellidos son expresiones de identidad de los grupos a los que éstos pertenecen. El análisis detallado de los antropónimos y de su distribución espacio-temporal en un área concreta como Casabindo permite identificar formas originales de denominación de las personas, conocer detalles sobre su origen, sobre la transmisión entre generaciones, su permanencia en el área y su dispersión geográfica como así también sobre las transformaciones ocurridas en la antroponimia de los casabindos.

El documento más antiguo con que se cuenta corresponde a una serie de nombres indígenas incluida en el Bautismo del cacique de Casabindo de 1557 (Martínez, 1992). A los fines de este trabajo, la serie de antropónimos de 1557 no permite un tratamiento más exhaustivo. Se trata de una muestra cuya representatividad es difícil de evaluar, al desconocerse la población total de los casabindos para esa fecha, y se encuentra sesgada, al contar con un mayor número de individuos de sexo femenino (12 mujeres vs. 7 varones). A pesar de esto, resulta interesante el registro de nombres para evaluar su perduración dentro del grupo en los siglos subsiguientes.

En este documento se registran siete nombres masculinos (Abracayte, Catihilamas, Caquitula, Corotare, Coyacona, Pataba y Quipiltur) y ocho nombres femeninos (Asli, Asli Sula, Basuma, Capisi (2), Chalotau, Tandor (2), Temis y Ulca). Si bien estos nombres corresponden a una muestra ínfima de la población, permiten realizar algunas observaciones de interés. En épocas precoloniales, los casabindos, aparentemente, carecían de patronímicos o apellidos y contaban exclusivamente con nombres (femeninos y masculinos), obviamente de origen indígena ${ }^{13}$. Entre éstos se destaca el uso de nombres compuestos, tanto entre los varones como entre las mujeres (Catihilamas, Asli Sula). También es notable la recurrencia de algunos nombres femeninos (Tandor, Asli, Capisi), aún en la reducida serie con que se cuenta.

13 Esto es una constante en los registros más tempranos de población andina (Sánchez, 1996; Zanolli, 2005; Medinacelli, 2003, por nombrar algunos). 
Considerando que Sula corresponde a Sulapa ${ }^{14}$, sólo dos nombres femeninos (Capisi y Ulca) no se repiten en el padrón de 1654. En el conjunto de nombres masculinos, y considerando a Catihilamas representado por Lamas, a mediados del siglo XVII no se registran tres de ellos (Coyacona, Corotare ${ }^{15} \mathrm{y}$ Caquitula).

Los datos hasta aquí analizados se toman sólo como referencia por tratarse de un registro muy escueto, las características de los nombres registrados en él sirven de aproximación al sistema nominativo autóctono a escasos 20 años del ingreso de los españoles al área.

El padrón de 1654, en cambio, constituye un registro completo de la población y permite realizar otros tipos de análisis. Se observa que entre los casabindos aún continúa el uso exclusivo de nombres con total ausencia de apellidos. Sin embargo, con la evangelización y el bautismo incorporan un nombre de origen español, generalmente relacionado con el cristianismo. Así, se observa la modalidad de utilizar un nombre español antepuesto a uno autóctono. Es decir, nombres cristianos masculinos antepuestos a nombres indígenas masculinos y lo mismo sucede con los nombres femeninos cristianos y autóctonos motivo por el cual cada sexo tiene un conjunto distintivo de apelativos; es por ello que no se analizan ambos sexos tomados conjuntamente.

Entendemos que el nombre aún no se trata de un apellido en nuestra concepción actual, en tanto no se transmite a los descendientes por vía paterna, ya que los descendientes tienen, en general, un segundo nombre diferente al del padre (Figura 3). 
Sin embargo, en ocho familias $(6.1 \%)$ se observa que madre e hija comparten el segundo nombre, en 19 casos padre e hijo (14.4\%) y en dos ocasiones $(1.5 \%)$ en la misma familia madre-hija y padre-hijo presentan el mismo segundo nombre (Figura 4).

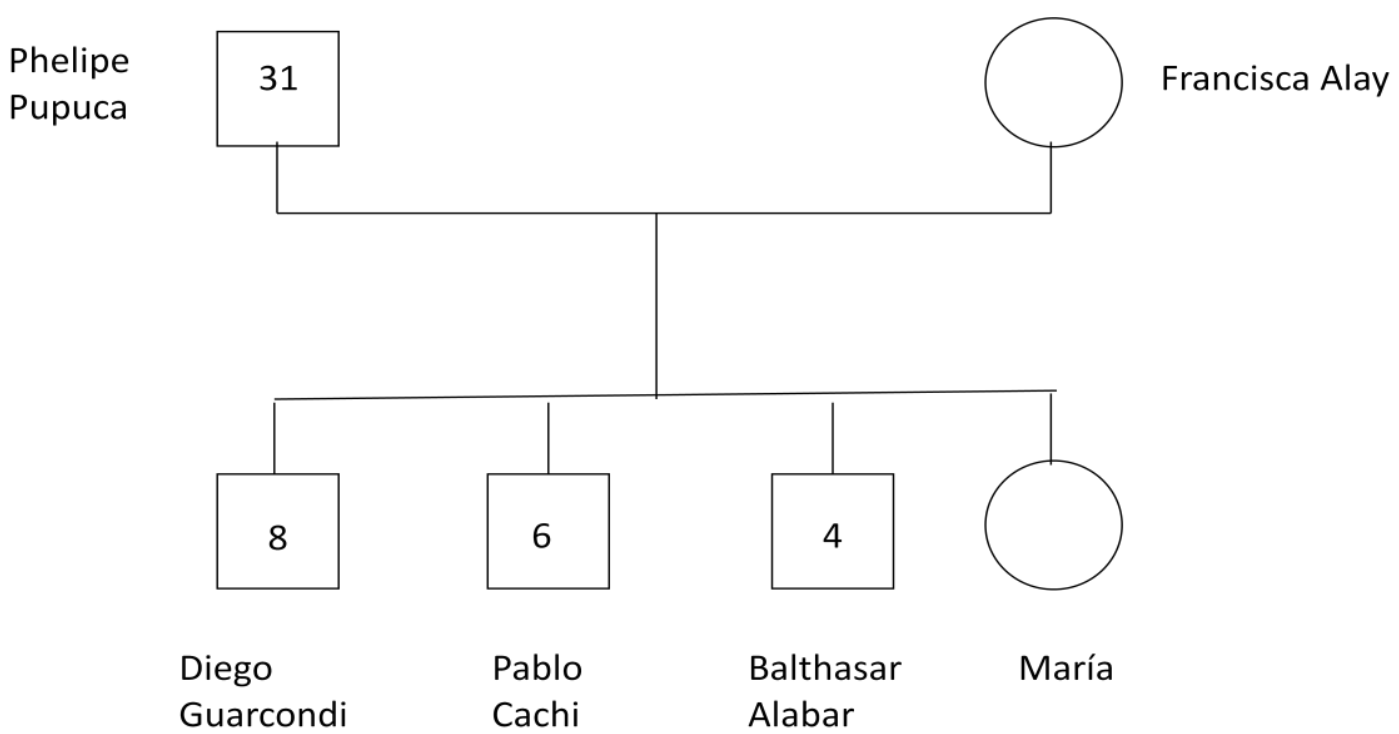

Figura 3: Ejemplo de una familia de 1654 donde los descendientes llevan un segundo nombre distinto al de los progenitores

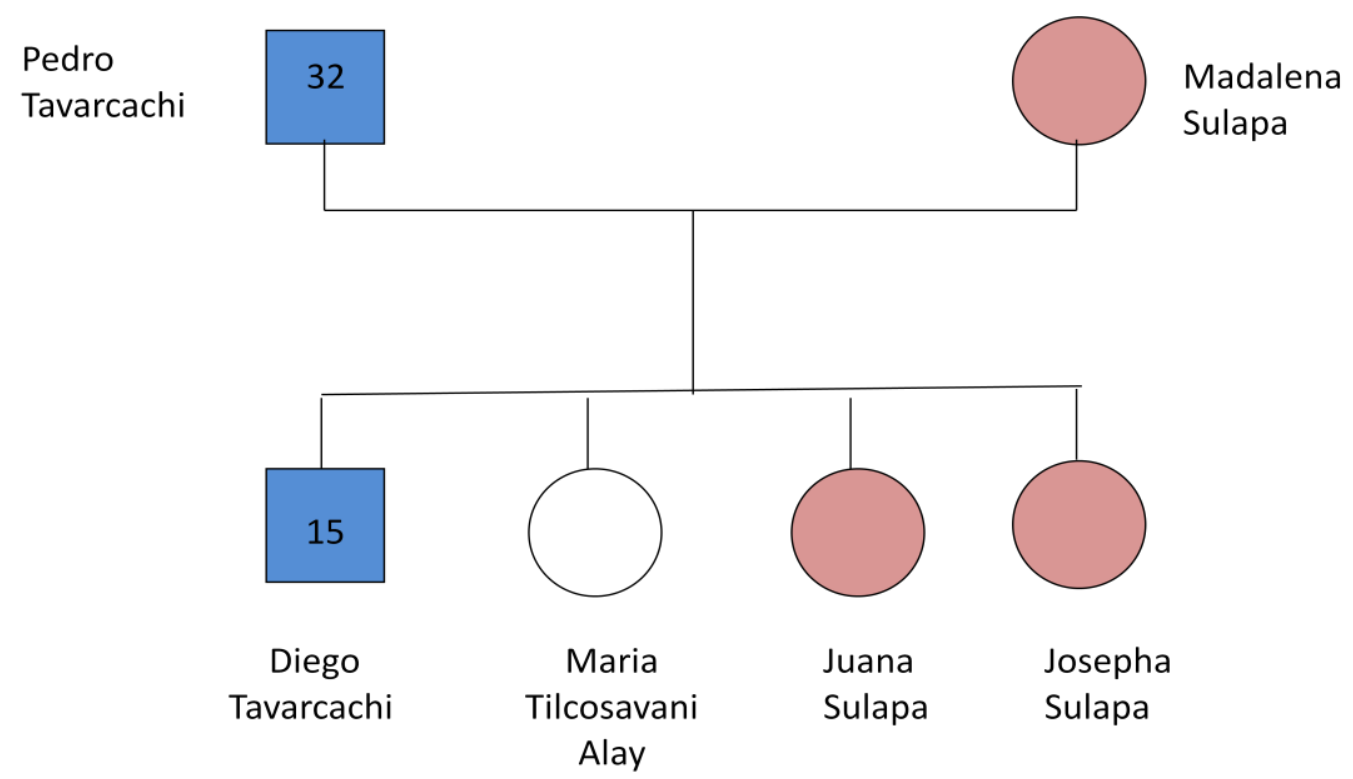

Figura 4: Ejemplo de una familia de 1654 donde el hijo varón lleva el segundo nombre del padre y dos de las hijas el de la madre. 
En el padrón de 1654 se registran 53 nombres masculinos diferentes y 32 nombres femeninos (Tabla 2). Los siete apelativos más frecuentes y la cantidad de individuos que los portan se presentan en la Tabla 6. Se observa que los nombres en uso a mediados del siglo XVII comprenden un espectro variado, entre los cuales aparecen nombres compuestos, tanto femeninos como masculinos (Sulapanalay, Chiritulay) y algunos que podrían catalogarse como apodos o sobrenombres entre los varones adultos (Lamas Feo, Guarcondi Ballestero). Entre los antropónimos cristianos resulta curioso el uso de García, entre los demás propios del santoral. Se observa una notable recurrencia de determinados nombres, en especial entre las mujeres (37 Sulapa y 27 Nalay). En este documento resulta curioso el caso de un varón huérfano que lleva un nombre femenino, Temes. Otro aspecto interesante está dado por el primer registro de un segundo nombre de origen español (Renxel) portado por un único varón.

En síntesis, este documento revela una diversidad importante de nombres simples y compuestos algunos de los cuales reflejan humor o burla. En este momento ya se registra el uso de un nombre cristiano otorgado en el bautismo, según las disposiciones del Concilio de Trento, aunque todavía no está establecida en Casabindo la trasmisión de apellidos de padres a hijos ya que no se registran apellidos como tales. Se advierte también que no hay coincidencia entre los antropónimos femeninos y masculinos lo que estaría de acuerdo con lo establecido en el Concilio Limense en 1583 en cuanto a que las mujeres lleven el nombre de sus madres y los varones los de sus padres (Capítulo II). 


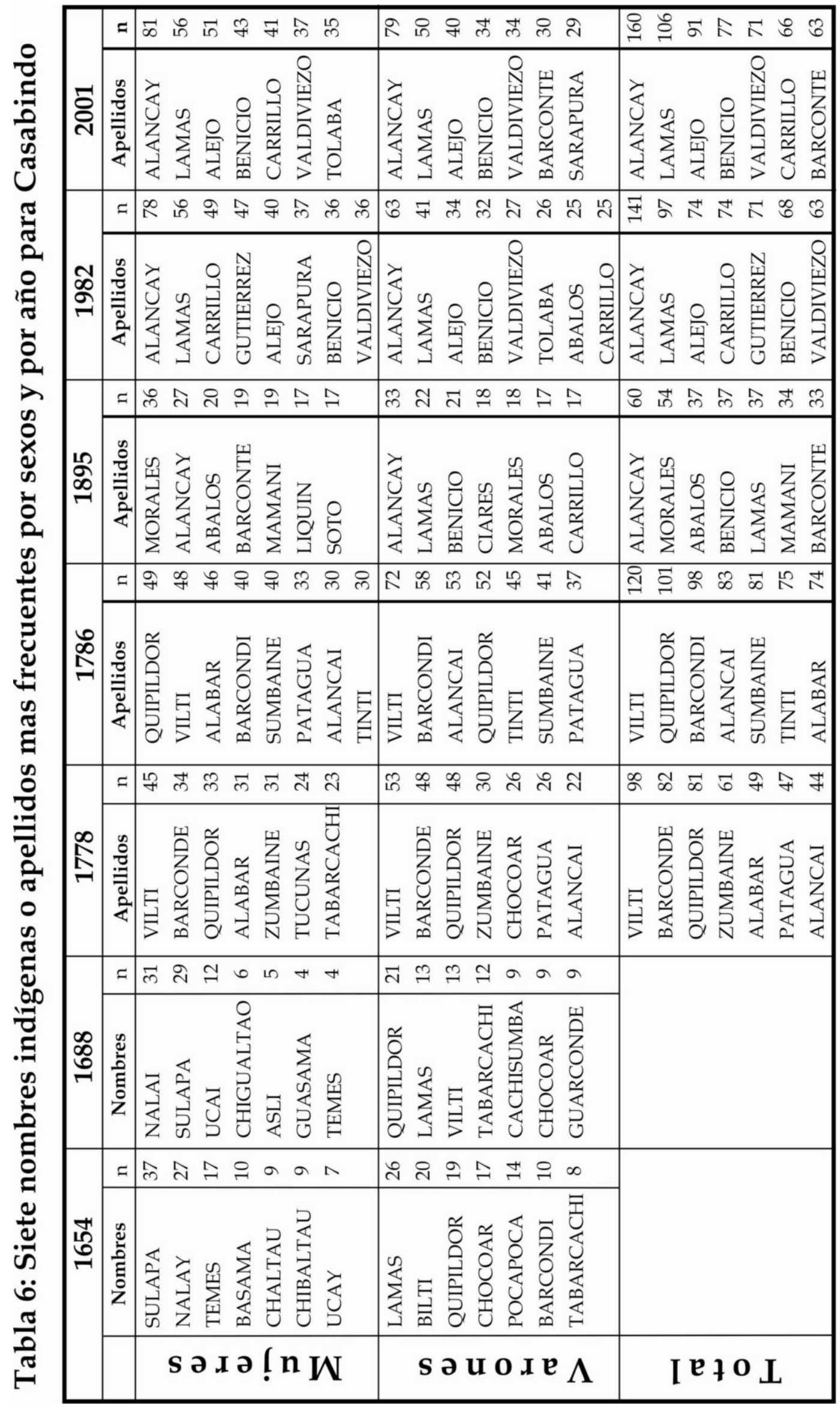


El registro de 1688 resulta sumamente interesante, en tanto pone en evidencia la transformación de los nombres indígenas masculinos en apellidos. Entre las familias registradas a fines del siglo XVIII se observan tres modalidades:

a) casos donde se continúa con el sistema precolonial y colonial temprano: el uso de nombres indígenas a los cuales se antepone un nombre español, donde no existe transmisión (43.2\% del total de familias),

b) casos en los cuales los varones portan el nombre indígena del padre $(40 \%)$ y las mujeres, el de la madre $(4.2 \%)$ y

c) casos en los cuales tanto varones como mujeres llevan como segundo nombre el nombre indígena del padre (5.3\%). Esta última modalidad tiene además características particulares ya que se observan familias con dos y tres generaciones consecutivas que comparten el segundo nombre pero también se registran casos donde lo hacen sólo la primera y tercera generación (Tabla 7).

Tabla 7: Ejemplos de transmisión de segundo nombre paterno en el padrón de 1688

\begin{tabular}{|l|l|l|}
\hline \multicolumn{1}{|c|}{$\begin{array}{c}\text { Primera generación } \\
\text { (abuelo) }\end{array}$} & \multicolumn{1}{|c|}{$\begin{array}{c}\text { Segunda generación } \\
\text { (padre) }\end{array}$} & \multicolumn{1}{|c|}{$\begin{array}{c}\text { Tercera generación } \\
\text { (hijo) }\end{array}$} \\
\hline Diego Cachisumba & $\begin{array}{l}\text { Bartolome Cachisumba } \\
\text { Andres Cachisumba Patagua } \\
\text { Pedro Cachisumba }\end{array}$ & Pablo Cachisumba \\
\hline Bartolome Alabar & Fernando Tucunas & Bartolome Alabar \\
\hline Juan Cachi Mil Pesos & Andres Patagua Mil Pesos & Diego Patagua \\
\hline Garcia Chocoar & $\begin{array}{l}\text { Juan Avichocoar } \\
\text { Juan Chocoar }\end{array}$ & Lorenzo Chocoar \\
\hline
\end{tabular}


Esto significa que los nombres indígenas masculinos comienzan a transformarse en apellidos con transmisión a la descendencia como lo dispusiera el Concilio Limense en 1583 y que recién comienza a generalizarse en Casabindo más de un siglo después. Como resultado de esto, las mujeres pasan a portar nombres que tradicionalmente eran de uso masculino $\mathrm{y}$, en consecuencia, los nombres femeninos irán desapareciendo paulatinamente. Continúa el uso de nombres o apellidos compuestos, a veces integrando uno de origen indígena con un segundo de raigambre hispana. En este documento se registran tres varones portadores de un segundo nombre de origen español (Alejandro, Bentura y Bernardo con un portador cada uno).

En el padrón de 1688 se registran para el total de la población 45 apelativos diferentes, 13 de los cuales son únicos, los varones presentan 29 en la primera categoría y seis en la segunda mientras que las mujeres tienen 24 y 10 respectivamente. $\mathrm{Al}$ analizar los nombres más frecuentes se aprecia que, en general, son coincidentes con los registrados en 1654, tanto en varones como en mujeres (Tabla 6).

Este registro aporta información sobre las transformaciones que van ocurriendo en el sistema nominativo en uso entre los casabindos a fines del siglo XVII, donde todavía se observa una presencia importante de nombres autóctonos propios de cada sexo y que revelan distintas formas de transmisión entre generaciones. Sin embargo, se advierte la incipiente transformación de estos nombres en lo que serían los apellidos del período colonial.

Más de un siglo después, el censo de $\mathbf{1 7 7 8}$ registra una población de 1089 personas (sólo 1006 cuentan con apellido) que exhibe un total de 59 apellidos diferentes (Tabla 2). A fines del siglo XVIII se evidencia claramente la imposición de la transmisión del apellido por vía paterna. Los pobladores de Casabindo de entonces se hallan individualizados con su correspondiente nombre cristiano y un apellido. Si se considera su origen, se observa que, en una alta frecuencia, deriva de los nombres indígenas utilizados en Casabindo a 
mediados del siglo XVII. A éstos se agregan escasos apellidos de origen autóctono propios de la zona andina (Tolava y Quispe que representan el 5.5\% de la población). Entre los 14 apellidos de origen hispano encontramos ocho portados por un solo individuo y seis que registran entre dos y 18 portadores (23.7\% del total de apellidos que cubren solamente el $5.9 \%$ de la población total). Se presentan, además, cinco apellidos catalogados como indeterminados (8.5\% del total de apellidos) y que no aparecen en los documentos anteriores. Se registran únicamente cuatro casos de nombres femeninos de mediados del XVII (Sulapa y Sisa) como apellido.

Sin embargo, dado que se trata de tres mujeres mayores (60, 62 y 86 años) y una joven, Tomasa Sisa Lacci de 30 años, es probable que se trate de una perduración del sistema de nominación utilizado en épocas anteriores (uno cristiano y otro indígena masculino). Según Aguiló (1983) el apelativo Sisa era exclusivo de las mujeres en la Arquidiócesis de Charcas (actual Chuquisaca, Bolivia) entre 1650 y 1730. Este autor sostiene que se trataría de un apellido impuesto en la sacristía a las hijas de madres solteras y padre desconocido. En este período el "apellido" Sisa representa entre el 20\% y el 40\% del total de apellidos pero luego registra un rápido declive y una desaparición progresiva entre 1820 y 1900. Es decir que en Charcas el apellido Sisa perdura casi cien años más que en la zona de Casabindo.

En la Tabla 8 se comparan, para este mismo censo, los siete apellidos más frecuentes en Casabindo, el Curato de Cochinoca y los otros tres Curatos de la puna de Jujuy (Yavi, Rinconada y Santa Catalina) (Alfaro et al., 1998). Para los curatos de Rinconada y Cochinoca se presentan ocho apellidos ya que los que se encuentran en séptimo y octavo lugar registran frecuencias idénticas. Se observa, que los apellidos más frecuentes en Casabindo se distinguen por varias razones: a) se trata, sin excepción, de apellidos de origen autóctono; b) representan casi el $46 \%$ de la población total; c) no se identifican apellidos propios de otras zonas andinas entre los más frecuentes. Al estar englobado Casabindo dentro del Curato de Cochinoca, el apellido más frecuente es coincidente en ambos grupos (Vilti). Por su parte, la alta frecuencia de Lamas en 
Yavi probablemente corresponda a los encomendados del Marqués de Yavi (casabindos o cochinocas) que residían o se encontraban momentáneamente en ese Curato al efectuarse el Censo.

Tabla 8: Comparación de los 7 apellidos más frecuentes y porcentaje de la población cubierta por ellos en Casabindo y en los cuatro curatos de la Puna de Jujuy según el Censo de 1778

\begin{tabular}{|c|c|c|c|c|}
\hline Yavi & Rinconada & $\begin{array}{c}\text { Santa } \\
\text { Catalina }\end{array}$ & Cochinoca & Casabindo \\
\hline Mamani & Cruz & Mamani & Vilti & Vilti \\
Tolava & Mamani & Guanco & Quipildor & Barconde \\
Cruz & Flores & Cari & Lamas & Quipildor \\
Lamas & Calisaya & Cruz & Tolava & Zumbaine \\
Condori & Lazaro & Condori & Pucapuca & Alabar \\
Cavana & Balderrama & Nieve & Barconde & Patagua \\
Quispi & Llampa/Martinez & Bautista & Quispi/Tucunas & Alancai \\
\hline $22.6 \%$ & $28.7 \%$ & $28.8 \%$ & $38.7 \%$ & $45.7 \%$ \\
\hline
\end{tabular}

Si se analizan los siete apellidos más frecuentes discriminados por sexo, cuatro de los apellidos de varones (Vilti, Barconde, Quipildor y Chocoar) se encuentran también entre los más frecuentes a mediados del siglo XVII (Tabla 6). Sin embargo, Alancai no se halla registrado como nombre en $1654^{16}$. De los seis apellidos únicos, es decir, portados por un solo individuo, tres son españoles y uno corresponde a otros grupos étnicos andinos. En el caso de las mujeres, sobre un total de 54 apellidos, los siete más frecuentes son sólo en parte coincidentes con los masculinos. Lo que resulta interesante entre las

16 Se plantea a título de hipótesis que el apellido Alarcaqui se transformó en Alancay en épocas posteriores. 
mujeres es el elevado porcentaje de apellidos únicos (33.3\%) (Tabla 2). De éstos, ocho son de indudable origen hispano, cinco tienen un origen indeterminado y dos se identifican como autóctonos provenientes otras partes de la zona andina.

Como se señala más arriba, son frecuentes los nombres compuestos, estos aparecen en 1557 y a fines de la época colonial continúan siendo numerosos los apellidos compuestos (Cachi Zumbaine, Lamas Caicondi).

Este documento representa un registro completo de la población del área Casabindo y muestra que los nombres femeninos característicos del siglo anterior han desaparecido casi por completo y muchos de los nombres autóctonos masculinos ya muestran una transmisión regular de los padres a toda la descendencia transformándose en apellidos. Éstos además presentan diferencias en cuanto a su distribución geográfica, marcando contrastes con el resto de las poblaciones que habitaban la Puna de Jujuy en este momento.

El padrón de 1786, levantado escasos ocho años después del censo virreinal que se acaba de presentar, acusa una población marcadamente mayor para Casabindo con un total de 70 apellidos diferentes. Veintidós de éstos son de origen español (31.4\% del total de apellidos), 46 son autóctonos (65.7\%) de los cuales cinco son característicos de otros grupos étnicos y uno corresponde a un topónimo correspondiente a la región de Cochabamba en Bolivia (Misque). Solamente en dos casos no se pudo determinar el origen del apellido (Abra y Cabana). Entre los apellidos autóctonos, 24 ya aparecen como nombres masculinos en 1654. Se registra solamente un caso con apellido doble, compuesto por uno indígena y otro español, se trata de Petrona Barcondi Ordoñez.

Los siete apellidos más frecuentes son coincidentes con los registrados en 1778 (Tabla 6) y representan el 43.5\% de la población total. Al considerar los apellidos portados por la población masculina, éstos ascienden a 44, entre los cuales se encuentran cuatro apellidos únicos (dos autóctonos, uno español y un gentilicio). Los siete más frecuentes, que cubren el 46.9\% del total de población, 
son coincidentes con los de 1778, excepto Chocoar que es reemplazado en este caso por otro apellido autóctono: Tinti (Tabla 6). Aquí aparece nuevamente Alancai como la excepción, el único apellido, entre los más frecuentes, que no se registró en 1654. De los apellidos autóctonos encontrados en este documento el $62 \%$ figura en el padrón de 1654 como nombres masculinos.

Tomando el conjunto de la población femenina, el número de apellidos distintos asciende a 68 , entre los cuales 21 son portados por un solo individuo (doce tienen origen español, dos tienen origen indeterminado y ya fueron mencionados y siete son autóctonos). Los siete apellidos más representados son casi coincidentes con los de la población masculina y también con los datos de 1778. Entre la población femenina, se registró el apellido Abracaite (dos individuos) que no aparece en la población masculina pero que se registraba como nombre masculino en 1654.

Si se considera nuevamente el documento más antiguo, el de 1557, de los 7 nombres masculinos registrados, cuatro continúan en uso en 1654 y persisten en la zona hasta fines de la época colonial. Dos de ellos, Quipildor y Patagua, tienen una importante representación en la población de Casabindo $(11.8 \%$ en conjunto en 1786). Al considerar el lapso transcurrido desde 1654 hasta 1786, casi un siglo y medio, se observa que de los 52 nombres masculinos presentes a mediados del siglo XVII, el $46 \%$ de ellos perdura como apellidos entre la población masculina a fines del siglo XVIII. Entre los apellidos que no fueron registrados en el siglo XVII aparecen escasos de origen hispano y algunos que se pueden adscribir a otros grupos andinos.

Este padrón, constituye un registro de población más completo que el realizado en 1778 por cuanto no se trata sólo del recuento poblacional con fines censales sino que en este caso el objetivo es fiscal y por lo tanto el cuidado puesto en el reconocimiento de todos los tributarios y próximos a tributar es mucho mayor. Este hecho puede explicar el aumento de población registrado con respecto a 1778. Al considerar los antropónimos presentes en este documento se observa una gran mayoría de "apellidos originarios" presentes 
en el área desde mediados del siglo XVII. Este hecho se relaciona con la presencia exclusiva de "originarios" en este momento en el área de Casabindo.

A fines del siglo XIX, el Censo de población de 1895 registra para Casabindo 1051 individuos, 500 varones y 551 mujeres, entre los cuales se reconocen 101 y 86 apellidos distintos respectivamente (Tabla 2). En los varones el $32.7 \%$ de los apellidos aparecen representados una sola vez y cubren el 29\% de la población, mientras que en las mujeres los apellidos únicos representan el $22.1 \%$ del total de apellidos y cubren el $28 \%$ de la población total. A partir de este momento se observa un cambio importante ya que la proporción de apellidos foráneos aumenta de manera significativa representando el 63\% del total de apellidos. Entre ellos se reconocen 58 de origen español y 13 vascos.

Se registran por primera vez tres apellidos foráneos entre los siete más frecuentes (Tabla 6). En los apellidos autóctonos se mantiene la alta frecuencia de derivados de los nombres indígenas masculinos registrados en la zona en los siglos precedentes (51\%) donde Alancay conserva una frecuencia mayoritaria tanto para el total como para ambos sexos por separado. Entre los más frecuentes aparecen otros apellidos autóctonos procedentes de otras zonas andinas (Mamani de origen aymara) (Tabla 7), con valores que oscilan entre 4.4 y 3.1\%. La mayoría de los apellidos utilizados por la población de Casabindo en este momento son de origen español (63.2\% del total de apellidos). Sin embargo, el $50.5 \%$ de la población porta un apellido de origen autóctono a pesar de que éstos representan sólo un tercio del total de apellidos (Figuras 5 y 6).

La situación a fines del siglo XIX estimada a partir del análisis del censo de 1895 refleja una situación de cambio con respecto a la presente a fines del siglo XVIII marcada, en el área Casabindo, por la abundancia de apellidos españoles aunque portados por un único individuo lo que estaría indicando su ingreso reciente a la población. 


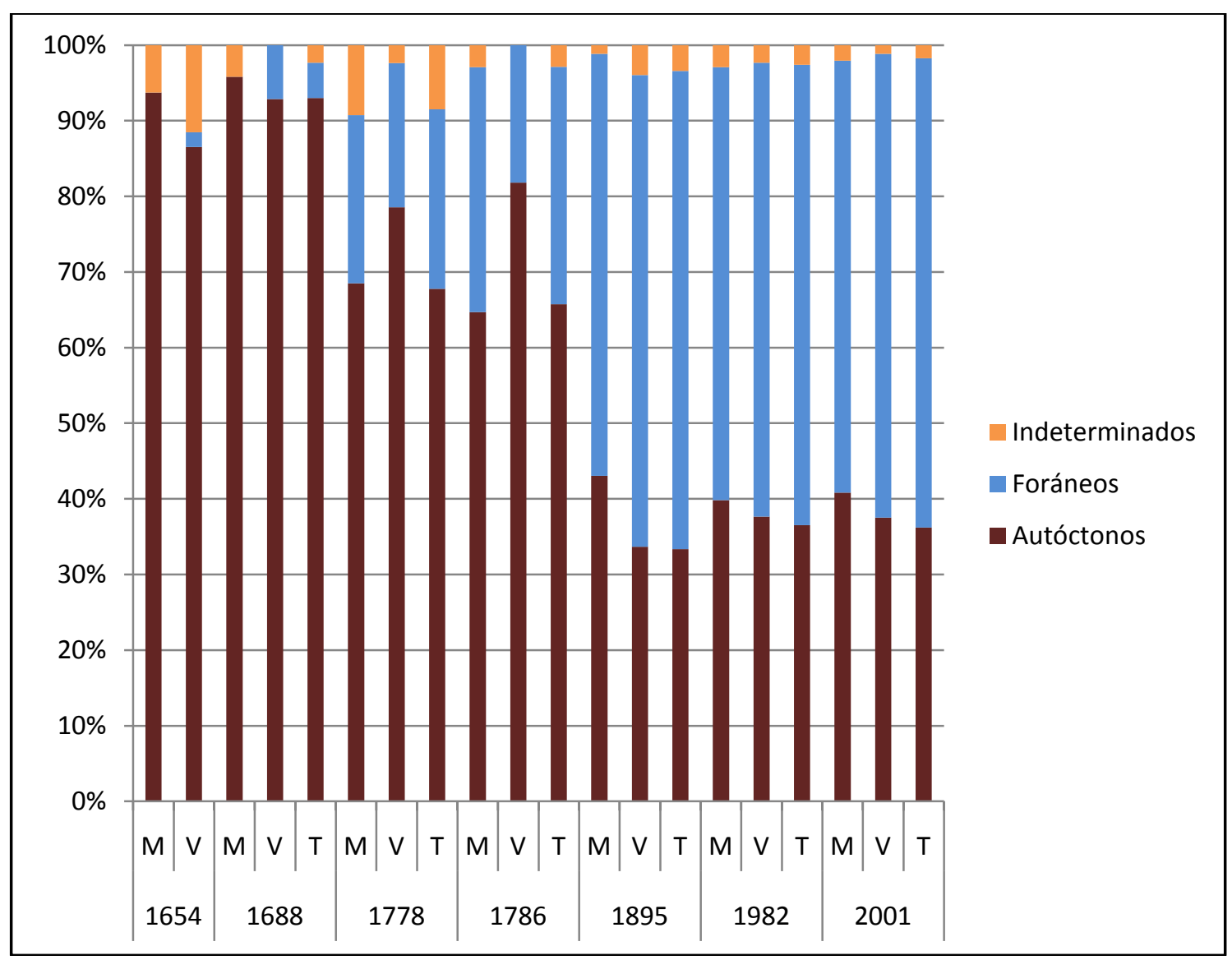

Figura 5: Distribución porcentual de los apellidos según su origen

En el caso del Padrón electoral de 1982, corte temporal distante 87 años del anterior, no se trata del total de la población sino sólo de los mayores de 18 años. Se registra un total de 1719 individuos de los cuales 697 son varones y 1022 mujeres con 85 y 103 apellidos diferentes respectivamente. El porcentaje de apellidos únicos en varones fue 22.3\% y en mujeres del 29.1\% (Tabla 2). Se mantiene el mayor número de apellidos foráneos (70/115 apellidos diferentes); sin embargo, muchos de ellos (24) están representados una sola vez. Los apellidos autóctonos si bien muestran una menor proporción en relación al total (Figura 5), son muy frecuentes y así, concentran una gran cantidad de individuos que los portan llegando al 50\% del total de población (Figura 6). 


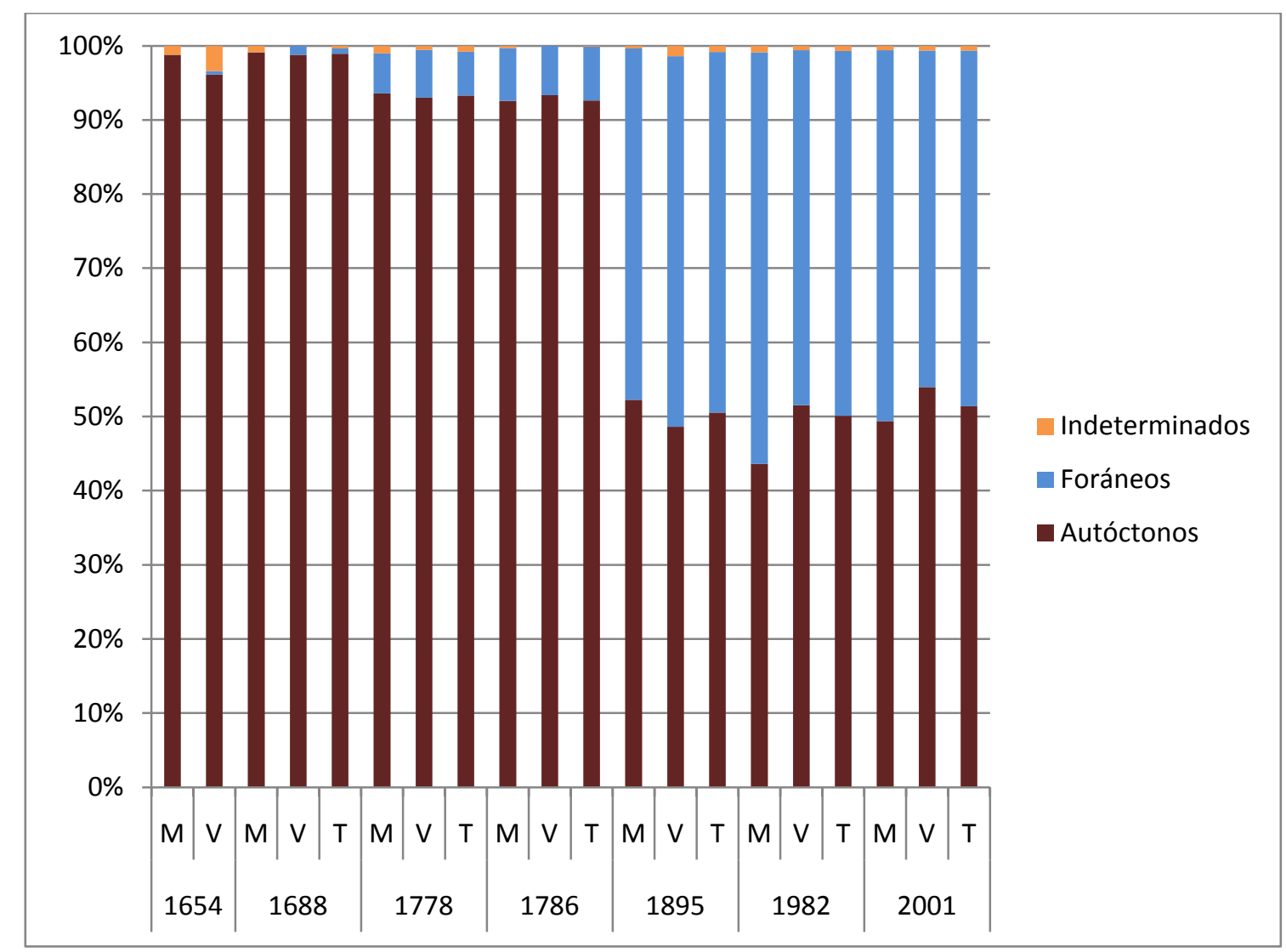

Figura 6: Distribución porcentual de la población según el origen del apellido

Entre los apellidos más frecuentes se encuentran cinco foráneos: Alejo, Carrillo, Gutiérrez, Benicio y Valdiviezo (Tabla 6) todos de origen hispano como la mayoría de los foráneos registrados en este padrón, seguidos en orden de frecuencia por los de origen vasco. Es destacable el caso de Alejo, apellido que aparece en la zona de Casabindo desde 1778. Los dos apellidos más representados son autóctonos y aparecen en el área desde mediados del siglo XVII (Lamas) o desde 1688 (Alancay).

Del padrón de 1654 se identificaron 25 nombres masculinos que perduraron como apellidos en la Puna o áreas vecinas en los siglos siguientes. Estos nombres son los siguientes: Abichocoar, Abracaite, Alarcaqui, Alavar, Barconte, Cachi, Cachisumba, Caiconde, Chocobar, Lacsi, Lamas, Liquin, 
Patagua, Pocapoca, Quipildor, Sarapura, Socomba, Sumbaine, Tabarcachi, Tabarcondi, Tinte, Toconas, Tolai, Vilte y Yonar17 (en cursiva y subrayados los que se registran desde el siglo XVI) ${ }^{18}$.

De los 25 apellidos que perduran desde 1654, todos se mantienen hasta fines del siglo XVIII. En cambio, antes del Segundo Censo Nacional de Población (1895) desaparecen 10 y uno más, antes del corte de 1982 (Fig. 7).

Los apellidos pertenecientes a este grupo representan en este momento una tercera parte de la población total, mientras que los apellidos clasificados como autóctonos tienen una representación poblacional del 50\%, manteniendo los foráneos frecuencias elevadas al igual que lo observado en 1895.

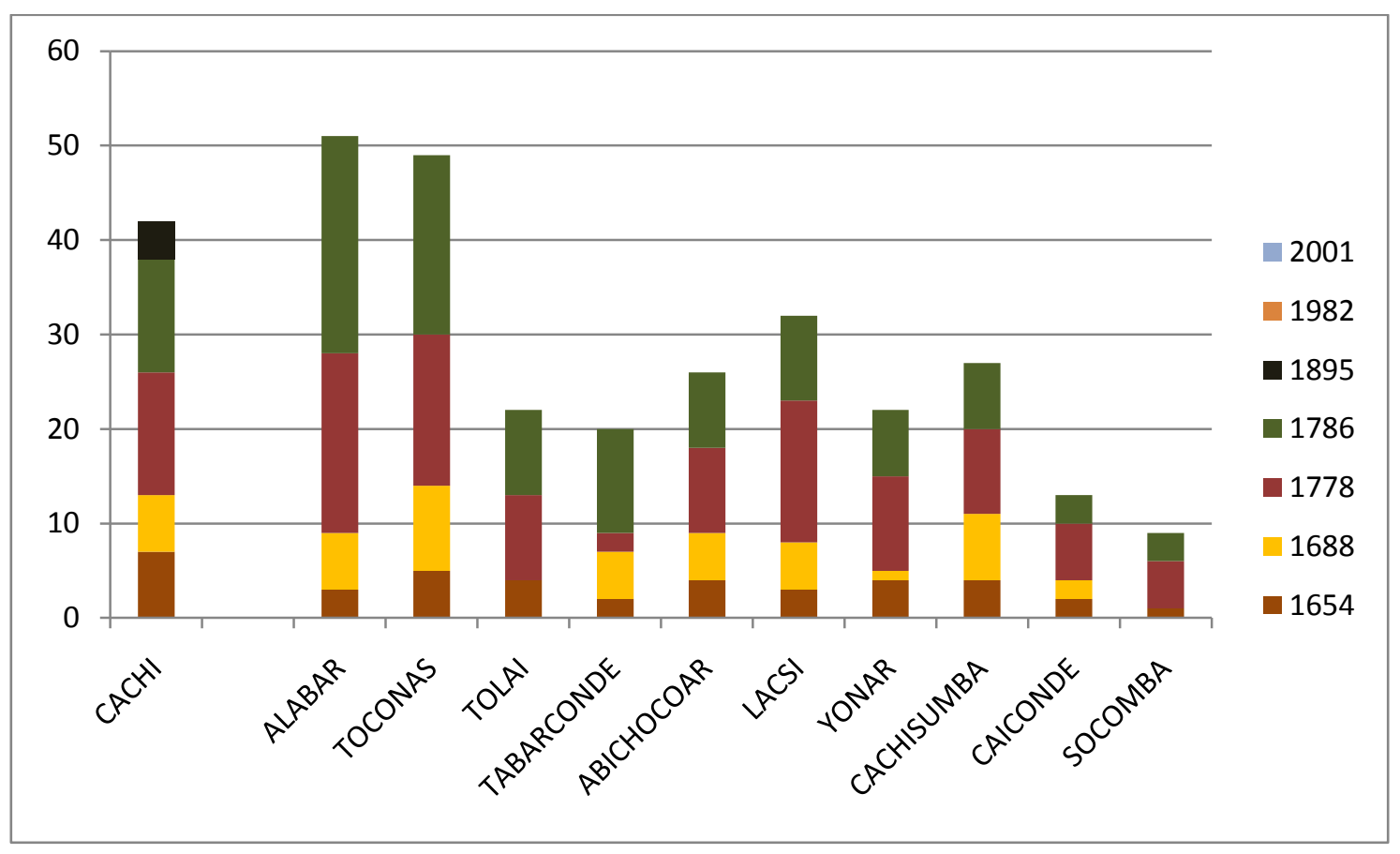

Figura 7: Apelativos presentes en 1654 que aparecen como apellidos en varones hasta los siglos XVIII y XIX

17 Se considera que Leonar y Yonar corresponden a diferentes grafías de un mismo nombre.

18 De estos apellidos sólo dos (Abichocoar y Poco) no han perdurado en el Noroeste Argentino hasta el siglo XX (Albeck et al. 2005a y b) 
El Padrón electoral de 2001 al igual que el anterior incluye solamente a los individuos mayores de 18 años y registra 1752 individuos repartidos entre 758 varones y 994 mujeres, con 88 y 98 apellidos diferentes respectivamente. Este registro que corresponde ya al siglo XXI, muestra, 19 años después, una situación muy similar en donde los apellidos foráneos son los más numerosos, pero los autóctonos se encuentran portados por un mayor número de individuos. Se registra un $45 \%$ de apellidos autóctonos propios de la zona andina, siendo Tolaba, Cusi y Mamani los más frecuentes con 61, 42 y 34 portadores respectivamente. Los 7 apellidos más frecuentes son en general coincidentes con los registrados en 1982 aunque se destaca la reaparición de algunos apellidos autóctonos muy frecuentes en los registros anteriores como Barconte y Sarapura (Tabla 6)

Los apellidos que perduran hasta hoy en lo que fue el espacio colonial de Casabindo y su frecuencia absoluta en los distintos documentos analizados se presentan en la Figura 8.

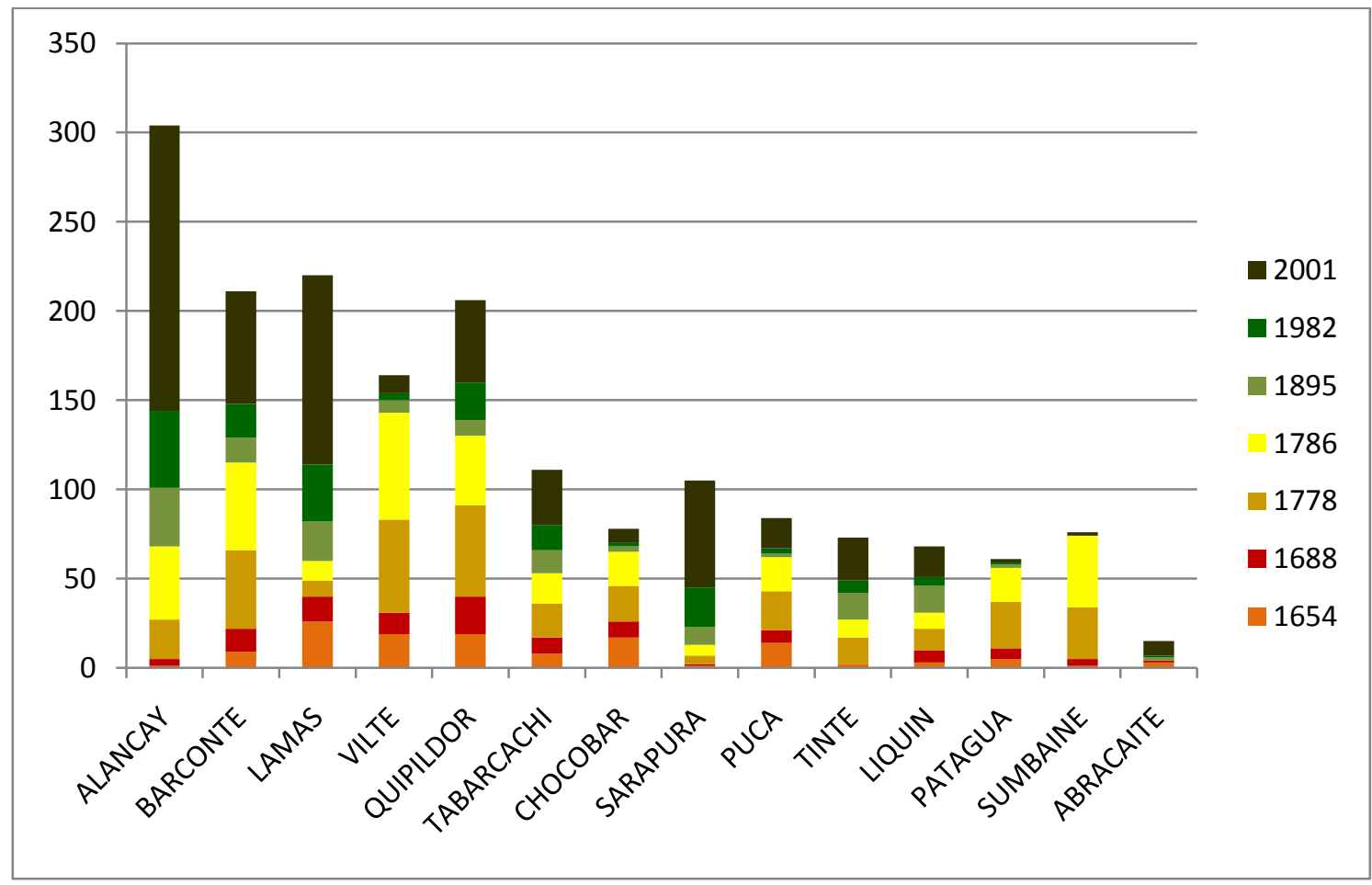

Figura 8: Apelativos presentes en 1654 que aparecen hasta hoy en varones 
A comienzos del siglo XXI puede apreciarse que, entre los mayores de 18 años empadronados en el área de Casabindo todavía se encuentran 14 de los 25 apellidos registrados desde 1654, cuatro de los cuales ya estaban presentes entre los casabindos en 1557 lo que marca una permanencia de más de 400 años en la zona.

Al considerar el origen de los apellidos en conjunto, pueden distinguirse tres etapas diferentes (Figura 6). Al principio del período analizado, durante el siglo XVII, más del 95\% de la población lleva un antropónimo autóctono y solamente los varones registran nombres foráneos. En un segundo momento, correspondiente al siglo XVIII, la situación es muy similar pero los apelativos foráneos ya aparecen entre las mujeres y aumentan su frecuencia en la población total llegando a cubrir casi al $10 \%$ de los individuos. Finalmente desde fines del siglo XIX hasta comienzos del XXI, se presenta el cambio más significativo con un aumento muy importante de la frecuencia de portadores de apellidos foráneos que alcanzan al 50\% de la población total de Casabindo. Este comportamiento refleja la diferente situación demográfica de esta población que registra una importante estabilidad hasta 1786 y una inmigración importante en 1895 como se analizará más adelante. 


\section{CAPÍTULO X: DISTRIBUCIÓN DE LOS PARÁMETROS ISONÍMICOS}

\section{CONSANGUINIDAD DE LAS POBLACIONES (Øii)}

La consanguinidad refleja las uniones entre individuos emparentados, relación establecida en este trabajo a través de la isonimia o identidad de apellidos entre los miembros de la pareja. Es un indicador que revela el grado de parentesco al interior de una población que, biológicamente resulta de gran interés por cuanto como se mencionara en el Capítulo VII la consanguinidad incide sobre la fertilidad y mortalidad de los individuos.

En la Tabla 9 se presentan los valores de la consanguinidad por isonimia al azar ( $\varnothing \mathrm{ii})$ para la población de Casabindo en conjunto y para cada una de las áreas en que se subdividió. Valores elevados de Øii, indican mayor afinidad intrapoblacional o consanguinidad de la población. Para el total se observa que en 1688 se registra el mayor valor, seguido por los calculados para el siglo XVIII. Al analizar el comportamiento de este parámetro en las distintas áreas se aprecia que, tanto para los registros finicoloniales como para los más recientes, los valores registrados en cada área son significativamente mayores que los obtenidos para Casabindo en conjunto. El Área Oeste presenta la mayor consanguinidad y la Norte, la menor, excepto en 1778 cuando ocurre lo contrario. 
Tabla 9: Promedio y desviación estándar de la consanguinidad por isonimia al azar ( $\varnothing \mathrm{ii})$ de la población de Casabindo por año (valores x100)

\begin{tabular}{|l|c|c|c|c|}
\hline Año & Casabindo & Área Norte & Área Este & Área Oeste \\
\hline 1654 & $0.96 \pm 0.1$ & -- & -- & -- \\
1688 & $1.22 \pm 0.2$ & -- & -- & -- \\
1778 & $1.11 \pm 0.07$ & $1.36 \pm 0.1$ & $1.44 \pm 0.2$ & $1.55 \pm 0.2$ \\
1786 & $1.02 \pm 0.06$ & $1.42 \pm 0.1$ & $1.37 \pm 0.1$ & $1.18 \pm 0.1$ \\
1895 & $0.54 \pm 0.04$ & -- & -- & -- \\
1982 & $0.72 \pm 0.04$ & $1.06 \pm 0.1$ & $1.29 \pm 0.1$ & $1.84 \pm 0.2$ \\
2001 & $0.79 \pm 0.05$ & $1.01 \pm 0.1$ & $1.49 \pm 0.1$ & $1.86 \pm 0.1$ \\
\hline
\end{tabular}

La consanguinidad estimada para el siglo XVII debe considerarse cuidadosamente por cuanto aun no se registra una transmisión regular de los antropónimos, razón por la cual los valores elevados podrían estar reflejando el polifiletismo y no uniones preferenciales. Sin embrago, durante el siglo XVIII la consanguinidad sigue siendo importante a pesar de estar instalada la transmisión de apellidos entre generaciones, lo que indica que se trata de una población cerrada. A partir de 1786 se manifiesta una tendencia claramente descendente y es a fines del siglo XIX donde se observa el valor más bajo de todo el período analizado en coincidencia con el ingreso de inmigrantes. La consanguinidad calculada para 1982 y 2001 ha aumentado en relación a la de 1895 lo que está en estrecha relación con la realidad sociodemográfica caracterizada por el crecimiento de la población con disminución de la emigración y prácticamente sin inmigración y que se analizará en profundidad al abordar la estructura demográfica. 


\section{INDICADORES DE AISLAMIENTO Y SEDENTARISMO}

La frecuencia de apellidos indica el grado de aislamiento y el sedentarismo de una población al proporcionar información sobre el porcentaje de población cubierta por apellidos únicos (Indicador A) donde valores bajos indican aislamiento poblacional por cuanto no se registra ingreso de apellidos nuevos a la población. Mientras que el porcentaje de población cubierta por los siete apellidos más frecuentes (Indicador B) evidencia sedentarismo en función de la cantidad de personas concentradas en muy pocos apellidos.

\section{INDICADORES A Y B}

En la Tabla 10 se presentan los valores de A y B para la población de Casabindo en los distintos períodos considerados.

Puede observarse que los valores extremos de A se presentan en 1654, en total coincidencia con la ausencia de apellidos y con el cambio de nombres entre generaciones mencionado anteriormente. Luego, en 1688, las mujeres presentan valores aún muy altos pero que, tanto en varones como en el total, son prácticamente tres veces más bajos que en 1654. Se registran diferencias sexuales con valores femeninos superiores en el siglo XVIII e inferiores en 1895, mientras que en 1982 y 2001 los valores entre ambos sexos no difieren entre sí. Se advierte un comportamiento oscilante de $\mathbf{A}$ en el total de la población desde 1688 a 2001 (Tabla 10) lo que también ocurre entre los varones, mientras que las mujeres presentan un descenso importante entre fines del siglo XVII y 1778 pero luego los valores permanecen prácticamente constantes hasta 2001. 
Tabla 10: Indicadores de aislamiento y sedentarismo para el total de la población de Casabindo, por sexo y por año

\begin{tabular}{|c|c|c|c|c|c|c|}
\hline \multirow{2}{*}{ Año } & \multicolumn{3}{|c|}{ A } & \multicolumn{3}{c|}{ B } \\
\cline { 2 - 7 } & Mujeres & Varones & Total & Mujeres & Varones & Total \\
\hline $\mathbf{1 6 5 4}$ & 10.4 & 12.6 & 11.3 & 71.2 & 55.3 & 44.7 \\
$\mathbf{1 6 8 8}$ & 10.5 & 3.6 & 3.6 & 79.8 & 52.1 & 47.7 \\
$\mathbf{1 7 7 8}$ & 3.7 & 1.1 & 1.9 & 45.9 & 47.8 & 45.7 \\
$\mathbf{1 7 8 6}$ & 3.0 & 0.5 & 1.5 & 45.8 & 46.9 & 43.5 \\
$\mathbf{1 8 9 5}$ & 3.4 & 6.6 & 3.7 & 28.1 & 29.2 & 27.8 \\
$\mathbf{1 9 8 2}$ & 2.9 & 2.7 & 1.8 & 37.1 & 39.2 & 34.2 \\
$\mathbf{2 0 0 1}$ & 3.3 & 3.3 & 2.1 & 34.6 & 39.0 & 36.2 \\
\hline
\end{tabular}

El indicador B presenta un patrón similar al de A en cuanto los valores mayores se registran durante el siglo XVII, descienden en el XVIII (de forma más importante en las mujeres) y presentan los valores más bajos en 1895. En los dos últimos cortes temporales aumentan nuevamente pero no llegan a alcanzar los valores coloniales (Tabla 10). Sólo para los primeros períodos se observa que las mujeres son más sedentarias que los varones mientras que en 1778, éstos presentan valores superiores aunque a veces las diferencias sólo ascienden al 1\% (Tabla 10).

Al analizar cada una de las áreas se observa que en el Área Norte el indicador A permanece estable entre 1778 y 1982 y aumenta levemente en 2001 (Tabla 11). Las mujeres presentan valores significativamente superiores en el siglo XVIII especialmente en 1786, situación que se revierte a fines del siglo XX y principios del XXI cuando los valores más elevados son los masculinos (Tabla 11).

El indicador B presenta porcentajes elevados y estables aunque muestra un descenso en 1982. En cuanto a las diferencias intersexuales los valores registran valores superiores excepto para 2001 donde el porcentaje es igual en ambos sexos (Tabla 11) 
Tabla 11: Indicadores de aislamiento y sedentarismo para el total de la población del Área Norte, por sexo y por año

\begin{tabular}{|c|c|c|c|c|c|c|}
\hline \multirow{2}{*}{ Año } & \multicolumn{3}{|c|}{ A } & \multicolumn{3}{c|}{ B } \\
\cline { 2 - 7 } & Mujeres & Varones & Total & Mujeres & Varones & Total \\
\hline $\mathbf{1 7 7 8}$ & 4.9 & 1.9 & 2.3 & 50.0 & 56.3 & 52.1 \\
$\mathbf{1 7 8 6}$ & 7.0 & 1.7 & 2.8 & 50.5 & 62.4 & 54.5 \\
$\mathbf{1 9 8 2}$ & 5.7 & 7.3 & 2.9 & 47.6 & 51.1 & 45.0 \\
$\mathbf{2 0 0 1}$ & 5.5 & 7.8 & 3.9 & 44.5 & 44.5 & 52.0 \\
\hline
\end{tabular}

En el Área Este el indicador A prácticamente duplica su valor entre 1778 y 2001. En la Tabla 12 se observa que las mujeres presentan valores que van aumentando a través del tiempo y, en general, son superiores a los registrados en el sexo masculino. En esta área el indicador B presenta poca variación temporal y muestra valores elevados, siempre superiores en los varones.

Tabla 12: Indicadores de aislamiento y sedentarismo para el total de la población del Área Este, por sexo y por año

\begin{tabular}{|c|c|c|c|c|c|c|}
\hline \multirow{2}{*}{ Año } & \multicolumn{3}{|c|}{ A } & \multicolumn{3}{c|}{ B } \\
\cline { 2 - 7 } & Mujeres & Varones & Total & Mujeres & Varones & Total \\
\hline $\mathbf{1 7 7 8}$ & 6.3 & 1.3 & 2.9 & 57.9 & 61.4 & 59.1 \\
$\mathbf{1 7 8 6}$ & 6.0 & 0.4 & 2.9 & 55.3 & 56.1 & 52.0 \\
$\mathbf{1 9 8 2}$ & 7.7 & 7.6 & 5.6 & 51.2 & 59.7 & 52.1 \\
$\mathbf{2 0 0 1}$ & 8.6 & 6.8 & 5.5 & 53.7 & 61.7 & 56.3 \\
\hline
\end{tabular}

En la Tabla 13 se presentan los valores de A y B para el Área Oeste para cada uno de los años considerados. El indicador A es mayor en las mujeres excepto para 1982, para el total de la población el valor superior se registra en 1778 descendiendo en 1786 - 1982 para aumentar nuevamente en 2001 presentando el valor más bajo de las tres áreas para dicho año. 
Al analizar el indicador B del total de la población se observa que, a diferencia de las otras áreas en donde se mantiene estable, aumenta desde 1778 hasta 2001, aunque registra un descenso en 1786, al igual que en los varones, mientras este aumento es sostenido sin registrar descensos en las mujeres (Tabla 13).

Tabla 13: Indicadores de aislamiento y sedentarismo para el total de la población del Área Oeste, por sexo y por año

\begin{tabular}{|c|c|c|c|c|c|c|}
\hline \multirow{2}{*}{ Año } & \multicolumn{3}{|c|}{ A } & \multicolumn{3}{c|}{ B } \\
\cline { 2 - 7 } & Mujeres & Varones & Total & Mujeres & Varones & Total \\
\hline $\mathbf{1 7 7 8}$ & 11.0 & 1.8 & 4.5 & 53.8 & 64.8 & 53.8 \\
$\mathbf{1 7 8 6}$ & 4.9 & 1.9 & 2.3 & 57.1 & 46.7 & 46.8 \\
$\mathbf{1 9 8 2}$ & 2.8 & 5.8 & 2.4 & 64.2 & 67.5 & 64.9 \\
$\mathbf{2 0 0 1}$ & 5.0 & 3.8 & 3.2 & 64.5 & 71.5 & 65.3 \\
\hline
\end{tabular}

En general los valores observados para ambos indicadores estarían reflejando un grado de aislamiento importante y un gran sedentarismo en la población de Casabindo con escaso movimiento poblacional durante el período analizado. Durante los dos primeros siglos esto podría explicarse por el hecho de tratarse de una población de encomendados que permanecen en su área de origen mientras que a fines del siglo XIX la situación muestra una apertura con ingreso de inmigrantes, coincidente con los bajos valores de consanguinidad registrados en ese momento. 


\section{INDICADORES DE DINÁMICA DE POBLACIÓN}

Los indicadores que se presentan a continuación se basan, como los anteriores, en la frecuencia de apellidos y se relacionan fundamentalmente con las migraciones recientes. La migración junto con la deriva génica y la consanguinidad son factores microevolutivos que condicionan la estructura de las poblaciones.

\section{$v$ DE KARLIN-MCGREGOR}

$\mathrm{Al}$ analizar este indicador de inmigración reciente, tanto para el total de la población de Casabindo como para cada sexo por separado, se identifican 4 grupos. El primer grupo que corresponde al siglo XVII, presenta valores elevados, el segundo está constituido por valores de 1778 y 1786 que muestran un descenso brusco en relación al grupo anterior. Para 1895 se observa un aumento y un nuevo descenso en el cuarto grupo con los registros correspondientes a fines del siglo XX y principios del XXI (Tabla 14).

En la Tabla 14, se observan las diferencias intersexuales. En el siglo XVII los varones registran una mayor inmigración reciente, lo que se repite en 1895 y 1982, mientras que las mujeres presentan valores mayores en 1778 y 1786 y en 2001 no se observan diferencias entre ambos sexos.

El comportamiento de este indicador presenta diferencias entre cada una de las áreas consideradas. Para este análisis no se considera el Censo de 1895 porque no se puede discriminar la población por áreas. El Área Norte presenta un aumento en 1982 y 2001 con respecto a los valores calculados para el siglo XVIII, muy marcado en el caso de los varones y menos pronunciado para el total de la población, mientras que en las mujeres permanecen prácticamente constantes (Tabla 15). Se observan importantes diferencias entre sexos, registrando las mujeres valores superiores para 1778 y 1786 y los varones para 1982 y 2001 mientras este último año es el que registra una diferencia mayor. 
Tabla 14: Promedio y desviación estándar de los indicadores v de KarlinMcGregor (valores x 100) y alfa de Fisher para el total de la población de Casabindo, por sexo y por año

\begin{tabular}{|c|c|c|c|}
\hline $\mathbf{A n ̃ o}$ & Mujeres & Varones & Total \\
\hline $\mathbf{1 6 5 4}$ & $5.1 \pm 1.0$ & $8.3 \pm 1.4$ & $6.8 \pm 0.9$ \\
$\mathbf{1 6 8 8}$ & $4.6 \pm 1.1$ & $9.9 \pm 1.8$ & $7.0 \pm 1.0$ \\
$\mathbf{1 7 7 8}$ & $4.6 \pm 0.5$ & $3.8 \pm 0.4$ & $2.1 \pm 0.2$ \\
$\mathbf{1 7 8 6}$ & $3.6 \pm 0.3$ & $2.8 \pm 0.2$ & $1.6 \pm 0.1$ \\
$\mathbf{1 8 9 5}$ & $7.7 \pm 0.8$ & $8.4 \pm 0.9$ & $4.3 \pm 0.3$ \\
$\mathbf{1 9 8 2}$ & $3.4 \pm 0.3$ & $4.4 \pm 0.4$ & $1.9 \pm 0.1$ \\
$\mathbf{2 0 0 1}$ & $3.3 \pm 0.2$ & $3.6 \pm 0.3$ & $1.7 \pm 0.1$ \\
\hline
\end{tabular}

Las áreas Este y Oeste presentan, para ambos sexos y para el total, un patrón similar ya que en ambas se registra un descenso gradual pero significativo de los valores de v entre 1778 y 2001, llegando al final a valores prácticamente 50\% menores que los iniciales en el Área Este y con una disminución mucho mayor en el Área Oeste (Tabla 15).

Al considerar las diferencias entre sexos en ambas áreas vemos que para el período 1778 - 1786 son las mujeres las que presentan mayor inmigración reciente, que lo contrario ocurre para 1982, y que se registran valores similares en mujeres y varones para 2001 (Tabla 15). 


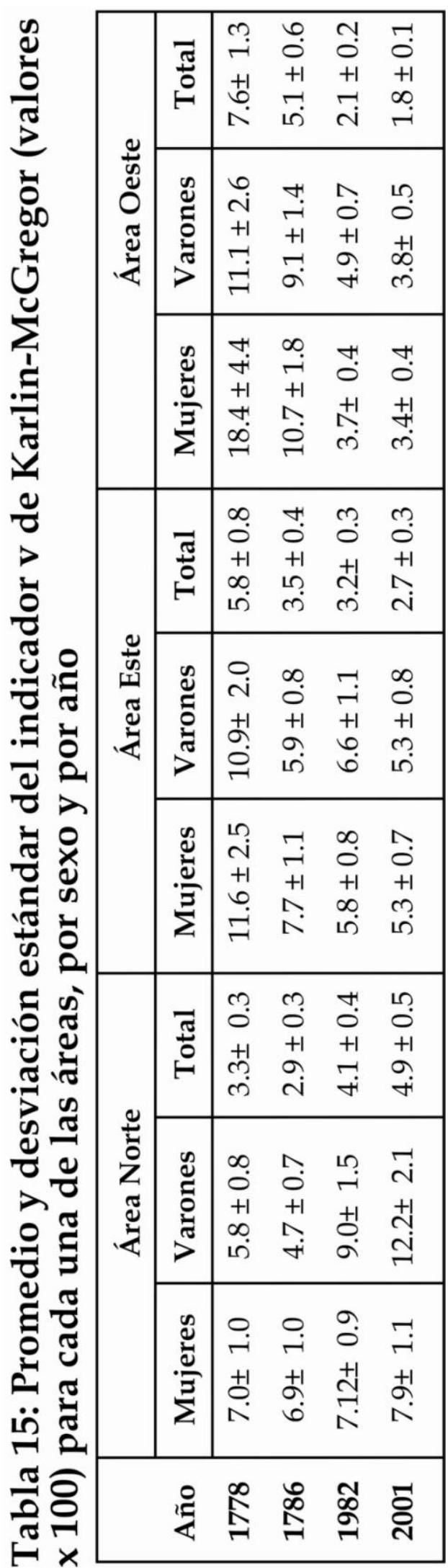




\section{$\alpha$ DE FISHER}

La diversidad de apellidos, estimada a través del indicador $\alpha$ de Fisher, se presenta en la Tabla 16 donde para el siglo XVII existe una gran diferencia intersexual a favor de los valores masculinos y en coincidencia con el cambio de nombres en cada generación. Estas diferencias se atenúan durante el siglo XVIII y, ya con la transmisión regular de apellidos, se observa que las mujeres muestran valores levemente mayores, lo que se repite para 1982 y 2001, mientras que en 1895 los valores en ambos sexos son iguales. En la Tabla 16 se aprecia que, tanto para el total como para ambos sexos, los valores de $\alpha$ aumentan entre 1778 y 2001 con un pico importante en 1895.

El comportamiento de este indicador de estructura de población registra diferencias entre las tres áreas consideradas observándose que en la Norte se produce un aumento entre 1778 y 2001, en la Este los valores permanecen constantes mientras que en la Oeste ocurre un descenso de los mismos entre el inicio y el final del período pero con un pico en 1786 (Tabla 17). En general las mujeres presentan valores superiores a los varones. 
Tabla 16: Promedio y desviación estándar del indicador alfa de Fisher para el total de la población de Casabindo, por sexo y por año

\begin{tabular}{|c|c|c|c|}
\hline Año & Mujeres & Varones & Total \\
\hline $\mathbf{1 6 5 4}$ & $9 \pm 1$ & $19 \pm 3$ & $28 \pm 3$ \\
$\mathbf{1 6 8 8}$ & $6 \pm 1$ & $19 \pm 3$ & $22 \pm 3$ \\
$\mathbf{1 7 7 8}$ & $24 \pm 2$ & $22 \pm 2$ & $23 \pm 1$ \\
$\mathbf{1 7 8 6}$ & $27 \pm 2$ & $23 \pm 1$ & $24 \pm 1$ \\
$\mathbf{1 8 9 5}$ & $46 \pm 5$ & $46 \pm 5$ & $48 \pm 3$ \\
$\mathbf{1 9 8 2}$ & $36 \pm 2$ & $33 \pm 3$ & $35 \pm 2$ \\
$\mathbf{2 0 0 1}$ & $34 \pm 2$ & $29 \pm 2$ & $32 \pm 1$ \\
\hline
\end{tabular}

Al igual que con los parámetros isonímicos comentados anteriormente en este caso, las estimaciones correspondientes al siglo XVII deben considerarse como valores indiciarios. En general se acepta que valores elevados de $v$ y $\alpha$ corresponden a poblaciones abiertas con altas tasas de migración. Casabindo presenta, en relación a estos indicadores, diferentes situaciones según el momento considerado que se relacionan con dos fenómenos demográficos no excluyentes entre sí y propios de la dinámica poblacional: la inmigración y la emigración.

En el seguimiento de los casabindos realizado en este trabajo pueden apreciarse momentos de estabilidad durante los dos primeros siglos relacionados con su condición de encomendados mientras que esta situación se revierte posteriormente revelando una importante apertura de la población con ingreso de inmigrantes a fines del siglo XIX y en el último corte temporal considerado un delicado balance entre inmigración y emigración. 


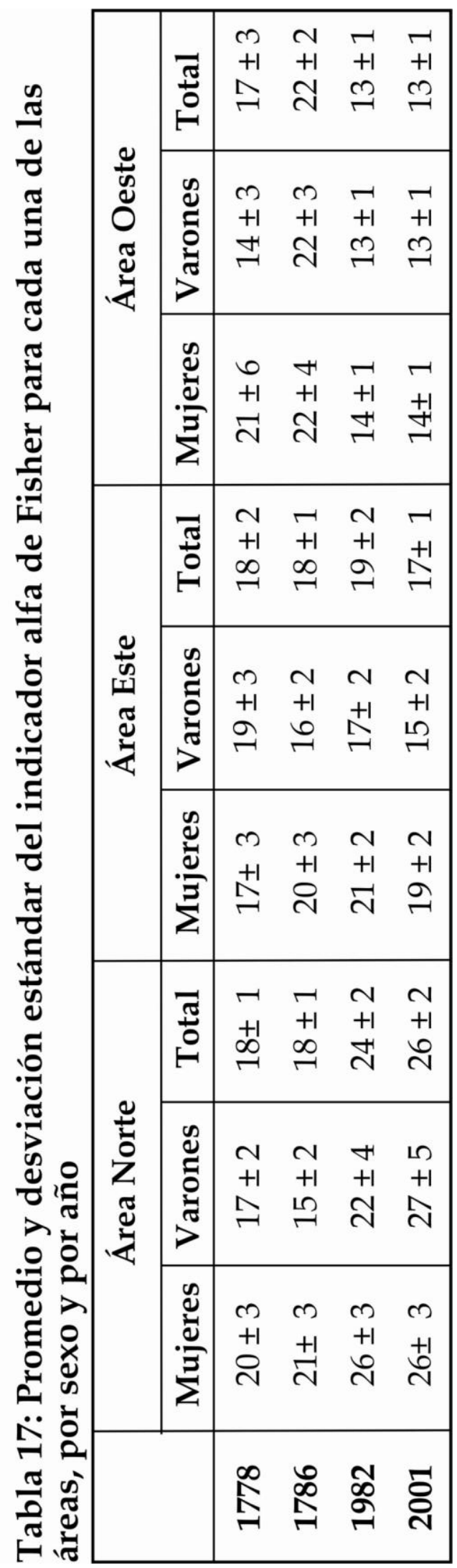




\section{CAPÍTULO XI: ANÁLISIS DE LOS DATOS DEMOGRÁFICOS}

Estos datos, considerados fundamentalmente desde un punto de vista cuantitativo, aportan información sobre el tamaño de la población, su constitución considerando la edad y el sexo de los individuos, el estado civil, el tamaño y la composición familiar. También revelan su evolución temporal e indirectamente los factores que han podido influir en ella (fertilidad, mortalidad, migraciones) que permiten intentar reconstruir la historia biológica de la población de Casabindo en el pasado y analizar su estructura actual.

Se considera el estado civil de los individuos, la cantidad de familias y su composición hasta 1895 en tanto los registros empleados en 1982 y 2001 corresponden a padrones electorales en los cuales no es posible establecer la estructura familiar.

Padrón de 1654: Comprende un total de 394 individuos, 213 varones y 181 mujeres. Todos los hombres, tributarios, jóvenes y niños, tienen consignada la edad pero no hay indicaciones de edad para las mujeres. El 37.6\% de la población masculina es menor de 15 años y sólo el 7.5\% de los individuos tiene más de 50 años por lo cual se la puede catalogar como una población joven (Figura 9). En la Figura 10 se observa que la proporción de varones supera el $50 \%$, al no contar con la edad de las mujeres no resulta posible analizar la variación de esta proporción en las diferentes etapas de la vida.

En este momento se registran 131 familias que presentan entre uno y ocho integrantes, y las más frecuentes son las integradas por dos y tres miembros (Figura 11).

Se presentan 81 parejas casadas y dos varones casados y sus esposas no se encuentran en el lugar (Tabla 18). En cuanto a la categoría solteros se presenta una dificultad para establecer la cantidad real ya que en los documentos originales sólo se mencionan 19 varones apareciendo, además de 
éstos, 20 individuos entre 18 y 30 años que se considerarían en edad de casarse. Entre las mujeres no se registra ninguna como soltera y, al no consignarse la edad, tampoco puede estimarse la proporción de las que estarían en edad de casarse. Se observa entre los viudos una marcada mayoría femenina (Tabla 18).

Padrón de tributarios de 1688: Incluye 351 individuos (170 mujeres y 181 varones) y no contabiliza a viudas y huérfanos. Al igual que en el documento anterior, sólo se consigna la edad de los varones, presentando casi un $49 \%$ de menos de 15 años y sólo un 1\% de mayores de 50 años. Se observa que para el grupo de 15 a 19 años, es decir los próximos a tributar, sólo registra un 1.6\% lo que podría representar un subregistro u ocultamiento ya que los grupos etáreos inmediatamente anterior y posterior presentan valores superiores al $10 \%$ (Figura 9). La proporción total de varones alcanza el 50\% representando una relación hombre/mujer de 1 a 1 independientemente de la edad (Figura 10).

Se registran 95 familias integradas por uno a siete miembros con predominio de aquéllas compuestas por entre dos y cinco integrantes (Figura 11). En este padrón aparecen 76 parejas casadas y se mantiene la diferencia a favor de las mujeres entre los viudos (Tabla 18). En este caso ocurre lo mismo que en el registro anterior donde solamente aparecen registrados como solteros siete varones y sólo tres más en edad de casarse. 
Tabla 18: Distribución de la población según estado civil en los distintos documentos

\begin{tabular}{|c|c|c|c|c|c|}
\hline Año & Area & Sexo & Solteros & Casados & Viudos \\
\hline \multirow{2}{*}{1654} & \multirow{2}{*}{ Casabindo } & $\bar{M}$ & & 81 & 15 \\
\hline & & V & 19 & 83 & 4 \\
\hline \multirow{2}{*}{1688} & \multirow{2}{*}{ Casabindo } & $\bar{M}$ & & 76 & 7 \\
\hline & & V & 7 & 76 & 3 \\
\hline \multirow{8}{*}{1778} & \multirow{2}{*}{ Casabindo } & $\bar{M}$ & 80 & 210 & 42 \\
\hline & & V & 134 & 210 & 14 \\
\hline & \multirow{2}{*}{ Norte } & $\mathrm{M}$ & 52 & 106 & 23 \\
\hline & & V & 73 & 106 & 9 \\
\hline & \multirow{2}{*}{ Este } & $\mathrm{M}$ & 12 & 57 & 13 \\
\hline & & V & 32 & 57 & 2 \\
\hline & \multirow{2}{*}{ Oeste } & $\mathrm{M}$ & 16 & 47 & 9 \\
\hline & & V & 29 & 47 & 3 \\
\hline \multirow{8}{*}{1786} & \multirow{2}{*}{ Casabindo } & $\bar{M}$ & 132 & 308 & 51 \\
\hline & & V & 168 & 308 & 24 \\
\hline & \multirow{2}{*}{ Norte } & $\mathrm{M}$ & 56 & 120 & 14 \\
\hline & & V & 59 & 120 & 9 \\
\hline & \multirow{2}{*}{ Este } & $\mathrm{M}$ & 44 & 102 & 20 \\
\hline & & $\mathrm{V}$ & 60 & 102 & 3 \\
\hline & \multirow{2}{*}{ Oeste } & $\mathrm{M}$ & 32 & 86 & 17 \\
\hline & & $\mathrm{V}$ & 49 & 86 & 12 \\
\hline \multirow{2}{*}{1895} & \multirow{2}{*}{ Casabindo } & $\bar{M}$ & 135 & 163 & 45 \\
\hline & & $\mathrm{V}$ & 95 & 160 & 19 \\
\hline
\end{tabular}




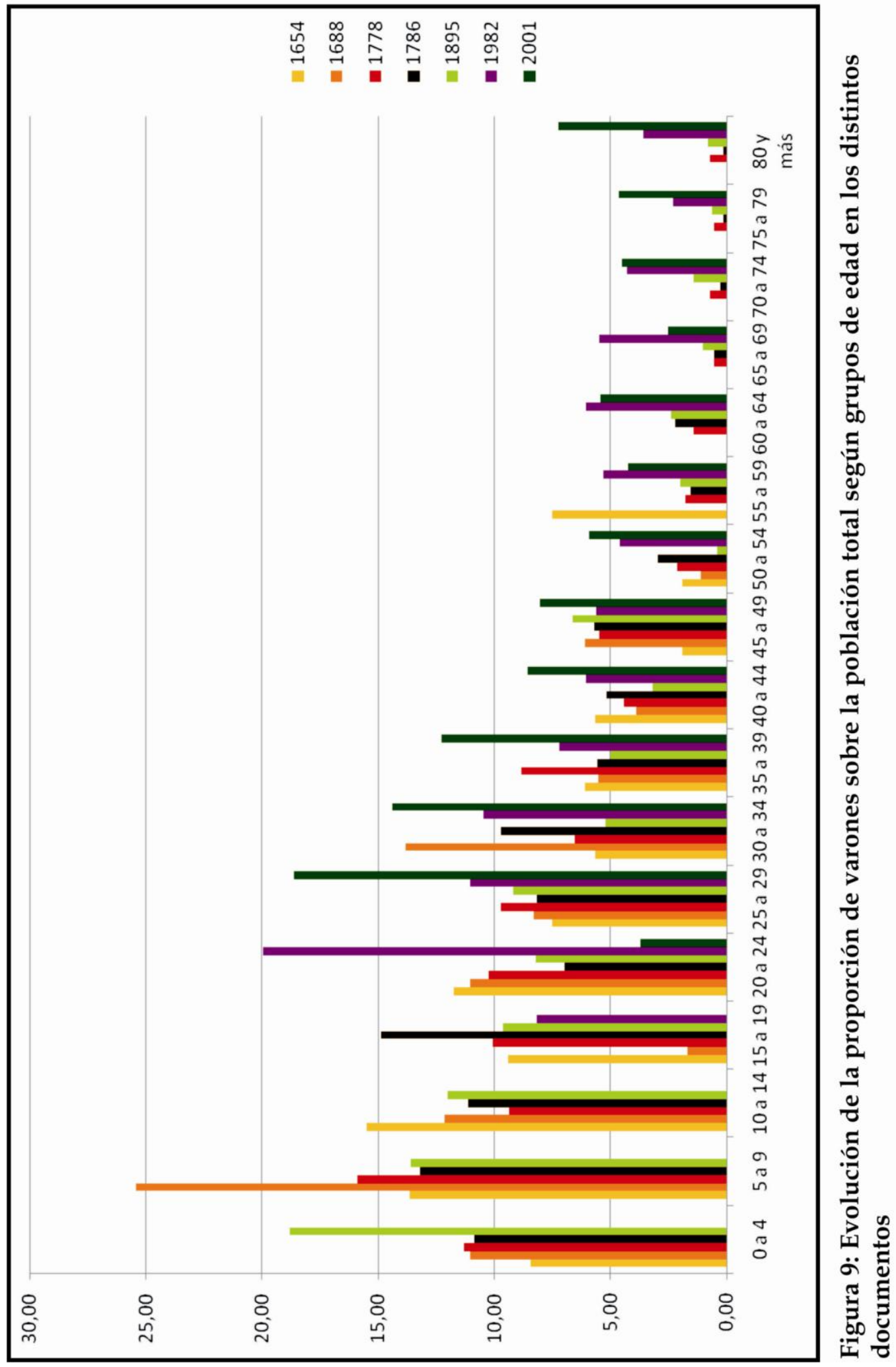




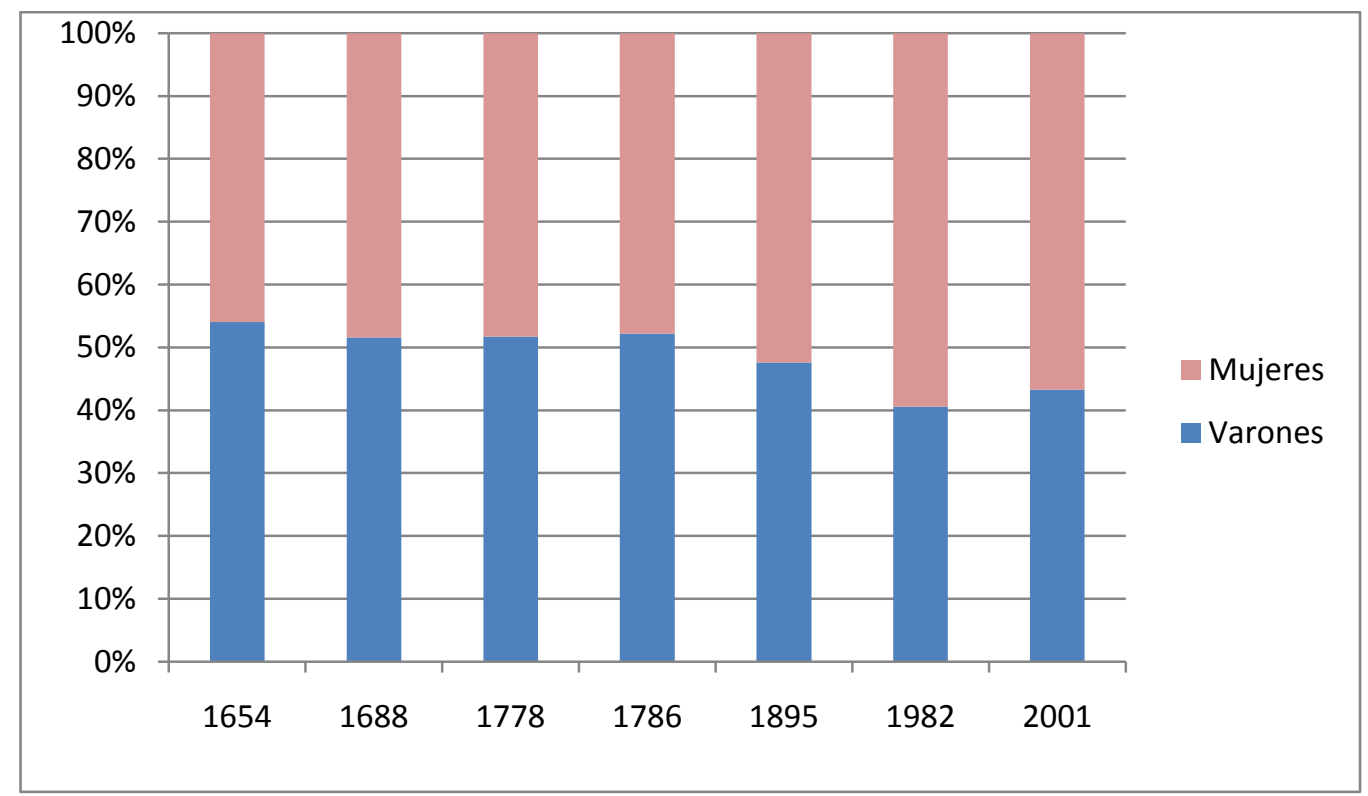

Figura 10: Proporción de varones en los distintos cortes temporales

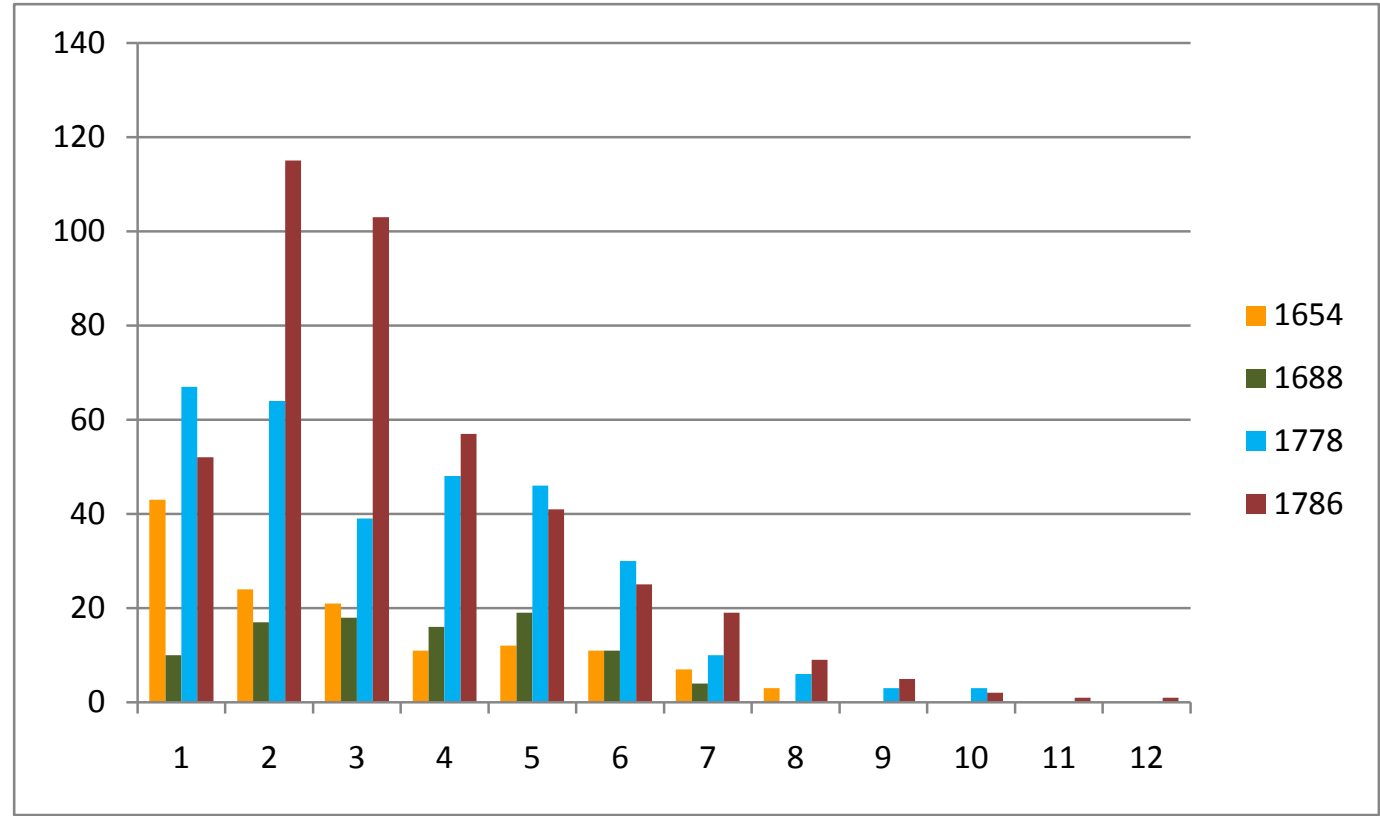

Figura 11: Evolución del tamaño familiar 
Censo de población de 1778: Para el área Casabindo registra 524 mujeres y 565 varones lo que hace un total de 1089 individuos. A diferencia de los documentos anteriores en este se indica la edad de toda la población, al punto de especificar cantidad de meses cuando se refiere a niños menores de un año. Alrededor del 35\% de la población es menor de 15 años, observándose más mujeres en el grupo de 0 a 4 años y más varones en el de 5 a 9 mientras que se registran valores similares en ambos sexos entre los 10 y 14 años (Figura 12). Entre los 15 y 49 años no se registran diferencias intersexuales excepto en el grupo de 35 a 39 años y en el 40 a 44 años a favor de los varones y de las mujeres respectivamente. La población mayor de 50 años es de 8\% aproximadamente observándose valores femeninos más elevados en el grupo de 60 a 64 años y sólo varones entre los 75 y 79 años.

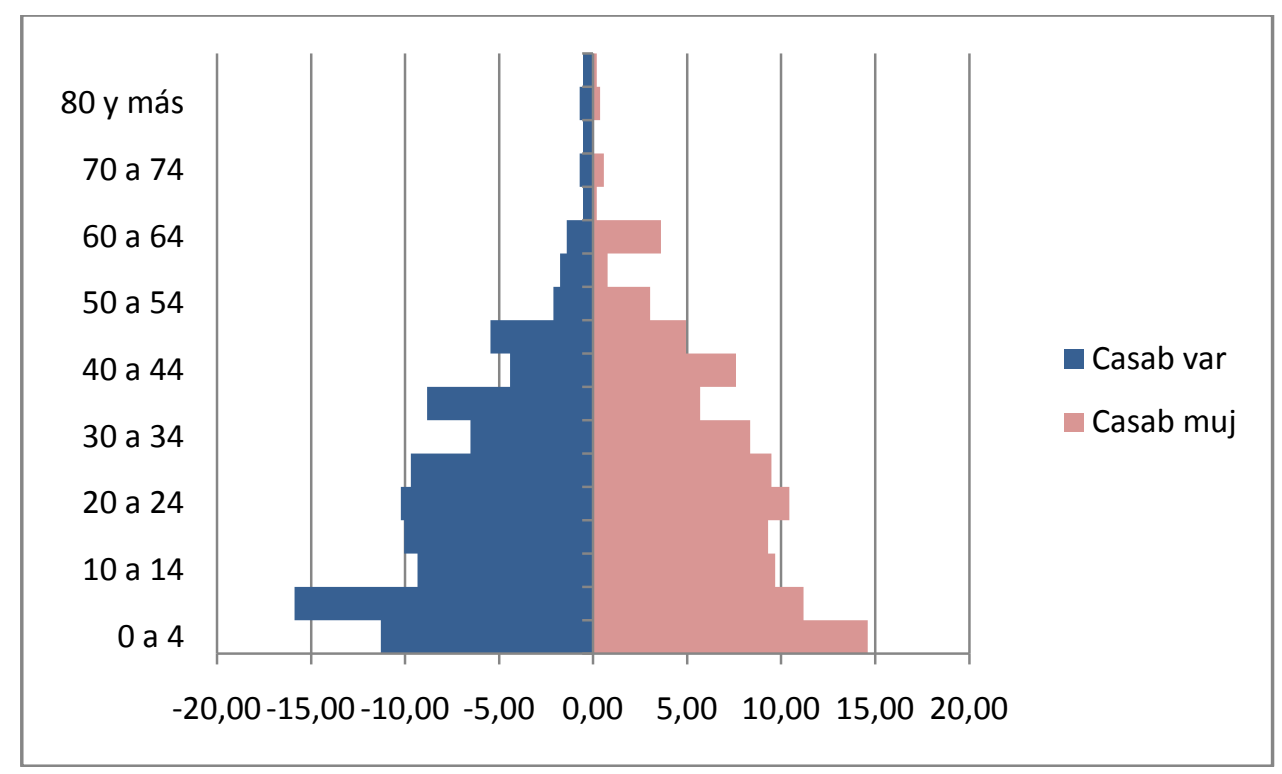

Figura 12: Pirámide poblacional de Casabindo 1778

Las personas fueron registradas mayormente como integrantes de una familia nuclear. La numeración se iniciaba con el padre (o esposo), seguido por la madre (o esposa) y a continuación los hijos, en orden cronológico. Se registraron 316 familias cuyos integrantes oscilan entre 1 y 10, mientras que las de 1 y 2 miembros son las más frecuentes (Figura 11). 
Para este corte temporal se mantiene una proporción de varones cercana al 50\% (Figura 10) y al contar con la edad para todos los individuos se calculó la proporción sexual en los distintos grupos etáreos. En la Figura 13 se observa un patrón oscilante, aunque muy próximo al equilibrio 1 a 1, en la mayoría de los grupos etáreos. Sólo en tres ocasiones se observan valores muy inferiores a 1, lo que representa una superioridad numérica femenina mientras que los valores superiores a 1 representan mayoría masculina y se registran en los siguientes intervalos 5 a 9, 35 a 39, 55 a 59 y de 65 a más de 80 años.

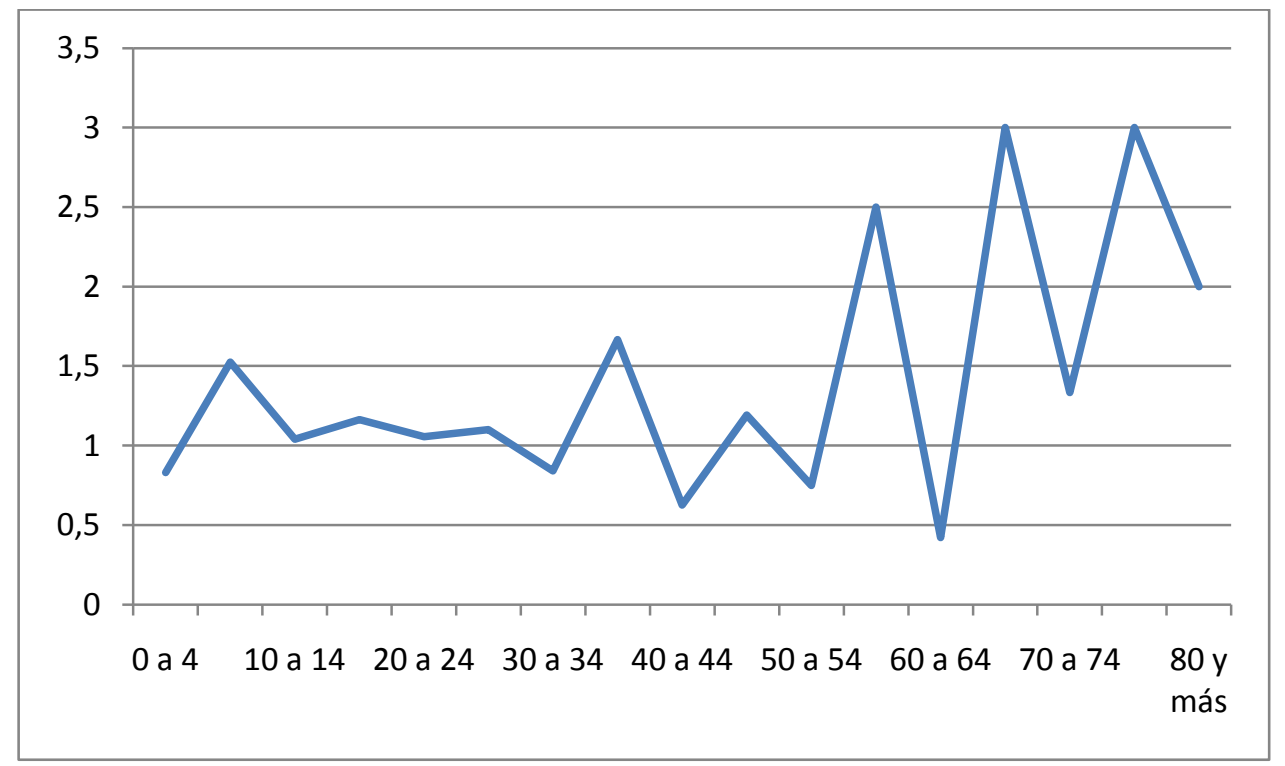

Figura 13: Proporción sexual terciaria en Casabindo 1778

En cuanto al estado civil se observa en la Tabla 18 que entre los viudos existe una mayoría femenina, al igual que los registros anteriores, mientras que para los solteros ocurre lo contrario.

$\mathrm{Al}$ analizar los aspectos demográficos en cada una de las áreas en que se subdividió el territorio Casabindo, se observa que la distribución de la población no es homogénea, presentándose la mayor cantidad de individuos en el área Norte y registrando siempre más varones que mujeres (Tablas 3 a 5).

Las pirámides poblacionales revelan que el Área Norte presenta, en general, un comportamiento muy similar al del total de Casabindo (Figura 14). 
Se destaca la ausencia de individuos de ambos sexos que tuvieran entre 65 y 69 años y de mujeres de 75 a 79 años.

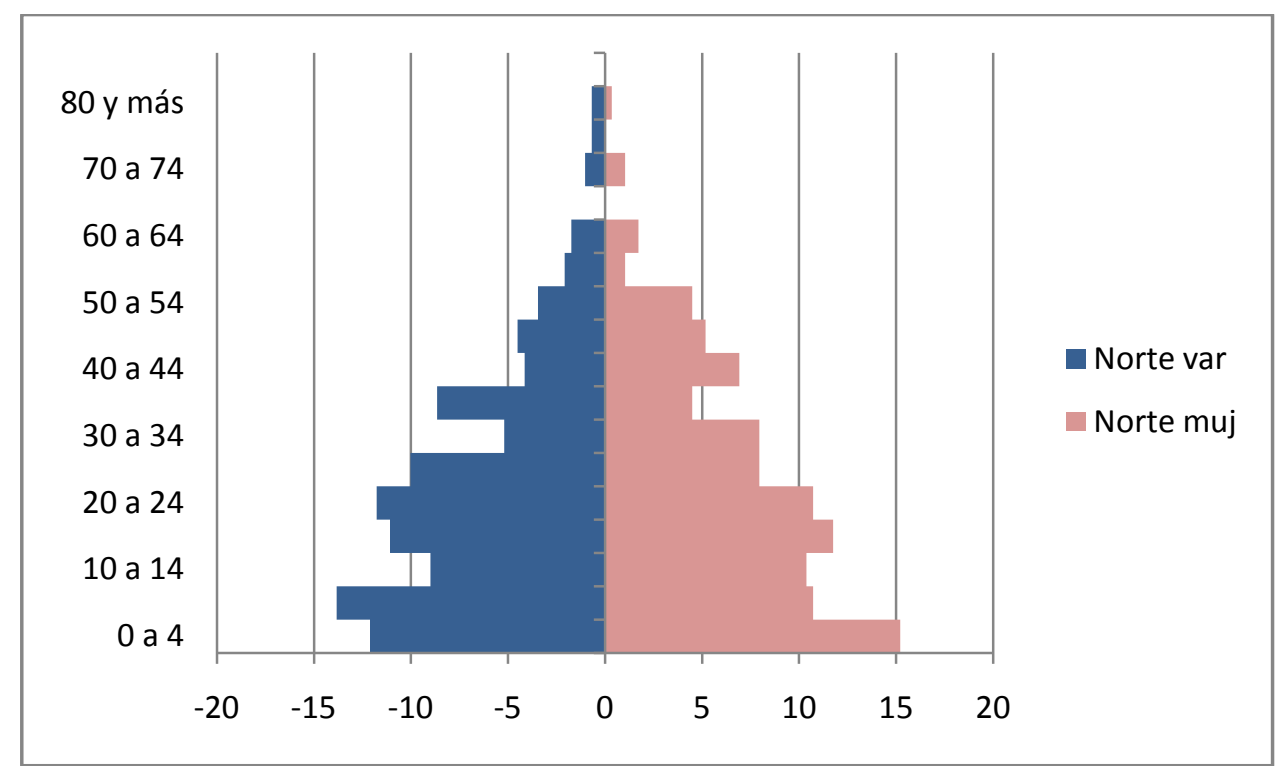

Figura 14: Pirámide poblacional del Área Norte 1778

El Área Este es la que presenta mayor cantidad de población de menos de 15 años. Esta supera el 40\% del total mientras que los mayores de 50 años no alcanzan al $4 \%$ por lo que se trata de una población joven. No se registran mujeres en los intervalos de 55 a 59 ni de 70 a 74 años y ningún individuo entre 50 a 54 ni mayores de 75 años (Figura 15).

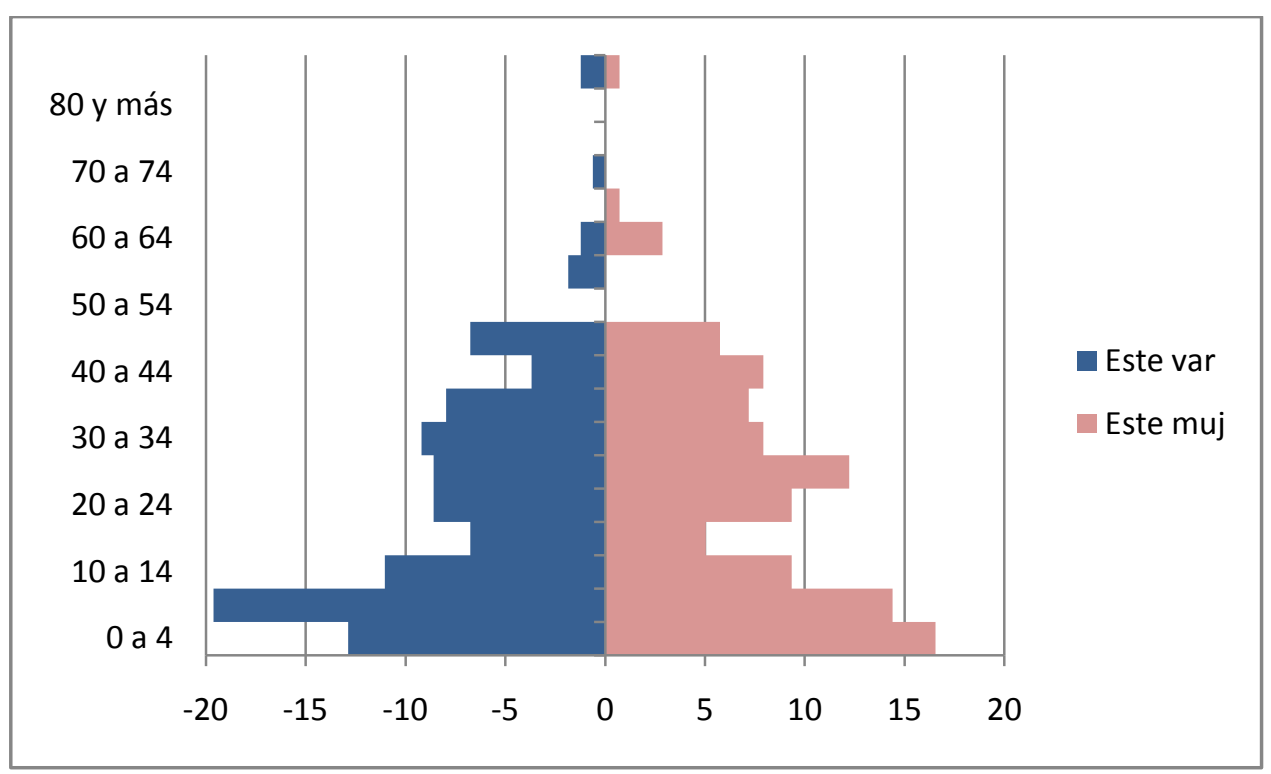

Figura 15: Pirámide poblacional de Área Este 1778 
En la Figura 16 se presenta la distribución por sexo y edad para el Área Oeste, en donde se aprecia que es totalmente diferente a las anteriores ya que en esta se observa una base mucho más estrecha y una distribución asimétrica entre sexos y grupos de edad que se aleja de la clásica forma de pirámide (Figura 16).

En la Tabla 18 se presenta la distribución de los individuos según su estado civil y puede observarse que se repite la situación descripta anteriormente con mayoría de hombres solteros y mujeres viudas en las 3 áreas.

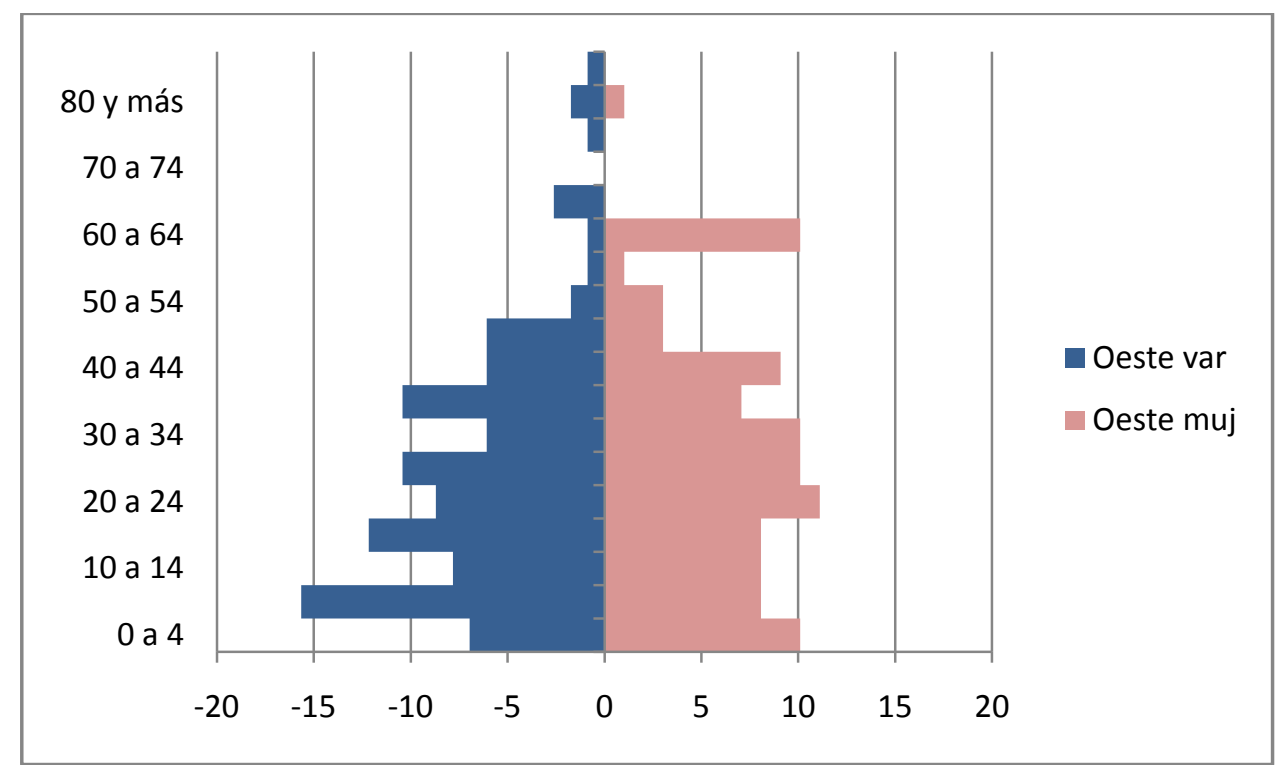

Figura 16: Pirámide poblacional de Área Oeste 1778

Padrón de tributarios de 1786: Comprende 1482 individuos con 702 mujeres y 773 varones. Este registro también se realizó por familia con el padre (o esposo) en primer término seguido luego por la madre (o esposa). Al anotar a los hijos menores de 18 años se puso en primer término a los varones jóvenes próximos a tributar y no se consignaron las edades de las mujeres mayores de 11 ó 12 años, que se anotaban como solteras. Al no contar con la información de la edad de las mujeres resulta imposible construir las pirámides poblacionales, razón por la 
cual la distribución sólo de los varones por grupo de edad se presenta en la Figura 9.

Se registran 430 familias diferentes que presentan entre uno y doce individuos. No deja de sorprender la cantidad de familias numerosas, con tres hasta ocho hijos. Se consideró a los solteros o viudas como una familia, en tanto por razones de registro frecuentemente no resulta posible reconstruir su genealogía. Como puede apreciarse en la Figura 11, la composición familiar más frecuente era la de dos a tres integrantes. Dichas familias comprendían en gran parte los casos de parejas de personas mayores, donde los hijos ya habían establecido sus propias familias, o las parejas jóvenes que aún no habían tenido hijos o contaban con apenas uno.

En relación al estado civil se observa que las parejas casadas son numerosas y que hay un aumento de los viudos con respecto a 1778 que no se presenta de igual forma en las tres áreas analizadas, continúa la diferencia intersexual entre los solteros con preponderancia masculina (Tabla 18).

Censo de población de 1895: En ese momento se registran 1051 individuos, 500 varones y 551 mujeres, y al igual que para el Censo de 1778, se indica la edad de toda la población. La distribución por edades y sexo se presenta en la Figura 17 donde se observa una base ancha donde el 18.8\% de los varones y el 16.9\% de mujeres son menores de 4 años. Se reconoce una población joven con casi el $40 \%$ de su población menor de 15 años y menos de un 5\% que supera los 65 años. En general la pirámide poblacional es simétrica con un leve predominio de los varones hasta los 29 años. A partir de esa edad en general se registra un mayor número de mujeres excepto para los 45 a 49 y 65 a 69 años, y no se presentan diferencias a los 55-59 y 75-79 años. En relación con la proporción de varones como transmisores del apellido, a partir de este momento es inferior al $50 \%$ lo que representa una mayoría femenina (Figura 10). 


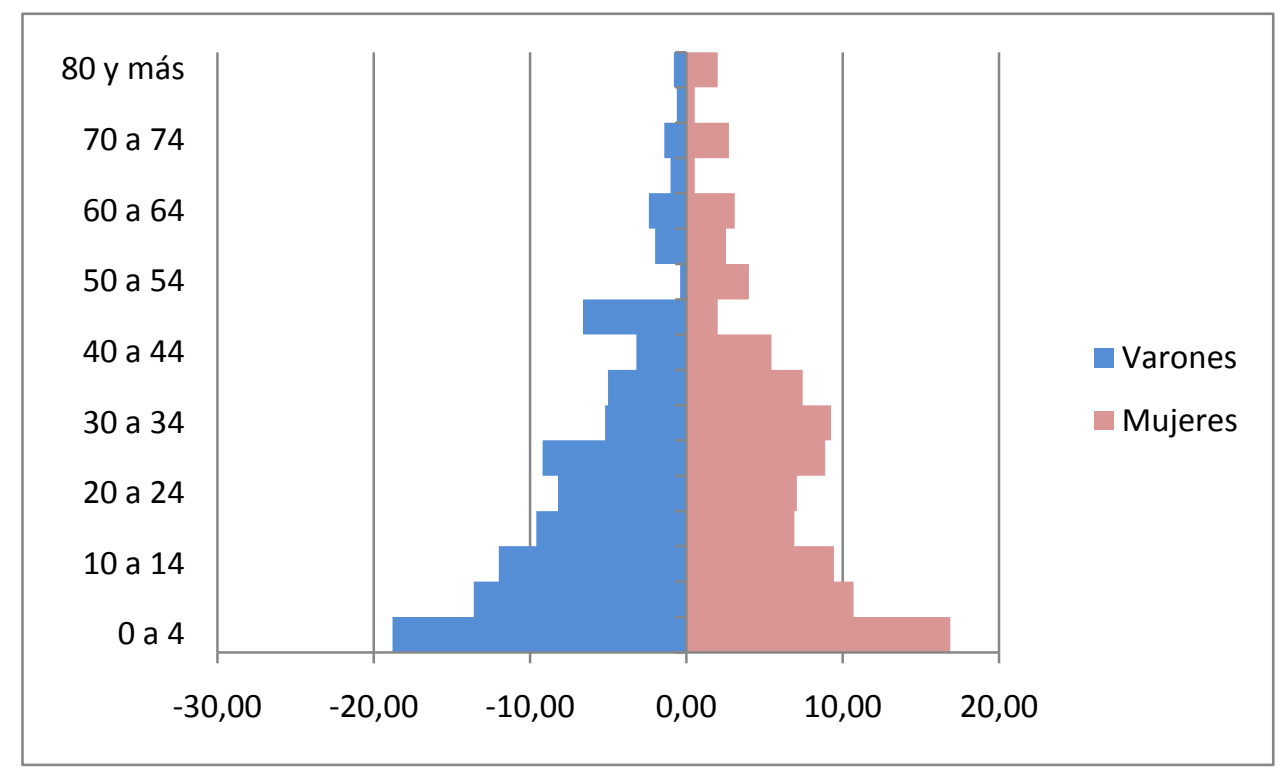

Figura 17: Pirámide poblacional de Casabindo 1895

En este documento no ha sido posible reconstruir las familias ya que no se especifica el parentesco entre los individuos incluidos en cada unidad censal. En cuanto al estado civil se observa una mayor proporción de solteras y viudas (Tabla 18).

Padrón electoral de 1982 y 2001: En el primer caso figura un total de 1719 individuos de los cuales 697 son varones y 1022 mujeres y en el segundo se registran 1752 individuos repartidos en 758 varones y 994 mujeres. En estos documentos puede calcularse la edad sólo de los varones ya que para ellos el padrón incluye la "clase" o año de nacimiento, lo que no ocurre para las mujeres. Se incluye solamente a los individuos mayores de 18 años y la distribución por edades se observa en la Figura 9. Se observa que entre el 15 y el 19\% de la población de cada registro tiene más de 65 años y para 1982 se registra un 8\% de menores de 20 años mientras que para 2001 no hay individuos en esta categoría para el área de Casabindo. Para ambos padrones el $49 \%$ de la población masculina tiene entre 20 y 40 años.

En ninguno de estos registros se especifica el estado civil de los empadronados. 
En general, puede observarse que durante los dos primeros siglos del período analizado, la población presenta estabilidad y que la etapa comprendida entre fines del siglo XVIII y fines del XIX se percibe como la de mayor desestructuración, mientras que el lapso temporal que cubre fines del siglo XX y principios del XXI refleja una nueva estabilidad con una tendencia general al incremento demográfico. 
COMPARACIÓN ENTRE DOS REGISTROS DE POBLACIÓN DE CASABINDO A FINES DEL SIGLO XVIII

Dada la proximidad temporal entre el Censo Virreinal de 1778/79 y el Padrón efectuado por José de Medeiros en 1786 y la diferencia poblacional registrada entre ambos se realizó un análisis detallado y una comparación entre ambos.

El breve lapso temporal que separa los registros mencionados permite caracterizar la composición de los grupos familiares en la población colonial de Casabindo y seguir la evolución de la población contrastándola con la diferencia numérica observada entre ambos documentos (Palomeque, 1994).

El análisis comparativo se realizó tanto a nivel de individuos como a nivel de familias. A partir de los gráficos genealógicos elaborados comenzó a verificarse la presencia (o no) de las familias de 1786 - o miembros de ellas - en la base de datos de 1778, es decir siete años antes. El análisis a nivel individual consideró la coincidencia de nombres, apellidos, edad y vínculos de cada individuo, además del lugar en que fue registrado en 1778. Se distinguieron varias categorías de individuos: presente, no registrado y nuevo (nacido en el lapso considerado) y a partir de ellas surgieron distintas categorías de familias: familias idénticas, familias diferentes (con individuos no registrados, con miembros nacidos o fallecidos en el lapso 1778-1786, con incorporación de otros miembros, parientes y entenados) y familias no registradas. El espacio de residencia, por su parte, se analizó acorde a los tres sectores ocupados por los casabindos en la época colonial denominados Norte, Este y Oeste (Figura 18).

Al analizar los registros de 1778 y 1786 se observó que las localidades consideradas en ambas oportunidades no figuraban con los mismos nombres, como ya fuera mencionado en el apartado Área de estudio (Capítulo VI). Se logró ubicar geográficamente las diferentes localidades censadas o empadronadas y situarlas en alguno de los tres núcleos principales de residencia de los casabindos (Tabla 1). A partir de allí se hizo entonces la comparación de los registros entre sectores (Tabla 19) y resultaron coherentes. 


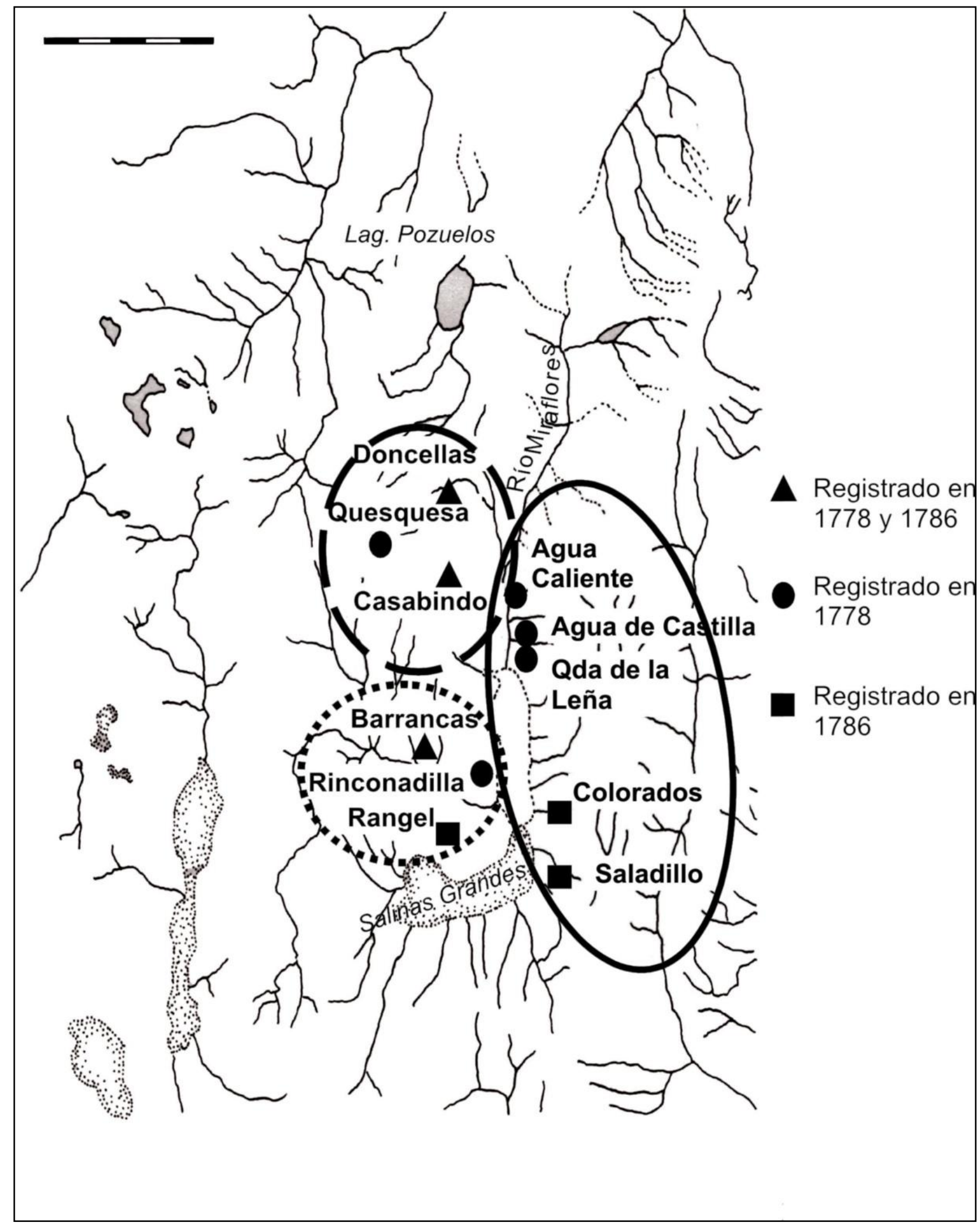

Figura 18: Principales núcleos de residencia de los casabindos a fines del siglo XVIII (Fuente Alfaro y Albeck, 2009) 
En 1778 en el sector norte fueron censadas Casabindo, Doncellas y Quesquesa en tanto que en 1786 la población fue empadronada como "Casabindo y Doncellas". El sector oriental, a su vez, comprendía en el primer registro los asentamientos de Agua Caliente, Quebrada de la Leña y Agua de Castilla mientras que en 1786 fue catalogado como "Colorados y Saladillo", la parte ubicada al occidente de la laguna incluía a las localidades de Rinconadillas y Barrancas en 1778 en tanto figuran bajo "Barrancas y Rangel" en 1786.

Tabla 19: Comparación de población entre localidades en 1778 y 1786

\begin{tabular}{|c|c|c|c|c|c|}
\hline \multirow[b]{2}{*}{ Área } & \multicolumn{2}{|l|}{1778} & \multicolumn{2}{|c|}{1786} & \multirow[b]{2}{*}{ Diferencia } \\
\hline & Localidades & $\begin{array}{l}\mathrm{N}^{\mathrm{o}} \\
\text { indiv }\end{array}$ & Localidades & $\begin{array}{c}\mathrm{N}^{\mathrm{o}} \\
\text { indiv }\end{array}$ & \\
\hline Norte & $\begin{array}{l}\text { Casabindo, Doncellas y } \\
\text { Quesquesa }\end{array}$ & 574 & $\begin{array}{l}\text { Casabindo y } \\
\text { Doncellas }\end{array}$ & 581 & 7 \\
\hline Este & $\begin{array}{l}\text { Agua Caliente, Quebrada } \\
\text { de la Leña y Agua de } \\
\text { Castilla }\end{array}$ & 301 & $\begin{array}{l}\text { Colorados y } \\
\text { Saladillo }\end{array}$ & 485 & 184 \\
\hline Oeste & Barrancas y Rinconadilla & 214 & $\begin{array}{l}\text { Barrancas y } \\
\text { Rangel }\end{array}$ & 401 & 187 \\
\hline Total & & 1089 & & 1467 & 378 \\
\hline
\end{tabular}

El análisis detallado de los datos permitió depurar las bases, al comprobarse que en algunos casos se daba la duplicación de algunas personas en el mismo registro $\mathrm{y}$, a veces, de una familia completa (en total cuatro familias).

A pesar de que los registros evidentemente tuvieron objetivos diferentes, corresponden a la misma población, asentada en un idéntico espacio geográfico y fueron realizados en fechas muy cercanas, poco más de siete años de diferencia entre cada uno, un lapso que resulta interesante para un análisis de corte antropológico y biodemográfico. Se observó que en ambos registros se siguió un criterio análogo a la hora de anotar a cada grupo familiar, primero se 
hacía figurar al padre, seguido por la madre y luego los hijos, lo que permite la comparación de los grupos familiares.

Al contrastar las numeraciones de 1778 y 1786 se evidenció una serie de diferencias en la manera en que habían sido anotadas las personas pero que sin embargo permitían asumir la identidad de las mismas. En primer término, algunos de los apellidos aparecen con diferente grafía, valen como ejemplo el apellido Yonar de 1778 que aparece además como Leonar ${ }^{19}$ en 1786, y el apellido Tinti de 1786 que había sido apuntado también como Zinti, Finti y Tiriti en 1778.

Otro caso es el cambio de nombres femeninos en masculinos o viceversa, es decir, una persona registrada con nombre de mujer en 1778 puede aparecer como varón en 1786. Resulta curioso el cambio de algunos nombres de pila, por ejemplo algunas mujeres registradas como Santusa y Lupisa en 1778, figuran en 1786 como María de los Santos y Guadalupe respectivamente.

\section{La comparación a nivel familiar}

Las familias registradas en 1786 ascienden a 430, presentan entre uno y doce individuos pero la composición más frecuente era la de dos a tres integrantes (Figura 19) y comprendían, en gran parte, los casos de parejas de personas mayores donde los hijos ya habían establecido sus propias familias, o las parejas jóvenes que aún no habían tenido hijos o contaban con apenas uno.

Sobre estas 430 familias, 32 se mantuvieron idénticas en ambos registros, sólo varió la edad de los miembros y pudo haberse modificado el lugar de residencia.

19 Hoy aparecen ambas grafías para dicho apellido 


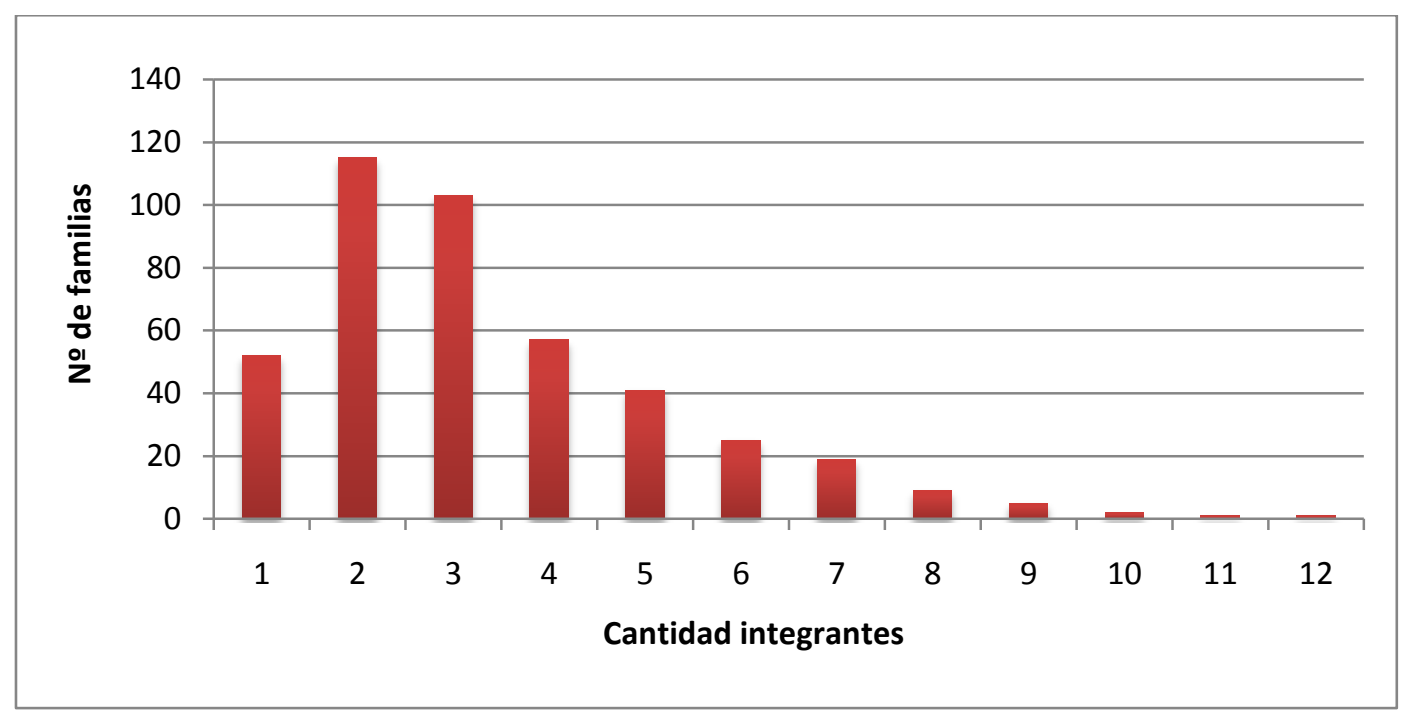

Figura 19: Composición familiar según número de integrantes

Otro caso está dado por los grupos familiares que presentan una estructura diferente a la registrada siete años antes, entre ellos están las familias:

1) con nacimiento de nuevos miembros,

2) con incorporación de "entenados", parientes cercanos o agregados,

3) con miembros no registrados en 1778 ,

4) con formación de parejas nuevas,

5) con fallecimiento de algún miembro y

6) con unión de familias preexistentes por casamiento de viudos o de viuda/o con soltero/a.

Lo más sorprendente es la falta de registro de alguno de los miembros de una familia, normalmente se trata de hijos; se pudo verificar la presencia de unidades familiares en las cuales faltó el registro de uno hasta cuatro miembros ${ }^{20}$. (Figura 20).

20 Familia No 194 de 1786. 


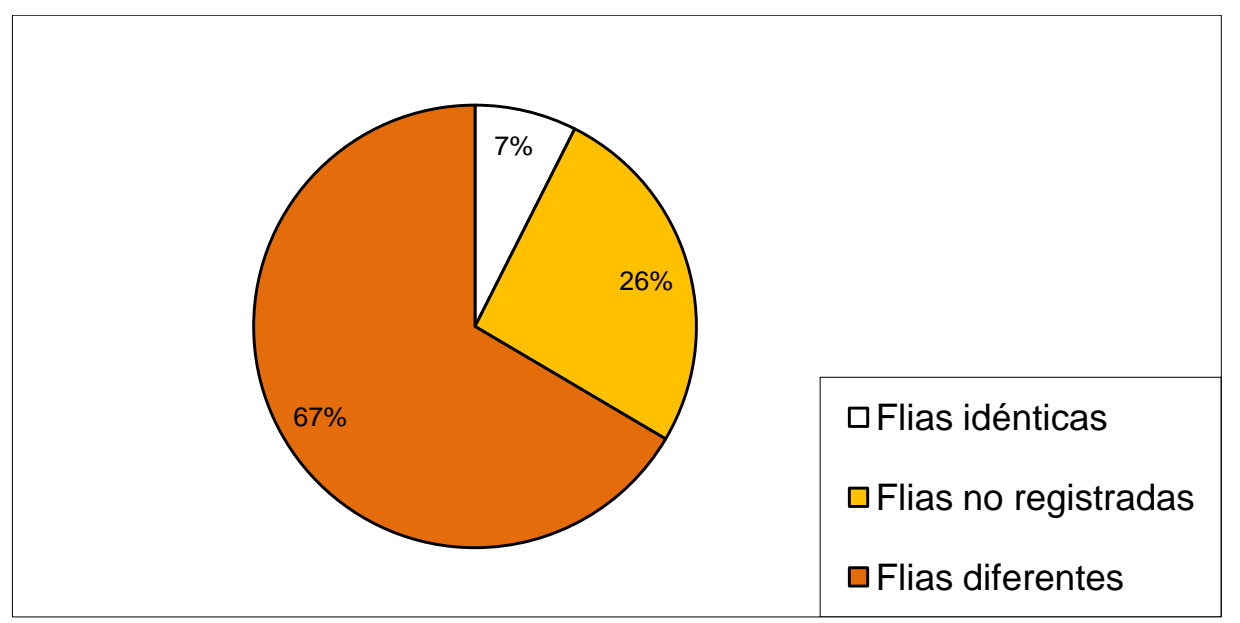

Figura 20: Distribución del total de familias de 1786 según su situación en 1778

Se registraron algunos casos de hermanos que residían en forma conjunta, entre los cuales resulta curioso el caso de una familia donde aparecen seis hermanos solteros que vivían juntos y que, en el censo previo, figuraban con los padres vivos aún.

Por otra parte, resultó sintomática la identificación de familias donde no se pudo establecer el registro previo de ninguno de sus miembros. Por ejemplo, la familia No 286 de Silvestre Sumbaine, no fue registrada en 1778. En 1786 se hallaba residiendo en Colorados y Saladillo y contaba con siete miembros, dos de ellos (Pasquala y María Antonia) nacidos en el lapso que medió entre ambas numeraciones. Es llamativo que Silvestre Sumbaine no haya sido registrado previamente tratándose del "alcalde", al menos en 1786 (Figura 21). 


\section{Registro 1786 (Familia 286 - Colorados y Saladillo)}

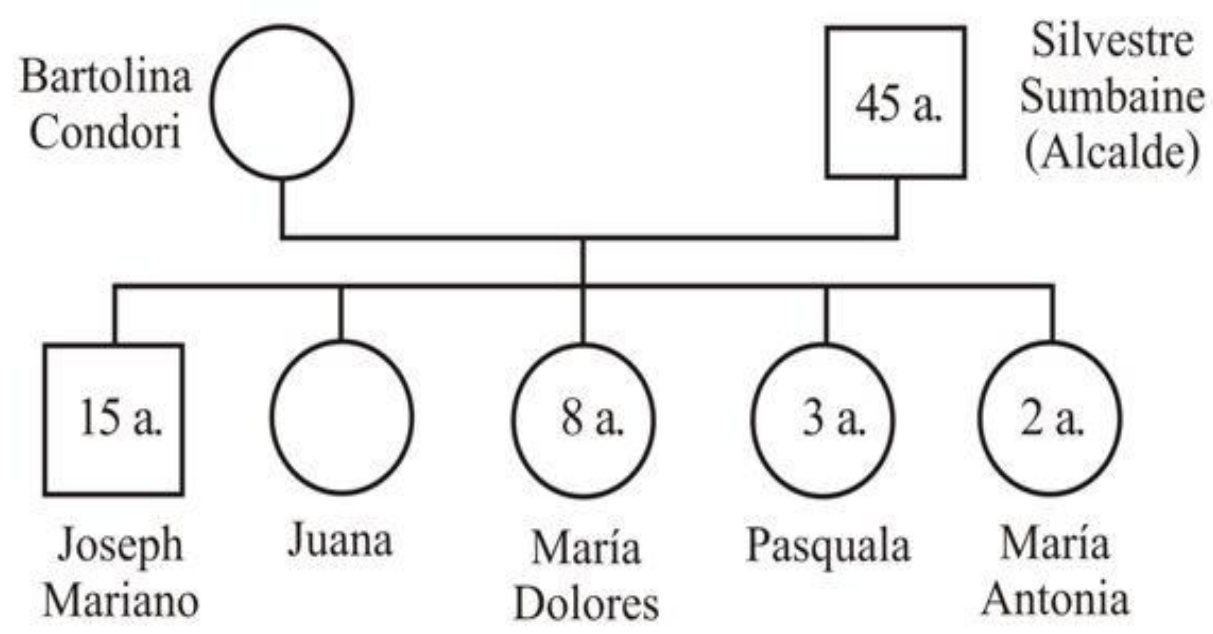

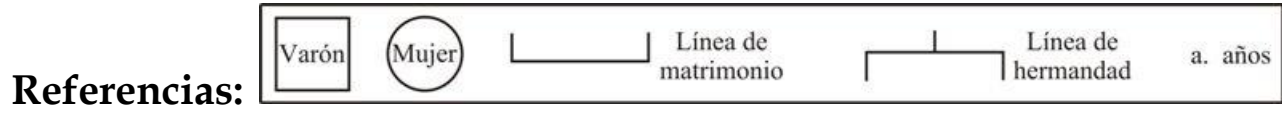

Figura 21: Genealogía de familia no registrada en 1778

Se identificaron 112 casos de falta de registro previo con un total que asciende a 390 personas (Figura 20), lo que representa un poco más de la cuarta parte de todas las familias registradas (26\%), mientras que las familias idénticas corresponden sólo a un 7\%. Entre estas últimas resulta curioso el caso de una familia de 1778 con diez miembros, que se mantuvo igual hasta 1786, aunque con la incorporación de dos entenados (Figura 22).

También en 1786, se registraron familias surgidas de la unión de dos familias de 1778 que habían perdido un cónyuge cada una ( $\mathrm{N}^{\circ} 244$ y $\mathrm{N}^{\mathrm{o}} 179$ ). En este caso se verificó el nacimiento de tres niños en un lapso de menos de ocho años (uno de ellos fruto de la nueva unión) y la pérdida de una niña, María Josefa, que en 1778 tenía un año (Figura 23). 


\section{Registro 1786 (Familia 142 - Casabindo y Doncellas)}

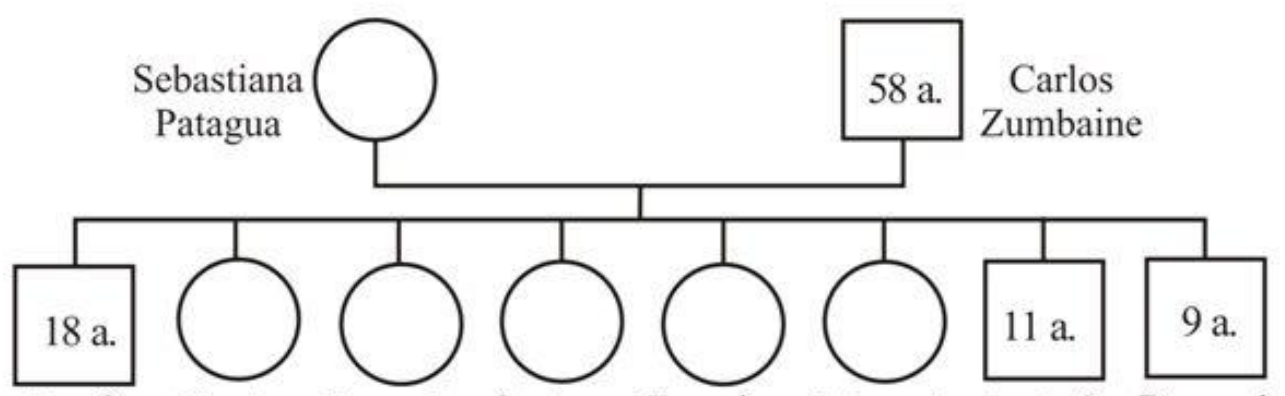

Josef María Pasquala Santusa Francisca Manuela Antonio Bernardo Felis

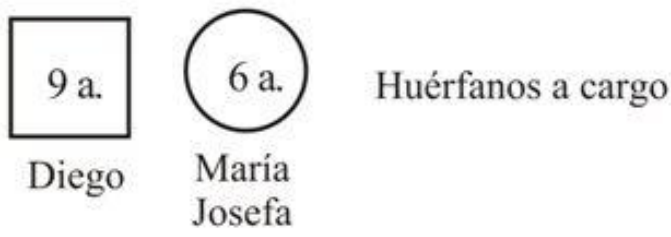

Registro 1778 (Familia 274 - Quesquesa)

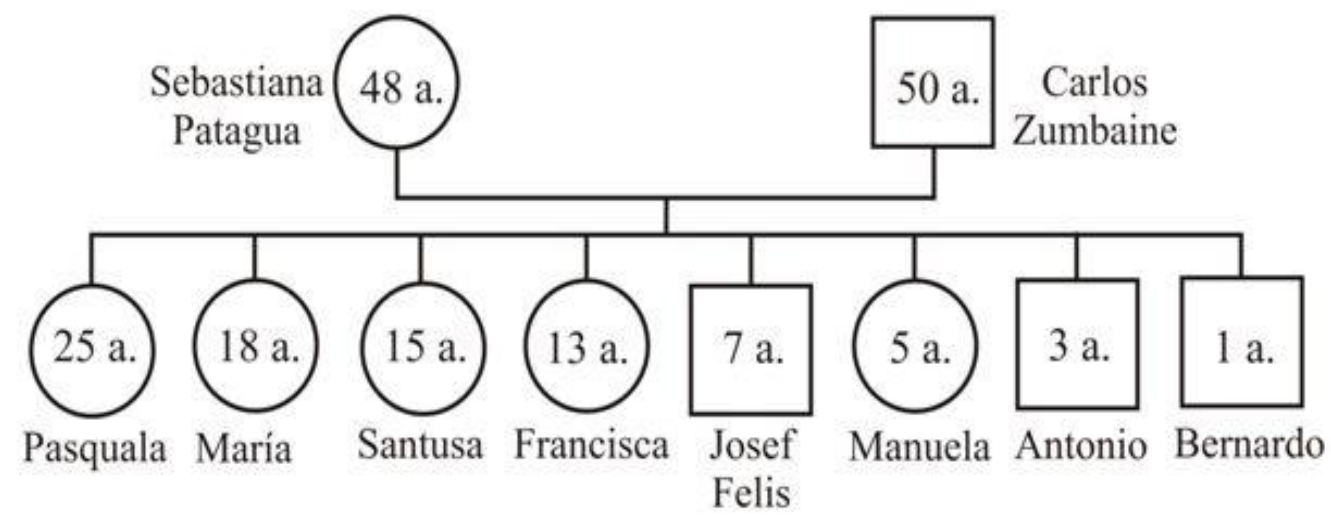

Referencias:

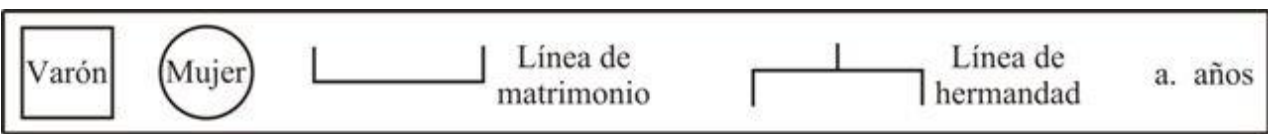

Figura 22: Genealogía de familia idéntica en el período analizado 


\section{Registro 1786 (Familia 366 - Colorados y Saladillo)}

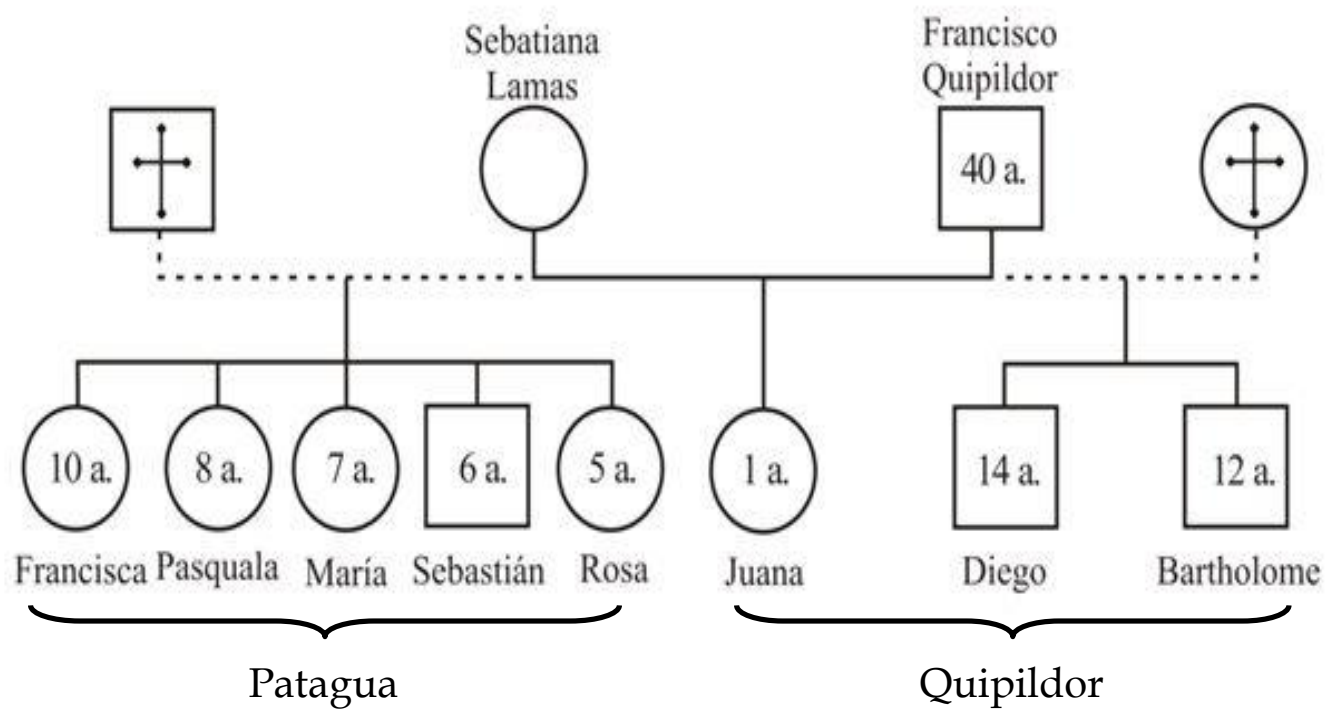

\section{Registro 1778}

Familia 244 - Quesquesa

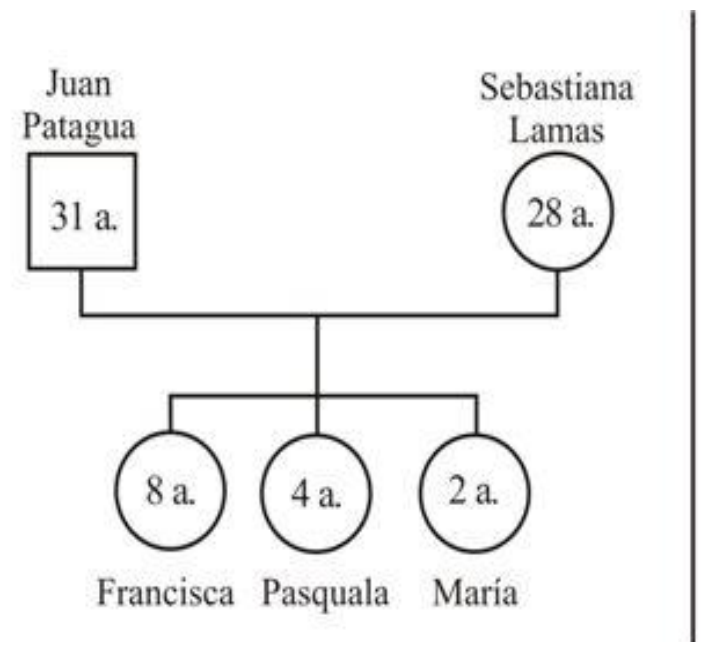

Familia 179 - Agua de Castilla

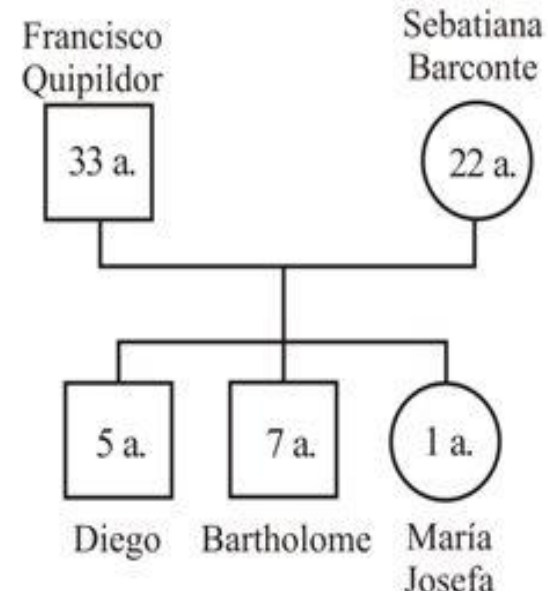

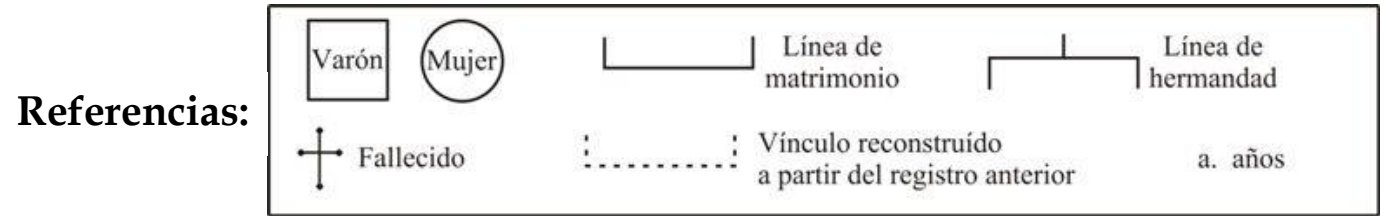

Figura 23: Genealogía de familia que difiere entre los dos registros analizados 


\section{La comparación a nivel individuos}

Del total de 1467 personas registradas en 1786, 730 habían sido censadas casi ocho años antes, 282 eran niños nacidos en dicho lapso, en cambio 390 individuos no habían sido registrados y en el caso de 65 personas era imposible establecer si se trataba o no de los mismos individuos y, por tanto debieron ingresar a una categoría de dudosos (Figura 24). Esto se debió a inconsistencias en datos como por ejemplo la edad, el nombre, el vínculo familiar, etc.

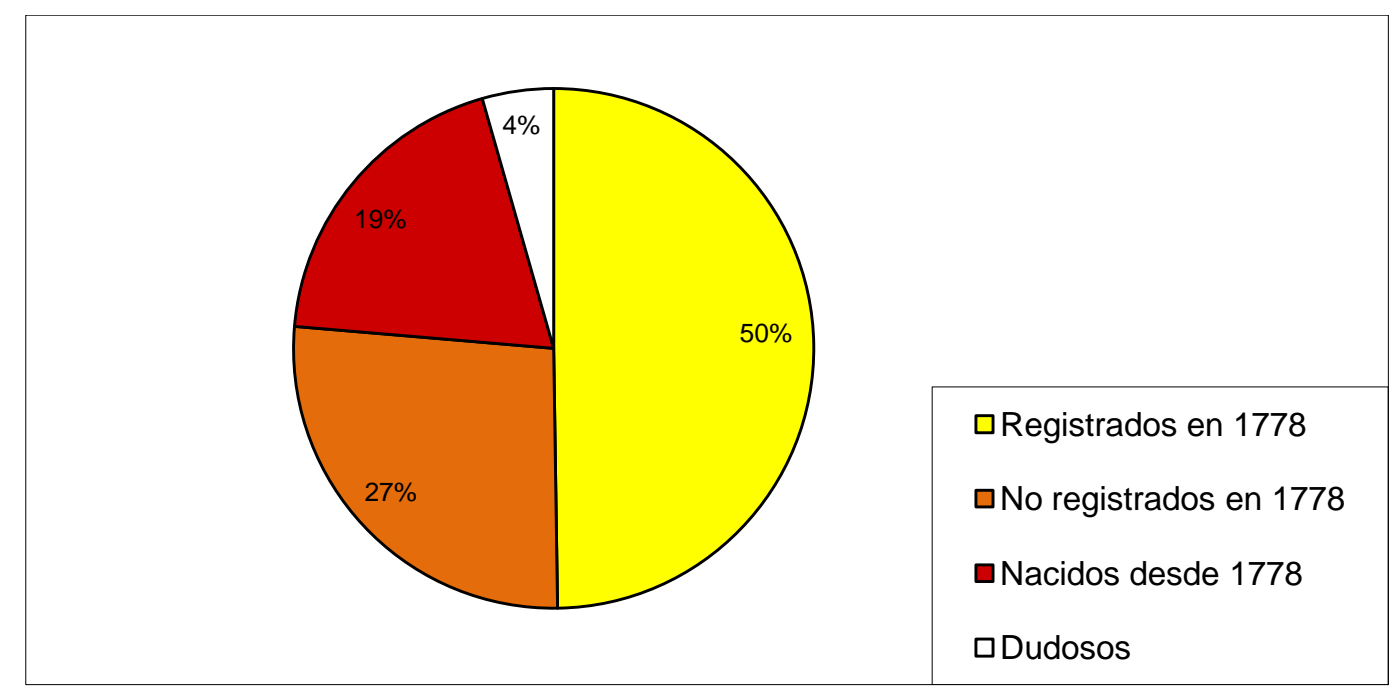

\section{Figura 24: Distribución del total de individuos de 1786 según su situación en 1778}

Si estas cantidades se comparan con la diferencia bruta de 378 individuos obtenida inicialmente entre los totales de 1778 y 1786 (Tabla 19), se observa claramente que la diferencia resulta mucho mayor porque en ella deben incluirse no sólo las personas no registradas sino también los niños nacidos en el lapso considerado, lo que daría un total de 672 personas, que representa $46 \%$ del total de la población registrada en 1786.

En la Figura 24 puede apreciarse que se registra una estabilidad poblacional del $50 \%$, un $19 \%$ de crecimiento evidenciado por los nacimientos y un error de registro del $27 \%$. De estos porcentajes se desprende que sólo la 
mitad de la población había sido registrada efectivamente en el censo previo, mientras que más de una cuarta parte de la población no había sido censada.

\section{Residencia de las familias}

Con respecto al espacio de residencia se buscó establecer, por una parte, la movilidad de las unidades familiares al interior del espacio comunitario de Casabindo y, por otra, identificar si existían diferencias en cuanto a la movilidad entre los distintos sectores reconocidos. Así se observó que la zona norte (que incluía al poblado cabecera y Doncellas) es donde se manifestaba una mayor estabilidad residencial, mientras que la movilidad en los otros dos sectores resulta similar (Tabla 20).

Tabla 20: Distribución de las familias según el lugar de residencia en 1786

\begin{tabular}{|l|c|c|c|c|}
\hline Familias & Norte & Este & Oeste & Total \\
\hline No aparecen en 1778 & 45 & 32 & 35 & $\mathbf{1 1 2}$ \\
\hline Residen en mismo lugar & 102 & 65 & 53 & $\mathbf{2 2 0}$ \\
\hline Residen en otro lugar & 16 & 45 & 37 & $\mathbf{9 8}$ \\
\hline Total & $\mathbf{1 6 3}$ & $\mathbf{1 4 2}$ & $\mathbf{1 2 5}$ & $\mathbf{4 3 0}$ \\
\hline
\end{tabular}

Si se considera a las familias que no aparecen previamente, se podría decir que no existen diferencias marcadas entre los tres sectores, la zona norte y la oeste presentan proporciones muy similares, aunque un poco mayores que las de la zona este (Figura 25). 


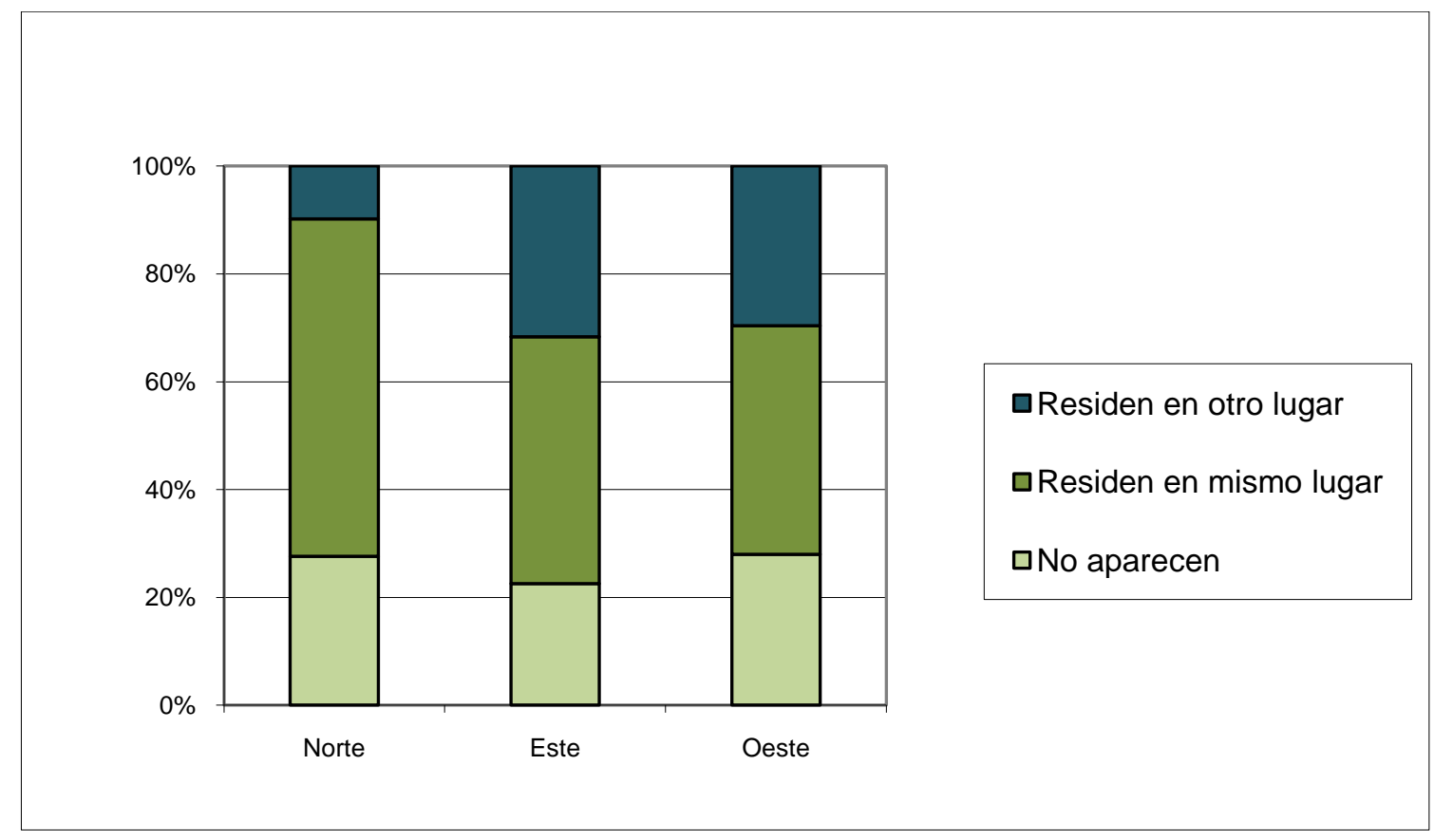

Figura 25: Distribución porcentual de la residencia familiar 


\section{DISCUSIÓN}

Mirar a las poblaciones autóctonas a través de los documentos, es decir desde una perspectiva etnohistórica, surge como consecuencia natural y complementaria de las tradicionales propuestas arqueológicas y antropológicas (Sánchez, 1996). En esta tesis sólo se utiliza información etnohistórica con un enfoque que abre un nuevo panorama de investigación a través del análisis de nombres y apellidos que figuran en esos documentos y que permiten explorar aspectos tales como consanguinidad y parentesco biológico intrapoblacional, patrones de distribución y origen geográfico, barreras lingüísticas, migraciones, etc.

El análisis de la estructura de la población a través de los nombres y apellidos tiene una relativamente larga historia en estudios de genética y de salud pública (Jobling, 2001), y más recientemente en estudios demográficos , en ausencia de otros datos, el origen de los apellidos se ha utilizado para otorgar una probabilidad de origen étnico a una población (Lauderdale y Kestembaum, 2000; Nanchanal et al., 2001). Esta técnica puede también ser utilizada para el estudio del origen étnico, geográfico o lingüístico de poblaciones completas, bien para comprender procesos actuales de inmigración o también para analizar procesos históricos de poblamiento que, como en el caso de los países de América Latina, han dejado un registro en la distribución actual de nombres y apellidos (Mateos et al., 2005).

Los apellidos como indicadores de relaciones entre poblaciones son de uso reciente en estudios históricos aunque se usan desde hace mucho tiempo para analizar e interrelacionar diferentes aspectos (antropológicos, históricos, demográficos y biológicos) de las poblaciones actuales (Colantonio et al., 2008, Mateos et al., 2006). Así por ejemplo Manrubia y Zanette (2002) desarrollaron un modelo que relaciona nacimientos, defunciones y tamaños familiares con la distribución de apellidos que se ajusta a datos poblacionales actuales de varios países. 
No obstante, quizás sean más numerosos aún los aportes que el análisis de apellidos ha hecho al conocimiento de poblaciones históricas. Su empleo ha sido tradicional en estudios demográficos para la reconstrucción de familias, desde el campo de la biología se lo empleó como indicador de ascendencia genética y de relaciones biológicas dentro y entre poblaciones humanas. La reconstrucción de familias y rastreo de antepasados a través de los apellidos no ha sido de interés solamente en ámbitos académicos, sino también en determinados círculos sociales donde el análisis genealógico sobre todo en familias tradicionales ha tenido un gran desarrollo (Binayán Carmona, 1999; De Luca, 1997).

En este trabajo se ha presentado una propuesta novedosa en el tratamiento de los registros coloniales de la población de los Andes Meridionales en general y de la región de Casabindo en particular. La misma se sustenta en la utilización de los nombres y apellidos para reconstruir la estructura de una población histórica que ha dejado pocos vestigios biológicos y culturales. Excepto el trabajo de Chakraborty et al. (1989) sobre poblaciones aymara actuales del norte de Chile y del este boliviano, de Dipierri et al. (1991) sobre la población colonial de la Parroquia de Humahuaca, de Medinaceli (2003) sobre las características del sistema nominativo aymara en el siglo XVII y algunas referencias someras de Martínez (1998), los antecedentes sobre esta problemática son escasos en el área de referencia. Para los Andes Septentrionales se cuenta con un interesante trabajo sobre onomástica indígena que permite discriminar territorios étnicos en la zona de Quito en Ecuador (Salomon y Grosboll 1990).

Desde la perspectiva cultural son cada vez más diversos los hechos que se descubren a través del análisis de apellidos, desde la conducta relacionada con procesos de elección de pareja (Gónzalez-Martin et al., 2006; Little y Malina, 2005; Sawchuk y Herring, 1989 entre otros), prácticas de residencia (De Silvestri y Guglielmino, 2004; Pavesi et al., 2003; Vernay, 2001; entre otros), origen étnico y geográfico de las personas (Colantonio et al., 2002; Smith y Bittles ,2002; Smith, 2002; entre otros) tanto en poblaciones actuales como históricas. 


\section{CAPÍTULO XII: DINÁMICA ANTROPONÍMICA}

La costumbre de usar apellidos en América fue una consecuencia más del proceso de conquista y colonización que reprodujo los sistemas económico, político, social y cultural imperantes en Europa. En Brasil, por ejemplo, los esclavos tomaron apellidos de significado devocional (Dos Santos), mientras que los indígenas los tomaron de animales o plantas y los europeos conservaron sus apellidos mayormente de origen portugués (Azevedo, 1980)

En las poblaciones prehispánicas venezolanas, la costumbre del uso de apellidos no parece haber existido, este hecho se deduce de la revisión de los padrones de indígenas realizados por los colonizadores españoles durante los primeros años de la conquista (Castro de Guerra, 1987). En esos padrones aparecen los indios registrados sólo con su nombre autóctono y en aquellos casos en que poseían dos nombres, el primero era español y el segundo indígena, funcionando éste, probablemente, como apellido (Castro de Guerra, 1987).

En la cultura andina prehispánica tampoco había apellidos. Las personas llevaban solamente un apelativo que podía ser simple, representado por una sola palabra o compuesto por dos o más palabras (Aguiló, 1983; Medinaceli, 2003), como se observa en 1557, en el documento del bautismo del cacique de Casabindo.

Si bien el documento de 1557 se toma sólo como referencia por tratarse de un registro muy escueto, refleja características del uso de los nombres en Casabindo como la primera aproximación al sistema nominativo autóctono en los primeros momentos de contacto con los españoles.

En 1654 se registra en Casabindo un espectro variado de nombres entre los que también aparecen nombres compuestos femeninos (Sulapanalay) y masculinos (Chiritulay). Además, entre los varones adultos algunos apelativos incorporan un apodo o sobrenombre como Pablo Lamas Feo, Felipe Guarcondi Ballestero, Juan Quipildor Pollo, Francisco Lamas Guitarra, Juan Cachi Mil Peços o 
Francisco Bilti Gallego. Medinaceli (2003) encuentra humor y burla en algunos nombres registrados en Sacaca en el siglo XVII, lo que mostraría una coincidencia en la denominación o en la forma de anotar algunos nombres en ambos sistemas nominativos.

A partir de los documentos analizados para el siglo XVII se advierten sistemas paralelos de nombres: uno femenino y otro masculino. Esto estaría cumpliendo, parcialmente, lo establecido en 1583 en el Tercer Concilio Limense. De aquí en adelante la norma a seguir fue el uso de un nombre cristiano como nombre de pila y como segundo nombre alguno de los antiguos nombres de origen nativo, así los varones continuaban usando nombres masculinos nativos y las mujeres los femeninos. Una situación similar se presenta entre los aymaras de Sacaca en el siglo XVII (Medinaceli, 2003).

El $20.5 \%$ de las familias registradas en Casabindo en 1654 presenta herencia del segundo nombre y las más frecuentes son aquéllas donde lo comparten padre e hijo (14.4\%). También se registran dos familias donde las hijas llevan el segundo nombre de la madre y los hijos el del padre (Fig. 4). Si bien las disposiciones del Tercer Concilio Limense se establecieron a fines del siglo XVI, éstas aún no se han generalizado en Casabindo a mediados del siglo XVII y, a pesar de las situaciones mencionadas, continúan siendo nombres al no transmitirse necesariamente de padres a hijos, por lo que aún no pueden considerarse apellidos en su concepción actual.

En 1688, todavía se presentan diversas modalidades. Se encuentran casos donde se continúa con el uso de nombres indígenas a los cuales se antepone un nombre español, otros donde no existe transmisión de una generación a la siguiente (43.2\% del total de familias), mientras que en algunas situaciones los varones portan el nombre indígena del padre (40\%) y las mujeres, el de la madre (4.2\%), según lo establecido en el Tercer Concilio Limense y, finalmente, casos en los que tanto varones como mujeres llevan como segundo nombre el nombre indígena del padre (5.3\%). Esta última modalidad tiene además características particulares ya que se observan familias con dos y tres 
generaciones consecutivas que comparten el segundo nombre pero también se registran casos donde sólo lo hacen la primera y tercera generación (Tabla 7). Lo que evidenciaría la transformación de los nombres femeninos y masculinos, que formaban dos conjuntos paralelos e independientes, en los apellidos del período colonial.

A partir de este momento las mujeres comenzaron a usar nombres que tradicionalmente usaban sólo los varones $\mathrm{y}$, en consecuencia, los nombres autóctonos femeninos fueron desapareciendo gradualmente. Según Sánchez (1996) en Tilcara en 1631 todos llevan un nombre cristiano y un apellido indígena mientras que en las mujeres sólo 9 presentan nombre indígena, mientras que en 1670 el 94\% de los varones y el 53.8\% de las mujeres registra un nombre cristiano y un apelativo indígena como segundo nombre, aunque no hace referencia a la forma de transmisión entre generaciones.

En los registros analizados hasta aquí se encuentran mujeres aparentemente sin segundo nombre o "apellido" y que llevan nombres compuestos como Bárbara Francisca o Josefa María que aparecen en Casabindo en 1688. Esta situación no se trataría de ausencia de "apellido" sino de la continuación de la lógica, observada entre los varones, de convertir el nombre indígena en "apellido", usando para ello otros nombres españoles combinando dos tradiciones culturales (Medinaceli, 2003). En este corte temporal también se registran 3 casos entre los varones (Alejandro, Bentura y Bernardo con un portador cada uno) que también habrían seguido esta lógica utilizando nombres españoles compuestos que pasaron a convertirse también en apellidos.

Esta modalidad nominativa representa una posible explicación para la diferencia existente entre el número de individuos y la cantidad de individuos que llevan un "apellido" que se observa hasta fines del siglo XVIII.

En 1688 también se registran varones adultos que presentan "apellidos" compuestos por un primer apelativo autóctono o foráneo y un segundo representado por un apodo o sobrenombre como por ejemplo Diego Lamas Portugues o Andrés Patagua Mil Pesos donde puede observarse claramente que 
este último ha recibido el sobrenombre de su padre Juan Cachi Mil Peços, mencionado anteriormente.

Si se analizan los siete nombres más frecuentes en los documentos del siglo XVII se aprecia que, en ambos sexos, son prácticamente los mismos (aunque con grafías algo diferentes) a pesar de los 34 años transcurridos. Es muy importante tener en cuenta que los nombres nativos, al igual que los europeos, vienen de una larga tradición y que la elección de un nombre se hace a partir de un conjunto de posibilidades limitadas a los que están en uso en determinado momento o a los que son conocidos dentro del grupo. También, las preferencias podrían establecerse en función de los significados de las palabras utilizadas como nombres personales aunque posteriormente perdieran su significado o sentido original (De Luca, 1997; Medinaceli, 2003).

En 1778, más de un siglo después, ya está completamente instalada la transmisión del apellido propiamente dicho por vía paterna y, prácticamente, han desaparecido todos los nombres femeninos del siglo XVII. La excepción la constituyen Sulapa y Sisa registrados en tres mujeres mayores (Sebastiana Sulapa de 86 años, Lucia Zulapa de 60 y Michaela Sisa de 62 años) y una joven de 30 años (Tomasa Sisa Lacci). En el caso de las mayores se interpreta como las últimas manifestaciones del antiguo sistema nominativo, mientras que la joven muestra la combinación con un nombre anteriormente sólo masculino.

A partir de este momento los nombres femeninos desaparecen por completo mientras que muchos de los nombres autóctonos masculinos logran perdurar hasta la actualidad como apellidos.

\section{Origen, frecuencia y perduración}

En cuanto al origen de los antropónimos en varios casos resultó difícil diferenciar entre autóctonos y foráneos ya que algunos pueden asignarse a ambas categorías, por ejemplo, Lamas que aparece como nombre en registros muy tempranos (1557) tanto entre los casabindos (Catihilamas) como entre los chichas (Chuchulamassa) (Albeck et al., 2000). 
Algunos nombres muy populares entre los casabindos como Vilti, Quipildor y Chocoar han sido catalogados como atacameños (Sica com. pers., Martínez 1998, Nardi 1986). Sin embargo, la alta frecuencia con que aparecen estos nombres entre los casabindos, indicaría que esta aseveración debería tomarse con cierto recaudo, hasta tanto se conozcan mejor los registros de otras zonas vecinas como atacama, chichas, lipes y omaguaca. Otros nombres, como Socomba entre los masculinos y Tanter entre los femeninos, en cambio, probablemente fueran atacameños, por la baja frecuencia con que aparecen en Casabindo y la alta representatividad que alcanzan entre los pobladores de los oasis chilenos (Martínez 1998).

En los documentos del siglo XVII prácticamente todos los nombres son autóctonos y las excepciones se registran sólo en los varones con un individuo en 1654 (Pedro Renxel) y con tres en 1688 (Juan Alejandro, Juan Bentura y Juan Bernardo).

Esta mayoría de apellidos autóctonos se mantiene en la segunda mitad del siglo XVIII con una contribución de algunos propios de la zona andina como Tolava y Quispe que en 1778 están presentes en el 5.5\% de la población total. Si bien los apellidos autóctonos siguen siendo mayoritarios y derivados en gran parte de los nombres masculinos usados en Casabindo a mediados del siglo XVII, la frecuencia de los apellidos foráneos supera el $20 \%$ sobre el total de apellidos. Sin embargo éstos registran pocos portadores representando sólo el $5.9 \%$ de la población, porcentaje equivalente al mencionado más arriba para dos apellidos autóctonos lo que muestra la gran cantidad de individuos que llevaban un antropónimo autóctono.

Entre los apellidos que no pudieron clasificarse encontramos en las mujeres Balioi, Cabana, Tina y Zinti con una representante cada uno y Finti que se presenta en ambos sexos (tres varones y una mujer) que no aparecían en los documentos anteriores pero que tienen una baja representación en la población. Tanto Zinti como Finti podrían tratarse de variantes del apellido Tinti que aparece en el padrón de 1654, mientras que los otros casos, y al tratarse 
exclusivamente de mujeres, podrían representar ingresos recientes a la población.

$\mathrm{Al}$ analizar los siete apellidos más frecuentes se observa que son todos autóctonos pero entre ellos no se identifica ninguno propio de otras zonas andinas. Cuatro ya se encontraban entre los siete más frecuentes en los varones de 1688 (Tabla 6). Llama la atención la aparición de Alancai, nombre que no se encontraba registrado como tal en los documentos anteriores y que, posiblemente, sea el resultado de la transformación de Alarcaqui. Sin embargo, dado el lapso temporal que separa los documentos analizados resulta imposible comprobarlo en este trabajo.

Lo anterior se relaciona con las diferentes grafías registradas a lo largo del período analizado que podrían explicarse por las diferentes etapas o "filtros" por los que debieron pasar las palabras hasta llegar a nuestras manos donde son frecuentes los intercambios $i / e, y / l l, r / l, s / z$. En primera instancia debemos considerar a quien anotaba los nombres, pronunciados en un idioma extraño, y decidía la forma consideraba la más correcta para escribirlos y finalmente es necesario tener en cuenta las posibles variaciones debidas a la lectura paleográfica realizada. Ejemplos de variantes gráficas encontradas en este trabajo Nalai/Nalay, Basama/Guasama, Chibaltau/Chigualtao, Vilti/Bilti, Barcondi/Guarconde, Sumbaine/ Zumbaine (Tabla 6).

Al comparar los siete apellidos más frecuentes en Casabindo en 1778 con los registros del mismo censo para otras partes de la puna de Jujuy (Alfaro et al., 1998) se observa que, en gran parte, son compartidos con los más frecuentes del Curato de Cochinoca, del que cual forma parte, pero claramente diferentes del resto de los curatos de la Puna (Tabla 8). Esto estaría indicando la "particularidad" de los antropónimos que conformaban el sistema nominativo de los casabindos, compuesto por un conjunto de nombres que, por su recurrencia, puedan ser considerados propios de Casabindo en el siglo XVII, sin por esto aseverar que son originarios de ese grupo social. 
Entre los varones sólo se registran seis apellidos únicos, es decir portados por un solo individuo, de éstos tres son foráneos de origen español, uno es autóctono procedente de otras zonas andinas, indicativos de un posible ingreso reciente de individuos. Esta situación se presenta más intensamente entre las mujeres que registran más del 30\% de apellidos únicos como puede apreciarse en la Tabla 2. De éstos ocho son foráneos españoles, dos autóctonos de la zona andina y en cinco casos no se ha podido asignar un origen.

Los apellidos compuestos siguen registrándose y resulta curiosa la reiteración de determinados morfemas que pueden combinarse de diferente manera en los nombres (Tabararcachi, Cachisumba, Sumbaym, Tabararcondi, Lamascondi) y que, en algunos casos, pueden aparecer aislados (Lamas, Cachi). Dichas combinaciones tal vez correspondan también a nombres compuestos, sin embargo, este planteo amerita un análisis lingüístico detallado que escapa a los objetivos de este trabajo.

En 1786 y en consonancia con el crecimiento poblacional registrado para ese momento se observa un aumento en la cantidad de apellidos diferentes que llegan a 70, de los cuales el 66\% son autóctonos, el 31\% está representado por apellidos foráneos de origen español y solamente dos apellidos han quedado como indeterminados. Entre los apellidos autóctonos, el 52\% ya se registraban como nombres masculinos en 1654 lo que indica la perduración de un conjunto importante de antropónimos en este grupo.

Al analizar el origen de los apellidos en mujeres y varones se observa que estos últimos presentan 44 apellidos diferentes de los cuales el 62\% ya figuraba en el padrón de mediados del siglo XVII y sólo 9\% son únicos. En el caso de las mujeres la cantidad de apellidos distintos es mayor, llegando a 68 de los cuales el 31\% está representado por apellidos únicos, marcando una diferencia significativa con lo registrado para los varones. También resulta curioso el registro de dos mujeres portadoras del apellido Abracaite que no aparece en la población masculina de Casabindo en 1778 pero que se registraba como nombre masculino en 1654 y 1557. 
En 1786 la población de Casabindo evidenciaba una marcada estabilidad con un mínimo aporte de migrantes procedentes de otras partes, hecho reflejado en la gran cantidad de población representada por unos pocos apellidos, como se observa en los valores del indicador B y en concordancia con el registro exclusivo de originarios como figura en el Padrón de Medeiros para la totalidad de la población de Casabindo. Sin embargo, este comportamiento de la población general presenta diferencias intersexuales con un gran porcentaje de mujeres portadoras de apellidos únicos indicadores de posible inmigración femenina reciente relacionada con una residencia virilocal.

En cuanto a la perduración de los apelativos registrados en Casabindo a mediados del siglo XVII, se observa que el $46 \%$ de los nombres masculinos presentes en 1654, no sólo perdura como apellido entre la población masculina casi un siglo y medio después sino que también se ha difundido entre la población femenina. Situación que diferencia a esta población de otras comunidades indígenas que iniciaron, durante la colonia, un proceso de integración cultural revelado, entre otros aspectos, por la desaparición de la onomástica original y su reemplazo por la del conquistador (Dipierri, 2004). Entre los tilcaras, por ejemplo, en 1785 el 89\% de los varones y el 78\% de las mujeres presentaban apellidos de origen indígena y en 1791 estos porcentajes eran del 89 y 72\% respectivamente (Sánchez, 1996). Sin embargo, según Platt (1996) en Latinoamérica sólo persisten 60.000 de los 250.000 apellidos hispánicos registrados en 1750, lo que implica la pérdida del 76\% de los patronímicos en tan sólo 10 generaciones (Bailliet et al., 2001).

Si se relaciona la antroponimia colonial con la toponimia actual en la zona de influencia de Casabindo y Cochinoca resultan evidentes determinadas recurrencias. La más notoria es la presencia del postfijo - ti con sus equivalencias o diversas grafías -te, -di, -de (Abracaite, Barcondi, Cayconde, Bilti), este postfijo es el más frecuente en la toponimia autóctona local (Abralaite, Chorbante, Liristi, Ascalte) (Albeck, 2000). 
En los 109 años transcurridos hasta el Segundo Censo Nacional de Población se observa un cambio significativo ya que en 1895 el 63\% de los apellidos son foráneos y de éstos el 96\% es de origen ibérico (78\% español y 18\% vasco). También por primera vez en el período analizado los apellidos foráneos aparecen entre los siete más frecuentes tanto en el total de la población como en ambos sexos. Sin embargo, a pesar de que los apellidos foráneos han aumentado su representatividad en el total de apellidos, el 50\% de la población sigue presentando apellidos de origen autóctono derivados de los nombres indígenas registrados en la zona anteriormente.

El aumento en la cantidad de apellidos foráneos y las elevadas frecuencias de apellidos únicos, tanto en varones como en mujeres, son indicativos del quiebre de la estabilidad observada a fines del siglo XVIII relacionados con la decadencia y ruptura de la sociedad de hacienda ligada a la red comercial tradicional del período colonial (Rutledge, 1992) ocurrida entre 1810 y 1880 en las regiones de la Puna y la Quebrada de Humahuaca, al igual que en el resto de América Latina (Mörner, 1987).

Hacia mediados del siglo XIX la población de la Puna se caracterizaba prácticamente por la ausencia de emigración a excepción del departamento de Yavi. En este departamento, de acuerdo a Madrazo (1991) se registran desplazamientos de la mano de obra en función de los intereses económicos de lo que fuera el Marquesado de Tojo que funcionaba como una empresa propietaria de varias haciendas. Por el contrario la inmigración procedente del sur de Bolivia, estimulada por el florecimiento de la minería aurífera, se observaba en los departamentos de Rinconada y Cochinoca (Madrazo, 1991) fenómeno que podría reflejarse en el aumento de apellidos únicos entre los varones en 1895 (Tabla 2).

En el período comprendido entre 1872 y 1875 en la Puna se suceden una serie de conflictos sociales que culminan con un levantamiento en gran escala de la población indígena (Fidalgo, 1988; Rutledge, 1992). Como consecuencia de este levantamiento la Corte Suprema de Justicia procede, entre 1877 y 1891, a la 
expropiación de las haciendas, que son declaradas tierras fiscales y entregadas al gobierno de la provincia de Jujuy. Pese a la lucha emprendida, hacia 1910 la mayoría de los indígenas continuaban viviendo como arrendatarios de fincas particulares (Paz, 1992). Estas circunstancias favorecieron aún más el despoblamiento de la Puna y la integración de sus poblaciones al sistema económico capitalista que comienza a instalarse en las tierras bajas a partir de 1870 (Paz, 1992).

En 1982, corte temporal correspondiente ya al siglo XX, se observa que ni el número de apellidos diferentes ni el porcentaje de población cubierta por los apellidos únicos ha variado sustancialmente. Se mantiene la mayoría de apellidos foráneos sin embargo muchos de ellos son los que están representados por un solo individuo, indicando un ingreso reciente a la población, al menos a la población electoral si se considera que por tratarse de un padrón electoral sólo incluye a los mayores de 18 años. En cuanto a los apellidos autóctonos continúan como 87 años antes cubriendo el 50\% del total de población indicando un sedentarismo importante (Figura 7).

Entre los siete apellidos más frecuentes los dos mayoritarios son autóctonos y aparecen en el área desde el siglo XVII pero la presencia de foráneos ha aumentado y en este momento se registran cinco, todos de origen hispano como la mayoría de los foráneos de este padrón. De estos cinco, Alejo está presente en la zona de Casabindo desde 1778.

Al comparar los cinco documentos analizados hasta aquí, resulta abrumadora la mayoría de apellidos autóctonos en vigencia desde mediados del siglo XVII hasta fines del XVIII. La sorpresa se da al comparar el registro de 1786 con el Segundo Censo Nacional de Población de 1895 donde la frecuencia de los apellidos foráneos ha aumentado de forma significativa y donde resulta notable el descenso de los que integraban anteriormente la categoría “originarios" (Figura 5). Lo mismo fue observado al considerar la presencia de apellidos de estos últimos, casi el $50 \%$ de los 25 apellidos considerados desaparece del área de Casabindo entre 1786 y 1895 (Figura 7). 
Se podría pensar que la abrumadora mayoría de apellidos españoles corresponde a antiguos "forasteros" no registrados en los primeros padrones, en tanto se registraba tan sólo los tributarios (originarios con tierras). Sin embargo, como ya se mencionara, Casabindo se destacaba en 1786 por la ausencia de individuos asignados a dicha categoría. Otro dato interesante que apoya esta interpretación es que la gran mayoría de los apellidos de origen español son portados por un único individuo, lo que estaría apuntando a una migración reciente.

Los datos aportados por el Padrón electoral de 1982 generan frecuencias casi idénticas a las observadas casi un siglo antes. En ambos casos, a pesar de un mayor registro de apellidos de origen español, predominan los de origen indígena. También resulta notable que los apellidos pertenecientes al conjunto de los 25 registrados desde mediados del siglo XVII representan casi una tercera parte de la población del área de Casabindo en la segunda mitad del siglo XX (Figuras 7 y 8 ).

El padrón de 2001 representa la situación a inicios del Siglo XXI donde se observa que en Casabindo no ha variado sustancialmente desde 1982, con una mayoría de apellidos foráneos pero una importante proporción de población que lleva un apellido autóctono, algunos de los cuales se han posicionado nuevamente entre los siete más frecuentes. Esta situación podía estar reflejando el regreso de población hacia la zona de Casabindo representada por individuos o familias que emigraron debido a la situación socioeconómica y que en este momento regresan a su lugar de origen. En general los hombres parten en busca de mejores condiciones de vida, quedando las mujeres con labores domésticas y agro-ganaderas. Sin embargo, actualmente se nota un tímido retorno a las zonas rurales. En la Puna se observa un índice de masculinidad inferior a cien, como resultado de la emigración de varones, producto de las escasas posibilidades laborales que ofrece la zona (Dipierri y Alfaro, 2000).

En relación a la perduración de los nombres indígenas en este lapso de más de 400 años se observa que de los siete nombres masculinos registrados en 
1557, cuatro continúan usándose en 1654. Del padrón de 1654, 25 nombres masculinos perduraron como apellidos en Casabindo o áreas vecinas de la Puna de Jujuy hasta fines del siglo XVIII. Hacia fines del siglo XIX han desaparecido diez de este conjunto y para 1982 se ha perdido uno más. Esto deja 14 apellidos derivados de nombres indígenas masculinos característicos del área Casabindo en el siglo XVII que han permanecido en su zona de origen.

Sin embargo el tronco original se ha dispersado a otras áreas de la Puna, de las provincias de Jujuy y Salta y algunos sectores del país. En efecto, Albeck et al. (2005; 2007) empleando el Padrón Electoral de 2001 analizaron la perduración y dispersión de estos 25 apellidos en cada uno de los departamentos de las provincias del NOA encontrando que actualmente todos están presentes en la provincia de Salta y 24 aparecen en Jujuy, con una representatividad muy poco significativa en las restantes provincias del Noroeste Argentino. Estos autores demuestran la persistencia en el territorio original y zonas circundantes (correspondientes al actual departamento de Cochinoca, provincia de Jujuy) constituyendo la quinta parte de población actual de esta zona y una importante representación en los territorios circunvecinos (Figura 26) (Albeck et al., 2005 m.s.; 2007). 


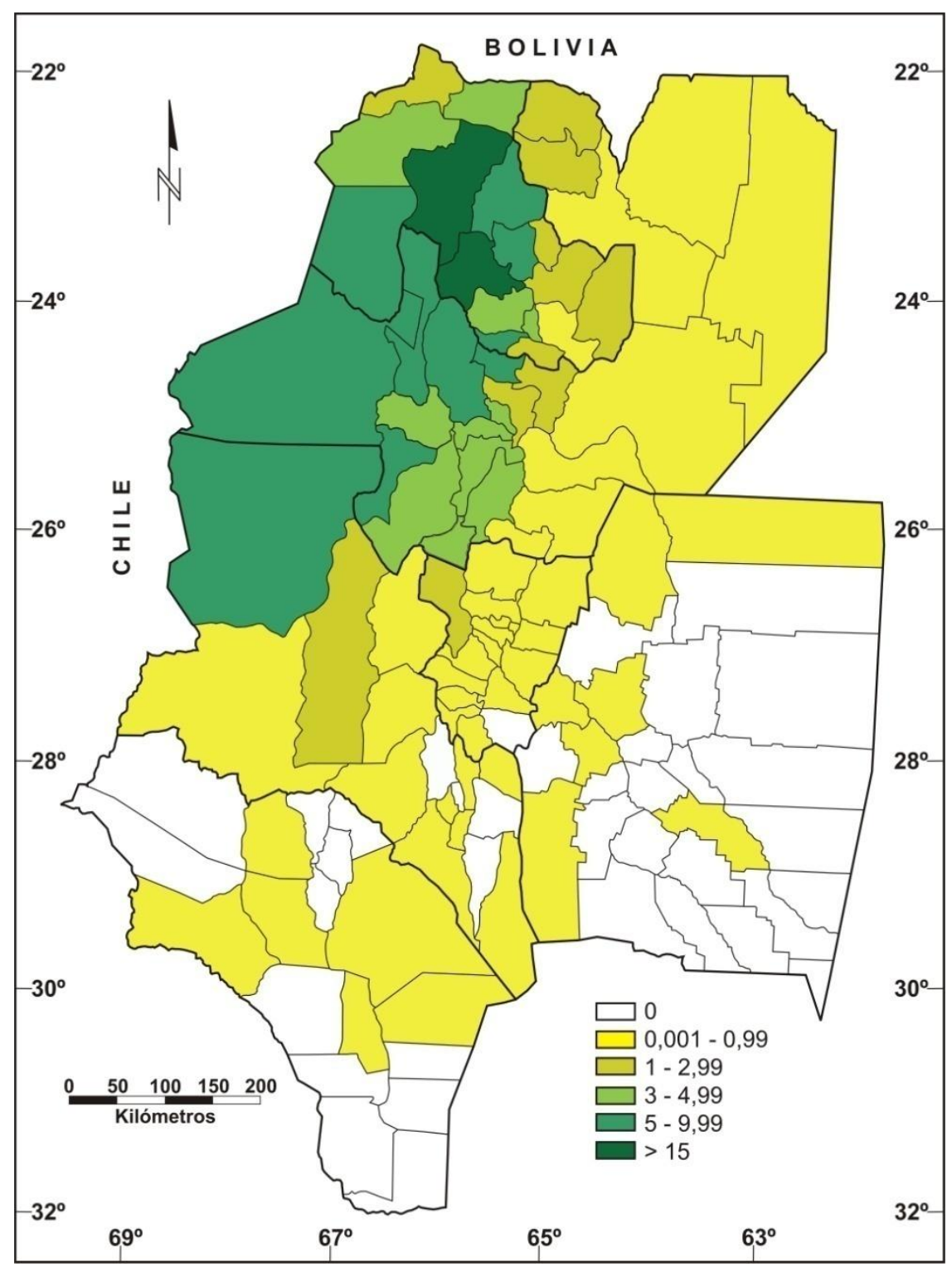

Figura 26: Porcentaje de individuos portadores de los 25 apellidos del núcleo de 1654 de Casabindo presentes hasta hoy en el NOA

(Fuente: Albeck et al., 2007)

Albeck et al (2005 m.s.), a partir de la misma fuente de información, analizaron también la presencia de los 25 apellidos identificados como núcleo original de Casabindo en 1654 en todo el territorio de la República Argentina encontrando que la mayor cantidad de portadores se presenta en las provincias de Jujuy y Salta (Figura 27) y que las frecuencias que le siguen en orden de magnitud corresponden a provincias que reciben inmigrantes procedentes de las antes mencionadas, reflejando una dispersión gradual selectiva del tronco 
antroponímico original de los casabindo en el NOA y en las otras regiones argentinas a principios del siglo XXI.

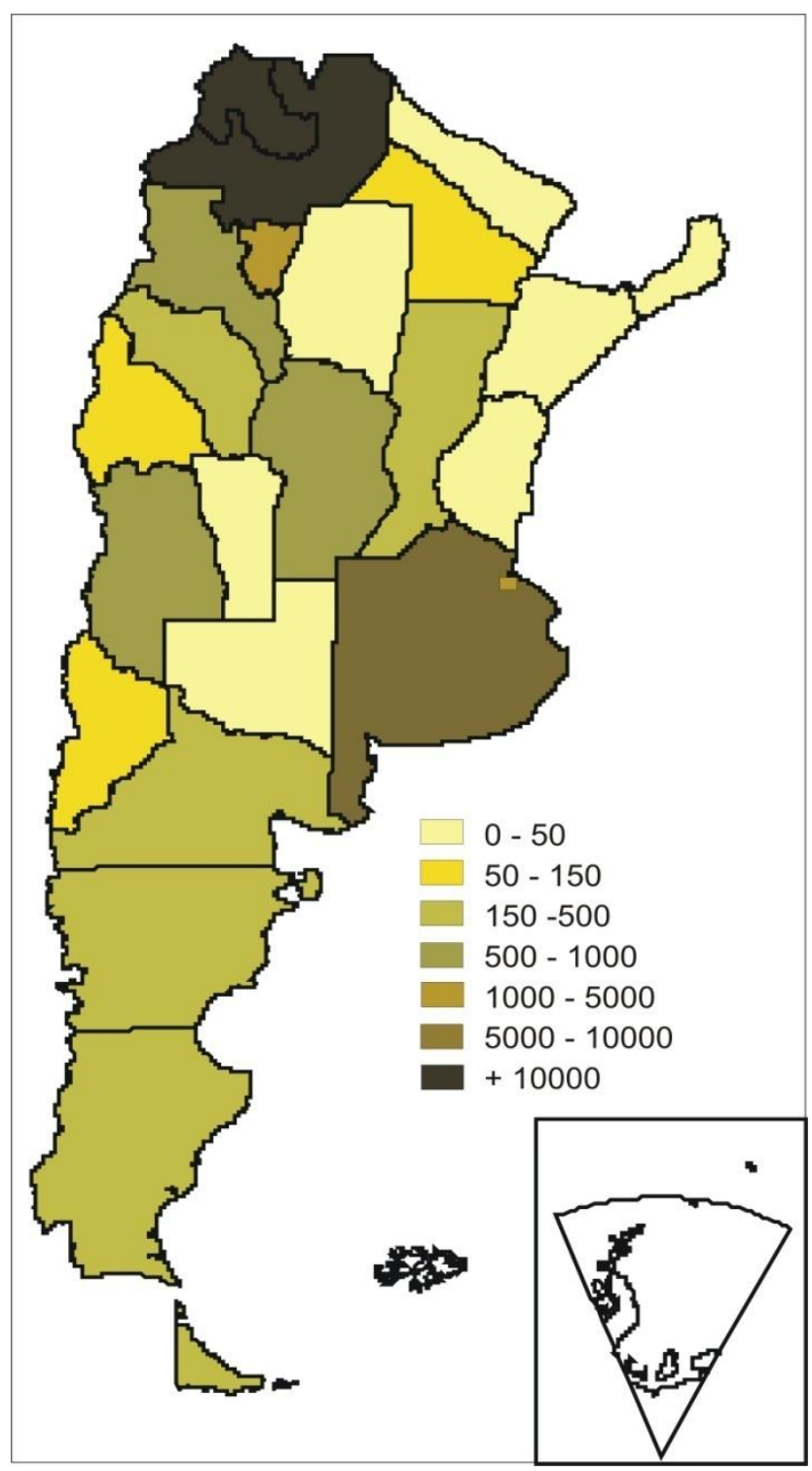

Figura 27: Cantidad de portadores, por provincia, de antropónimos del núcleo original de 1654 de Casabindo (Fuente: Albeck et al., 2005m.s.) 


\section{CAPÍTULO XIII: ESTRUCTURA DEMOGENÉTICA}

\section{PARÁMETROS ISONÍMICOS}

Existen escasos antecedentes sobre la estructura de poblaciones coloniales andinas recurriendo a parámetros isonímicos y con la profundidad temporal como los empleados en este trabajo; muchos de los antecedentes bibliográficos son trabajos preliminares realizados en el marco de esta tesis.

Entre los pocos trabajos referidos a esta temática en marcos temporales similares, se puede mencionar a Dipierri et al. (1991) quienes analizaron la consanguinidad por isonimia de la población histórica de Humahuaca a partir de los registros bautismales entre 1734 y 1810. Estos autores encuentran que el coeficiente de consanguinidad aumenta con el tiempo y que, al principio de este período, el 66\% de los individuos tenía apellidos de origen español (Dipierri et al., 1991). En este sentido la Parroquia de Humahuaca no difiere de otros asentamientos contemporáneos, tal como el de Oruro, donde en 1786, luego de un largo proceso de desestructuración, un tercio de sus habitantes se registraba con apellidos aborígenes (Sánchez Albornoz, 1974).

Costa-Junqueira et al. (2000), empleando el método isonímico, analizaron la evolución de la consanguinidad y parentesco en la Puna de Atacama entre 1800 y 1950. A partir de los apellidos registrados en los libros de defunciones ocurridas en Susques (Argentina), San Pedro de Atacama y Toconao (Chile) determinaron el coeficiente de consanguinidad por isonimia al azar, el indicador de inmigración v (de Karlin-Mc Gregor), la abundancia de apellidos o a de Fisher y el indicador B de aislamiento. Globalmente, a través del tiempo la región presentó una fase temprana de gran movilidad poblacional y luego otra de progresivo aislamiento de las poblaciones situadas a ambos lados de la Cordillera de los Andes. En cuanto a las diferencias entre las distintas localidades analizadas, Susques resultó la más consanguínea y sedentaria al presentar los valores más elevados de consanguinidad y sedentarismo y la menor inmigración reciente y diversidad de apellidos. 
Colantonio et al. (2002; 2006; 2007a; 2007b) recurrieron a la isonimia para analizar varios aspectos de las poblaciones coloniales de la provincia de Córdoba (Argentina) como relaciones de parentesco y movimientos poblacionales. Sin embargo, a pesar de cubrir lapsos temporales que se solapan con los analizados en esta tesis, el contexto histórico y la composición de las poblaciones cordobesas en la época de la colonia son totalmente diferentes a las analizadas en esta tesis.

La estructura demogenética de una población está fuertemente condicionada por una serie de factores geográficos, económicos, demográficos y los relacionados con el grado de ruralización-industrialización de la población (Barrai et al., 1962; Abelson, 1978; Pettener, 1985; Calderón, 1989; Jorde y Pitkanen, 1991; Calderón et al., 1993; Varela et al., 1997).

En los últimos años se ha prestado especial atención al impacto de los factores socio-culturales en la consanguinidad humana, puesto que en algunos estudios se ha demostrado que cualquier limitación en la selección de pareja impuesta por diferencias étnicas y/o lingüísticas puede repercutir en la estructura genética de la población, a través de un aumento de la endogamia étnica y de los niveles de matrimonios consanguíneos (Biondi et al., 1993; Danubio y Pettener, 1997; Hussain y Bittles, 1998).

La consanguinidad por isonimia al azar $\left(\varnothing_{\text {ii }}\right)$ estimada en la población de Casabindo en los primeros documentos analizados, es decir en los correspondientes al siglo XVII, se observan valores elevados que deben ser considerados como valores "indiciarios" ya que en 1654 aún no se registraba una transmisión regular de apelativos de una generación a la siguiente. En 1688 se presenta el mayor valor de todo el período analizado (Tabla 9) y corresponde al momento de transición del sistema nominativo, donde comienza la herencia de los nombres autóctonos masculinos y su transmisión a toda la descendencia conformando los apellidos tal como los conocemos actualmente.

De este modo, en este período se puede encontrar tanto una sobreestimación de la consanguinidad debido al polifiletismo de los 
antropónimos como también una subestimación de la misma debido al cambio de nombres de una generación a la siguiente, tomando como no emparentados a quienes en realidad si lo estaban.

Al no contar con estimaciones similares que permitan comparaciones, la interpretación de estos valores elevados podría basarse en el hecho de que los casabindos se encontraban reducidos y encomendados, constituyendo un grupo particular que no compartía el destino de otras poblaciones indígenas de las zonas vecinas que, como resultado de un proceso de desestructuración diferencial (Lorandi, 1997), iniciaron una integración que se manifestó, entre otros rasgos, por la desaparición de la onomástica nativa y el reemplazo por la europea (Dipierri, 2004).

Consistentemente con la consanguinidad elevada, el indicador A (\% de la población cubierta por apellidos únicos), considerado como un estimador de migración, muestra su mayor valor en 1654 en ambos sexos (Tabla 10) en total coincidencia con sistemas nominativos independientes. Es decir, que en este momento no se registraría una migración importante marcada por los altos valores de A, sino que éstos se justifican por la inestabilidad del sistema nominativo caracterizado por la falta de transmisión regular entre generaciones.

Para 1688 este indicador revela el momento de transición donde la transmisión comienza a establecerse primero entre los varones, mostrando una marcada diferencia intersexual. Mientras que en las mujeres los valores no han variado en 34 años, los varones presentan un descenso significativo (Tabla 10).

La consanguinidad elevada continúa registrándose durante el siglo XVIII, donde la transmisión de los apellidos a toda la descendencia ya estaba totalmente instalada, aunque este momento ya se manifiesta una clara tendencia descendente (Tabla 9). La mayor consanguinidad es coincidente con los indicadores de aislamiento y sedentarismo, donde para el indicador A se observan diferencias intersexuales siempre a favor de las mujeres señalando que el movimiento poblacional sólo ocurriría a partir de ellas y la estabilidad 
poblacional estaría dada fundamentalmente por los varones, en total acuerdo con la ausencia de forasteros plasmada en los documentos analizados.

La consanguinidad encontrada en este trabajo puede compararse con la calculada por Dipierri et al. (1991) para la parroquia de Humahuaca en el período de 1734 a 1810. Estos autores utilizan la isonimia marital para estimar la consanguinidad y encuentran valores inferiores tanto para todo el período (0.0031) como para cada una de las subdivisiones temporales consideradas, 1734 a $1772(0.0023)$ y 1773 a 1810 (0.0034) que los encontrados en Casabindo para 1778 (0.0111) y 1786 (0.0102) (Tabla 9). Estos autores concluyen que la consanguinidad registrada en Humahuaca se debe a que la población aborigen de esta zona se comportaría como una unidad panmíctica donde no se advierten desviaciones de las uniones al azar.

Las diferencias, de un orden de magnitud, entre estas estimaciones podrían atribuirse a las características de cada una de las poblaciones analizadas. Mientras Casabindo presenta de una población cerrada sin presencia de forasteros, localizada y mantenida por el encomendero en un área geográfica restringida, la parroquia de Humahuaca incluye a una población compuesta tanto por indígenas como por españoles y mulatos. Otras explicaciones posibles para estas diferencias serían los métodos de estimación. En el caso de Humahuaca se empleó la isonimia marital considerando las parejas efectivamente formadas y en Casabindo se utilizó la isonimia al azar. Además de las diferencias metodológicas, las fuentes de información son totalmente disímiles, libros de bautismo donde la información era registrada por funcionarios religiosos en un caso y censos de población y padrones de tributarios realizados por funcionarios del gobierno en el otro.

Al analizar la consanguinidad en cada una de las áreas del territorio Casabindo se observa que tanto para 1778 como para 1786, las estimaciones son mayores que las obtenidas para la población total. Sin embargo, al considerar los valores en cada área en ambos registros, se observa que el Área Este siempre registra los valores intermedios, mientras que la Oeste es la más consanguínea 
en 1778 y la norte en 1786 y que, además, es la única que registra un muy leve aumento en los ocho años transcurridos entre las dos numeraciones.

Posiblemente esto se explique por la diferencia de registro establecida a partir de la comparación de ambos documentos donde se estableció que mayor estabilidad en cuanto a la residencia de las familias se registra precisamente en el Norte, mientras que el cambio de residencia se presenta en las otras áreas como así también la diferencia poblacional más importante, como se analizará en detalle más adelante.

Así, la mayor consanguinidad no se debería solamente a un fenómeno biodemográfico o a uniones preferenciales sino también a un subregistro de individuos y en consecuencia de apellidos en el área Oeste.

Los valores considerados hasta aquí revelan una consanguinidad muy importante en toda el área de Casabindo que, posiblemente, esté relacionada con la estructura del "ayllu" organización propia de las comunidades andinas consistente en una agrupación de familias que se consideraba descendiente de un lejano antepasado común, que trabaja en forma colectiva en un territorio de propiedad común y que se reproduce, por lo general, al interior del mismo (Nicolas et al., 2005).

Si se considera todo el período analizado se observa que la consanguinidad más baja se presenta en 1895, coincidentemente con el ingreso de individuos foráneos o apertura de la población, observada al analizar el origen de los apellidos y en concordancia con el aumento registrado en el indicador A que evidencia el ingreso de individuos, particularmente varones, portadores de apellidos nuevos para la población, mientras que los valores femeninos no han variado.

Al comparar la consanguinidad estimada a fines del siglo XIX en Casabindo con la calculada por Costa-Junqueira et al. (2000) en localidades chilenas y argentinas de la Puna de Atacama, se observa que para el período 1851-1900, los valores de Casabindo son significativamente menores que los registrados para Susques y Toconao pero muy similares a los de San Pedro de 
Atacama, que son los más bajos calculados por Costa-Junqueira et al. (2000). Esta baja consanguinidad coincide con los antecedentes históricos de las poblaciones atacameñas caracterizadas por su gran movilidad y por la intensa articulación social a través del intercambio no sólo económico sino también biológico (Nuñez y Dillehay, 1995), relacionado con el control vertical y por funcionar San Pedro de Atacama como centro formal administrativo y económico.

Con respecto al indicador de sedentarismo constituido por el porcentaje de población cubierta por los 7 apellidos más frecuentes (indicador B) muestra, en el caso de la población de Casabindo, un comportamiento regular en ambos sexos y en el total poblacional. Se registran importantes porcentajes a lo largo de todo el período analizado evidenciando un descenso significativo (casi del $40 \%)$ entre 1654 y 1895.

Al comparar las estimaciones de B en Casabindo con las registradas por Costa-Junqueira el al. (2000) en la Puna de Atacama, se advierte una situación similar a la observada al analizar la consanguinidad ya que estos parámetros se encuentran estrechamente relacionados, cuanto mayor es el sedentarismo y aislamiento de la población, más endogamia y consanguinidad se registra en la misma.

La consanguinidad estimada para fines del siglo $\mathrm{XX}$ y para comienzos del XXI muestra un aumento en relación con la de 1895, lo que está en estrecha relación con la realidad sociodemográfica caracterizada por el crecimiento poblacional con disminución de la emigración y prácticamente sin inmigración, y que se analizará en profundidad al abordar la estructura demográfica pero reflejada en el aumento del indicador B y descenso del A, respectivamente (Tabla 10).

Para 2001 la consanguinidad de Casabindo presenta un valor de 0.0079 (Tabla 9) el doble del registrado para el mismo momento en la ciudad de Abra Pampa cabecera del departamento Cochinoca que asciende a 0.0036 y sólo superado por Susques (0.014) como ya se registrara a fines del siglo XIX. Esta 
situación de aislamiento y sedentarismo se mantiene a pesar de que, para este momento, el sistema de encomiendas que podía entenderse como una barrera que mantenía aislada a la población de Casabindo durante los siglos XVII y XVIII ha finalizado hace más de 200 años. Sin embargo perdura el comportamiento de "endogamia étnica" (Biondi et al., 1993).

En general cuando se encuentran valores elevados de los indicadores A y B se sospecha que existe escaso aislamiento pero gran sedentarismo. Como ocurriría en la población de Casabindo donde, además, los elevados valores de B registrados estarían en relación con un aislamiento de tipo administrativo representado por la encomienda más que con un aislamiento geográfico como ocurre en otras poblaciones.

El comportamiento de los indicadores de dinámica evolutiva ( $v$ de inmigración reciente y a diversidad de apellidos) es coincidente con los analizados hasta aquí, revelando para 1688 el punto de inflexión relacionado con la regularidad en la transmisión de los antropónimos.

Tanto $\mathbf{v}$ como a indican una gran estabilidad de la población de Casabindo hasta fines del período colonial. Hasta ese momento y en general, estos indicadores presentan diferencias intersexuales significativas que muestran que durante el siglo XVIII la dinámica poblacional fue consecuencia, principalmente, del comportamiento migratorio femenino respetando el patrón de residencia virilocal. A partir de 1895 el movimiento poblacional se relaciona fundamentalmente con migraciones masculinas de tipo laboral, como se analizará en detalle al considerar la estructura demográfica.

Estos resultados son consistentes con los encontrados empleando otras fuentes de información y otros indicadores tanto isonímicos como moleculares (Ver Antecedentes locales, Capítulo IV) que revelan que las poblaciones de la puna son las más endógamas y consanguíneas de la provincia de Jujuy y las que han recibido menor aporte migratorio, sobre todo de las poblaciones europeas. 


\section{ESTRUCTURA DEMOGRÁFICA}

Si bien Madrazo (1982) estimó que, al momento de la llegada de los españoles, la población de la Puna y de la Quebrada de Humahuaca no superaba los 20.000 habitantes de acuerdo a las evidencias arqueológicas, esta cifra está sujeta a revisión al no haberse publicado nuevas estimaciones para el área de Casabindo. Sin embargo, Zaburlín (2009) estima que el pucara de Tilcara (ocupado entre 800 y 1500 d.c.), pudo alcanzar una población promedio de 1614 personas, con un mínimo de 538 y un máximo de 2690 individuos en función de la cantidad de recintos habitacionales. En base al mismo criterio y registrando más de 600 recintos entre 1000 y 1400 d.c. , Albeck (2009b) estima que en Pueblo Viejo de Tucute habría entre 600 y 3000 individuos, si se considera que en cada recinto podrían habitar entre 1 y 5 personas.

En general, los estudios acerca de los cambios demográficos de las poblaciones indígenas históricas se realizan sobre la información de padrones, visitas, revisitas, retasas, registros parroquiales y otros documentos similares que contienen recuentos de población (Bolsi, 1994). Estas numeraciones o matrículas constituyen relaciones nominales de los habitantes de un determinado pueblo o repartimiento donde se especifican algunas características de los mismos como edad, estado civil y otros.

Los sistemas de recuentos parciales o totales que han servido de base para los estudios de las poblaciones históricas han sido confeccionados por diferentes motivos y con distintos fines (administrativos, militares, políticos, profesionales, judiciales, religiosos). Los criterios para su confección no fueron homogéneos y mucho menos exactos. En general se efectuaron siguiendo directivas explícitas de las autoridades que ordenaban los registros, aunque los criterios de los funcionarios que levantaban los censos variaba según sus propias capacidades, intereses y recursos. A pesar de las falencias, estos documentos resultan imprescindibles para la reconstrucción de los procesos demográficos, económicos y sociales de las poblaciones coloniales. 
Sin dudas que las fuentes privilegiadas por la historia demográfica son las emanadas del Estado colonial y la Iglesia que, aunque ofrecen un criterio clasificatorio excesivamente rígido y estático de la población, especialmente en su interés por "identificar" a la población según su pertenencia jurídica y fiscal (López, 2006), son los únicos que permiten establecer una visión de conjunto.

En general en los documentos analizados, excepto el censo de población de 1895 y los padrones electorales correspondientes al siglo XX, la población fue registrada por unidad doméstica. No obstante, debe recordarse que los padrones de tributarios no siempre respetaron las unidades domésticas y familiares originarias y sus lazos parentales. Según Loza (1997), la innovación de las reformas del Virrey Toledo es haber unificado los criterios para la recolección de datos poblacionales a partir de objetivos fiscales, así se abandonó la inscripción de las familias y unidades domésticas y se la reemplazó por una "unidad fiscal". Las instrucciones de 1570 señalan que los registros debían realizarse considerando a los grupos familiares compuestos por hombres de 18 a 50 años con su mujer y sus hijos menores, representando una unidad económica elemental, el hogar, que constituye la unidad fiscal de base y que no siempre tiene correspondencia con la composición de las unidades domésticas o familiares (López, 2006; Sánchez, 1996). En este trabajo se consideró a los solteros o viudas como una "familia", en tanto por razones de registro con frecuencia no resulta posible reconstruir la genealogía.

Al no contar con información sobre la población de Casabindo para el siglo XVI, no puede hacerse una estimación del tamaño poblacional para ese momento. Se sabe que la población indígena de la región fue víctima de epidemias de viruela y sarampión que se sucedieron entre 1619 y 1628 (Sánchez, 1996). A lo anterior se suman las periódicas plagas que atacaron las plantaciones, afectando la economía campesina, en gran medida de autoconsumo; por ejemplo, la plaga de langosta y gusano que 
contemporáneamente atacaron Tucumán en el año 1613 dejando la región en una desolada situación (Sánchez, 1996) ${ }^{21}$.

Tomando como base la población consignada en los documentos correspondientes al siglo XVII, se observa un descenso poblacional del 11\% entre 1654 y 1688 (Tabla 2). Muy probablemente, esta disminución se deba a que en el padrón de 1688 no fueron registrados ni las viudas ni los huérfanos, como se mencionara anteriormente y que posiblemente también se haya ocultado a los jóvenes en edad de tributar. El impacto de las epidemias mencionadas (1619 y 1628) estaría manifestándose en 1654 en los porcentajes correspondientes a la franja etárea de 30 a 54 años que oscilan entre 5.6 y 1.9\% respectivamente del total de población masculina.

Para los documentos correspondientes al corte temporal del siglo XVII, en los que sólo se consigna la edad de los varones, se observa una población joven, con una proporción de casi 38\% y 49\% de menores de 15 años en 1654 y 1688 respectivamente. En los 34 años que separan ambos documentos los mayores de 50 años se han reducido de forma significativa, de $9.4 \%$ a $1.1 \%$ lo que también podría deberse al impacto de las pestes. Esta población se encuentra registrada conformando, en 1654, 131 familias o "unidades fiscales" que presentan entre uno y ocho integrantes, siendo las más frecuentes aquellas compuestas por entre uno y tres miembros, representadas fundamentalmente por las parejas casadas (Tabla 18, Fig 11). A fines del siglo XVII y en consonancia con la disminución poblacional se observan menor cantidad de grupos familiares, aunque al presentar entre uno y siete miembros siguen siendo familias numerosas, predominando las compuestas por entre dos y cinco integrantes (Fig. 11).

Con respecto al estado civil y debido a que los documentos analizados para el siglo XVII no registran la edad en las mujeres y sólo mencionan el estado civil en algunos varones, no fue posible estimar la proporción real de solteros. Sin embargo, en 1654 los varones solteros llegarían casi al 20\%.

21 Se desconoce en qué medida estas plagas pudieron afectar a la Puna 
La "fuerza de trabajo" de la que disponía la comunidad estaría representada por los jóvenes próximos a tributar y los hombres adultos, cuyo porcentaje para ambos documentos es de alrededor del $50 \%$ de la población masculina. Sánchez (2006) analiza la variación de la fuerza laboral en los tilcara y encuentra que entre 1631 y 1694 la misma se redujo del 37\% al 18\%, valores muy inferiores a los encontrados en Casabindo.

Dichos valores resultan muy reveladores teniendo en cuenta que estos documentos son padrones de encomienda y que la encomienda o repartimiento fue la institución más importante que reguló las relaciones entre españoles e indios durante la época colonial. Su rasgo básico y universal fue la asignación de grupos de indios a colonos españoles, los encomenderos, para recibir tributos y mano de obra. Los términos encomienda y repartimiento se referían esencialmente a la misma institución, aunque el último remarcaba literalmente el acto de distribución y asignación de indios; mientras que el primero enfatizaba la responsabilidad del encomendero hacia sus indios (Sánchez, 1996; Gibson, 1990).

Cabe destacar que a lo largo de la América hispana, la encomienda se adaptó a las estructuras básicas de las poblaciones locales, es decir, a las riquezas de la región y al mayor o menor número de población, distinciones que obviamente emergieron al momento de estipular el tributo (Lockhart, 1990; Sánchez, 1996). Este tributo se pagaba a la Corona en calidad de "súbditos o vasallos" del Rey quien lo cedía a los encomenderos a cambio del cuidado, protección y evangelización de las poblaciones locales.

Sin embargo, esto no significaba que el encomendero se hiciera cargo del sustento de sus indios encomendados. Muy por el contrario, ellos debieron asegurar su alimentación y autorreproducción, recargados ahora por el peso de nuevas obligaciones, es por eso que resulta de suma importancia para la comunidad el tener casi la mitad de sus varones dispuestos para el trabajo (Gil Montero, 2007, López, 2006; Sánchez, 1996). 
En 1778, casi cien años después, se observa que la población total se ha triplicado pero es necesario recordar que también para este relevamiento se ha ampliado el área de registro ya que, tanto en el padrón de 1654 como en el de 1688 figura como localidad de empadronamiento "Santa Ana de Casabindo" que era el nombre de la reducción sin detallar otras localidades menores ${ }^{22}$, lo que si se observa claramente en los registros de fines del siglo XVIII.

Al analizar la estructura etárea se observa una pirámide poblacional de base ancha con valores superiores al 10\% en ambos sexos para los grupos de 0 a 4 y de 5 a 9 años (Fig. 12), lo que podría interpretarse como una consecuencia de una alta natalidad acompañada de bajo riesgo de muerte en los primeros años de vida. En este momento, alrededor del 35\% de la población tiene menos de 15 años y sólo el $8 \%$ es mayor de 50 años, entre los cuales hay seis individuos de más de 80 años, lo que podría asociarse a buenas condiciones económicas, sociales y naturales durante la vida de estas personas longevas.

Cuando se considera cada una de las áreas que conforman el territorio Casabindo, la distribución poblacional es heterogénea, registrándose los valores mayores en el Norte mientras que en el Oeste la población es casi la mitad de la anterior (Tablas 3 a 5). Esta diferencia puede explicarse analizando las pirámides poblacionales correspondientes a cada área que, en general, presentan estructuras (formas) similares a la descripta para el total de Casabindo con bases amplias, excepto para el Área Oeste que presenta una base estrecha y una distribución asimétrica entre sexos. Posiblemente esto no se deba a fenómenos demográficos específicos sino a un problema de registro como se analizará más adelante.

Durante el siglo XVIII con recuentos poblacionales más numerosos, la cantidad de familias se ha triplicado llegando a 316 en 1778. Si bien las más frecuentes son las integradas por uno o dos miembros, es destacable que el 7\% presenta más de seis integrantes (Fig 11). Para 1786 el número de familias asciende a 430 y algunas cuentan con hasta 12 integrantes (Fig. 19) con una 
importante cantidad de familias numerosas que tienen desde tres hasta ocho hijos. Por otra parte, la cantidad de familias numerosas reflejaría, además, la presencia de un grupo social con un estado de salud relativamente bueno.

En los registros del siglo XVIII aparece claramente consignado el estado civil y se observa que los solteros de ambos sexos representan el 30\% de la población adulta con una clara mayoría masculina (Tabla 18), situación que se repite si el análisis se realiza en las tres áreas que conforman el territorio Casabindo, excepto en el Área Norte en 1786.

En el corto lapso transcurrido entre 1778 y 1786 se observa un llamativo aumento de población de 378 personas (Tabla 2) y que resulta aún más sorprendente si se tienen en cuenta las referencias a la existencia, en el lapso intermedio, de una peste que causó una gran mortandad (Palomeque, 2006). Este aumento poblacional ya había sido señalado en los totales registrados por Palomeque (1994) para todo el curato de Cochinoca donde se observa una diferencia demográfica de 1279 habitantes entre el Censo de 1778 y el Padrón de tributarios de 1786.

La diferencia encontrada, para el caso del área de influencia de Casabindo, de más de 300 individuos entre estos mismos registros, podría deberse a la incorporación de población migrada desde los espacios aledaños u otras áreas de los Andes Centro Sur (Alfaro y Albeck, 2009) proceso descartado al comprobarse que el "aumento demográfico" se daba mayormente a partir de personas que llevaban apellidos propios de la zona de Casabindo (Alfaro et al. 1998, Albeck et al. 2000). Esto puede observarse en las primeras dos columnas de la Tabla 21 donde consta la frecuencia, en ambos registros, de los 27 apellidos característicos de Casabindo para la etapa colonial.

Otra explicación posible para esta diferencia sería que los individuos no registrados anteriormente, pero presentes en 1786, hubieran sido censados en los demás curatos de la Puna en 1778. Por otra parte, los individuos no registrados en 1778 también podrían haber sido registrados en Yavi, que contaba con la presencia de "originarios" de Casabindo y Cochinoca por ser la 
sede del Marquesado de Tojo que tenía a cargo la encomienda de estos grupos. Esta posibilidad se rechazó ya que al analizar la Tabla 21 resulta indiscutible que gran parte de los apellidos frecuentes en Casabindo tenían poca o nula representatividad en los demás curatos de la Puna, si se exceptúan algunos compartidos con Cochinoca, y muchos de los apellidos aumentaron en más de 20 representantes entre uno y otro documento, sin haber sido registrados para otras áreas de la puna (sombreados en la Tabla 21).

Por último, la diferencia poblacional se atribuyó a un problema de registro luego de verificar que las inconsistencias demográficas eran mayores en algunas localidades, principalmente las más aisladas como las del Área Oeste (Tabla 19) ya que según López (2006) los empadronadores raras veces recorrían exhaustivamente los territorios censados para cerciorarse del estado real de la población. A esto se agrega como posible causa de esta importante diferencia poblacional la razón por la cual fue realizada cada numeración.

El censo de 1778 tuvo como objetivo obtener una idea del total de población existente, aparentemente la gente debía ser registrada en los lugares en que residía y, muy probablemente, sólo se anotaba a las personas presentes. Resulta evidente que el censo fue realizado por diferentes personas aunque el registro para los cuatro curatos de la Puna es firmado por el tercer Marqués de Yavi y Tojo (Juan Joseph Martierena del Barranco). Los tiempos necesarios para el traslado entre las diferentes localidades resultan inconsistentes con las fechas en las cuales se efectuó el registro de población en cada una de ellas, a esto se suman los criterios dispares de organización espacial seguidos al realizar cada numeración (Alfaro y Albeck, 2009). 
Tabla 21: Comparación entre 1778 y 1786 de la frecuencia de 27 apellidos característicos de Casabindo

\begin{tabular}{|c|c|c|c|c|c|c|}
\hline Apellido & $\begin{array}{c}1786 \\
\text { Casabindo }\end{array}$ & Casabindo & Cochinoca $^{23}$ & $\begin{array}{l}1778 \\
\text { Yavi }\end{array}$ & Santa Catalina & Rinconada \\
\hline Abichocoar & 43 & 21 & 0 & 0 & 0 & 0 \\
\hline Abracaite & 2 & 0 & 26 & 10 & 0 & 0 \\
\hline Alabar & 74 & 49 & 0 & 0 & 0 & 0 \\
\hline Alancay & 83 & 49 & 1 & 6 & 0 & 3 \\
\hline Barconte & 98 & 85 & 2 & 4 & 0 & 0 \\
\hline Cachi & 32 & 20 & 0 & 6 & 0 & 0 \\
\hline Cachisumba & 30 & 17 & 3 & 0 & 0 & 0 \\
\hline Caiconde & 6 & 11 & 0 & 0 & 0 & 0 \\
\hline Chocobar & 54 & 36 & 0 & 0 & 0 & 0 \\
\hline Lacsi & 38 & 26 & 0 & 1 & 0 & 0 \\
\hline Lamas & 44 & 21 & 78 & 75 & 4 & 3 \\
\hline Liquin & 33 & 26 & 0 & 0 & 1 & 5 \\
\hline Patagua & 70 & 50 & 0 & 3 & 0 & 0 \\
\hline Poco & 5 & 0 & 0 & 0 & 0 & 0 \\
\hline Pucapuca & 54 & 37 & 55 & 13 & 28 & 0 \\
\hline Quipildor & 99 & 89 & 25 & 22 & 0 & 0 \\
\hline Repe & 12 & 9 & 0 & 5 & 0 & 0 \\
\hline Sarapura & 12 & 8 & 26 & 8 & 3 & 2 \\
\hline Socomba & 6 & 8 & 0 & 0 & 0 & 0 \\
\hline Sumbaine & 81 & 61 & 0 & 1 & 0 & 0 \\
\hline Tabarcachi & 37 & 42 & 17 & 11 & 0 & 0 \\
\hline Tabarconde & 19 & 5 & 0 & 0 & 0 & 0 \\
\hline Tinte & 75 & 38 & 3 & 0 & 0 & 0 \\
\hline Tolay & 19 & 16 & 0 & 11 & 0 & 0 \\
\hline Tucunas & 43 & 41 & 31 & 28 & 0 & 0 \\
\hline Vilte & 120 & 98 & 100 & 14 & 1 & 1 \\
\hline Yonar & 30 & 20 & 1 & 4 & 0 & 0 \\
\hline Total & 1219 & 883 & 368 & 222 & 37 & 14 \\
\hline
\end{tabular}

23 Las frecuencias del Curato de Cochinoca se calcularon excluyendo los residentes en el área de Casabindo (Alfaro y Albeck, 2009) 
A partir del orden en que se mencionan las diferentes localidades puede reconstruirse el recorrido realizado por los encargados de censar a la población de Casabindo en 1778. La primera localidad censada fue el poblado cabecera, Casabindo, donde se comienza con el registro del "governador" y demás notables del pueblo, para continuar con el resto de los residentes. A continuación se numeró Agua Caliente, en el sector este, al pie de la Sierra del Aguilar. De allí se trasladaron a Barrancas, luego a Rinconadillas (el sector oeste), para volver a la margen opuesta de la Laguna de Guayatayoc, donde se encuentran las localidades de Quebrada de la Leña y Agua de Castilla. Para finalizar se registraron Doncellas y Quesquesa, ambas localidades pertenecientes a la zona norte. En este contexto, llama la atención la gran cantidad de población registrada en Quesquesa que, seguramente, debió incluir una serie de localidades menores que no fueron discriminadas. El censo completo de los cuatro curatos de la Puna de Jujuy fue realizado entre diciembre de 1778 y enero de 1779.

En el caso del padrón de 1786, el objetivo fue el registro de tributarios y prontos a tributar, información muy importante ya que el ingreso a las arcas del estado colonial dependía de la cantidad de personas apuntadas en dichas categorías. Por esta razón, el celo puesto en registrar la totalidad de los integrantes en cada una de las familias (destacando tributarios, reservados y próximos a tributar), fue mucho mayor que el utilizado en un simple registro poblacional como el de 1778.

En 1786 la numeración también se inició en el poblado cabecera anotando a las autoridades, que eran diferentes a las de 1778, y abarcó además todo el distrito que anteriormente había sido registrado como Doncellas y Quesquesa. De allí los empadronadores se dirigieron hacia el sur, al sector oeste, donde la población se incluyó en el registro de Barrancas y Rangel (que también comprendía a la población censada previamente en Rinconadillas). Finalmente se empadronaron Colorados y Saladillo, ubicadas al este de las Salinas Grandes y al sur de la Sierra del Aguilar pero que incluyen, a su vez, a gran parte de la población que había sido registrada anteriormente en las localidades ubicadas 
sobre la vertiente occidental de la Sierra del Aguilar (Aguas Calientes, Quebrada de la Leña y Agua de Castilla) (Fig. 18).

Además del problema de registro mencionado, también es posible que parte de la diferencia de población se pueda deber a razones climáticas. Si uno se atiene al momento del año en que se realizó el censo, en plena temporada de lluvias, y considerando las características geográficas del espacio casabindo, no sería extraño que los que realizaban el censo se hayan visto impedidos de acceder a una serie de lugares (Alfaro y Albeck, 2009).

$\mathrm{Al}$ analizar a nivel de familias e individuos los registros poblacionales de Casabindo de 1778 y 1786, se refuerza el planteo previo de que el "aumento demográfico" no se debió a la incorporación de inmigrantes recientes, en tanto en 1786 sólo se registran veinticinco individuos portadores de veintitrés apellidos que no aparecen en 1778, lo que representa un número sumamente bajo (Tabla 21). El grueso de la diferencia numérica se da a partir de familias íntegras que no fueron censadas, a las cuales se suma la falta de registro de algunos de sus miembros lo que muy probablemente se deba a que sólo se anotaba a las personas presentes en los lugares censados. Cuando se cotejan los apellidos de las familias no registradas, corresponden casi sin excepción a los que son propios de la zona de Casabindo desde el siglo XVII (Albeck et al. 2000). En algunos casos hasta se menciona el parentesco del padre o la madre con algún miembro de otra familia que efectivamente había sido censada; revelando a todas luces que se trata de un problema de registro.

Como síntesis de la comparación efectuada, se podrían destacar algunos aspectos referidos a las características de la población analizada, a su dinámica, a los registros realizados y a la naturaleza de las tareas desarrolladas en el presente trabajo.

En 1786 la población de Casabindo evidenciaba una marcada estabilidad con un mínimo aporte de migrantes procedentes de otras partes, hecho reflejado en la gran cantidad de población representada por unos pocos apellidos como se observa en los valores del indicador B (Tabla 11) y la baja 
inmigración reciente según los valore de v (tabla 14). A esto se debe agregar que el Padrón de Medeiros discriminaba entre originarios y forasteros y que la totalidad de la población de Casabindo correspondía a la primera categoría tributaria.

El patrón de residencia brinda información interesante, por un lado reafirma lo planteado sobre el espacio colonial perteneciente a los casabindos y, por otro, apoya hipótesis referidas a la residencia múltiple (Gil Montero, 1997) propia de sociedades con un patrón económico básicamente pastoril. En la comparación efectuada sobre la residencia de las familias se encuentran algunos casos notables como el del cacique Diego Barconte y su esposa Brígida Peloc, presentes en Casabindo en 1786 y que, en 1778, figuraban residiendo en Rinconadillas; otro es el de Andrea Cachi, que en 1778 se encontraba en Casabindo como esposa de Sebastián Favián Quipildor, hijo del cacique (don Pedro Quipildor, de 80 años) y heredero del cacicazgo; en 1786 Andrea ha enviudado y reside con sus hijos menores en Barrancas. Estos datos, además de muchos otros casos, permiten reforzar el planteo de que el área registrada pertenecía, sin lugar a dudas, a una misma comunidad.

Un abordaje como este permite alcanzar un grado de conocimiento mucho más cercano de una serie de aspectos que posibilitan obtener una visión abarcadora de una reducida población colonial y brindó datos insospechados sobre su organización. En este contexto resulta destacable la solidaridad interna del grupo social estudiado, reflejada en 1786 por la inclusión de huérfanos en diferentes familias luego de una peste.

Los últimos años de dominación colonial se caracterizaron no sólo por las reformas político-administrativas, sino también por el fuerte crecimiento del comercio, el aumento de la producción rural y artesanal, la expansión hacia las fronteras y la ocupación de tierras marginales (Bolsi, 1994; Lorandi, 1997). Todo ello estuvo acompañado de un aumento demográfico sostenido que fue producto tanto del crecimiento vegetativo como del aporte inmigratorio (López, 2006). Fue una época de gran movilidad geográfica que atrajo a la gobernación 
de Tucumán un importante número de inmigrantes peninsulares así como indios y mestizos del Alto Perú. La debilitación del sistema de encomienda y la alta movilidad social, producto del mestizaje y el acelerado "blanqueamiento" logrado a través de matrimonios exogámicos, fue acompañada también de mejores oportunidades para el ascenso económico (Faberman y Gil Montero, 2002; López, 2006).

En contraposición, las dos primeras décadas del período independiente fueron épocas de retracción económica y demográfica. La revolución y la guerra por la independencia marcaron los ritmos de los reacomodamientos políticos, sociales y productivos. La pérdida de los mercados altoperuanos, el sostenimiento de los ejércitos revolucionarios, las requisas y saqueos, la desmonetización generalizada, fueron los signos que se reflejaron en los volúmenes y composición de la población (Gil Montero, 2007; Lopez, 2006). La guerra, sin duda, fue el factor que más afectó a los habitantes de la región: las levas masivas, la incertidumbre y las alineaciones políticas generadas por las diferentes coyunturas se tradujeron en continuas migraciones de exilados y desertores. Las delimitaciones administrativas alteraron la distribución de la población imponiendo barreras para la movilidad, al menos desde el punto de vista legal.

Aunque no se dispone de información para el período 1830-1860, cuando comenzaron a afianzarse las políticas locales, terminaron las guerras civiles y se restauró relativamente la seguridad general, los cambios demográficos operados parecen haber sido cruciales para permitir el aumento ininterrumpido de la población regional hasta el Primer Censo Nacional realizado en 1869 (Gil Montero, 2007; López, 2006). En esta tesis no se analizan los datos correspondientes a este censo por cuanto no discrimina las diferentes localidades consignando sólo la población para todo el departamento de Cochinoca.

Todos los acontecimientos ocurridos durante la brecha de 109 años que separa las estimaciones poblacionales del siglo XVIII con la realizada en 1895, 
podrían explicar el descenso poblacional del 29\% que se registra en el Segundo Censo Nacional de Población. Si bien la población se ha reducido, se observa un marcado "rejuvenecimiento" de la misma ya que el $40 \%$ de los individuos es menor de 15 años y los mayores de 65 años no alcanzan el 5\% del total (Fig. 17). Para 1895 se observa que la proporción de solteros aumenta a 37\% y en este momento la mayoría corresponde al sexo femenino (Tabla 18).

Entre 1654 y 1895 se observa que los viudos representan entre el 7 y el $10 \%$ con una significativa mayoría femenina. Esto puede atribuirse a las guerras, a las pestes y a la mayor longevidad femenina.

Desde 1654 hasta 1786 y sin considerar la edad, se observa una muy leve mayoría masculina que apenas supera el 50\% sobre la población total. En 1895 la situación se revierte y en 1982 y 2001 la proporción de varones disminuye al $40 \%$ (Fig. 10). Estos resultados son coincidentes con lo encontrado por Dipierri et al. (2000) al analizar el cambio socioeconómico y la evolución del equilibrio sexual terciario en la provincia de Jujuy. Estos autores encuentran que la región de la Puna, en la que se encuentra incluida el área de Casabindo, presenta desde 1869 hasta 1991 la menor proporción de varones de toda la provincia de Jujuy y que si bien no se observa un patrón homogéneo en el lapso temporal analizado, las diferencias interanuales son estadísticamente significativas. Dipierri et al. (2000) atribuyen estos resultados a las migraciones de tipo laboral como el principal factor involucrado ya que las diferencias en la proporción de sexos se dan fundamentalmente en los grupos de edad que corresponden a la población económicamente activa.

Para Gil Montero (2007) lo que caracteriza a la Puna en general a lo largo del siglo XIX, fue que su población mantuvo un tamaño estable durante casi un siglo combinando alta mortalidad y emigración sexual diferencial lo que influyó en la composición de la población donde comenzó a observarse predominio femenino.

El siglo XX, empezó con algunos cambios que repercutieron en la población modificando la tendencia del siglo anterior reflejándose en general en 
un incremento demográfico. Entre 1982 y 2001 se observa estabilidad y un crecimiento poblacional del $63 \%$ con respecto a los valores obtenidos para fines del siglo XIX a partir del Segundo Censo de Población (Tabla 1). Sin embargo este aumento seguramente es más importante, ya que en su estimación sólo se incluye a los mayores de 18 años que es la información contenida en los padrones electorales.

Gil Montero (2007) plantea que el crecimiento poblacional registrado en la región de la Puna pudo deberse a la disminución de la emigración ya que no se observa una inmigración significativa. Mientras que Teruel (1993) plantea un cambio significativo es tanto que a fines del siglo XIX el mayor peso demográfico se hallaba en las regiones de altura (Puna y Quebrada), a principios del siglo XX éste se traslada a las tierras bajas. El crecimiento demográfico de las tierras bajas en desmedro de las tierras altas en la Provincia de Jujuy continúa entre 1960 y 1985. En términos comparativos, mientras la población de la Puna se multiplicó por tres, a lo largo del siglo XX, la del resto de la provincia se incrementó ocho veces (Gil Montero, 2007).

Entre 1950 y 1985 se verificó el mayor flujo emigratorio de la región Puna ya que esta región funcionaba como expulsora de fuerza de trabajo, no porque no existieran núcleos productivos con potenciales capacidades de generar una demanda de trabajo, sino por la falta de solución a sus problemas estructurales y las características del modelo de crecimiento adoptado en la provincia. Los migrantes eran principalmente hombres que iban a trabajar en la cosecha de caña y tabaco en los valles subtropicales y más tarde a la cosecha de frutas en el sur del país (Gil Montero, 2007). Esta sería la explicación para la mayoría femenina que se registra en el área de Casabindo desde 1895 hasta la actualidad. 
Es así, que la historia de la Puna en general y de Casabindo en particular presenta en los cuatro últimos siglos una transformación muy importante, ya que pasó de ser una zona rica y muy poblada a ser expulsora de población. Su historia entonces sólo puede entenderse reconociendo los momentos de cambio e identificando aquellos aspectos que, como los nombres, perduraron en el tiempo. 


\section{CONCLUSIONES}

El estudio de una serie de nombres y apellidos en una población indígena concreta, por un lapso tan extendido constituye un caso inédito en las investigaciones bioantropológicas de nuestro país.

Las fuentes analizadas permitieron conocer algunos antropónimos usados en Casabindo en épocas prehispánicas que sufrieron un cambio, probablemente relacionado con la administración colonial, que transformó los nombres nativos masculinos en apellidos y provocó la desaparición de los nombres femeninos.

A partir del análisis realizado se puede caracterizar la antroponimia de los casabindos en los últimos 400 años por:

a) la mayor representación de los apelativos de origen autóctono que supera el $90 \%$ de la población en épocas coloniales y se reduce al $50 \%$ en la etapa republicana debido al aumento de portadores de apellidos foráneos, $\mathrm{y}$

b) la persistencia en el territorio original y zonas circundantes de un núcleo de 25 apellidos, con raíces en épocas prehispánicas e identificados a mediados del siglo XVII que han sufrido un largo proceso selectivo y que actualmente constituyen la quinta parte de la población de la zona.

Entre 1654 y 2001 la población de Casabindo presenta una composición etárea demográficamente joven, con equilibrio entre sexos, donde la mayoría de la población adulta se encuentra constituyendo matrimonios y donde entre los solteros predominan los varones y se observa una mayor longevidad femenina al registrar una mayor proporción de viudas. El tamaño poblacional se presenta estable en cada uno de los siglos analizados pero con variaciones diacrónicas debidas a diferentes procesos de desestructuración como pestes (durante los siglos XVII y XVIII) o migraciones (siglos XIX y XX). 
La estructura genética revela una consanguinidad y un sedentarismo elevados a lo largo de todo el período analizado, con valores significativos para los indicadores de aislamiento, sobre todo durante los dos primeros siglos, donde las barreras no serían geográficas sino que estarían relacionadas con la organización familiar y administrativa colonial representada por el ayllu y la encomienda respectivamente. Además de estos motivos, contribuyen a definir a la población de Casabindo como cerrada, al menos hasta fines del siglo XIX, los bajos valores registrados para los indicadores de inmigración reciente y diversidad de apellidos. Estos indicadores muestran diferencias intersexuales que estarían marcando que las mujeres fueron las responsables del escaso movimiento poblacional registrado en Casabindo, relacionado con la residencia virilocal propia del sistema de encomiendas.

El sistema antroponímico y los procesos demogenéticos se integran debido a que la localización geográfica y la permanencia temporal de los antropónimos también son indicadores indirectos de la existencia de consanguinidad y aislamiento de una población, ya que el lugar donde los apelativos muestran mayor frecuencia podría ser el sitio de origen de los mismos y por lo tanto podrían articular relaciones de parentesco biológico, al contrario de lo que ocurre con los nombres o apellidos únicos que por su baja frecuencia en la población evidencian su ingreso reciente al área.

La identificación de las formas originales de denominación de los casabindos y su persistencia revelada por la elevada frecuencia de los antropónimos en la zona probable de origen, permite disponer de un indicador antroponímico que puede asociarse fácilmente con marcadores moleculares, ofreciendo nuevas posibilidades para estudios genéticos en la población actual y en restos humanos arqueológicos, que contribuyan a profundizar el conocimiento sobre la identidad y el patrimonio biológico y cultural de la población actual de la zona Casabindo y de la provincia de Jujuy. 


\section{BIBLIOGRAFÍA}

ABELSON, A (1978) Population structure in the Western Pyrenees: social class, migration and the frequency of consanguineous marriages, 1850-1910. Ann.Hum. Biol., 5: 165-178.

ACRECHE, N; ALBEZA, MV; CARUSO, GB; BROGLIA, VG; ACOSTA, R (2000) Diversidad biológica humana en la Provincia de Salta. Cuadernos FHyCS. 14:7.

AGUILÓ, F (1983) Una posible pista sobre la presencia de "mitmakuna" en la zona de Pampa Yampara. Historia Boliviana III/2: 157-171.

ALBECK, ME (2000) Toponimia indígena en Casabindo. Contribución Arqueológica 5(2): 571-587. Museo Regional de Atacama. Copiapó, Chile.

ALBECK, ME (2003) El territorio casabindo. Una búsqueda desde la Historia y la Arqueología. Pacarina 2: 12-20, FHyCS, UNJu.

ALBECK, ME (2009a) Poblados arqueológicos de la Puna de Jujuy como topónimos en los siglos XVI y XVII. Cuadernos del INAPL (en prensa).

ALBECK, ME (2009b) Pueblo Viejo de Tucute. Una sociedad interpretada a través de la construcción del espacio. En: El hábitat prehispánico. Ed. Albeck, ME; Scattolin, MC y Kornstamje, MA. En prensa.

ALBECK, ME; ALFARO, E; DIPIERRI, JE (2005 m.s.) Estudios de antroponimia en Casabindo. VIII Jornadas Regionales de Investigación en Humanidades y Ciencias Sociales. San Salvador de Jujuy, Jujuy, Argentina.

ALBECK, ME; ALFARO, E; DIPIERRI, JE (2005) Antroponimia e identidad en Casabindo. Revista Argentina de Antropología Biológica 7(1): 63.

ALBECK, ME; ALFARO, EL; DIPIERRI, JE (2007) Apellidos y estructura sociodemográfica: cambio y continuidad en Casabindo (siglos XVII al XX). En SEPOSAL 2005 Seminario sobre Población y Sociedad en América Latina. Tomo I. Compiladores. Mario Boleda y María Cecilia Mercado. GREDES. Salta

ALBECK, ME; ALFARO, EL; DIPIERRI, JE; MORALES, J, VÁSQUEZ, O (2000 m.s.) Antropónimos indígenas del siglo XVII: Una mirada a Casabindo y Atacama. XV Congreso Nacional de Arqueología Chilena. Arica, Chile.

ALBECK, ME; ALFARO; E; DIPIERRI, JE; PALOMEQUE; S; MORALES, J (2001) La identidad de los casabindo a través del origen de sus apellidos. Actas del XIII Congreso Nacional de Arqueología Argentina. pp:183-197.

ALBECK, ME; PALOMEQUE, SR (2009) Ocupación española de las tierras indígenas de la Puna y "Raya del Tucumán" durante el período colonial temprano. Memoria Americana. Cuadernos de Etnohistoria 17(2): 173-212.

ALBECK, ME; RUIZ, MS (1998) Casabindo: Las sociedades del Período tardío y su vinculación con las áreas aledañas. Estudios Atacameños 14:211-222., Universidad Católica del Norte. San Pedro de Atacama, Chile. 
ALFARO, E; ALBECK, ME (2009) Análisis comparativo entre dos registros de población de Casabindo a fines del siglo XVIII. Revista Relaciones, Sociedad Argentina de Antropología 34: 11-28.

ALFARO, E; ALBECK, ME; DIPIERRI, JE (2005) Apellidos en Casabindo entre los siglos XVII y XX. Continuidades y cambio. Revista ANDES Antropología e Historia 16: 147-165.

ALFARO, E; ALBECK, ME; DIPIERRI, JE; MORALES, JO, VÁZQUEZ, O (2001) Apellidos y estructura poblacional en la Puna de Jujuy. Revista Argentina de Antropología Biológica 3(2): 25.

ALFARO, E; DIPIERRI, JE (1995) Consanguinidad por isonimia y distancia marital en la Provincia de Jujuy. Cuadernos-FHyCS 5:15-17.

ALFARO, E; DIPIERRI, JE (1996) Isonimia, endogamia, exogamia, y distancia marital en la Provincia de Jujuy. Revista Argentina de Antropología Biológica 1(1):41-56.

ALFARO, E; DIPIERRI, JE (1997) Consanguinidad y uniones matrimoniales en poblaciones jujeñas de altura. Rev. Esp. Antrop. Biol. 18: 57-71.

ALFARO, E; DIPIERRI, JE (2000) Estructura demogenética del noroeste argentino: provincias de Jujuy, Catamarca y La Rioja. Cuadernos FHyCS 14: 8.

ALFARO, E; DIPIERRI, JE; ALBECK, ME; MORALES, J (1998 m.s.) Estructura genética por isonimia en poblaciones históricas de la Puna Jujeña. V Congreso de la Asociación Latinoamericana de Antropología Biológica, VI Simposio de Antropología Física "Luis Montané", La Habana, Cuba.

ALFARO, E; DIPIERRI, JE; ALBECK, ME; MORALES, JO (1999 m.s.) Consanguinidad e identidad en el Casabindo Colonial. IV Jornadas Nacionales de Antropología Biológica, San Salvador de Jujuy, Jujuy, Argentina

ALFARO, E; DIPIERRI, JE; RODRÍGUEZ-LARRALDE, A; BARRAI, I (2007) Apellidos y aislamiento en la provincia de Jujuy. En SEPOSAL 2005 Seminario sobre Población y Sociedad en América Latina. Tomo I. Compiladores. Mario Boleda y María Cecilia Mercado. GREDES. Salta

AVENA, S; GOICOECHEA, AS; DUGOUJON, JM; SLEPOY, MG; SLEPOY, AS; CARNESE; FR (2001) Análisis antropogenético de los aportes indígena y africano en muestras hospitalarias de la Ciudad de Buenos Aires. Revista Argentina de Antropología Biológica. Vol. 3, No 1.

AZEVEDO E, FREIRE N (1983) Nôme e sobrenomes na intrepretaçao da historia do povo. Ciencia e Cultura 36 (5): 753-758.

AZEVEDO, ES (1980) Anthropological and cultural meaning of family names in Bahia, Brazil. Current Anthropology 21:360-363.

BAILLIET, G; CASTILLA, EE; ADAMS, JP; ORIOLI, MI; MARTÍNEZ MARIGNAC, VL; RICHARD, S; BIANCHI, NO (2001) Correlation between molecular and conventional genealogies in Aicuña: a rural population from North-western Argentina. Hum. Hered. 51:150-159. 
BARRAI, I; BARBUJANI, G; BERETTA, M; MAESTRI, I; RUSSO, I; FORMICA, G; PINTO-CISTERNAS, J (1987) Surnames in Ferrara: distribution, isonymy and levels of inbreeding, Ann. Hum. Biol., 14:415-423.

BARRAI, I; CAVALLI-SFORZA, LL; MORONI, A (1962) Frequencies of pedigrees of consanguineous marriages and mating structure of the population. Ann. Hum. Genet., 25: 347-377.

BARRAI, I; FORMICA, G; SCAPOLI, C; BERETTA, M; VOLINIA, S; BARALE, R; AMBROSINO, P; FONTANA, F (1992) Microevolution in Ferrara: isonymy 1890-1990. Ann. Hum. Biol., 19:371-385.

BARRAI, I; RODRÍGUEZ LARRALDE, A; DIPIERRI, J; ALFARO, E (2005) Análisis de la migración argentina y su distribución espacial por el método isonímico. AEPA "VII Jornadas Argentinas de Estudios de Población. Universidad Nacional de Tucumán, Tafí del Valle, provincia de Tucumán, 2003", AEPA, Buenos Aires. Tomo I, pp.351-364.

BARRAI, I; RODRÍGUEZ-LARRALDE, A; MAMOLINI, E; MANNI, F; SCAPOLI, C (2000) Elements of the surname structure of Austria. Ann. Hum. Biol. 27: 607-622.

BARRAI, I; RODRÍGUEZ-LARRALDE, A; MAMOLINI, E; MANNI, F; SCAPOLI, C (2001) Isonymy structure of the USA population. Am. J. Phys. Anthrop. 114: 109-123.

BARRAI, I; RODRÍGUEZ-LARRALDE, A; MAMOLINI, E; SCAPOLI, C (1999) Isonymy and isolation by distance in Italy. Hum. Biol. 71: 947-961.

BARRAI, I; RODRÍGUEZ-LARRALDE, A; MANNI, F; SCAPOLI, C (2002) Isonymy and isolation by distance in the Netherlands. Hum. Biol. 74: 263-281.

BARRAI, I; SCAPOLI, C; BERETTA, M; NESTI, C; MAMOLINI, E; RODRÍGUEZ-LARRALDE A (1996) Isonymy and the genetic structure of Switzerland. I. The distribution of surnames. Ann. Hum. Biol. 23: 431-455.

BARRAI, I; SCAPOLI, C; BERETTA, M; NESTI, C; MAMOLINI, E; RODRÍGUEZ-LARRALDE, A (1997) Isolation by distance in Germany. Hum. Genet. 100: 684.

BARRAI, I; SCAPOLI, C; CANELLA, R; FORMICA, G; BARALE, R; BERETTA, M (1991) Isonymy in records of births and deaths in Ferrara. Ann. Hum. Biol., 18(5):395-404.

BEJARANO, IF; DIPIERRI, JE; ANDRADE, A; ALFARO, EL. (2009) Geographic altitude, surnames, and height variation of Jujuy (Argentina) conscripts. Am J Phys Anthropol. 138(2): 158-163.

BERETTA, M; MAMOLINI; E; RAVANI, A; VULLO, C; SCAPOLI, C; BARALE, R; RODRÍGUEZ-LARRALDE, A; BARRAI, I (1993). Comparison of structures from frequencies of genes and surnames in the population of Ferrara. Hum. Biol., 65: 225-235. 
BINAYÁN CARMONA, N (1999) Historia Genealógica Argentina. Ed Emecé. Argentina.

BIONDI, G; LASKER, GW; RASPE, P; MASCIE-TAYLOR, CGN (1993) Inbreeding coefficients from the surnames of grandparents of the schoolchildren in Albanian-speaking Italian villages. J. Biosoc. Sci., 25: 63-71.

BOLEDA, M; MERCADO, C (1991) Introducción a la demografía histórica del noroeste argentino (NOA). Cuadernos del GREDES, 11, 6-59.

BOLSI, AS (1994) La población americana en el tiempo de la colonia. Población y Sociedad No 1: 211-222.

BOMAN, E [1908] (1992) Antigüedades de la región andina de la República Argentina y del desierto de Atacama. EDIUNJU.

BRONBERG, RA; DIPIERRI, JE; ALFARO, EL; BARRAI, I; RODRÍGUEZLARRALDE, A; CASTILLA, EE; BAILLIET, G (2009) Isonymy Structure of Buenos Aires City. Hum Biol 81(4): 59-73

CALDERÓN, R (1989) Consanguinity in the Archbishopric of Toledo, Spain, 1900-79: Types of consanguineous mating in relation to premarital migration and its effects on inbreeding levels. J. Biosoc. Sci., 21: 253-266.

CALDERÓN, R; PEÑA, JA; MORALES, B; GUEVARA; JI (1993) Inbreeding patterns in the Basque Country (Alava province, 1831-1980). Hum. Biol., 65: 743770 .

CANALS FRAU, S (1940) La distribución geográfica de los aborígenes del Noroeste Argentino. Anales de Etnografía Americana 1:217-233. Univ. Nac. de Cuyo.

CARRIZO, JA (1989) Cancionero popular de Jujuy. Serie Jujuy en el Pasado. Universidad Nacional de Jujuy.

CASTRO DE GUERRA, D (1987) Uso de apellidos para determinar estructura de población en pueblos negros de la costa norcentral de Venezuela. Tesis de Grado Magister Scientiarum en Biología. Centro de Estudios Avanzados. IVIC, Caracas.

CASTRO DE GUERRA, D; RODRÍGUEZ-LARRALDE, A; PINTOCISTERNAS, J (1990) Distribución de los apellidos y estructura de población en algunas poblaciones de origen negro de la zona costera norcentral de Venezuela. Acta Científica Venezolana 41:241-249.

CAVALLI-SFORZA, LL; BODMER, WF (1981) genética de las Poblaciones Humanas. Omega, Barcelona

CAVALLI-SFORZA, LL; MENOZZI, P; PIAZZA, A (1994) The history and geography of human genes. Princeton University Press, New Jersey.

CHAKRABORTY, R; BARTON, SA; FERRELL, R; SCHULL, W (1989) Ethnicity determination by names among the Aymara of Chile and Bolivia. Hum. Biol., 61(2):159-177. 
COLANTONIO, SE (1998) Estructura poblacional a partir de apellidos y migración: Departamento Pocho (Provincia de Córdoba, Argentina) Revista Española de Antropología Biológica. Vol. 19.

COLANTONIO, SE; FUSTER, V; FERREYRA MC; LASCANO, JG (2006) Isonymic relationships in ethno-social categories (Argentinean Colonial period) including illegitimate reproduction. J Biosoc Scie 38: 381-398.

COLANTONIO, SE; FUSTER, V; GHIRARDI, MM (2007a) Córdoba (Argentina) en 1813: relaciones de parentesco y movimientos poblacionales descubiertos a través de los apellidos. Rev Esp Antrop Fís 27: 103-112.

COLANTONIO, SE; FUSTER, V; KÜFFER, C (2007b) Isonymous Structure in the White Population of Córdoba, Argentina, in 1813. Hum Biol 79(5):491-500.

COLANTONIO, SE; FUSTER, V; KÜFFER, C (2008) El uso de los apellidos como marcador de procesos biológicos y sociales: recientes aportes a la Demografía Histórica. Revista de Demografía Histórica XXVI (I): 205-223.

COLANTONIO, SE; FUSTER, V; MARCELLINO, AJ (2002) Inter-population relationship by isonymy: Application to ethno-social groups and illegitimacy. Hum Biol 74: 871-878.

COLANTONIO, SE; LASKER, GW; KAPLAN, BA; FUSTER, V (2003) Use of Surname Models in Human Population Biology: A Review of Recent Developments. Hum Biol 75(6): 785-807.

COSTA-JUNQUIERA, M; MARTINEZ CAMPOS, M; DIPIERRI, J; BEJARANO, I; ALFARO, E (2000) Evolución de la consanguinidad y parentesco por isonimia en la Puna de Atacama. Revista Española de Antropología Biológica. 21:21-28.

CROW, JE; MANGE, AP (1965) Measurements of inbreeding from the frequency of marriages between persons of the same surnames. Eugenic Quarterly 12:190-203.

DANUBIO, ME; PETTENER, D (1997) Marital structure of the Italian community of Boston, Massachusetts, 1880-1920. J. Biosoc. Sci., 29: 257-269.

DE LUCA, RM (1997) Historia de los Apellidos Argentinos. Editorial Skorpio.

DE SILVESTRI, A; GUGLIELMINO, CR (2004) Sicilian provinces: population subdivisions revealed by surname frequencies. Hum Biol 76: 901-920 .

DEMARCHI, D; CLARIA, DM; DIPIERRI, JE; GARDENAL, CN (2000) Genetic structure of native populations from Argentina inabiting at different altitudes. Hum. Biol. 72(3):519-525.

DIPIERRI, JE (2004) Apellidos del Noroeste Argentino: Distribución, Isonimia, Estructura y Dinámica Poblacional. Tesis de Maestría en Teoría y metodología de las Ciencias Sociales. Facultad de Humanidades y Ciencias Sociales. Universidad Nacional de Jujuy. 
DIPIERRI, JE, ALFARO E (1996) Indicadores de aislamiento y sedentarismo en poblaciones de altura de la Provincia de Jujuy (República Argentina). Acta Científica Venezolana 47:178-184.

DIPIERRI, JE; ALFARO GÓMEZ, EL; RODRÍGUEZ LARRALDE, A; BARRAI, I (2006) Apellidos, aislamiento y sedentarismo en el Noroeste Argentino. En: Diversidad Biológica y Salud Humana. Editor: Andrés MartínezAlmagro Andreo. Quaderna Editorial. Murcia, España. Pág. 77-85.

DIPIERRI, JE; ALFARO, E (1996a) Indicadores de aislamiento y sedentarismo en poblaciones de altura de la Provincia de Jujuy (República Argentina). Acta Científica Venezolana 47(3):178-184.

DIPIERRI, JE; ALFARO, E; BEJARANO, I (1999) Surnames, ABO system and miscegenation in highlands population of province of Jujuy (Northwest Argentine). Homo 50(1): 14-20.

DIPIERRI, JE; ALFARO, E; BEJARANO, IF (2000) Cambio socioeconómico y evolución del equilibrio sexual terciario en la provincia de Jujuy. Revista Pacarina Arqueología y Etnografía Americana 1 (1): 49 - 54.

DIPIERRI, JE; ALFARO; EL, SCAPOLI, C; MAMOLINI, E; RODRIGUEZLARRALDE, A; BARRAI, I (2005) Surnames in Argentina - A Population Study Through Isonymy. Am J Phys Anthropol 128(1): 199-209.

DIPIERRI, JE; OCAMPO, SB; LOMBARDO, A (1994) Parentesco intra e interpoblacional por isonimia en poblaciones de altura de la Provincia de Jujuy (Rep. Arg.) Mendeliana 10(2):133-149.

DIPIERRI, JE; OCAMPO, SB; RUSO, A (1991) An estimation of inbreeding from isonymy in the historical (1734-1810) population of the Quebrada de Humahuaca. J. Bios. Sci. (England), 23(1):23-31.

DIPIERRI, JE; RODRÍGUEZ LARRALDE, A; ALFARO, EL; ANDRADE, A; CHAVES, E; BARRAI, I (2005) Distribución de apellidos y migración en el Noroeste Argentino. Antropo 10: 35-50. www.didac.ehu.es/antropo.

DIPIERRI, JE; RODRÍGUEZ-LARRALDE, A; ALFARO, E; BARRAI, I (2007) Isonimyc Structure of the Argentine Northwest. Ann Human Biol 34(4): 498-503.

ELIÁN, JS (2001) El gran libro de los apellidos y la heráldica. American Bar Association.

ERDMAN, LE (1964) Patronimia del Noroeste Argentino. Rev. Instituto de Antropología (Universidad Nacional de Córdoba), Tomo III:121-134.

FABERMAN, J; GIL MONTERO, R (2002) Los pueblos de indios del Tucumán colonial: pervivencia y desestructuración. Universidad Nacional de Quilmas - EdiUnju, Argentina.

FAURE, R; RIBES, MA; GARCIA, A (2001) Diccionario de Apellidos Españoles Madrid: Espasa Calpe.

FIDALGO, A (1988) ¿De quién es la Puna? Editorial Digus, Jujuy. Argentina. 
FISHER, RA (1943) The relation between the number of species and the number of individuals in a random sample of animal population. J Anim Ecol 12:42-58.

FUSTER, V (2005) Biodemografía. En: Rebato, E; Susanne, C y Chiarelli, B (Eds) Para comprender La Antropología Biológica. Evolución y Biología Humana. Editorial Verbo Divino. Navarra, España.

GENTILE, M (1989) Correspondencias etnohistóricas de dos estilos alfareros prehispánicos puneños: evidencias, hipótesis y perspectivas. En: El Imperio Inka. Comechingonia 9:219-243. Número especial. Córdoba.

GIBSON, C (1990) Las sociedades indias bajo el dominio español. En: Historia de América Latina. Ed: Leslie Bethell. Cambridge University Press-Ed. Crítica, Barcelona.

GIL MONTERO, R (1997) Unidades domésticas con residencias múltiples: puna de Jujuy (Argentina), fines del siglo XVIII. Andes 8: 47-76. Centro Promocional de Investigaciones en Historia y Antropología. Salta.

GIL MONTERO, R (2007) La Puna: Población, recursos y estrategias. En: Teruel, A; Lagos, M Jujuy en la historia. De la colonia al siglo XX. $2^{\mathrm{a}}$ edición. EdiUNJu. Argentina.

GINZBURG, C; PONI, C (1991) El nombre y el cómo: intercambio desigual y mercado historiográfico. Historia Social 10: 63-70.

GONZALEZ-MARTIN, A; GARCIA-MORO, C; HERANDEZ, M; MORAL, P (2006) Inbreeding and Surnames: A Projection Into Easter Island's Past. Am J Phys Anthropol 129: 435-445.

GUGLIELMINO, CR; ZEI, G; CAVALLI-SFORZA, LL (1991 Genetic and cultural transmission in Sicily as revealed by names and surnames. Hum. Biol. 63(5):607-627.

HENRY, L (1983) Manual de demografía histórica. Ed Crítica, Barcelona.

HUSSAIN, R; BITTLES, A (1998) The prevalence and demographic characteristics of consanguineous marriages in Pakistan. J. Biosoc. Sci., 30: 261275.

JOBLING, MA (2001) In the name of the father: Surnames and genetics. Trends in Genetics 17(6): 353-357.

JORDE, LB; PITKÄNEN, KJ (1991) Inbreeding in Finland. Am. J. Phys. Anthropol., 84: 127-139.

KARLIN, S; MACGREGOR, J (1967) The number of mutant forms maintained in a populations. Proceedings of the Fifth Berkeley Symposium on Mathematics, Statistics and Probability, 4, pp 415-438.

KEYFITZ, N; FLIEGER, W (1971) Population. Facts and Methods of Demography. Freeman and Company. USA 
KRAPOVICKAS, P (1978) Los indios de la Puna en el Siglo XVI, Relaciones 12: 71-93, Bs. As.

KRAPOVICKAS, P (1983) Las poblaciones indígenas históricas del sector oriental de la puna. Relaciones 15. Buenos Aires.

KREBS, CJ (1985) Ecología. Estudio de la distribución y abundancia. HARLA, México.

LASKER GW, MASCIE-TAYLOR CGN (1993) Research strategies in human biology: field and survey studies. Cambridge University Press.

LASKER, GW (1977) A coefficient of relationship by isonymy: a method for estimating the genetic relationship between populations. Hum. Biol., 49:489-493.

LASKER, GW (1980) Surnames in the study of Human Biology. Am. Anthropol. 82(3):525-538 .

LASKER, GW (1985) Surnames and Genetic Structure. Cambridge University Press.

LASKER, GW (1991) Revisión: datos sobre los apellidos hispanoamericanos en los estudios de biología humana. An. Antrop. (México):107-128.

LAUDERDALE, D; KESTENBAUM, B (2000) Asian American ethnic identification by surname. Population Research and Policy Review 19(3):pp. 283300 .

LITTLE, BB; MALINA, RM (2005) Inbreeding avoidance in an isolated indigenous Zapotec community in the valley of Oaxaca, southern Mexico. Hum Biol 77: 305-316.

LOCKHART, J (1990) Organización y cambio social en la América española colonial. En: Historia de América Latina. Ed: Leslie Bethell. Cambridge University Press-Ed. Crítica, Barcelona.

LÓPEZ, C (2006) El espacio y la gente: la dinámica sociodemográfica de la población del Tucumán tardo y poscolonial. Andes 17(6).Disponible en Internet: http://redalyc.uaemex.mx/redalyc/src/inicio/ArtPdfRed.jsp?iCve=12701706.

LORANDI, AM (1997) El Tucumán colonial y Charcas. Serie Libros. Facultad de Filosofía y Letras. Universidad de Buenos Aires.

LORANDI, AM; OTONELLO, M (1992) Argentina: completando la historia. Ciencia e Investigación. Tomo 45 (2):84-99.

LOZA, CB (1997) ¿Estatuto fiscal contra identidad étnica? Criterios de diferenciación social en el sur del Perú (1569-1579). CBC 15, (2): 387-419. CUSCO - PERU.

MACBETH, H; COLLISON, P (2002) Human Populations Dynamics. CrossDisciplinary Perspectives. Cambridge University Press.

MADRAZO, GB (1982) Hacienda y encomienda en los Andes. La puna argentina bajo el Marquesado de Tojo. Siglos XVII a XIX. Fondo Editorial, Buenos Aires. 
MADRAZO, GB (1991) Cambio y permanencia en el Noroeste Argentino. El caso de Jujuy a mediadios del siglo XIX. Andes 4: 93-141.

MANNI, F; TOUPANCE, B; SABBAGH, A; HEYER, E (2005) New method for surname studies of ancient patrilineal population structures, and posible application to improvement of Y-chromosome sampling. Am J. Phys Anthropol 126:214-228.

MANRUBIA, SC; ZANETTE, DH (2002) At the boundary between biological and cultural evolution: the origin of surnames distributions. J. Theor. Biol. 216(4):461477.

MARTÍNEZ, JL (1991) Acerca de las etnicidades en la Puna Arida en el siglo XVI. II Congreso Internacional de Etnohistoria. Coroico.

MARTÍNEZ, JL (1992) España. Como vinieron de paz los yndios de Casabindo e se bautizaron el cazique su muger e hijos. AGI Patronato 188 No1. (Año 1557). Estudios Atacameños 10:11. Universidad Católica del Norte. San Pedro de Atacama. Chile.

MARTÍNEZ, JL (1998) Pueblos del chañar y el algarrobo. Los atacamas en el siglo XVII. Ediciones de la Dirección de Bibliotecas, Archivos y Museos. Santiago. Chile.

MASCIE-TAYLOR, CGN; LASKER, GW (1990) The distribution of surnames in England and Wales: A model for genetic distribution. Man 25(3): 521-530.

MASCITTI, V; DIPIERRI, JE; OCAMPO, SB (1991) Sistema ABO, apellidos y miscegenación en poblaciones a diferentes niveles altitudinales. Cuadernos FHyCS N 2: 63-66.

MEDINACELI, X (2003) ¿Nombres o apellidos?. El sistema nominativo aymara Sacaca, siglo XVII. Instituto de Estudios Bolivianos, La Paz, Bolivia.

MORALES, J; ALFARO, E; DIPIERRI, JE; BEJARANO, IF (2003) Apellidos y sistema $\mathrm{Rh}(\mathrm{d} / \mathrm{D})$ en poblaciones jujeñas. Revista Argentina de Antropología Biológica 5(2): 7-14.

MORNER, M (1987) Terratenientes y campesinos latinoamericanos y el mundo exterior durante el período nacional. En: Duncan, $\mathrm{K}$ y Rutledge, I (Comp) La tierra y la mano de obra en América Latina. Fondo de la Cultura Económica, México.

MOURRIERAS, B; DARLU, P; HOCHEZ, J; HAZOUT, S (1995) Surnames distribution in France: a distance analysis by a distorted geographical map. Ann. Hum. Biol. 22(3):183-198.

NANCHAHAL, K; MANGTANI, P, ALSTON, M; DOS SANTOS SILVA, I (2001) Development and validation of a computerized South Asian Names and Group Recognition Algorithm (SANGRA) for use in British Health-related studies. Journal of Public Health Medicine 23(4):pp. 278.

NARDI, RLJ (1979) El kakán, lengua de los Diaguitas. Sapiens 3:1-33. Museo Arqueológico O.F.A. Menghin. Chivilcoy. 
NARDI, RLJ (1986) Observaciones sobre nombres indígenas documentados en el Noroeste Argentino. En: Gentile "El Control Vertical en el NOA - Notas sobre los Atacamas en el Valle Calchaquí. C. Quirós, Editor. Bs. As.

NICOLAS, V; ZAGARRA, S; POZO M (2005) Los ayllus de Tinkipaya. Estudio etnohistórico de su organización social y territorial. Programa de Investigación Estratégica en Bolivia. Investigaciones regionales, Potosí. La Paz Bolivia.

NÚÑEZ, L; DILLEHAY, T (1995) Movilidad Giratoria, Armonía Social y Desarrollo en los Andes Meridionales: Patrones de Tráfico e Interacción Económica. Segunda Edición. Universidad Católica del Norte, Antofagasta.

OCAMPO, SB; DIPIERRI, JE; RUSO; A; MARCELLINO, AJ (1988) Estimación del coeficiente de parentesco (Ri) de la población histórica (1734-1810) de la Parroquia de Humahuaca (Pcia. de Jujuy, Rep. Arg.) Bioanthropos 1:43-52.

PALOMEQUE, S (1994) Intercambios mercantiles y participación indígena en la "Puna de Jujuy" a fines del Período Colonial. Andes 6, UNSa.

PALOMEQUE, S. e.p. Los antiguos habitantes de la puna de Jujuy: La historia de los caciques de Casabindo y Cochinoca. EdUNJu.

PALOMEQUE, S; TEDESCO, E. m.s. Padrón de Casabindo y Cochinoca de 1654. Transcripción.

PALOMEQUE, SR (2006) Historia de los señores étnicos de Casabindo y Cochinoca. Andes 17: 139-194. CEPIHA. Salta

PAVESI, A; PIZZETTI, P; SIRI, E; LUCCHETTI, E; CONTERIO, F (2003) Brief communication: coexistence of two distinct patterns in the surname structure of Sicily. Am J Phys Anthropol 120: 195-199.

PAZ, G (1992) Campesinos, terratenientes y Estado. Control de tierras y conflicto en la Puna de Jujuy a fines del siglo XIX. En: Isla, A (Comp) Sociedad y articulación en las tierras altas jujeñas. Editorial MLAL, Argentina.

PETTENER, D (1985) Consanguineous marriages in the upper Bologna Appenine (1565-1980): Microgeographic variations, pedigree structure, and correlation of inbreeding secular trend with changes in population size. Hum. Biol., 57: 267-288.

PIAZZA, A; RENDINE, N; ZEI, G; MORONI, A; CAVALLI-SFORZA, LL (1987) Migration rates of human populations from surname distributions. Nature 329: 714-716.

PINEDA-SANTÍS, H; ARCOS-BURGOS, M; BRAVO-AGUIAR, ML (1999) Aproximación a la estructura genética de la población de Granada, Antioquia (Colombia) a través de isonimia. Actual. Biol. 21: 29-36.

PINTO CISTERNAS, J; CASTRO DE GUERRA, D (1988) Utilidad de los apellidos en estudios de biología humana. Rev. Med. Chile 116:1191-1197. 
PINTO CISTERNAS, J; PINEDA, I; BARRAI, I (1985) Estimation of inbreeding by isonymy in Iberoamerican populations: an extension of the method of Crow and Mange. Am. J. Hum. Genet., 37:373-385.

PLATT, LD (1996) Hispanic surnames and family history. Baltimore. Genealogical Publishing Co.

PLATT, T; BOUYSSE-CASSAGNE, T; HARRIS, O (2006) Qaraqara-Charka. Mallku, Inka y Rey en la provincial de Charcas (siglos XV-XVII). IFEA/Plural editores/FBCB/University of St. Andrews.

PRESSAT, R (1983) El análisis demográfico. Métodos, resultados, aplicaciones. Fondo de Cultura Económica, Mexico.

PRESTA, AM (2001) "Hermosos, fértiles y abundantes". Los valles centrales de Tarija y su población en el siglo XVI. En Historia, Ambiente y Sociedad en Tarija, Bolivia. Stephan Beck, Narel Paniagua y David Preston Editores. Instituto de Ecología. La Paz.

RAE (2009) Real Academia Española. Diccionario de la lengua española. Disponible en: $\underline{w w w . r a e . e s}$

RAWLING, CP (1973) A study of isonymy. In: Genetic variation in Britain, Ed. Roberts, DF, Sunderland, E. Taylor and Francis, London, pp. 83-93.

RELETHFORD, JH (1988) Estimation of kinship and genetic distance from surnames. Hum. Biol., 60:475-492.

RODRIGUEZ LARRALDE, A (1990) Distribución de los apellidos y su uso en la estimación de aislamiento y sedentarismo en los municipios del estado Lara, Venezuela. Acta Científica Venezolana 41:163-170.

RODRÍGUEZ-LARRALDE, A (1986) Estimadores de aislamiento en base a distribución de apellidos. XXXVI Convención Anual de AsoVAC, Valencia, Venezuela.

RODRÍGUEZ-LARRALDE, A (1993) Genetic Distance estimated through surname frequencies of 37 counties from the State of Lara, Venezuela. J. Biosoc. Sci. 25: 101-110.

RODRÍGUEZ-LARRALDE, A (1997) Dendrograma basado en la frecuencia de apellidos como indicador de aislamiento y migración en el Estado Guárico, Venezuela. Estudios de Antropología Biológica. Ramos Rodríguez, R.M. y Peña Reyes, M.E., Eds. Univ. Nac. Autónoma de México, Inst. Inv. Antrop. 8: 259-271.

RODRÍGUEZ-LARRALDE, A; BARRAI, I (1997a) Estructura genética por isonimia de los Estados Anzoátegui y Trujillo, Venezuela. Rev. Esp. Antrop. Biol. 18: 39-56.

RODRÍGUEZ-LARRALDE, A; BARRAI, I (1997b) Estructura genético poblacional del Estado Guárico, Venezuela, estimada a través de isonimia. Acta Cient. Venez., 48: 160-166.

RODRÍGUEZ-LARRALDE, A; BARRAI, I (1997c) Isonymy structure of Sucre and Táchira: Two Venezuelan States. Hum. Biol. 69: 715-731. 
RODRÍGUEZ-LARRALDE, A; BARRAI, I (1998a) Estudio genético demográfico del Estado Zulia, Venezuela, a través de isonimia. Acta Cient. Venez., 49: 134-143.

RODRÍGUEZ-LARRALDE, A; BARRAI, I; ALFONZO JC (1993a) Isonymy structure of four Venezuelan States. Ann. Hum. Biol., 20: 131-145.

RODRÍGUEZ-LARRALDE, A; BARRAI, I; NESTI, C; MAMOLINI, E; SCAPOLI, C (1998b) Isonymy and isolation by distance in Germany. Hum. Biol. 70: 1041-1056.

RODRÍGUEZ-LARRALDE, A; CASIQUE, J (1993) Estructura genético demográfica del Estado Aragua, Venezuela, estimada a través de apellidos. Acta Cient. Venez., 44: 224-232.

RODRÍGUEZ-LARRALDE, A; FORMICA, G; SCAPOLI, C; BARETTA, M; MAMOLINI, E; BARRAI, I (1993b) Microevolution in Perugia: Isonymy 18901990. Ann. Hum. Biol., 20: 261-274.

RODRÍGUEZ-LARRALDE, A; GONZÁLEZ-MARTÍN, A; SCAPOLI, C; BARRAI, I (2003) The names in Spain: a study of the isonymy structure of Spain. Am. J. Phys. Anthrop. 121(3):280-292.

RODRÍGUEZ-LARRALDE, A; MORALES, J; BARRAI, I (2000) Surname frequency and the isonymy structure of Venezuela. Am. J. Hum. Biol. 12: 352362.

RODRÍGUEZ-LARRALDE, A; PAVESI, A; SCAPOLI, C; CONTERIO, F; SIRI, G; BARRAI, I (1994). Isonymy and the genetic structure of Sicily. J. Biosoc. Sci., 26: 9-24.

RODRÍGUEZ-LARRALDE, A; SCAPOLI, C; BERETTA, M; NESTI, C; MAMOLINI, E; BARRAI, I (1998c) Isonymy and the genetic structure of Switzerland. II. Isolation by distance. Ann. Hum. Biol. 25: 533-540.

ROJAS, R (1913) Acta Capitular de Jujuy. Tomo 1.

RUTLEDGE, I (1992) La rebelión de los campesinos indígenas de las tierras altas del Norte Argentino, 1872-75. En Isla, A (Comp) Sociedad y articulación en las tierras altas jujeñas. Editorial MLAL, Argentina.

SALOMON, F, Y S. GROSBOLL (1990) Nombres y gente en el Quito incaico: recuperación de un proceso histórico indocumentado a través de la antroponimia y la estadística. En C. Landázuri (comp.) Visita y numeración de los pueblos del valle de los Chillos 1551-1559. Marka. Ed. Abya-Yala. Quito.

SÁNCHEZ, S (1996 m.s.) Fragmentos de un tiempo largo. Tilcara entre fines del siglo XVI y principios del XIX. Tesis de Licenciatura. Facultad de Humanidades y Ciencias Sociales. Universidad nacional de Jujuy.

SÁNCHEZ ALBORNÓZ N (1974) La dénomination des personnes en Amérique Espagnole.Nôme et Prénoms. Ordina, Liége. 
SAWCHUK, A; HERRING, DA (1989) A socioeconomic analysis of secular trends in isonymy in the jew ish community of Gibraltar: 1820 to 1939. International Journal of Anthropology 4: 209-218.

SERRANO, A (1930) Los primitivos habitantes del Territorio Argentino. Librería y Editorial "La Facultad", Bs. As.

SICA, G (2006) Del Pukara al Pueblo de indios. El proceso de construcción de la sociedad indígena colonial en Jujuy, Argentina. Siglo XVII. Tesis Doctoral. Facultad de Geografía e Historia. Universidad de Sevilla.

SMITH, MT (2002) Isonymy analysis: the potential for application of quantitative analysis of surname distributions to problems in historical research. Human Biology and History, London: Taylor and Francis.

SMITH, MT; BITTLES, AH (2002) Genetic structure of the Ards Peninsula, Northern Ireland: evidence from civil registers of marriage 1840-1911. Hum Biol 74: 507-534.

SOKAL, RR; HARDING, RM; LASKER, GW; Mascie-TAYLOR, CGN (1992) A spatial análisis of 100 surnames in England and Wales. Ann Hum Biol 19(5): 445-476.

TAPINOS, G (1988) Elementos de demografía. Espasa-Calpe S. A. Madrid.

TERUEL, A (1993) Población, mano de obra y transformación social en Jujuy a fines del siglo XIX y comienzos del XX. Jujuy en la historia, Avances de Investigación I.

VALLS, A (1982) Antropología de la consanguinidad. Ed. Universidad Complutense, Madrid. España

VARELA, TA; LODEIRO, R; FARIÑA, J (1997) Evolution of consanguinity in the Archbishopric of Santiago de Compostela (Spain) during 1900-1979. Hum. Biol., 69: 517-531.

VASQUEZ, N.O. m.s. Padrón de Casabindo 1688. Transcripción paleográfica.

VERNAY, M (2001) Repartition géographique des patronymes et structure génetique: le département de l'Ârdèche au début du Xxe siècle. C.R. Acad Sci Paris, Sciences de la vie 324: 589-599.

VIGNATI, MA (1931) Los elementos étnicos del Noroeste Argentino. Notas preliminares del Museo de La Plata 1, 2a entrega:115-156. UNLP

WILSON, S (1998) The Means of Naming. A social and cultural history of personal naming in western Europe. UCL Press Limited, London, UK.

WRIGHT, S (1951) The genetical structure of populations. Ann. Eugen. 15:323354.

ZABURLIN, MA (2009) Arquitectura y organización urbana en el Pucara de Tilcara (Jujuy, Argentina). En: El hábitat prehispánico. Ed. Albeck, ME; Scattolin, MC y Kornstamje, MA. En prensa. 
ZANOLLI, CE (2005) Tierra, encomienda e identidad: Omaguaca (1540-1638). Colección Tesis Doctorales. Soc. Arg. de Antropología.

ZEI G, GUGLIELMINO MATESSI R, SIRI E, MORONI A, CAVALLISFORZA LL (1983) Surnames in Sardinia. I. Frequency distribution for neutral alleles and genetic population structure. Ann. Hum. Genet., 47:329-352. 


\section{ANEXO}

LISTADO DE ANTROPÓNIMOS Y SU FRECUENCIA EN CADA UNO DE LOS DOCUMENTOS ANALIZADOS 


\section{Casabindo 1654}

\begin{tabular}{|c|c|c|c|c|c|}
\hline $\begin{array}{l}\text { Nombres } \\
\text { femeninos }\end{array}$ & $\begin{array}{c}\text { Cantidad } \\
\text { portadores }\end{array}$ & \begin{tabular}{|l|}
$\begin{array}{l}\text { Nombres } \\
\text { masculinos }\end{array}$ \\
\end{tabular} & $\begin{array}{c}\text { Cantidad } \\
\text { portadores }\end{array}$ & \begin{tabular}{|l|}
$\begin{array}{l}\text { Nombres } \\
\text { masculinos }\end{array}$ \\
\end{tabular} & $\begin{array}{c}\text { Cantidad } \\
\text { portadores }\end{array}$ \\
\hline ALAY & 4 & ABICHOCOAR & 4 & POCAPOCA & 14 \\
\hline ANALAY & 1 & ALABAR & 3 & PUPUCA & 1 \\
\hline ASLI & 5 & ALARCAQUI & 1 & PUYAPIRCA & 1 \\
\hline AUCAY & 1 & AVRACAITE & 3 & QUESIRAL & 1 \\
\hline AYI & 1 & BARCONDI & 10 & QUIPILDOR & 19 \\
\hline AYUNTA & 1 & BILTI & 20 & QUISLIN & 1 \\
\hline BASAMA & 10 & CACHA & 2 & RENXEL & 1 \\
\hline CAQUI & 6 & CACHI & 7 & SOCOMBA & 1 \\
\hline CHACHAL & 1 & CACHICABIA & 1 & SUMBAYM & 3 \\
\hline CHALTAGUA & 5 & CACHISUMBA & 5 & TABARCACHI & 8 \\
\hline CHALTAU & 9 & CAPOTE & 1 & TABARCONDI & 2 \\
\hline CHIBALTAU & 9 & CARAPURA & 2 & TABARSUPE & 2 \\
\hline COCAR & 1 & CARUPAR & 1 & TAGUAR & 1 \\
\hline GUASAMAYA & 1 & CATAGUA & 1 & TAPAGUA & 1 \\
\hline LINGA & 1 & CATAY & 1 & TEMES & 1 \\
\hline NALAY & 27 & CAYCONDE & 2 & TINTI & 3 \\
\hline OCAY & 2 & $\mathrm{CHACHI}$ & 2 & TOLAY & 4 \\
\hline ORALAS & 1 & CHANCHI & 1 & TUBENAS & 1 \\
\hline PULU & 1 & CHILLACA & 1 & TUCUNAS & 5 \\
\hline SEMES & 1 & CHIRITULAI & 1 & YONAR & 6 \\
\hline SULAPA & 37 & CHOAR & 1 & & \\
\hline TALTAO & 1 & CHOCOAR & 17 & & \\
\hline TANTER & 2 & CHUCHULAMAS & 1 & & \\
\hline TEMES & 17 & ECACHI & 1 & & \\
\hline TILCO & 3 & LAISE & 2 & & \\
\hline TUCAY & 1 & LAMAS & 26 & & \\
\hline UCAY & 7 & LAMASCONDI & 1 & & \\
\hline ULAY & 1 & LAYAPANA & 1 & & \\
\hline VICAY & 1 & LAYSE & 1 & & \\
\hline VILCO & 1 & LIQUIN & 4 & & \\
\hline YI & 1 & MACHANI & 1 & & \\
\hline YLLIMSE & 3 & PATAGUA & 5 & & \\
\hline
\end{tabular}


Casabindo 1688

\begin{tabular}{|l|c|l|c|}
\hline $\begin{array}{l}\text { Nombres } \\
\text { femeninos }\end{array}$ & $\begin{array}{c}\text { Cantidad } \\
\text { portadores }\end{array}$ & $\begin{array}{l}\text { Nombres } \\
\text { masculinos }\end{array}$ & $\begin{array}{c}\text { Cantidad } \\
\text { portadores }\end{array}$ \\
\hline ABICHOCOAR & 3 & ABICHOCOAR & 5 \\
\hline ALARCAQUI & 1 & ALABAR & 6 \\
\hline ASLI & 4 & ALARCAQUI & 4 \\
\hline CAQUI & 1 & ALEJANDRO & 1 \\
\hline CHALTABA & 3 & AURACAITI & 1 \\
\hline CHALTAO & 1 & BENTURA & 1 \\
\hline CHIGUALTAO & 6 & BERNARDO & 1 \\
\hline CLEMENCIA & 1 & CACHI & 6 \\
\hline GUAICHO & 1 & CACHISUMBA & 8 \\
\hline GUARCONDE & 3 & CAICONDE & 2 \\
\hline GUASAMA & 4 & CHOCOAR & 9 \\
\hline LAMAS & 2 & GUARCONDE & 13 \\
\hline LIQUIN & 2 & LACSI & 5 \\
\hline NALAI & 29 & LAMAS & 14 \\
\hline POCAPOCA & 1 & LIQUIN & 7 \\
\hline QUESLA & 1 & PATAGUA & 6 \\
\hline SIMBAINI & 1 & POCAPOCA & 7 \\
\hline SISA & 1 & POCO & 3 \\
\hline SULAPA & 29 & QUIPILDOR & 21 \\
\hline TANTER & 2 & QUISPE & 3 \\
\hline TEMES & 4 & SARAPURA & 1 \\
\hline TILCO & 1 & SUMBAINE & 4 \\
\hline UCAI & 12 & TABARCACHI & 12 \\
\hline VILTI & & TABARCONDE & 5 \\
\hline & & TAGUARSUPE & 3 \\
\hline & & TULABA & 3 \\
\hline & VILTI & 9 \\
\hline YONAR & 12 \\
\hline & & & \\
\hline & & & \\
\hline & & & \\
\hline & & & \\
\hline
\end{tabular}


Casabindo 1778 - Apellidos registrados en mujeres

\begin{tabular}{|l|c|l|c|}
\hline Apellidos & $\begin{array}{c}\text { Cantidad } \\
\text { portadores }\end{array}$ & Apellidos & $\begin{array}{c}\text { Cantidad } \\
\text { portadores }\end{array}$ \\
\hline ABICHOCOAR & 11 & TABARCONDE & 3 \\
\hline ALABAR & 31 & TINA & 1 \\
\hline ALANCAI & 22 & TINTI & 16 \\
\hline ALEXO & 3 & TOLAI & 7 \\
\hline BALIOI & 1 & TOLAVA & 9 \\
\hline BARCONDE & 34 & TUCUNAS & 24 \\
\hline CABANA & 1 & VIBAS & 1 \\
\hline CACHI & 8 & VILTI & 45 \\
\hline CACHISUMBA & 7 & YONAR & 8 \\
\hline CACHISUMPI & 1 & ZAJAMA & 1 \\
\hline CAICONDE & 5 & ZARAPURA & 3 \\
\hline CHOCOAR & 10 & ZINTI & 1 \\
\hline CHOROLQUI & 1 & ZUMBAINE & 31 \\
\hline CRUZ & 1 & & \\
\hline CULCUL & 1 & & \\
\hline FINTI & 1 & & \\
\hline FLORES & 1 & & \\
\hline LACCI & 7 & & \\
\hline LAMAS & 12 & & \\
\hline LASARO & 1 & & \\
\hline LIONAR & 1 & & \\
\hline LIQUIN & 14 & & \\
\hline LLOQUE & 5 & & \\
\hline LOPES & 1 & & \\
\hline LUCAS & 5 & & \\
\hline MARCOS & 8 & & \\
\hline ORDONES & 2 & & \\
\hline PATAGUA & 21 & & \\
\hline PELOC & 6 & & \\
\hline PEPE & 1 & & \\
\hline PUCAPUCA & 17 & & \\
\hline QUIPILDOR & 33 & & \\
\hline QUISPI & 19 & & \\
\hline REPE & 5 & & \\
\hline SEBERINA & 1 & & \\
\hline SESARO & 23 & & \\
\hline SILISQUE & & & \\
\hline SISA & & & \\
\hline SOCONBA & & \\
\hline SULAPA & & \\
\hline TABARCACHI & & \\
\hline
\end{tabular}




\section{Casabindo 1778 - Apellidos registrados en varones}

\begin{tabular}{|c|c|c|c|}
\hline Apellidos & Cantidad portadores & Apellidos & Cantidad portadores \\
\hline ABICHOCOAR & 9 & TUCUNAS & 16 \\
\hline ALABAR & 18 & VILTI & 53 \\
\hline ALANCAI & 22 & YONAR & 11 \\
\hline ALEXO & 5 & ZARAPURA & 5 \\
\hline BARCONDE & 48 & ZUMBAINE & 30 \\
\hline $\mathrm{CACHI}$ & 11 & & \\
\hline CACHISUMBA & 9 & & \\
\hline CACHIZUNBAINE & 1 & & \\
\hline CAICONDE & 6 & & \\
\hline CHOCOAR & 26 & & \\
\hline CONDOR & 1 & & \\
\hline FINTI & 3 & & \\
\hline LACCI & 16 & & \\
\hline LAMAS & 9 & & \\
\hline LASARO & 1 & & \\
\hline LIQUIN & 10 & & \\
\hline LLOQUE & 6 & & \\
\hline LUCAS & 10 & & \\
\hline MARCOS & 10 & & \\
\hline OLOFRE & 1 & & \\
\hline ORDOÑES & 3 & & \\
\hline PATAGUA & 26 & & \\
\hline PEDER & 1 & & \\
\hline PELOC & 5 & & \\
\hline PEPE & 3 & & \\
\hline PUCAPUCA & 17 & & \\
\hline QUIPILDOR & 48 & & \\
\hline QUISPI & 19 & & \\
\hline REPE & 5 & & \\
\hline SILISQUE & 1 & & \\
\hline SOCONBA & 5 & & \\
\hline TABARCACHI & 19 & & \\
\hline TABARCONDE & 2 & & \\
\hline TINTI & 17 & & \\
\hline TIRITI & 3 & & \\
\hline TOLAI & 9 & & \\
\hline TOLAVA & 9 & & \\
\hline
\end{tabular}


Casabindo 1786 - Apellidos registrados en mujeres

\begin{tabular}{|c|c|c|c|}
\hline Apellidos & Cantidad portadores & Apellidos & Cantidad portadores \\
\hline ABICHOCOAR & 20 & PELOX & 12 \\
\hline ABRA & 1 & POCO & 1 \\
\hline ABRACAITI & 2 & PUCAPUCA & 23 \\
\hline ALABAR & 46 & QUIPILDOR & 49 \\
\hline ALANCAI & 30 & QUISPI & 25 \\
\hline ALEJANDRO & 3 & RAMOS & 1 \\
\hline ALEJO & 3 & REPE & 4 \\
\hline ARAMAYO & 1 & RUEDA & 1 \\
\hline BARCONDI & 40 & SAJAMA & 2 \\
\hline BARRAN & 1 & SARAPURA & 5 \\
\hline BAUTISTA & 1 & SILISQUE & 3 \\
\hline BEJARANO & 1 & SILISQUI & 1 \\
\hline CABANA & 1 & SOLANO & 1 \\
\hline CACHI & 19 & SUCUMBA & 3 \\
\hline CACHISUMBA & 16 & SUMBAINE & 40 \\
\hline CAICONDI & 2 & TABARCACHI & 20 \\
\hline CALCHAQUI & 1 & TABARCONDI & 8 \\
\hline CARDOSO & 1 & TARITOLAI & 1 \\
\hline CHOCOAR & 13 & TINTI & 30 \\
\hline CHOCOBAR & 6 & TOLAI & 10 \\
\hline CHUICHUI & 1 & TOLAVA & 10 \\
\hline CONDORI & 2 & TUCUNAS & 23 \\
\hline CRUZ & 2 & VALE & 2 \\
\hline CULCUL & 1 & VILCA & 1 \\
\hline DE LA ROSA & 1 & VILTI & 48 \\
\hline DIONISIO & 7 & YONAR & 6 \\
\hline FERNANDEZ & 2 & ZESPEDES & 1 \\
\hline FLORES & 2 & & \\
\hline GUANAXTOLAI & 2 & & \\
\hline LACSI & 14 & & \\
\hline LAMAS & 25 & & \\
\hline LAZARO & 9 & & \\
\hline LEONAR & 8 & & \\
\hline LIQUIN & 20 & & \\
\hline LLOQUE & 6 & & \\
\hline LUCAS & 6 & & \\
\hline MARCOS & 4 & & \\
\hline ORDOÑES & 5 & & \\
\hline PATAGUA & 33 & & \\
\hline PELLISCO & 1 & & \\
\hline
\end{tabular}


Casabindo 1786 - Apellidos registrados en varones

\begin{tabular}{|c|c|c|c|}
\hline Apellidos & Cantidad portadores & Apellidos & Cantidad portadores \\
\hline ABICHOCOAR & 23 & TOLAI & 9 \\
\hline ALABAR & 28 & TOLAVA & 10 \\
\hline ALANCAI & 53 & TUCUNAS & 20 \\
\hline ALEJANDRO & 5 & VILTI & 72 \\
\hline ALEJO & 7 & YONAR & 5 \\
\hline ARAGON & 1 & & \\
\hline BARCONDI & 58 & & \\
\hline CACHI & 13 & & \\
\hline CACHISUMBA & 14 & & \\
\hline CAICONDI & 4 & & \\
\hline CHOCOAR & 27 & & \\
\hline CHOCOBAR & 8 & & \\
\hline DIONISIO & 12 & & \\
\hline GUANAXTOLAI & 1 & & \\
\hline LACSI & 24 & & \\
\hline LAMAS & 19 & & \\
\hline LAZARO & 10 & & \\
\hline LEONAR & 11 & & \\
\hline LIQUIN & 13 & & \\
\hline LLOQUE & 9 & & \\
\hline LUCAS & 8 & & \\
\hline MARCOS & 5 & & \\
\hline MISQUE & 1 & & \\
\hline ORDOÑES & 3 & & \\
\hline PATAGUA & 37 & & \\
\hline PELOC & 1 & & \\
\hline PELOX & 9 & & \\
\hline POCO & 4 & & \\
\hline PUCAPUCA & 31 & & \\
\hline QUIPILDOR & 52 & & \\
\hline QUISPI & 22 & & \\
\hline REPE & 8 & & \\
\hline SARAPURA & 7 & & \\
\hline SILISQUE & 2 & & \\
\hline SUCUMBA & 3 & & \\
\hline SUMBAINE & 41 & & \\
\hline TABARCACHI & 17 & & \\
\hline TABARCONDI & 11 & & \\
\hline TINTI & 45 & & \\
\hline
\end{tabular}


Casabindo 1895- Apellidos registrados en mujeres

\begin{tabular}{|c|c|c|c|c|c|}
\hline Apellidos & $\begin{array}{c}\text { Cantidad } \\
\text { portadores }\end{array}$ & Apellidos & \begin{tabular}{|c|c}
$\begin{array}{c}\text { Cantidad } \\
\text { portadores }\end{array}$ \\
\end{tabular} & Apellidos & \begin{tabular}{|c|c} 
Cantidad \\
portadores
\end{tabular} \\
\hline ABALOS & 20 & GUERRA & 1 & VALDIVIEZO & 2 \\
\hline ABRACAITE & 3 & GUTIERRES & 7 & VILCA & 4 \\
\hline ALABAR & 1 & HUANUCO & 3 & VILTE & 10 \\
\hline ALANCAY & 27 & LAMAS & 15 & ZARATE & 7 \\
\hline ALEJO & 14 & LAZARO & 2 & & \\
\hline ARJONA & 3 & LEAÑO & 3 & & \\
\hline AVENDAÑO & 1 & LIQUIN & 17 & & \\
\hline BALDERRAMA & 8 & MAISARES & 3 & & \\
\hline BALERIO & 3 & MAMANI & 19 & & \\
\hline BARCONTE & 19 & MENDEZ & 5 & & \\
\hline BASQUES & 1 & MENDOZA & 2 & & \\
\hline BEDIA & 5 & MERCADO & 1 & & \\
\hline BELASQUES & 3 & MORALES & 36 & & \\
\hline BENICIO & 16 & OCHOA & 6 & & \\
\hline BURGOS & 2 & OLMOS & 6 & & \\
\hline $\mathrm{CACHI}$ & 4 & PALACIOS & 1 & & \\
\hline CALA & 6 & PATAGUA & 7 & & \\
\hline CALISAYA & 1 & PIÑERO & 5 & & \\
\hline CALLATA & 5 & PRIETO & 1 & & \\
\hline CARI & 1 & PUCA & 5 & & \\
\hline CARRILLO & 7 & PUCAPUCA & 1 & & \\
\hline CASTILLO & 1 & QUIPILDOR & 13 & & \\
\hline CHABEZ & 8 & QUISPE & 4 & & \\
\hline CHAPARRO & 2 & RAMOS & 8 & & \\
\hline CHIRE & 1 & REYES & 1 & & \\
\hline CHOCOBAR & 8 & RUEDA & 1 & & \\
\hline CHOQUI & 9 & SAJAMA & 2 & & \\
\hline CIARES & 11 & SALAS & 2 & & \\
\hline COLQUI & 3 & SALBA & 1 & & \\
\hline CONDORI & 3 & SARAPURA & 12 & & \\
\hline CRUZ & 10 & SERPA & 2 & & \\
\hline CUSI & 13 & SOLANO & 5 & & \\
\hline DIAS & 1 & SOLIS & 1 & & \\
\hline DIONICIO & 4 & SOTO & 17 & & \\
\hline FABIAN & 6 & SUARES & 4 & & \\
\hline FERNANDEZ & 9 & TABARCACHI & 5 & & \\
\hline FLORES & 7 & TINTE & 15 & & \\
\hline GONZA & 1 & TITO & 16 & & \\
\hline GONZALES & 3 & TOCONAS & 7 & & \\
\hline GUANACTOLAY & 4 & TOLABA & 7 & & \\
\hline GUARI & 4 & VALCASER & 1 & & \\
\hline
\end{tabular}


Casabindo 1895 - Apellidos registrados en varones

\begin{tabular}{|c|c|c|c|c|c|}
\hline Apellidos & $\begin{array}{c}\text { Cantidad } \\
\text { portadores }\end{array}$ & Apellidos & \begin{tabular}{|c|c} 
Cantidad \\
portadores
\end{tabular} & Apellidos & $\begin{array}{c}\text { Cantidad } \\
\text { portadores }\end{array}$ \\
\hline ABALOS & 17 & ESQUIVIL & 1 & SARAPURA & 10 \\
\hline ABRACAITE & 2 & ESTRADA & 1 & SERPA & 3 \\
\hline AGUDO & 1 & FABIAN & 2 & SOLANO & 7 \\
\hline AGUIRRE & 2 & FERNANDEZ & 2 & SOLIS & 1 \\
\hline ALANCAY & 33 & FILGUEIRA & 1 & SOSA & 1 \\
\hline ALEJO & 11 & FLORES & 1 & SOTO & 6 \\
\hline ARAPO & 2 & GONZALES & 3 & SUARES & 5 \\
\hline ARJONA & 7 & GUANACTOLAY & 3 & TABARCACHI & 13 \\
\hline AVENDAÑO & 1 & GUARI & 3 & TINTE & 15 \\
\hline BALDERRAMA & 5 & GUTIERRES & 11 & TITO & 2 \\
\hline BALERIO & 3 & HUANUCO & 1 & TOLABA & 5 \\
\hline BARCONTE & 14 & LAMAS & 22 & TOMASEZ & 1 \\
\hline BASQUES & 2 & LAZARO & 4 & TORRES & 4 \\
\hline BEDABLE & 1 & LEAÑO & 3 & URQUIZA & 1 \\
\hline BEDIA & 11 & LEDESMA & 1 & VALDIVIEZO & 2 \\
\hline BEJARANO & 1 & LEIBA & 1 & VEGA & 3 \\
\hline BELASQUES & 3 & LEON & 1 & VILCA & 2 \\
\hline BENICIO & 21 & LIQUIN & 15 & VILTE & 7 \\
\hline BETANCUR & 1 & LOPEZ & 1 & ZARATE & 12 \\
\hline BONIFACIO & 1 & LUNA & 1 & & \\
\hline CABEZAS & 1 & MAISARES & 2 & & \\
\hline $\mathrm{CACHI}$ & 4 & MAMANI & 15 & & \\
\hline CALA & 6 & MARTINEZ & 1 & & \\
\hline CALLATA & 7 & MENDEZ & 4 & & \\
\hline CAMARGO & 1 & MOLLE & 1 & & \\
\hline CARI & 3 & MORALES & 18 & & \\
\hline CARRILLO & 17 & OCHOA & 5 & & \\
\hline CATACATA & 1 & OLMOS & 3 & & \\
\hline CHABEZ & 3 & PASTRANA & 1 & & \\
\hline CHAPARRO & 1 & PATAGUA & 2 & & \\
\hline CHOCOBAR & 3 & PIÑERO & 5 & & \\
\hline CHOQUI & 4 & PRIETO & 1 & & \\
\hline CIARES & 18 & PUCA & 2 & & \\
\hline COLQUI & 2 & QUIPILDOR & 9 & & \\
\hline CONDORI & 2 & QUISPE & 2 & & \\
\hline CORIMAYO & 1 & RAMOS & 1 & & \\
\hline COSTA & 1 & REYES & 5 & & \\
\hline CRUZ & 3 & RIOS & 1 & & \\
\hline CUSI & 8 & RIVERO & 3 & & \\
\hline DIONICIO & 8 & SAJAMA & 5 & & \\
\hline ECHENEQUE & 1 & SALAS & 2 & & \\
\hline
\end{tabular}


Casabindo 1982 - Apellidos registrados en mujeres

\begin{tabular}{|c|c|c|c|c|c|}
\hline Apellidos & $\begin{array}{c}\text { Cantidad } \\
\text { portadores }\end{array}$ & Apellidos & $\begin{array}{c}\text { Cantidad } \\
\text { portadores }\end{array}$ & Apellidos & $\begin{array}{c}\text { Cantidad } \\
\text { portadores }\end{array}$ \\
\hline ABALOS & 32 & GONZA & 1 & SUAREZ & 9 \\
\hline ABRACAITE & 1 & GUANUCO & 7 & SULCA & 1 \\
\hline ALANCAY & 78 & GUARI & 17 & TABARCACHI & 18 \\
\hline ALEJO & 40 & GUTIERREZ & 47 & TAPIA & 1 \\
\hline AMANTE & 1 & HOYOS & 16 & TINTE & 9 \\
\hline APAZA & 1 & ISOLINA & 1 & TITO & 5 \\
\hline BALDERRAMA & 5 & LAGUNA & 1 & TOCONAS & 1 \\
\hline BALERIO & 1 & LAMAS & 56 & TOLABA & 31 \\
\hline BARCONTE & 34 & LEAÑO & 8 & TORRES & 2 \\
\hline BARRIONUEVO & 1 & LIQUIN & 8 & URBANO & 1 \\
\hline BEJERANO & 2 & LLAMPA & 3 & URQUIZA & 1 \\
\hline BENICIO & 36 & LOPEZ & 4 & VALDIVIEZO & 36 \\
\hline CALA & 14 & MAITA & 1 & VALERIO & 2 \\
\hline CALISAYA & 1 & MAIZARES & 8 & VASQUEZ & 10 \\
\hline CALIZAYA & 2 & MAMANI & 16 & VEDIA & 20 \\
\hline CALLATA & 7 & MARTINEZ & 4 & VELASQUEZ & 12 \\
\hline CALPANCHAY & 2 & MAYO & 3 & VILTE & 8 \\
\hline CARI & 1 & MENDEZ & 1 & YAMPA & 2 \\
\hline CARRILLO & 49 & MORALES & 28 & ZARATE & 14 \\
\hline CASIMIRO & 2 & OCHOA & 1 & ZERDA & 3 \\
\hline CASTILLO & 1 & OLLOS & 2 & ZERPA & 4 \\
\hline CAYO & 2 & OLMOS & 5 & & \\
\hline CHAÑI & 3 & OSSORIO & 1 & & \\
\hline CHAVES & 10 & OVANDO & 1 & & \\
\hline CHIRI & 2 & PALACIOS & 1 & & \\
\hline CHOCOBAR & 3 & PATAGUA & 4 & & \\
\hline CHOQUE & 14 & PIÑERO & 17 & & \\
\hline CIARES & 19 & PUCA & 11 & & \\
\hline COLQUE & 6 & QUIPILDOR & 21 & & \\
\hline CONDORI & 2 & QUIROGA & 1 & & \\
\hline CORIA & 1 & QUISPE & 5 & & \\
\hline CRUZ & 6 & RAMOS & 1 & & \\
\hline CUSSI & 26 & RIVERO & 6 & & \\
\hline DIAZ & 6 & ROMERO & 1 & & \\
\hline FARFAN & 6 & SAJAMA & 15 & & \\
\hline FERRIL & 2 & SALAS & 3 & & \\
\hline FLORENCIA & 1 & SALVA & 2 & & \\
\hline FLORES & 13 & SARAPURA & 37 & & \\
\hline GALLARDO & 1 & SOLANO & 15 & & \\
\hline GARZON & 1 & SOLIS & 1 & & \\
\hline GERONIMO & 6 & SOTO & 10 & & \\
\hline
\end{tabular}


Casabindo 1982 - Apellidos registrados en varones

\begin{tabular}{|c|c|c|c|c|c|}
\hline Apellidos & \begin{tabular}{|c|c}
$\begin{array}{c}\text { Cantidad } \\
\text { portadores }\end{array}$ \\
\end{tabular} & Apellidos & \begin{tabular}{|c|c}
$\begin{array}{c}\text { Cantidad } \\
\text { portadores }\end{array}$ \\
\end{tabular} & Apellidos & $\begin{array}{c}\text { Cantidad } \\
\text { portadores }\end{array}$ \\
\hline ABALOS & 25 & LOPEZ & 3 & ZARATE & 5 \\
\hline ABRACAITE & 1 & MACEDO & 1 & ZERDA & 1 \\
\hline ALANCAY & 63 & MAIZARES & 7 & ZERPA & 3 \\
\hline ALEJO & 34 & MAMANI & 18 & & \\
\hline BALDERRAMA & 5 & MANCILLA & 1 & & \\
\hline BALERIO & 1 & MARTINEZ & 3 & & \\
\hline BARCONTE & 19 & MAYO & 1 & & \\
\hline BEJERANO & 3 & MERCADO & 2 & & \\
\hline BENICIO & 32 & MORALES & 14 & & \\
\hline CALA & 6 & MORENO & 1 & & \\
\hline CALLATA & 4 & OCHOA & 3 & & \\
\hline CAMINO & 1 & OLMOS & 2 & & \\
\hline CARRILLO & 25 & OSSORIO & 1 & & \\
\hline CASTILLO & 1 & OVANDO & 1 & & \\
\hline CHAÑI & 2 & PATAGUA & 1 & & \\
\hline CHAVES & 8 & PIÑERO & 7 & & \\
\hline CHIRI & 2 & PUCA & 8 & & \\
\hline CHOCOBAR & 5 & QUIPILDOR & 21 & & \\
\hline CHOQUE & 4 & QUISPE & 4 & & \\
\hline CIARES & 11 & RAMOS & 1 & & \\
\hline COLQUE & 4 & RIVERO & 5 & & \\
\hline CONDORI & 3 & SAJAMA & 10 & & \\
\hline CRUZ & 9 & SALAS & 3 & & \\
\hline CUSSI & 23 & SALVA & 1 & & \\
\hline DIAZ & 4 & SARAPURA & 22 & & \\
\hline ESQUIBEL & 1 & SILBESTRE & 1 & & \\
\hline FARFAN & 6 & SOLANO & 7 & & \\
\hline FERNANDEZ & 2 & SOTO & 2 & & \\
\hline FLORES & 11 & SUAREZ & 7 & & \\
\hline GASPAR & 1 & TABARCACHI & 14 & & \\
\hline GERONIMO & 3 & TINTE & 10 & & \\
\hline GIMENEZ & 2 & TITO & 5 & & \\
\hline GUANUCO & 4 & TOLABA & 26 & & \\
\hline GUARI & 7 & TORRES & 4 & & \\
\hline GUTIERREZ & 24 & URSAGASTE & 1 & & \\
\hline HOYOS & 2 & VALDIVIEZO & 27 & & \\
\hline HUANCO & 1 & VALERIO & 5 & & \\
\hline LAMAS & 41 & VASQUEZ & 2 & & \\
\hline LEAÑO & 2 & VEDIA & 10 & & \\
\hline LIQUIN & 6 & VELASQUEZ & 11 & & \\
\hline LLAMPA & 2 & VILTE & 5 & & \\
\hline
\end{tabular}


Casabindo 2001 - Apellidos registrados en mujeres

\begin{tabular}{|c|c|c|c|c|c|}
\hline Apellidos & $\begin{array}{c}\text { Cantidad } \\
\text { portadores }\end{array}$ & Apellidos & $\begin{array}{c}\text { Cantidad } \\
\text { portadores }\end{array}$ & Apellidos & $\begin{array}{c}\text { Cantidad } \\
\text { portadores }\end{array}$ \\
\hline ABALOS & 28 & GERONIMO & 6 & TABARCACHI & 15 \\
\hline ABRACAITE & 3 & GUANUCO & 4 & TINTE & 15 \\
\hline ALANCAY & 81 & GUARI & 14 & TITO & 4 \\
\hline ALEJO & 51 & GUTIERREZ & 34 & TOLABA & 35 \\
\hline AMANTE & 1 & HOYOS & 15 & TORRES & 5 \\
\hline ARMELLA & 1 & INCA & 1 & URBANO & 1 \\
\hline BALDERRAMA & 4 & JUAREZ & 1 & VALDIVIEZO & 37 \\
\hline BARCONTE & 33 & LAGUNA & 1 & VALERIO & 3 \\
\hline BARRIONUEVO & 1 & LAMAS & 56 & VASQUEZ & 11 \\
\hline BAUTISTA & 1 & LEAÑO & 5 & VEDIA & 24 \\
\hline BEJARANO & 1 & LIQUIN & 10 & VELASQUEZ & 16 \\
\hline BENICIO & 43 & LLAMPA & 3 & VENTURA & 2 \\
\hline CALA & 12 & LOPEZ & 4 & VILTE & 7 \\
\hline CALIZAYA & 1 & MAITA & 1 & ZARATE & 13 \\
\hline CALLATA & 6 & MAIZARES & 10 & ZERDA & 1 \\
\hline CALPANCHAY & 1 & MAMANI & 20 & ZERPA & 5 \\
\hline CANAVIRE & 1 & MARTINEZ & 5 & & \\
\hline CARRILLO & 41 & MAYO & 1 & & \\
\hline CASIMIRO & 1 & MENDEZ & 1 & & \\
\hline CASTILLO & 1 & MERCADO & 1 & & \\
\hline CAYO & 2 & MORALES & 29 & & \\
\hline CHAÑI & 2 & OLMOS & 4 & & \\
\hline CHAVES & 14 & OLOS & 1 & & \\
\hline CHIRI & 2 & PATAGUA & 1 & & \\
\hline CHOCOBAR & 5 & PIÑERO & 11 & & \\
\hline CHOQUE & 9 & PUCA & 9 & & \\
\hline CIARES & 16 & QUIPILDOR & 23 & & \\
\hline COLQUE & 5 & QUIROGA & 1 & & \\
\hline CONDORI & 1 & QUISPE & 5 & & \\
\hline CORIA & 1 & RAMOS & 3 & & \\
\hline CRUZ & 3 & RIOS & 1 & & \\
\hline CUSSI & 27 & RIVERO & 6 & & \\
\hline DIAZ & 3 & SAJAMA & 16 & & \\
\hline ERAZO & 1 & SALAS & 6 & & \\
\hline FABIAN & 1 & SANTOS & 1 & & \\
\hline FARFAN & 6 & SARAPURA & 31 & & \\
\hline FERRIL & 1 & SOLANO & 16 & & \\
\hline FLORES & 15 & SOTO & 6 & & \\
\hline GALLARDO & 1 & SUAREZ & 5 & & \\
\hline GARZON & 1 & SULCA & 1 & & \\
\hline GASPAR & 1 & SUMBAINO & 2 & & \\
\hline
\end{tabular}




\section{Casabindo 2001 - Apellidos registrados en varones}

\begin{tabular}{|c|c|c|c|c|c|}
\hline Apellidos & \begin{tabular}{|c|} 
Cantidad \\
portadores
\end{tabular} & Apellidos & \begin{tabular}{|c|} 
Cantidad \\
portadores
\end{tabular} & Apellidos & \begin{tabular}{|c} 
Cantidad \\
portadores
\end{tabular} \\
\hline ABALOS & 18 & LAMAS & 50 & VEDIA & 10 \\
\hline ABRACAITE & 5 & LEAÑO & 1 & VELASQUEZ & 12 \\
\hline ALANCAY & 79 & LIQUIN & 7 & VILCA & 1 \\
\hline ALEJO & 40 & LOPEZ & 3 & VILTE & 3 \\
\hline ARANA & 1 & MACEDO & 1 & ZARATE & 8 \\
\hline ARMELLA & 1 & MAIZARES & 6 & ZERPA & 5 \\
\hline BALDERRAMA & 6 & MAMANI & 14 & & \\
\hline BARCONTE & 30 & MANCILLA & 1 & & \\
\hline BEJARANO & 2 & MARTINEZ & 3 & & \\
\hline BENICIO & 34 & MERCADO & 1 & & \\
\hline CALA & 13 & MORALES & 18 & & \\
\hline CALLATA & 11 & MORENO & 1 & & \\
\hline CALPANCHAY & 1 & OCHOA & 2 & & \\
\hline CAMINO & 1 & OLMOS & 3 & & \\
\hline CARRILLO & 25 & OSSORIO & 2 & & \\
\hline CHAVES & 9 & OVANDO & 2 & & \\
\hline CHIRI & 3 & PATAGUA & 1 & & \\
\hline CHOCOBAR & 3 & PIÑERO & 8 & & \\
\hline CHOQUI & 4 & PRIETO & 1 & & \\
\hline CIARES & 9 & PUCA & 8 & & \\
\hline COLQUI & 9 & QUIPILDOR & 23 & & \\
\hline CONDORI & 1 & QUISPE & 2 & & \\
\hline CRUZ & 4 & RAMOS & 1 & & \\
\hline CUSE & 2 & RIVERO & 6 & & \\
\hline CUSSI & 13 & SAJAMA & 7 & & \\
\hline DIAS & 1 & SALAS & 3 & & \\
\hline ESQUIBEL & 1 & SALVA & 1 & & \\
\hline FABIAN & 1 & SANTOS & 2 & & \\
\hline FARFAN & 5 & SARAPURA & 29 & & \\
\hline FERNANDES & 1 & SOLANO & 6 & & \\
\hline FLORENCIA & 1 & SOTO & 1 & & \\
\hline FLORES & 13 & SUAREZ & 3 & & \\
\hline GARZON & 1 & TABARCACHI & 16 & & \\
\hline GASPAR & 1 & TINTE & 9 & & \\
\hline GERONIMO & 2 & TITO & 4 & & \\
\hline GIMENEZ & 2 & TOLABA & 26 & & \\
\hline GUANACTOLAY & 1 & TORRES & 3 & & \\
\hline GUANUCO & 5 & URZAGASTE & 1 & & \\
\hline GUARI & 14 & VALDIVIEZO & 34 & & \\
\hline GUTIERREZ & 25 & VALERIO & 2 & & \\
\hline HOYOS & 4 & VAZQUEZ & 5 & & \\
\hline
\end{tabular}


